University of Rhode Island

DigitalCommons@URI

Open Access Dissertations

1994

\title{
Localized Electrochemical Study on Corrosion Behavior of Nitride Thin Films
}

Mohd Norazmi Alias

University of Rhode Island

Follow this and additional works at: https://digitalcommons.uri.edu/oa_diss

\section{Recommended Citation}

Alias, Mohd Norazmi, "Localized Electrochemical Study on Corrosion Behavior of Nitride Thin Films" (1994). Open Access Dissertations. Paper 564.

https://digitalcommons.uri.edu/oa_diss/564

This Dissertation is brought to you for free and open access by DigitalCommons@URI. It has been accepted for inclusion in Open Access Dissertations by an authorized administrator of DigitalCommons@URI. For more information, please contact digitalcommons-group@uri.edu. 


\section{LOCALIZED ELECTROCHEMICAL STUDY ON \\ CORROSION BEHAVIOR OF NITRIDE THIN FILMS}

BY

MOHD NORAZMI ALIAS

A DISSERTATION SUBMITTED IN PARTIAL FULFILLMENT OF THE REQUIREMENTS FOR THE DEGREE OF DOCTOR OF PHILOSOPHY

IN CHEMICAL ENGINEERING 
DOCTOR OF PHILOSOPHY DISSERTATION

OF

MOHO NORAZMI ALIAS

APPROVED :

Dissertation committee

Major Professor Richard Bora

Airman. Rochet

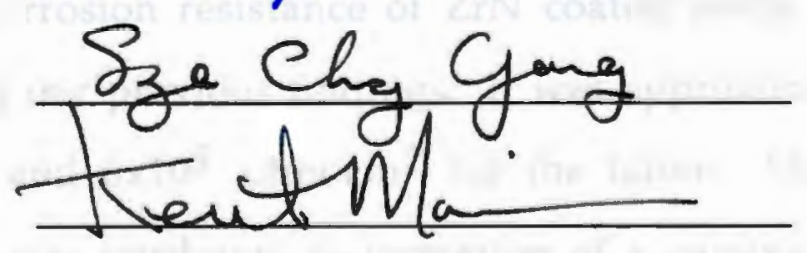

DEAN OF THE GRADUATE SCHOOL

UNIVERSITY OF RHODE ISLAND

1994 


\section{ABSTRACT}

Eletrochemical studies were conducted on $\mathrm{TiN}$ and $\mathrm{ZrN}$ coated 304 stainless steels in $0.5 \mathrm{~N}$ chloride containing solution to identify the effect of film thickness and $\mathrm{Ti}$ or $\mathrm{Zr}$ interlayer between $\mathrm{TiN}$ or $\mathrm{ZrN}$ coatings, respectively, on their corrosion properties. Time dependent corrosion behavior was monitored utilizing the widely used electrochemical impedance spectroscopy (EIS) technique. The corrosion resistance values were justified by the polarization resistance obtained from linear polization. Active to passive transition behavior was studied utilizing the potentiodynamic cyclic polarization test.

The charge transfer resistance values obtained from both EIS and linear polarization indicated higher corrosion resistance of $\mathrm{ZrN}$ coated steels than the TiN coated steels; justifying our previous findings. It was approximately $10^{6} \mathrm{ohm} . \mathrm{cm}^{2}$ for the former and $6 \times 10^{5} \mathrm{ohm} . \mathrm{cm}^{2}$ for the latter. Higher resistance of $\mathrm{ZrN}$ coated steels was attributed to formation of a passive film on the coating. Increasing the film thickness from 5 to $10 \mu \mathrm{m}$ and laying a metal interlayer between two coating layers did not significantly change the charge transfer resistance suggesting the mechanism for protection is dominated by surface phenomena like formation of an oxide film.

Cyclic polarization scans indicated that the corrosion potential of $\mathrm{ZrN}$ coated steels was lower than the bare steel and that of TiN coated steels slightly higher than the bare steel. The critical current density for film formation was an order of magnitude lower for $\mathrm{ZrN}$ coated steels than $\mathrm{TiN}$ coated steels; approximately $10^{-3}$ for the former and $10^{-2}$ for the latter. This 
suggested easier formation of oxide film on $\mathrm{ZrN}$ than on TiN. The passive films were in the form of $\mathrm{ZrO}_{2} \cdot 2 \mathrm{H}_{2} \mathrm{O}$ for the former and $\mathrm{TiO}_{2} \cdot \mathrm{H}_{2} \mathrm{O}$ for the latter. Increasing the coating thickness and laying an interlayer between the coating layers increased the coating breakdown potential where pits formed. The higher corrosion resistance of $\mathrm{ZrN}$ was then attributed to the easier formation of oxide film on its surface as suggested by the lower critical current density for film formation.

Formation of passive oxide film on $\mathrm{ZrN}$ was investigated utilizing electron spectroscopy for chemical analysis (ESCA). A layer of approximately 1000 Angstrom thick containing oxygen formed on the $\mathrm{ZrN}$ surface after exposure for more than 60 days. This layer was identified by $\mathrm{ZrO}_{2}$ from the binding energy value of the core electron of $\mathrm{Zr}$. It was suggested that this oxide existed in the hydrated form during exposure to aqueous environment but dehydrated after removal and exposure to a laboratory environment. A broad oxygen $O$ is peak suported this argument. However, insignificant change in the oxygen content was found for TiN exposed for more than 60 days.

Oxide film formation on $\mathrm{ZrN}$ but not on $\mathrm{TiN}$ was proposed as driven by the potential difference between coating and steel substrate. Lower potential of $\mathrm{ZrN}$ than steel promotes oxidation of the nitride to form oxide film as a protective layer. Higher potential of TiN than the substrate will not promote oxidation of the nitride. The substrate oxidizes and its corrosion protective ability will depend on the passive film on the substrate. 
Thermodynamic calculations were carried out to construct the $\mathrm{pH}-$ potential or Pourbaix diagram for $\mathrm{ZrN}$ in water which potentially can be used as protective coating. Equilibrium potential for oxide formation from nitride is higher than from its base metal. The shape of immunity, passivity and corrosion regions of nitride follow closely that of the base metal. Theoretial prediction for choosing good protective coatings for particular metal or alloys can be made using this diagram.

A local electrochemical impedance spectroscopy (LEIS) technique was developed to enhance understanding of overall impedance of passive systems like stainless steel and aluminum alloys. Local impedance of passive area and pits were measured by this technique. Contribution of these local areas to the overall impedance measured by EIS were identified. Pit may not significantly change the overall impedance because the current from the small pit spread laterally to the larger passive area. The pit response is masked by the response of the passive area. Information on the local corrosion rate of pit and passive area, and pit growth behavior are obtainable from this local impedance technique which is not available from the overall impedance which only provide surface averaged response. Local charge transfer resistance and capacitance values can be used to justify the active pit model for pit in pasive system.

Application of LEIS technique to monitor damage in carbon/glass/vinyl ester composite under simulated galvanic coupling in $0.5 \mathrm{~N} \mathrm{NaCl}$ was carried out. Differences of local impedance over blisters and polymer removal regions were measured. Under open circuit condition, significant variation in local impedanec over glass and carbon regions were 
identified suggesting differences in electrolyte diffusion into the composite. at these regions.

LEIS technique was found as very useful to measure local corrosion rate and monitor damage. Further investigations on application of this technique to other corrosion system should be conducted to fully utilized its capability to map the impedance of entire corroding surface. 


\section{ACKNOWLEDGMENTS}

I would like to thank my major professor Dr. Richard Brown for his guidance and patience during my graduate years at the University of Rhode Island.

I would like to take this opportunity to thank the Office of Naval Research, Ray Fontana of Multi Arc, and the ALCOA foundation for their financial support and providing samples to make this dissertation possible.

I am very greatful to Dr. Rockett and Dr. Yang for serving on my dissertation committee.

To all my colleagues at Corrosion Laboratory, Mike Kane, Bill Reynolds, and Jialiang Qin, I would like to express my appreciation for all the helpful discussions in regards to my research.

Support from my families give me the strength to continue my study away from home. I would like to thank them for standing behind me all the time.

I am dedicating this dissertation to my beloved wife, Emi, who patiently stood by me through the difficult times during my study. 


\section{PREFACE}

This dissertation is written in the Manuscript form according to guidelines of the Graduate School of the University of Rhode Island. Six manuscipts are written in the appropriate format for submission to journals. An introduction chapter was written to present the purpose of research and background of materials and experimental techniques employed in the study.

Chapters II and III discussed electrochemical studies on the effect of film thickness and an interlayer on corrosion behavior of TiN and $\mathrm{ZrN}$ coated 304 stainless steel in chloride containing solution. Active to passive transition behavior and time dependent corrosion rate were obtained and discussed to propose the corrosion protective mechanism of nitride thin films.

Chapter IV discussed the surface analysis study by ESCA on TiN and $\mathrm{ZrN}$ thin films exposed to chloride containing solution. Depth profile and chemical shift data justify the formation of oxide film on nitride to enhance the corrosion resistance.

Chapter $\mathrm{V}$ discussed the construction of $\mathrm{pH}$-potential or Pourbaix diagram to predict the immunity, passivity and corrosion regions for $\mathrm{ZrN}$ in water.

Chapter VI and VII discussed the application of local electrochemical impedance spectroscopy technique to monitor corrosion of nitride coated alloys and polymer matrix composite, respectively.

Most of this work was presented at international conferences and few papers were published as listed in the Appendix. 


\section{TABLE OF CONTENTS}

Page

Abstract

ii

Acknowledgments

vi

Preface vii

Table of Contents viii

Chapters

I.

INTRODUCTION

Introduction

2

Theoretical Backgrounds

8

Experimental Procedures

References

II. EFFECT OF FILM THICKNESS AND AN INTERLAYER ON CORROSION BEHAVIOR OF ION PLATED TIN

ON 304 STAINLESS STEEL

Abstract

Introduction

Experimental Procedures

Experimental Results

Discussions

Conclusions

Acknowledgment

References 
III.

EFFECT OF FILM THICKNESS AND AN INTERLAYER ON CORROSION BEHAVIOR OF ION PLATED ZrN ON 304 STAINLESS STEEL

Abstract

Introduction

Experimental Procedures

Experimental Results

Discussions

Conclusions

Acknowledgment

References

IV.

AN ESCA INVESTIGATION ON OXIDATION

OF NITRIDE FILMS IN AQUEOUS SOLUTION

Abstract

Introduction

Experimental Procedures

Experimental Results

Discussions

Conclusions

Acknowledgments

References

V.

THERMODYNAMIC EQUILIBRIA OF ZrN IN WATER

Abstract

Introduction 
$\begin{array}{ll}\text { Consideration of Substances } & 100\end{array}$

$\begin{array}{ll}\text { Free Energy Values } & 100\end{array}$

$\begin{array}{ll}\text { Reactions and Equilibrium Formulae } & 101\end{array}$

Construction of Diagrams 103

$\begin{array}{ll}\text { Discussions } & 105\end{array}$

$\begin{array}{ll}\text { Conclusions } & 107\end{array}$

$\begin{array}{ll}\text { References } & 108\end{array}$

VI. LOCAL ELECTROCHEMICAL IMPEDANCE SPECTROSCOPY STUDY ON CORROSION OF NITRIDE COATED ALLOYS 113

$\begin{array}{ll}\text { Abstract } & 114\end{array}$

$\begin{array}{ll}\text { Introduction } & 115\end{array}$

Experimental Procedures 116

$\begin{array}{ll}\text { Experimental Results } & 119\end{array}$

$\begin{array}{ll}\text { Discussions } & 121\end{array}$

$\begin{array}{ll}\text { Conclusions } & 123\end{array}$

$\begin{array}{ll}\text { References } & 125\end{array}$

VII. APPLICATION OF SCANNING POTENTIAL MICRO-PROBE TECHNIQUES TO MONITOR

DAMAGE IN FIBER REINFORCED COMPOSITES $\quad 141$ $\begin{array}{ll}\text { Abstract } & 142\end{array}$

Introduction 143

$\begin{array}{ll}\text { Experimental Procedures } & 145\end{array}$

Experimental Results 149

Discussions 153 
Conclusions

References

VIII.

FUTURE STUDY

175

IX.

APPENDIX : LIST OF PUBLICATIONS

177

$x$

BIBLIOGRAPHY

178 


\section{CHAPTER I}

\section{INTRODUCTION}




\section{INTRODUCTION}

This dissertation will present the results from research investigating the effect of film thickness and metal interlayer on the corrosion behavior of TiN and $\mathrm{ZrN}$ coated 304 stainless steels in $\mathrm{NaCl}$ chloride environment. The justifications for the formation of the passive oxide film films on these coatings from the electrochemical testings and surface analysis and theoretical considerations using the Pourbaix diagrams are discussed. The mechanism for the corrosion protection ability of these coatings are presented.

The local electrochemical impedance spectroscopy study on nitride coated stainless steels and aluminum alloys also shed some light on the effect of defects and pitting corrosion on the overall impedance measured by conventional EIS. Local impedance measured at the pit and over passive area shown differences in the impedance and phase angle behavior throughout wide frequency range. These findings are discussed in this dissertation.

LEIS study on the degradation of carbon/glass/vinyl ester composite shown differences in impedance between blisters over regions where glass fibers closest to the surface and polymer damages over regions where carbon fibers closest to the surface when subjected to applied cathodic potential in $\mathrm{NaCl}$ solution. These findings are also discussed in detail in this dissertation.

Electrochemical impedance spectroscopy (EIS) study was conducted previously on zirconium nitride ( $\mathrm{ZrN}$ ) and titanium nitride ( $\mathrm{TiN})$ coated 304 
stainless steels in $0.5 \mathrm{~N} \mathrm{NaCl}$ solution which indicated higher resistance to charge transfer of an order of magnitude on $\mathrm{ZrN}$ coated sample compared to TiN coated sample and bare stainless steel 1 . It was suggested that the difference was due to easier formation of passive surface films on the latter coating. Formation of passive films was determined from changes in low frequency impedance and phase angle behavior. Further studies were carried out to investigate the formation of passive films on $\mathrm{TiN}$ and $\mathrm{ZrN}$ coated 304 SS in similar environment utilizing potentiodynamic cyclic polarization technique, and to determine the effect of film thickness and a noble metal interlayer between two layers of $\mathrm{TiN}$ or $\mathrm{ZrN}$ coating on the corrosion behavior of stainless steels utilizing the EIS and linear polarization techniques 2,3. Formation of oxide film on the $\mathrm{TiN}$ and $\mathrm{ZrN}$ coated stainless steels exposed to $\mathrm{NaCl}$ solution during the EIS experiments was analyzed by electron spectroscopy for chemical analysis (ESCA) 4. Thermodynamic calculations for the construction of Pourbaix or $\mathrm{pH}$-potential diagrams were carried out to determine the immunity, passivity and corrosion regions of various nitride coatings in water 5 . This would provide theoretical explanation for the formation of oxide films in aqueous solution. Findings from EIS, linear polarization, cyclic polarization and ESCA experiments have shed some light on the mechanism for formation of passive films on these coatings.

Coating used in these studies were produced by the cathodic arc plasma deposition or CAPD technique 6,7. The advantages of this technique over other plating or sputtering techniques are its ability to deposit coating very rapidly and produce thick and dense coatings with better adhesion of the coatings to the substrate. One supposed disadvantage of this technique is 
microdroplets deposits on the coatings ranging in size from 0.2 to $1.0 \mu \mathrm{m}$. $\mathrm{ZrN}$ coatings developed by this technique were shown to have lesser microdroplets density than TiN due to the higher melting point of the former.

Coatings studied showed two types of defects 1-3, type I defect appears as depression below the average coating thickness and type $\Pi$ defect appears as islands growth over the average coating thickness. These are shown schematically in figure 1. Type II defect appears in a thin cylindrical shape on the TiN surface, but in a hemispherical shape on $\mathrm{ZrN}$ surface. These growth defects or microdroplets are shown to be metal-rich at least for those on TiN surface 7 . Type I defects is due to loss of adhesion of the microdroplets to the surface which are loosely held in the coating matrix. The size of these defects observed are between 10 to $100 \mu \mathrm{m}$ in diameter.

Electrochemical impedance spectroscopy (EIS) studies of these coatings indicated two maxima of time constant due to regions with defects and regions of average coating thickness. This was modelled with two parallel RC circuits in series, figure 2. It was found that the two maxima were more clearly distinguished when the size and density of defects are relatively large, ie. $100 \mu \mathrm{m}$ in diameter 2,3 . The distinguishability of the two maxima is governed by the ratio of the two time constants 8,9 . The two maxima behavior can also be attributed to the passive oxide film in series to the electrical double layer at oxide/solution interface 10. It is suggested that both the geometrical shape of the surface due to defects and the passive oxide layer have contributions to the frequency dispersion to produce two. It is then necessary to measure separately the impedance over a locally corroded site 
and that over the non-corroding area, and to understand the separate contributions of both the physical chemical heterogeneities on the surface to the measured impedance response by conventional EIS technique.
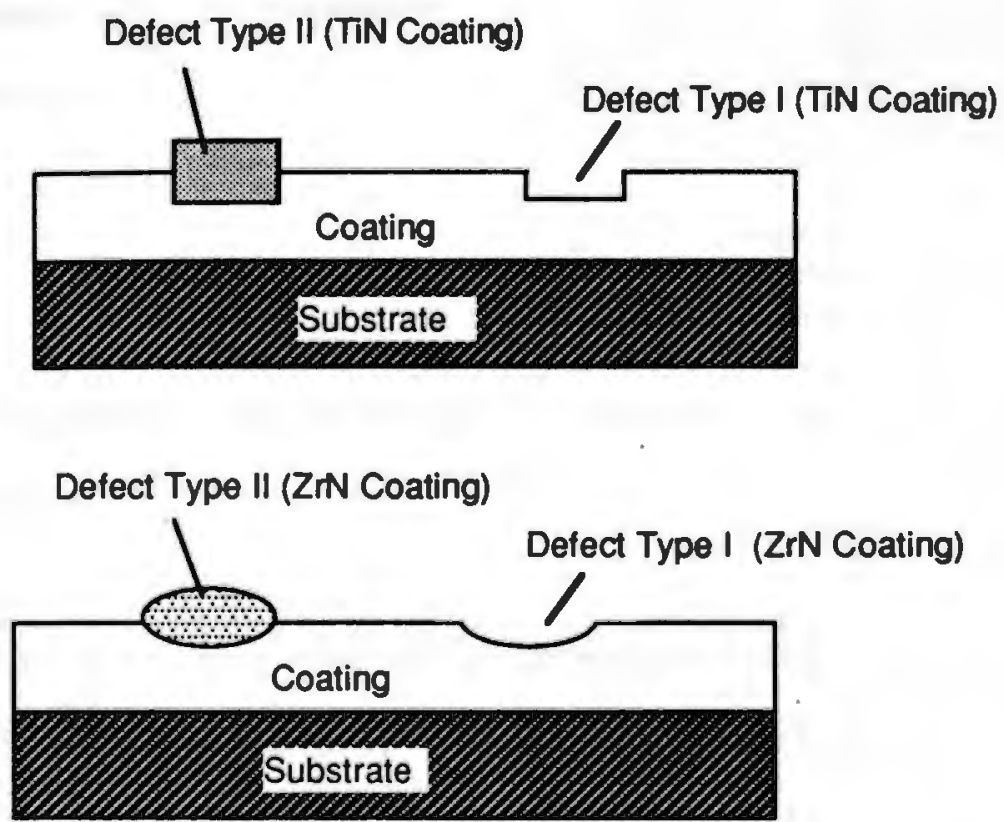

Figure 1. Schematic of defects observed on $\mathrm{TiN}$ and $\mathrm{ZrN}$ coating on 304 stainless steels deposited by cathodic arc plasma deposition process.

In addition to the micrometer size defects shown earlier, a porous coating could directly expose the substrate to the environment. The EIS data may produce two maxima of phase angle behavior on the Bode -phase angle plot which dependent on the ratio of the time constants of the two maxima. If the two maxima are nearly identical, the two maxima would overlap and will appear as a single maxima in the Bode-phase angle plot. 

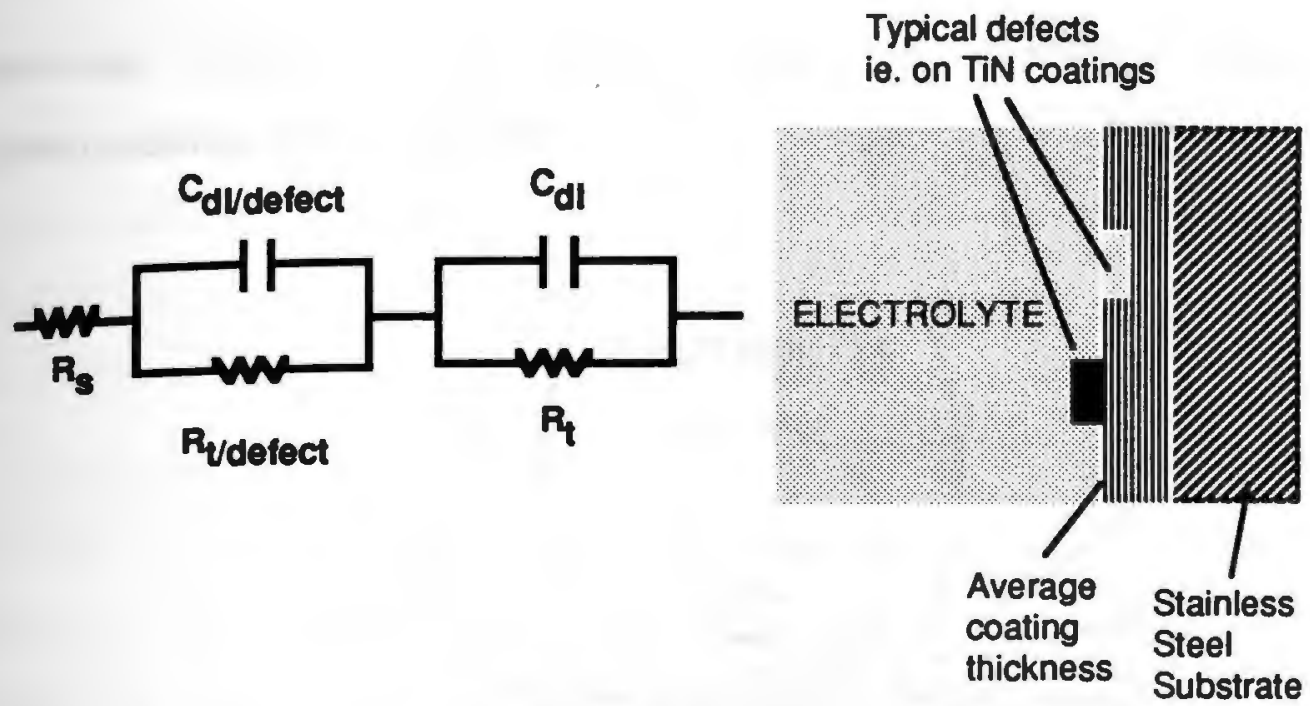

Figure 2. Equivalent circuit model to represent the coating with defects exposed to solution.

Analysis and interpretation of impedance data by conventional EIS approach becomes problematic when dealing with passive systems like stainless steel and aluminum alloys which undergo localized corrosion 1,11,12, and carbon/glass/polymer composites which undergo both blistering and polymer damages in galvanic coupling conditions 13,14 . Initiation of pits may or may not be seen from the impedance response caused by the dominant capacitive response of the larger passive area. Wide frequency range of dispersion often referred as constant phase angle behavior are often reported due to variation in the properties of the surface film laterally and with its depth 15,16, and may also be due to variations in the conductivity and valency across the oxide film 17. Physical surface heterogeneity such as defects, growths, steps, kinks etc. can also contribute to the frequency dispersion. The local variations in physical and chemical properties lead to non-uniform potential and current distributions which were measured as 
average values by the conventional EIS technique which makes interpretation rather difficult.

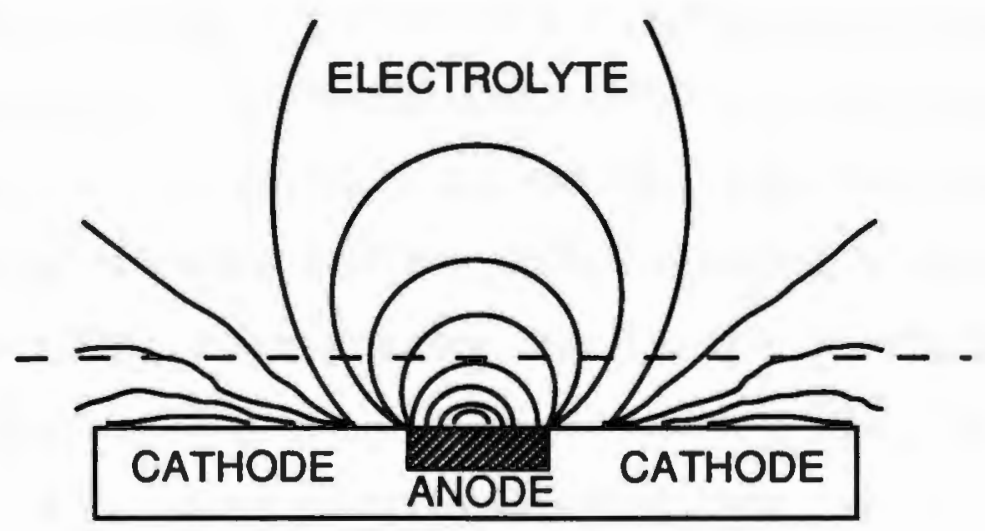

(a)

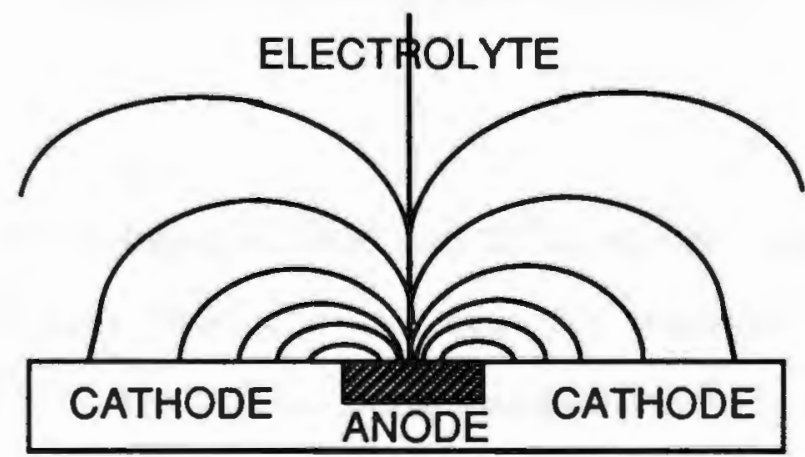

(b)

Figure 3. Schematic representation of potential (a) and current (b) lines in a galvanic couple system.

It is suggested that scanning potential micro-probe techniques like the scanning reference electrode (SRET) and local electrochemical impedance spectroscopy (LEIS) could be entoyed to address these problems 18-27. Hypothetically, differences in local properties at the defects and average coating thickness areas will produce local anodes and cathodes to make up a 
micro-galvanic cell as shown in figure 3. Defects on more noble coating that exposed the active substrate can also create a galvanic cell and produce current and potential variations in the solution. The micro-reference electrode use in SRET experiment can detect small potential variations in the order of several $\mathrm{mV}$ due to localization. This means small increase in anodic current within a passive matrix can be measured by this electrode. Local impedance property on the heterogeneous surface was detected by EIS technique. Applicability of SRET and LEIS technique to monitoring of degradation of carbon/glass/vinyl ester composite and pitting of nitride coated stainless steels and aluminum alloys was studied and discussed in chapters VI and VII.

\section{THEORETICAL BACKGROUNDS}

\section{Theory of SRET}

During the period between 1980 and 1990, studies had been devoted to an in situ measurements of anodic and cathodic reactions during localized corrosion $18,19,22,24$. The aim of these studies was to separate clearly the anodic and cathodic reactions without interfering or altering the processes taking place. The in situ measurements provide mapping of potentials in the solution and physical separation of anodic and cathodic areas to provide measurements of current flow between them. This technique will also enable us to measure the changes in anodic or cathodic currents between the different areas.

The scanning reference technique does not directly measure the potential field across the metal/solution interface, but only the potential variation in the solution 18 . The potential variation is associated to the ionic 
current flow from anode to cathode. In other words, it is dependent on the polarization behavior of the metal surface more than its surface potential.

The minimum distance between the reference electrode tip to the substrate that will give a reliable reading is approximately the outer diameter of the tip. Therefore, a tip of several $\mu \mathrm{m}$ in diameter will only give a good resolution at distance of several $\mu \mathrm{m}$ between the tip and substrate. This will not show any changes when scanning through the defects mentioned on the nitride coatings if the electrochemical difference between the defects and average coating area is small and the size of these defects is relatively smaller than the size of the tip. Small changes in potential and current distributions, ie. between defects and average coating area or between coating and defect that exposed the active substrate, might not be observed using a mm size tip due to the higher capacitive effect of the passive layer. It was shown from calculation of potential and current distribution around the tip that setting the tip at a distance much less than the outer tip diameter will affect the resolution of the measurement. It is necessary to make the tip of the reference electrode as small as possible in the $\mu \mathrm{m}$ range.

The potential and current distributions can be theoretically calculated from the Laplace equation

$$
\nabla^{2} E=0
$$

and Ohm's law

$$
i=-K \nabla E
$$


such that $E$, $i$, and $K$ are potential (V), current density $\left(A / \mathrm{cm}^{2}\right)$, and solution conductivity (ohm.cm)-1, respectively 18 . The potential field in $\mathrm{V} / \mathrm{cm}$ can be obtained through the potential difference between the microreference electrode which will scan through the active-passive region and a stationary saturated calomel reference electrode located several $\mathrm{mm}$ away above the passive or less affected region, all divided by the separation distance between the two electrodes. The current can be calculated from experiments when the solution conductivity is known.

\section{Theory of LEIS}

The local impedance of specific sites was measured through the development of the scanning reference electrode and scanning vibrating electrode techniques $20,23,25$. The latter can improved the measured current resolution to nano-amps $/ \mathrm{cm}^{2}$. A local electrochemical impedance spectroscopy technique was developed further using a bi-micro electrode 27 . By measuring the ac potential difference between the two micro electrodes at variable frequency range, the current response can be obtained and the local impedance normal to the surface can be calculated when the bulk solution conductivity is known. These are given by equations (3) and (4) as following

$$
\mathrm{i}(\omega)_{\text {local }}=\Delta \mathrm{V}(\omega)_{\text {probe }} \sigma / 1
$$

where $\mathrm{i}(\omega)_{\text {local }}$ is the local ac solution current density $\left(\mathrm{amps} / \mathrm{cm}^{2}\right), \Delta \mathrm{V}(\omega)_{\text {probe }}$ is the ac potential difference at the probe (V), $\sigma$ is the solution conductivity (ohms.cm) -1 , and 1 is the separation distance between the two 


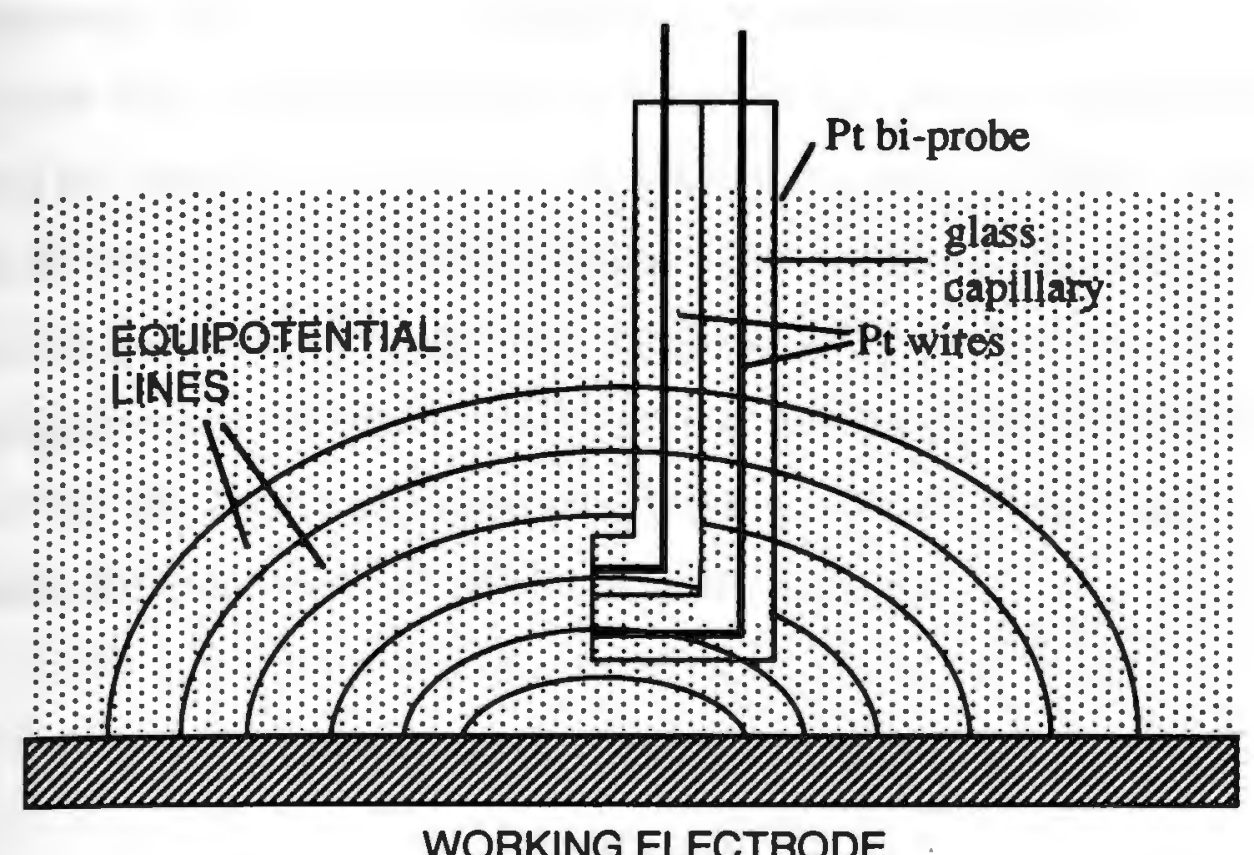

Figure 5. Bi-probe used for LEIS measurement shown cutting through potential lines.

micro electrodes $(\mathrm{cm})$. The ac potential drop is measured between two potential lines parallel to the surface, figure 5. The magnitude of local impedance is derived as

$$
|Z(\omega)|_{\text {local }}=V(\omega)_{\text {applied }} / \mathrm{i}(\omega)_{\text {local }}
$$

where $V(\omega)$ applied is the magnitude of the applied voltage perturbation between the reference and the working electrode, and $|Z(\omega)|_{\text {local }}$ is the local impedance in ohms. $\mathrm{cm}^{2}$. This equation was derived assuming all of the ac current travels normal to the tip such that the ac solution current density at the probe tip is proportional to the current density at the electrode surface. 
Knowing the local electrochemical behavior at different sites on coating with high degree of surface inhomogeneity, we would understand the role of the defects in corrosion processes and reactivity of different sites on the surface due to attack of chloride ions. The oxidation behavior of local sites can be gathered through these localized probe measurements. The effects of geometrical difference, passive films, and localized corrosion can be separated by the localized impedance technique when these may not be significantly differentiated by conventional EIS technique.

\section{EXPERIMENTAL PROCEDURES}

An apparatus to perform the SRET and LEIS experiments was developed in the Corrosion Laboratory at the Chemical Engineering department.

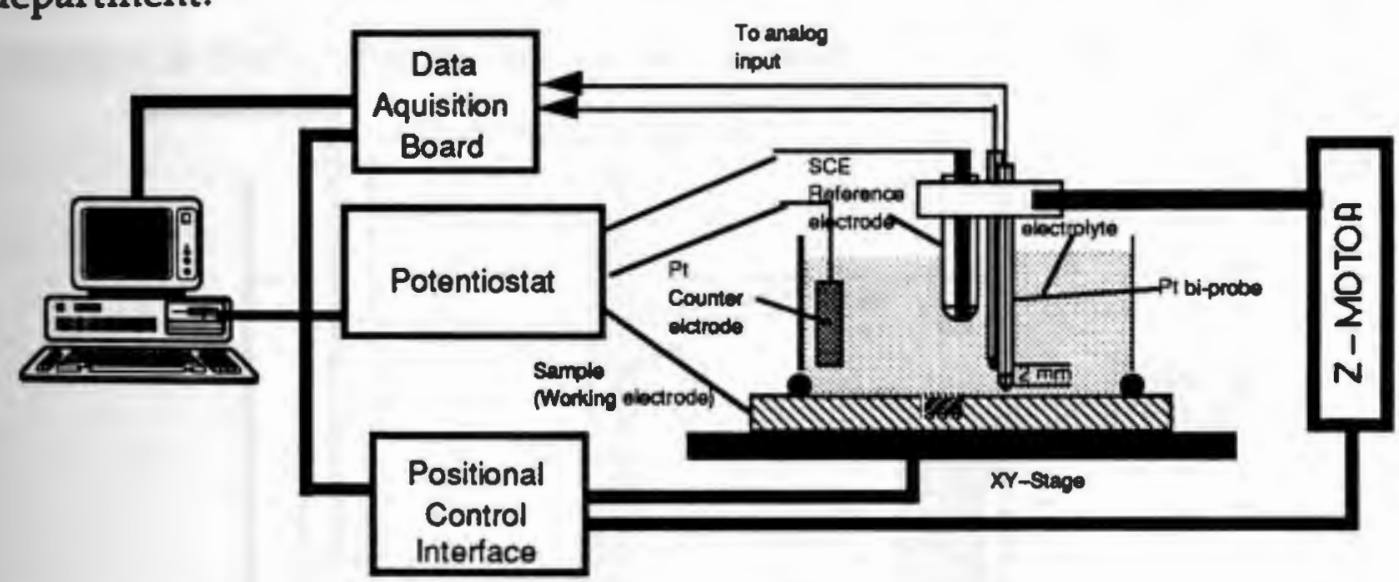

Figure 6. Schematic of the scanning reference electrode technique apparatus.

The experimental setup for the SRET experiment shown in figure 6 consists of a potentiostat to measure the potential difference between the $\mathrm{Pt}$ micro-reference electrode and the stationary calomel reference electrode, a personal computer to control the experiments and for data acquisition, three 
stepping motors, an xy stage, a vertical stand to hold the micro electrode over the surface, three motor control boards, a data aquisition board, a power supply to drive the motors and the control boards, and an electrochemical cell consisting of the micro-reference electrode, a saturated calomel electrode, electrolyte and the sample as a working electrode. The electrochemical cell for the SRET is detailed in figure 7. In nonbiased conditions, the potential difference is measured between the micro-reference electrode placed vertically several hundreds $\mu \mathrm{m}$ above the surface and a standard calomel reference electrode located further away from the surface. Under biased conditions, the potential difference can be measured between the two $\mathrm{Pt}$ micro-reference electrode tips displaced $2 \mathrm{~mm}$ vertically between them. Once the local potential measurements are conducted the local current density can be calculated by equation (2). Potential or current density variation in the $x y$ dimension can be graphed.

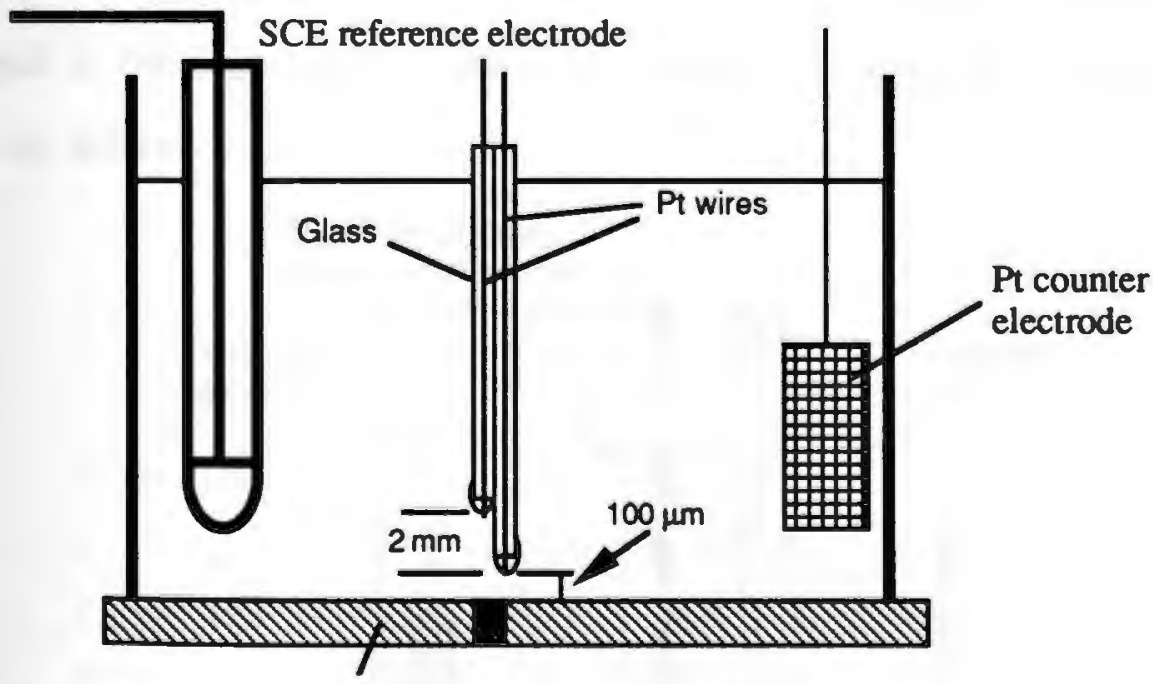

Figure 7. Schematic diagram of electrochemical cell for SRET experiment.

In the LEIS experiments, the $\mathrm{Pt}$ bi-probe was placed several hundreds $\mu \mathrm{m}$ vertically above the site of interest, figure 8 . The impedance measurement was conducted utilizing PARC M388 Impedance software 
through a frequency response analyzer and a potentiostat, figure 8. Applied potential perturbation was maintained between the working electrode and the reference electrode. Since the current and potential lines are perpendicular to one another, by measuring the ac potential drop between planes parallel to the electrode the ac current density normal to the surface can be calculated as given by equation (3). The local potential response in the solution over a specific site is measured at the two tips of $\mathrm{Pt}$ bi-probe and amplified through an amplifier and input to the current channel of the frequency response analyzer. This is measured as ratio of the output voltage perturbation to the measured potential difference at the tips. The measured data was normalized to ohm.cm ${ }^{2}$ by the tip separation distance of the biprobe, solution conductivity, amplifier gain and the selected current range of the potentiostat. On the potentiostat a constant current range has to be maintained throughout the experiment to provide accurate readings. The impedance data obtained through conventional impedance technique were compared to the local impedance data obtained at specific locations whether passive or active.

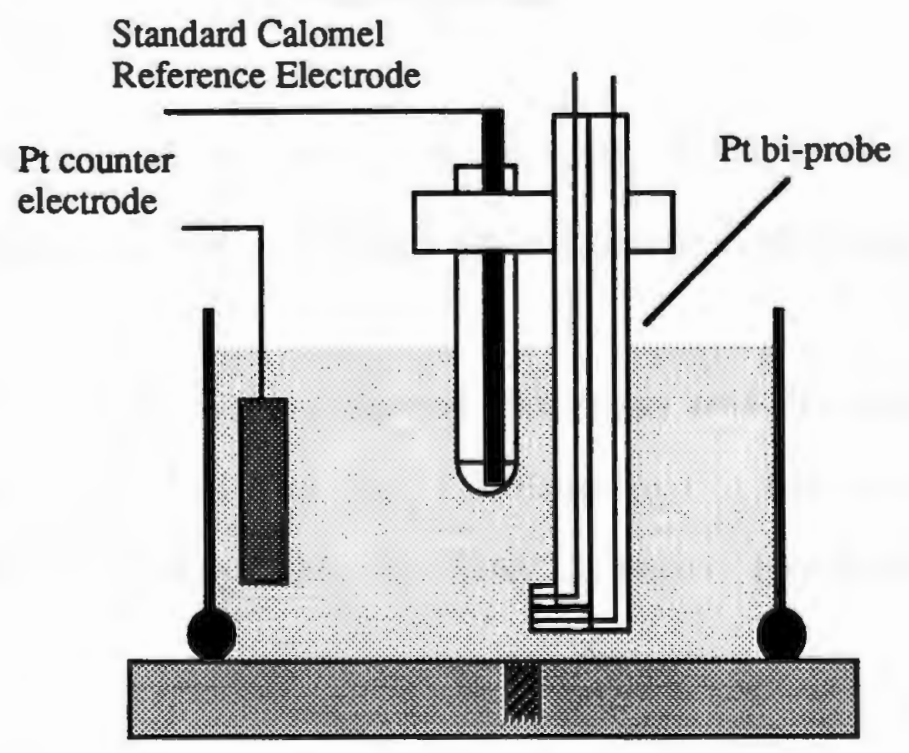

Working electrode 
Figure 8. Electrochemical cell for LEIS experiment showing the Pt bi-probe.

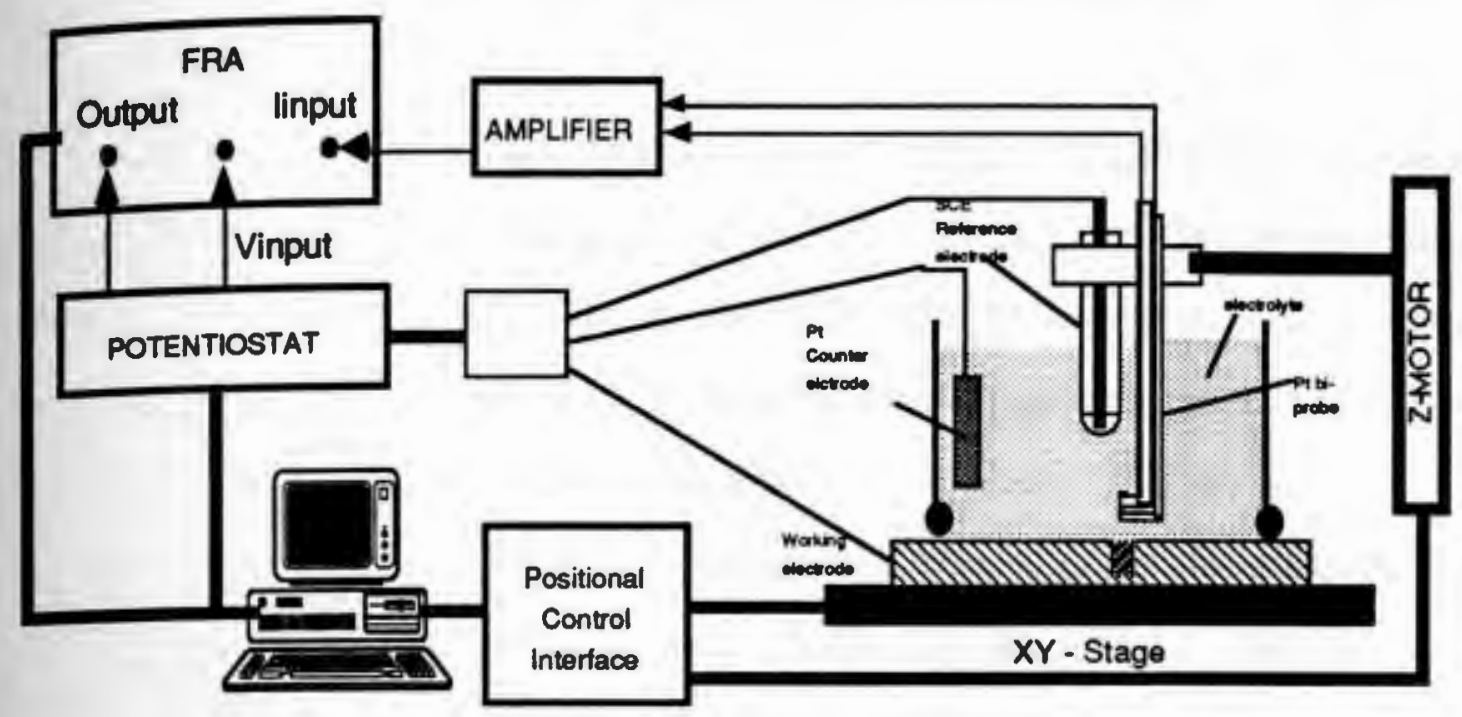

Figure 9. Schematic of apparatus for LEIS experiments.

Software to control the mechanical movements of the stage and read the measured potential by the potentiostat, and store the data was written in BASIC.

\section{REFERENCES}

1. L. van Leaven, M. N. Alias, R. Brown, "Corrosion Behavior of Ion Plated and Implanted Films", Surface and Coatings Technology, v53 (1992), 25-34

2. M. N. Alias, R. Brown, "Effect of Thickness and Process Parameters on Corrosion Behavior of $\mathrm{ZrN}$ and TiN Coatings in the Marine Environment", NACE CORROSION 93, Paper No. 30, NACE, Texas, Houston, 1993 
M. N. Alias, R. Brown, "Effect of Thickness and Composition on Corrosion Resistance of Nitride Films", Surface and Coatings Technology, v62 (1993), 467-473

4.

R. Brown, M. N. Alias, "Oxidation of Nitride Thin Films in Aqueous Solution : Correlation Between Surface Analysis and Electrochemical Studies", NACE Corrosion 94, Paper No. 322, NACE, Houston, Texas, 1994

5. R. Brown, M. N. Alias, "Thermodynamic Equilibrium Diagrams of $\mathrm{ZrN}, \mathrm{HfN}, \mathrm{TaN}, \mathrm{NbN}$ and $\mathrm{CrN}$ in Water"

6. H. Randhawa, P. C. Johnson, "Technical Note: A Review of Cathodic Arc Plasma Deposition Process and Their Applications", Surface and Coatings Technology, v31 (1987), 303-318

7. P. C. Johnson, H. Randhawa, "Zirconium Nitride Films Prepared by Cathodic Arc Plasma Deposition Process", Surface and Coatings Technology, v33 (1987), 53-62

8. M. Klietz, J. H. Kennedy, "Resolution of Multicomponent Impedance Diagrams", in Fast Ion Transport in Solids, P. Vashista, J. N. Mundy, and G. K. Shenoy eds., p.185-188, Elsevier-North Holland, New York, 1979

9. G. W. Walter, "Application of Impedance Measurements to Study Performance of Painted Metals in Aggressive Solutions", Journal of Electroanalytical Chemistry, v118 (1981), 259-273

10. A. E. Bohe, J. R. Vilche, K. Juttner, W. J. Lorenz, W. Kautek, W. Paatsch, "An Electrochemical Impedance Spectroscopy of Passive Zinc and Low Alloyed Zinc Electrodes in Alkaline and Neutral Aqueous Solutions", Corrosion Science, v32 (1991), 621-633

11. H. Shih, F. Mansfeld, "A Fitting Procedure for Impedance Spectra Obtained for Cases of Localized Corrosion", Corrosion, v45 (1989), 610-614 
K. Juttner, "Electrochemical Impedance Spectroscopy (EIS) of Corrosion Processes on Inhomogeneous Surfaces", Electrochimica Acta, v35 (1990), 1501-1508

13.

D. Kaushik, M. N. Alias, R. Brown, "An Impedance Study of a Carbon Fiber Vinyl Ester Composite", Corrosion, v47 (1992), 859-867

14. M. N. Alias, R. Brown, 'Damage to Composites from Electrochemical Processes", Corrosion, v48 (1993), 373-378

15. J. A. Bardwell, M. C. H. McKubre, "ac Impedance Spectroscopy of the Anodic Film on Zirconium in Neutral Solution", Electrochimica Acta, v36 (1991), 647-653

16. M. G. S. Ferreira, and J. L. Dawson, I. Electrochemical Society v132 (1985), p.760

17. A. G. G. Allah, A. A. Mazhar, "Impedance Studies on the Anodic Passivity of Titanium in Aqueous Media of Different pH", Corrosion, v45 (1989), 381-386

18. H. S. Isaacs, B. Byas, "Scanning Reference Electrode Techniques in Localized Corrosion", Electrochemical Corrosion Testing, ASTM STP 727, F. Mansfeld, U. Bertocci, eds., American Society for Testing Materials, 1981, 319. B. Vyas, H. S. Isaacs, "Detecting Susceptibility to Intergranulaar Corrosion of Stainless Steel Weld Heat-Affected Zones", Intergranular Corrosion Testing, ASTM STP 656, R. F. Steigerwald, ed., Americal Society for Testing Materials, 1987, 133-145

20. H. S. Isaacs, "The Effect of Height on the Current Distribution Measured with a Vibrating Electrode Probe", Journal of the Electrochemical Society, v138 (1991), 722-728

21. K. Tokuda, T. Geushi, K. Aoki, H. Matsuda, "Finite-Element Method Approach to the Problem of the IR-Potential Drop and Overpotential 
Measurements by Means of a Luggin-Haber Capillary", Journal of the Electrochemical Society, v132 (1985), 2390-2398

22. H. S. Isaacs, "Application of Current Measurement Over Corroding Metallic Surfaces", Ionic Currents in Developments, 1986, 37-44

23. H. S. Isaacs, "Detection of Defects and Metallurgical Variations in Metal Surfaces", Novel NDE Methods for Materials, B. K. Rath ed., The Metallurgical Society of AIME, 1983, 63-76

24. H. S. Isaacs, "The Localized Breakdown and Repair of Passive Surfaces During Pitting", Corrosion Science, v29 (1989), 313-323

25. H. S. Isaacs, M. W. Kendig, "Determination of Surface Inhomogeneities Using a Scanning Probe Impedance Technique", Corrosion, v36 (1980), 269-274

26. J. V. Standish, H. Leidheiser, Jr., "The Electrical Properties of Organic Coatings On a Local Scale-Relationship to Corrosion", Corrosion, v36 (1980), 390-395

27. R. S. Lillard, P. J. Moran, H. S. Isaacs, "A Novel Method for Generating Quantitative Local Electrochemical Impedance Spectroscopy", Journal of the Electrochemical Society, v139 (1992), 1007-1012 


\section{CHAPTER II}

\section{EFFECT OF THICKNESS AND AN INTERLAYER ON CORROSION}

BEHAVIOR OF ION PLATED TIN COATINGS ON 304 SS 


\section{ABSTRACT}

The effect of film thickness and $\mathrm{Ti}$ interlayer on corrosion behavior of ion plated titanium nitride coatings on stainless steel substrate was investigated utilizing potentiodynamic and ac impedance techniques. A charge transfer resistance of $6 \times 10^{5} \mathrm{ohms. \textrm {cm } ^ { 2 }}$ was calculated for all thickness conditions indicating that film thickness did not affect the the corrosion resistance. A similar result was noted for samples with an intermediate layer. Thicker coating and coatings with $\mathrm{Ti}$ interlayer have greater potential range of passive films and more noble breakdown potential than the bare 304 SS and $5 \mu \mathrm{m}$ TiN coated 304 SS. 


\section{INTRODUCTION}

Titanium nitride is a hard ceramic coating primarily known for its wear resistance 1,2. However its protective capacity was questioned as localized corrosion was reported by several researchers 3-6. In a previous study of a $5 \mu \mathrm{m}$ thick ion plated coating, extensive localized corrosion on TiN coated 52100 steel and 304 stainless steel exposed to $\mathrm{NaCl}$ solution was found7. Ion implantion of the $\mathrm{TiN}$ coating with $\mathrm{Au}$ and $\mathrm{Ti}$ did not improve the resistance. Porosity extending to the substrate from the exposed surface contributed to localized corrosion and in some cases galvanic corrosion between the electrochemically dissimilar substrate and coating 8-10. Microdefects and columnar structures in TiN coatings are common and contribute to poor substrate protection. It is then desirable to either deposit thicker coatings or introduce intermediate layers to attempt to disrupt the permeation path for electrolyte. Interfacial layers of metal between substrate and coatings, eg. Ti between steel and TiN, were used to isolate the substrate

completely from the corrosive medium 11-13. Slight reduction in passive current density was found for $\mathrm{TiN}$ with $\mathrm{Cr}, \mathrm{Ni}$ or $\mathrm{Ti}$ interlayer when compared to a single TiN layer. One useful coating technique is cathodic ion plating technique as it is known for its rapid deposition rates in comparison to sputtering and was the technique chosen in this study to develop these thicker coatings $1,2,14,15$.

The objective of the research was to identify which process parameters were most effective in improving corrosion resistance, either film thickness or in presence of $\mathrm{Ti}$ interlayer. The interlayer in this case is not for coating adhesion but for corrosion protection. It was placed within the TiN rather 
than at the substrate/coating interface to determine if passivation reactions were enhanced. Results from cyclic and linear polarization experiments conducted to reinforce impedance spectroscopy data are discussed.

\section{TABLE 1: TIN COATING SPECIFICATIONS}

Single layer

1. TiN

2. TiN
Thickness $(\mu \mathrm{m})$

5

10
Multi layer

3. $\mathrm{TiN} / \mathrm{Ti} / \mathrm{TiN}$

4. $\mathrm{TiN} / \mathrm{Ti} / \mathrm{TiN}$

5. TiN/Ti(b)/TiN/Ti(b)/TiN

(TiN layer is interrupted with $\mathrm{Ti}$ ions bombarded at $-1000 \mathrm{~V}$ )

6. $\mathrm{TiN} / \mathrm{Ti} / \mathrm{TiN}$

$5.2 / 0.9 / 2.4$

(large defects are visible on coating)

\section{EXPERIMENTAL PROCEDURES}

Materials

Substrates used were AISI 304 stainless steel with the composition noted in a previous paper 7 . Substrate dimensions were $3.2 \mathrm{~cm}$ diameter and $0.2 \mathrm{~cm}$ thick. The coatings were applied using cathodic arc ion plating technique at Multi Arc Scientific Coatings, New Jersey. Precleaning of the substrates was carried out by degreasing with non-freon degrease (NFD), rinsing with tap water, spraying with deionized water, and drying. Different 
thicknesses of coating of single TiN and multilayer coatings were applied to the stainless steel and they are detailed in table 1.

For comparative data the electrochemical behavior of titanium used as the starting material for the deposition process, and 304 SS were also studied.

Experimental Techniques

Pre-exposure surface characterization of the samples were conducted using SEM. Samples were examined again after exposure.

Corrosion experiments were conducted in $0.5 \mathrm{~N} \mathrm{NaCl}$, naturally aerated. Three different electrochemical techniques employed were ac impedance, cyclic polarization and linear polarization. Ac impedance measurements were conducted employing a three electrode cell shown elsewhere 7. Samples were exposed to electrolyte up to 60 days. Applied ac voltage amplitude was $5 \mathrm{mV}$, over bandwidth of $0.001 \mathrm{~Hz}$ to $100 \mathrm{kHz}$, and at open circuit potential. Surface area exposed was $6 \mathrm{~cm}^{2}$. Non-linear least squares fitting procedure EQUIVCRT was employed to simulate the experimental data 16. Corrosion behavior of coatings are discussed in terms of parameters from equivalent circuit model that give a best fit to the experimental data.

Potentiodynamic cyclic polarization and linear polarization were conducted in naturally aerated $0.5 \mathrm{~N} \mathrm{NaCl}$ solution over $1 \mathrm{~cm}^{2}$ area. Stable free corrosion potential was achieved before experiments were conducted. In cyclic polarization, the potential was scanned from $-50 \mathrm{mV}$ of the free corrosion potential in the noble direction, and reversed once the current density reached $1000 \mu \mathrm{A} / \mathrm{cm}^{2}$. The linear polarization measurements were 
conducted at three potential ranges; $+/-10,15$, and $20 \mathrm{mV}$ from the free corrosion potential, to show the effect of potential on the polarization resistance. These values were then compared to those extracted from equivalent circuit modelling of impedance data.

\section{EXPERIMENTAL RESULTS}

\section{Pre-exposure Surface Characterization}

The surface features of coated TiN exhibited several different defect morphologies, see figure 1, as well as reproducing the substrate surface finish indicated by the linear markings on the coatings surface. The defects did not expose the substrate to the environment. Two different categories were noted; type I defects that were above the average surface height and type II defects whose surface was below the average surface height. Within these two categories two subdivisions were found. For the increased height defects, some appeared to be small microdroplets around $2 \mu \mathrm{m}$ in diameter, while others were much larger, around $20 \mu \mathrm{m}$ in diameter. The larger defects were characterized by a flat plateau region which made their shape very short cylinders. For defects where coating was absent these occurred as small circular depressions around $2 \mu \mathrm{m}$ in diameter. These were probably regions where small droplets lost adhesion. Other larger irregular absent defects were found. Their shape was related to the truncated cylinders defect as was their size. In addition to these microscopic features, the TiN coating with $\mathrm{Ti}$ interlayer exhibited visually observable defects about $100 \mu \mathrm{m}$ in diameter, figure $1 b$.

Electrochemical Impedance Spectroscopy 


\section{a. Single layer coatings}

Corrosion was previously reported on a $5 \mu \mathrm{m}$ TiN coated 304 SS due to the large porosity in the coatings 7 . In this study, on a different sample with similar thickness and defects typical of that shown in figure 1a, no corrosion was observed over the test period. Initially the data showed high phase angle at frequencies higher than $1 \mathrm{~Hz}$. The impedance is high slightly above $10^{5}$ ohm at low frequency, figure 2. Both increased with time in the low frequency region below $1 \mathrm{hz}$ with further exposure.

The $10 \mu \mathrm{m}$ sample initially shown high phase angle behavior approaching $80^{\circ}$ over a wide range of frequency and impedance approaching $10^{5} \mathrm{ohm}$ at low frequency, figure 3. Increasing exposure increased the phase angle and impedance at low frequency. No corrosion was observed on this sample.

\section{b. Multi layers coatings}

Initial impedance behavior for coatings \#3, 4 and 5 was high approaching $10^{5} \mathrm{ohm}$ at low frequency, and the phase angle was high nearly $80^{\circ}$ over wide range of frequency, figure 4 and 5 . Except for coating \#3, all three coatings shown increased in impedance and phase angle at low frequency with increasing exposure. The coating seem to peel from an area on the thicker coating with $\mathrm{Ti}$ interlayer \#3. This was indicated by significant decreased in impedance and phase angle after 5 days exposure. Both the impedance and phase angle increased again approaching $10^{5} \mathrm{ohm}$ and $80^{\circ}$ at low frequency region, respectively, with further exposure. No corrosion was observed on all three coatings. 
Initial impedance behavior of coating \#6 with larger defects shown two maxima behavior with the impedance nearly similar to those of other multilayer TiN coatings, figure 6. With increasing exposure, a slight increased in phase angle at frequencies less than $1 \mathrm{~Hz}$ was observed. No corrosion of the substrate was observed.

\section{Potentiodynamic Behavior}

The cyclic polarization scans plot of 304 SS and titanium are shown in figure 7. The stainless steel has a corrosion potential ( $\mathrm{E}_{\text {corr }}$ ) at $90 \mathrm{mV}$ (SCE). The scan shown a typical anodic Tafel behavior followed by a passive region with the primary passivation potential $\left(\mathrm{E}_{\mathrm{pp}}\right)$ and the critical current density of film formation ( $\mathrm{I}_{\mathrm{crit}}$ ) at $120 \mathrm{mV}(\mathrm{SCE})$ and $0.005 \mu \mathrm{A} / \mathrm{cm}^{2}$, respectively. The breakdown potential $\left(\mathrm{E}_{\mathrm{b}}\right)$ of the passive film on 304 SS is approximately at $330 \mathrm{mV}(\mathrm{SCE})$. The scan for titanium also indicated an anodic Tafel behavior followed by a passsive region with the $E_{c o r r}, E_{p p}, I_{c r i t}$ and $E_{b}$ at $-386 \mathrm{mV}(\mathrm{SCE}),-80 \mathrm{mV}(\mathrm{SCE}), 0.6 \mu \mathrm{A} / \mathrm{cm}^{2}$ and $1100 \mathrm{mV}$ (SCE), respectively.

The cyclic polarization scans plot of various TiN coated 304 stainless steels are shown in figure 8. They are characterized by an anodic Tafel region followed by a passive region until the breakdown potential is reached. All but the $10 \mu \mathrm{m}$ TiN coated 304 SS have Ecorr slightly more noble than the bare 304 SS, see table II. 
TABLE II

CXCLIC POLARIZATION CHARACTERISTICS OF TIN COATINGS

\begin{tabular}{|c|c|c|c|c|}
\hline Coatings & Ecorr & $\mathrm{E}_{\mathrm{PP}}$ & $I_{\text {crit }}$ & $E_{b}$ \\
\hline & (mV vs.SCE) & (mV vs.SCE) & $\left(1 \mathrm{~A} / \mathrm{cm}^{2}\right)_{2}$ & $(\mathrm{mV}$ vs.SCE) \\
\hline Bare 304 SS & 90 & 120 & 0.005 & 330 \\
\hline $\mathrm{Ti}$ & -386 & -80 & 0.600 & 1100 \\
\hline $5 \mu \mathrm{m} \mathrm{TiN}$ & 137 & 160 & 0.004 & 260 \\
\hline $10 \mu \mathrm{m} T \mathrm{TN}$ & 36 & 30 & 0.020 & 1060 \\
\hline M/layer TiN \#3 & 118 & 160 & 0.010 & 1080 \\
\hline M/layer TiN \#4 & 152 & 160 & 0.010 & 400 \\
\hline $\operatorname{monN} \#=5$ & 133 & 160 & 0.010 & 740 \\
\hline
\end{tabular}

TABLE III : POLARIZATION RESISTANCE $\left(\mathbf{R}_{\mathbf{p}}\right)$

Coating

Potential Range $\quad \mathbf{R}_{\mathbf{p}}$

a. $5 \mu \mathrm{m}$ TiN

$+/-10 \mathrm{mV}$

(ohm.cm 2 )

b. $10 \mu \mathrm{m}$ TiN

$+/-20 \mathrm{mV}$

$5.63 \mathrm{E}+5$

$6.78 \mathrm{E}+5$

$+/-10 \mathrm{mV}$

$6.49 \mathrm{E}+5$

$+/-15 \mathrm{mV}$

$4.25 \mathrm{E}+5$

$+/-20 \mathrm{mV}$

$7.95 \mathrm{E}+5$

c. M/layer TiN \#3

$+/-10 \mathrm{mV}$

$2.43 E+5$

$+/-15 \mathrm{mV}$

$4.29 \mathrm{E}+5$

$+/-20 \mathrm{mV}$

$7.05 \mathrm{E}+5$

d. M/layer TiN \#4

$+/-10 \mathrm{mV}$
$+/-15 \mathrm{mV}$
$+/-20 \mathrm{mV}$

$1.28 \mathrm{E}+5$

$6.11 \mathrm{E}+5$

$5.16 E+5$

e. M/layer TiN \#5

$+/-10 \mathrm{mV}$

$+/-20 \mathrm{mV}$

$7.74 \mathrm{E}+5$

$5.34 \mathrm{E}+5$ 
The critical current density for film formation on TiN coated 304 SS is slightly higher than that on bare 304 SS. The $10 \mu \mathrm{m}$ coating and coatings with Ti interlayer have more noble breakdown potential than that of 304 SS. Coatings of approximately $10 \mu \mathrm{m}$ thick, both the single layer and with $\mathrm{Ti}$ interlayer, have breakdown potential closer to that on titanium.

The linear polarization measurements results are tabulated in table III. A general trend of the polarization resistance increasing slightly with thickness was noted when values determined at the same potential range are compared. The multi-layer TiN exhibited marginally lower values than its equivalent thickness single layer coatings. The values for all the coatings are within the same order of magnitude in the range 1 to $8 \times 10^{5} \mathrm{ohms.cm}$.

\section{Free Corrosion Potential}

The free corrosion potential of all samples shown increased to nearly 250-300 $\mathrm{mV}(\mathrm{SCE})$ with increasing exposure, with the exception of the TiN with Ti interlayer \#6 having large defects, figure 9. The potential decreased to more negative values as time increased. The sudden decrease in potential for coating \#3 after 5 days was observed corresponding to peeling of coating.

\section{Post-Exposure Surface Characterization}

No significant differences of the exposed surface from that prior to exposure were observed on all samples with exception of $\mathrm{TiN}$ with $\mathrm{Ti}$ interlayer \#3. Figure 10 shown the region where coating was peeled from the substrate. An intergranular pattern from the underlying stainless steel which was exposed by the peeling can be seen. It should be noted that the initial 
coating with large defects did not show this intergranular effect as can be seen by comparing figure $1 \mathrm{~b}$ and figure 10 which are at comparable magnifications.

\section{DISCUSSION}

Impedance Analysis

The equivalent circuit shown in figure 11 was succesfully used to model all the impedance data in this study. $R_{S}$ is the solution resistance, $R_{t}$ $\mathrm{Cdl}_{\mathrm{dl}}$ sub-circuit describes the interfacial processes at flat coating regions, and the $R_{t}$ (defect) $-C_{d l}$ (defect) sub-circuit describes the interfacial processes at the defects. These sub-circuits are built in series due to fact that the defects do not expose the substrate directly to the solution. This is similar to the circuit to describe the oxide films on aluminum alloys 17 .

The charge transfer resistance $\left(R_{t}\right)$ and double layer capacitance $\left(C_{d l}\right)$ obtained from data modeling are shown in figure 12 . $\mathbf{R}_{\mathbf{t}}$ for the single layer coatings increased with time due to formation of oxide films on the coating 18-20. This is supported by the corresponding increase of the free corrosion potential into the passive range as shown in cyclic polarization scans. Higher $R_{t}$ for the $5 \mu \mathrm{m}$ sample in this study than that was previously reported 7 is mainly due to improved coverage of the coating, confirming the role of porosity in protective coating to enhance localized corrosion of the substrate $8-10$.

The charge transfer resistance for the all multilayer coatings increased above $10^{5} \mathrm{ohm} . \mathrm{cm}^{2}$ with increasing time of exposure except that of the multilayer TiN \#6 with larger defects. The charge transfer resistance of this coating increased to nearly $10^{5} \mathrm{ohm} . \mathrm{cm}^{2}$ in the first 5 days but decreased 
nearly a half order of magnitude upon further exposure. This strongly indicated the effect of defects on the overall charge transfer resistance.

The charge transfer resistance for coating with titanium interlayer \#3 decreased rapidly to about $10^{4}$ ohms.cm ${ }^{2}$ after 5 days due to peeling of coating, but increased again with increasing exposure for this coating due to repassivation of the peeled region. This was indicated by increase of the corrosion potential to the level of those of other coatings days after peeling occurred. Peeling of coating layer is possibly due to poor adhesion between the thicker coating and substrate. Discussion of this subject is beyond the scope of this study, but can be found elsewhere 21-23.

The charge transfer resistance of $\mathrm{TiN}$ with interlayer \#4 increased approaching $10^{6} \mathrm{ohms.cm^{2 }}$ during the exposure period, higher than almost all other coating schemes used in this study. This coating adhered to the substrate better than the thicker TiN with interlayer \#3. The TiN with interlayer \#5 coating also adhered better to the substrate than TiN with interlayer \#3. The charge transfer resistance is slightly lower than TiN with interlayer \#4 but is more stable throughout the test period.

\section{Potentiodynamic behavior}

The cyclic polarization scan plot of titanium shown anodic passive region due to formation of oxide film, $\mathrm{TiO}_{2} \cdot \mathrm{H}_{2} \mathrm{O} 24$. It was theoretically shown that similar oxide layer can be formed by oxidation of $\operatorname{TiN} 25$. The passive region on TiN coated 304 stainless steels is possibly due to formation of this oxide film on the coating. Other studies had suggested the formation of $\mathrm{TiO}_{x} \mathrm{~N}_{y}$ phase by partial transformation of $\mathrm{TiN}$ into an oxidized layer 26 or 
by incorporation of oxygen into the TiN layer beneath the oxidized layer due by diffusion of oxygen 27 . However, XPS analysis of the $5 \mu \mathrm{m}$ TiN coating exposed at open circuit condition did not indicate transformation of TiN to oxide filims 28 .

The effect of increasing TiN coating thickness was to increase the passive region to more noble potentials for both the single and interlayer coatings. The thicker coatings have more titanium for further oxidation to thicken the passive film which extend the passive region to higher potential. The critical current density for film formation on all coatings are nearly identical, with the interlayer and the bombarded $\mathrm{Ti}$ ions not affecting the kinetics of TiN oxidation and indicating the pseudo passive range is a surface dominated process. However, the higher breakdown potential $\left(E_{p}\right)$ for thicker coating suggesting a relatively greater stability of oxide during the breakdown and repair processes. Similar explanation is applicable for the approximately $5 \cdot \mu \mathrm{m}$ coating thickness where the breakdown potential for TiN coating interrupted with $\mathrm{Ti}$ ions bombardment is higher than those of a single layer and with $\mathrm{Ti}$ interlayer coatings.

The polarization resistance measurements shown values of $R p$ very similar, table III, for different coatings indicate very small effect of thickness and interlayer on the corrosion resistance which may be due to the surface domination for the process for these particular films. 


\section{CONCLUSIONS}

1. Better corrosion resistance of stainless steel in sodium chloride media is shown for a single layer titanium nitride coating due to lesser porosity and defects, and by increasing the coating thickness.

2. Intermediate titanium layer in the titanium nitride coating improved the charge transfer resistance at the minimal coating thickness, ie. pproximately $5 \mu \mathrm{m}$, possibly due to better coating adhesion through the interlayer and better coating coverage of the substrate. Similar could be possible for coating interrupted with $\mathrm{Ti}$ ions though shown smaller charge transfer resistance but most stable with time.

3. Increased charge transfer resistance with time are contributed to formation of oxide film on nitride coating.

\section{ACKNOWLEDGMENT}

Authors would like to thank Ray Fontana at Multi Arc Coatings, New Jersey for providing the PVD coatings.

\section{REFERENCES}

1. J. Danroc, A. Aubert, and R. Gillet, Thin Solid Films v153 (1987), p.281

2. O. A. Johansen, J. H. Dontje, and R. L. D. Zenner, Thin Solid Films, v153 (1987), p.75 
3.

E. I. Meletis, A. Erdemir, and R. F. Hochman, I. of Materials Engineering, v7 (1985), p.173

4.

Y. Massiani, J. Crousier, L. Fedrizzi, A. Cavalleri, and P. L. Bonora, 5.

Conce and Engineering, v69 (1985), p89

6.

E. I. Meletis, W. B. Carter, and R. F. Hochman, Microstructural Science, v13 (1986), p.417

7. L. van Leaven, M. N. Alias, and R. Brown, Surface and Coatings Technology, v53 (1992), p.25

8. M. J. Park, A. Leyland, A. Matthews, Surface and Coatings Technology v43/44 (1990), p.481

9. P. V. Nazarenko, A. G. Molyar, I. E. Polishchuk, O. G. Yachinskaya, and A. A. Il'in, Translated from Metallovedenie i Termicheskaya Obrabotka Metallov No. 4 (April 1990), p.61

10. V. A. Dmitriev, L. A. Khvorostukhin, M. A. Tolstaya, Yu. I. Pavlov, A. E. Bolmanenkov, and A. A. Emel'yanov, Translated from Zaschita Metallov v26 (1990), p.151

11. V. V. Lyubimov, A. A. Voevodin, S. E. Spassky, and A. L. Yerokhin, Thin Solid Films, v207 (1992), p.117

12. A. M. Kotlyar, E. K. Sevidova, and T. V. Steglik, Elektronnaya Oprabotka Materialov, No. 4 (1989), p.52-55

13. S. J. Bull, P. R. Chalker, C. F. Ayers, and D. S. Rickerby, Materials and Thence Engineering, vA139 (1991), p.71

14. H. Randhawa, and P. C. Johnson, Surface and Coatings Technology v31 (1987), p. 303 
15

P. C. Johnson, and H. Randhawa, Surface and Coatings Technology v33 (1987), p.53

16.

B. A. Boukamp, EOUIVCRT-Users Manual, 2nd ed., revised, University of Twente, Netherlands, 1989

17. J. Hitzig, K. Juttner, W. J. Lorenz, and W. Paatsch, I. of the Thatrochemical Society, v133 (1986), p.887

18. J. Bardwell, and M. C. H. McKubre, Electrochimica Acta v36 (1991), p. 647

19. M. G. S. Ferreira, and J. L. Dawson, I. of the Electrochemical Society, v132 (1985), p.760

20. M. E. Curly-Fiorino, and G. M. Schmid, Corrosion Science, v20 (1980), p.313

21. T. Arai, H. Fujita, and M. Watanabe, Thin Solid Films, v154 (1987), p.387

22. J. Seijka, C. Cherki, and J. Yahalom, Electrochimica Acta, v17 (1972), p.2371

23. J. Yahalom, and A. Poznansky, in Passivity of Metals, P. Frankenthal, ed., The Electrochemical Society, Pennington, New Jersey, 1972

24. M. J. N. Pourbaix, Atlas of Electrochemical Equilibria in Aqueous Solutions, Pergamon, New York, 1966

25. A. K. Gorbachev, Translation from Zashchita Metallov v19 no.2 (1983), p.253

26. Y. Massiani, A. Medjahed, P. Gravier, L. Argeme, and L. Fedrizzi, Mhin Solid Films, v191 (1990), p.305

27. I. Montero, C. Jimenez, and J. Perriere, Surface Science, v251/252 (1991), p.1038 
28. R. Brown, M. N. Alias, "Oxidation of Nitride Films in Aqueous Solutions: Correlation Between Surface Analysis and Electrochemical Studies", paper No. 21, NACE Corrosion '94, Baltimore, Maryland, 1994 
(a)

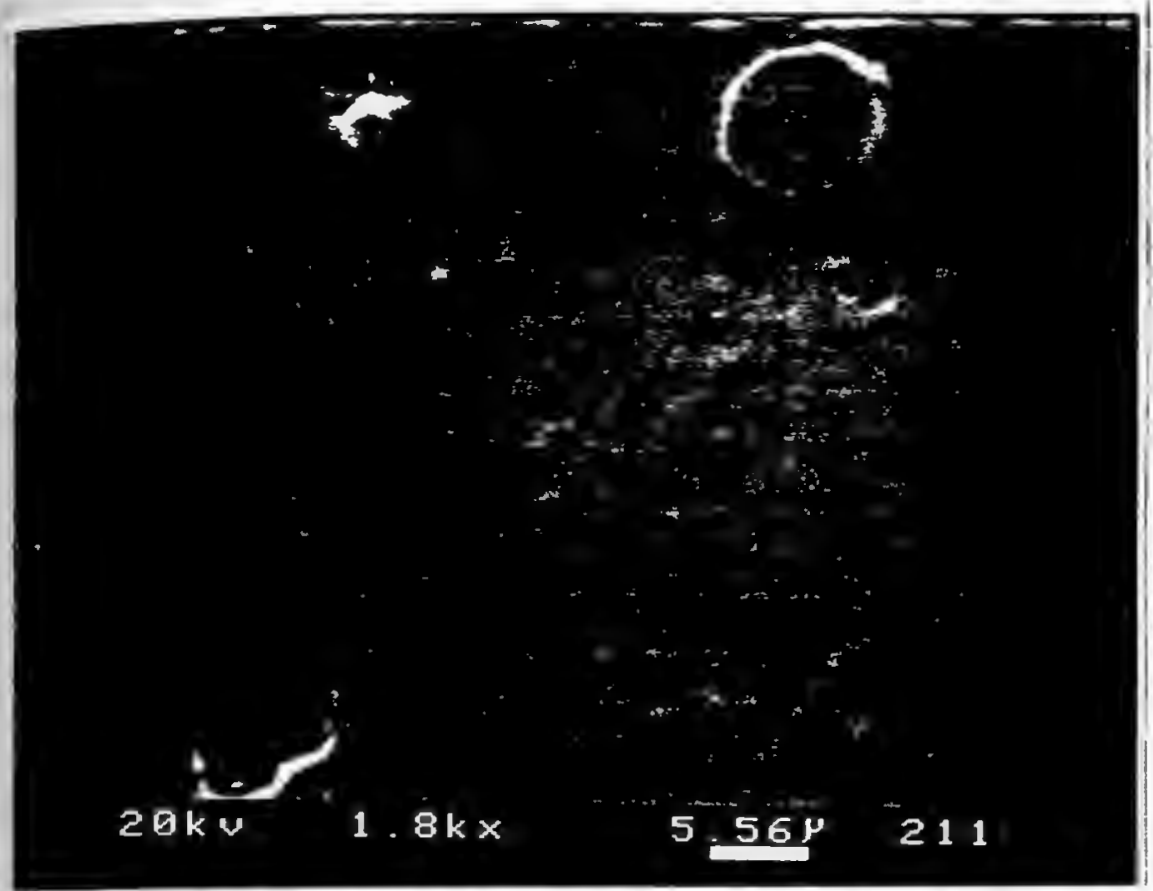

(b)

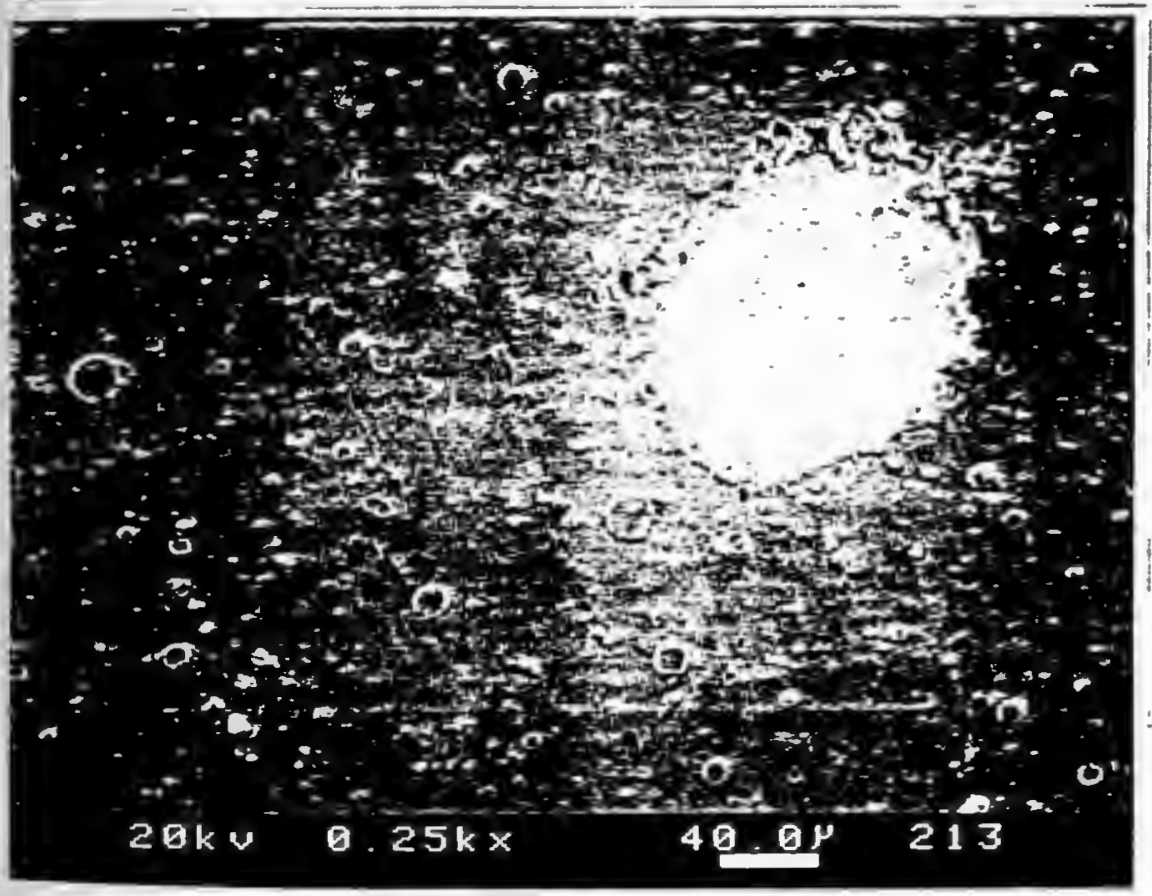

Figure 1. (a) Typical surface microstructure found on TiN coated stainless steel shown small defects and growths, and (b) surface of TiN coating with Ti interlayer \#6 shown relatively larger defects of approximately $100 \mu \mathrm{m}$ in diameter but do not exposing the substrate. 

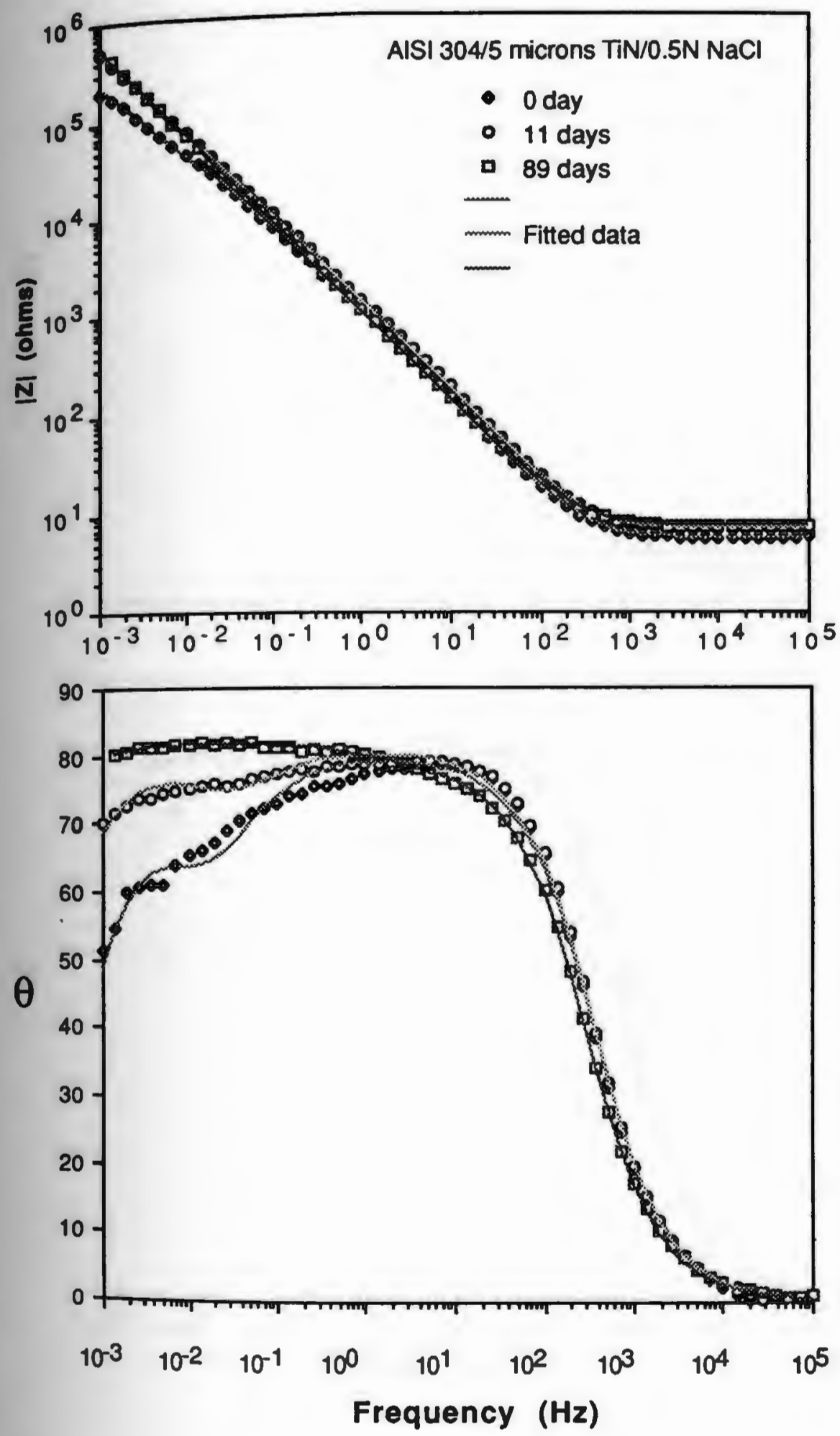

Figure 2. Bode plots of $5 \mu \mathrm{m}$ titanium nitride coated 304 stainless steel. 

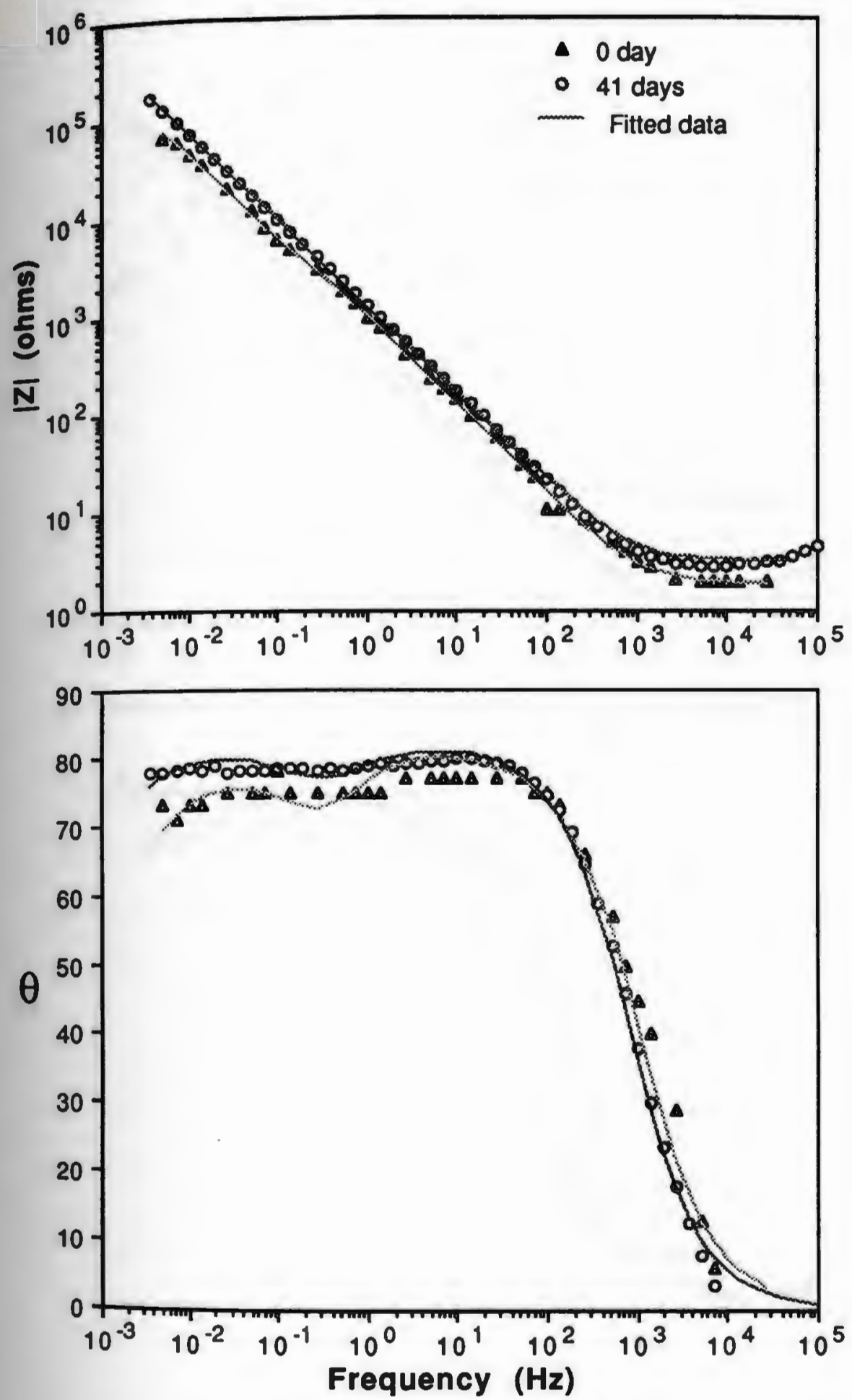

Figure 3. Bode plots of $10 \mu \mathrm{m}$ TiN coated 304 SS. 

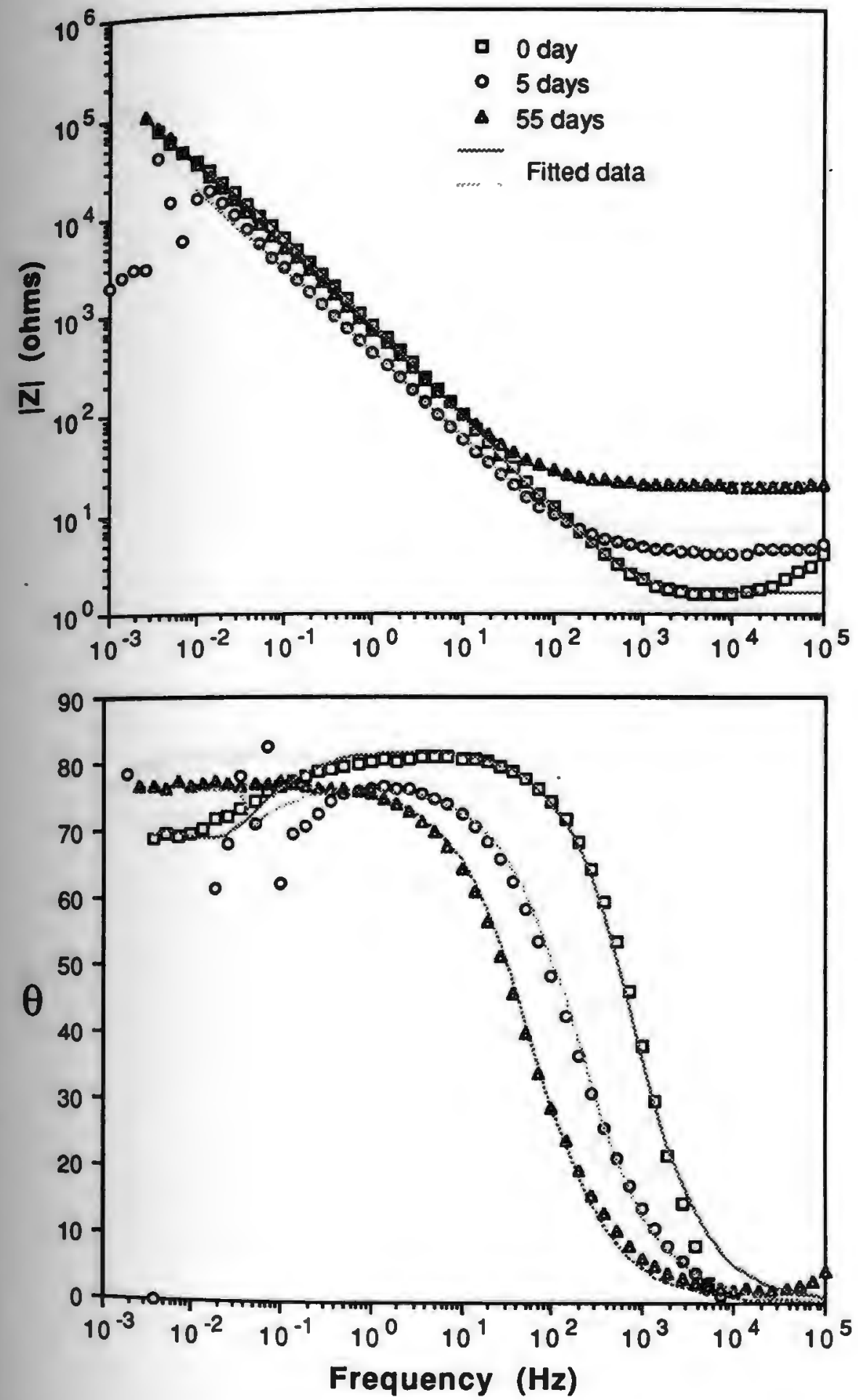

Figure 4. Bode plots of TiN coating with Ti interlayer \#3 on 304 SS. 

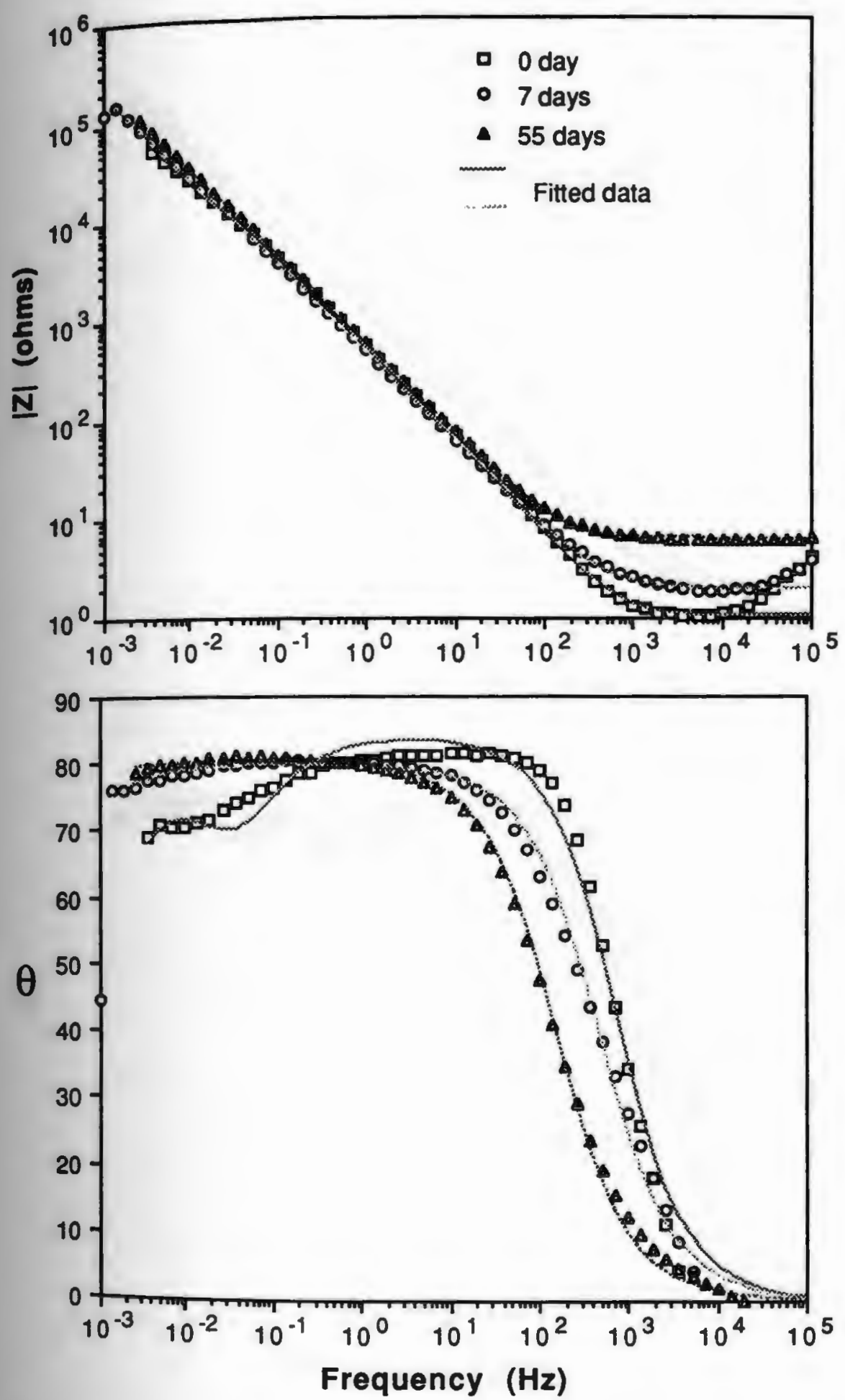

Figure 5. Bode plots for TiN coating with Ti interlayer \#4 on 304 SS. 

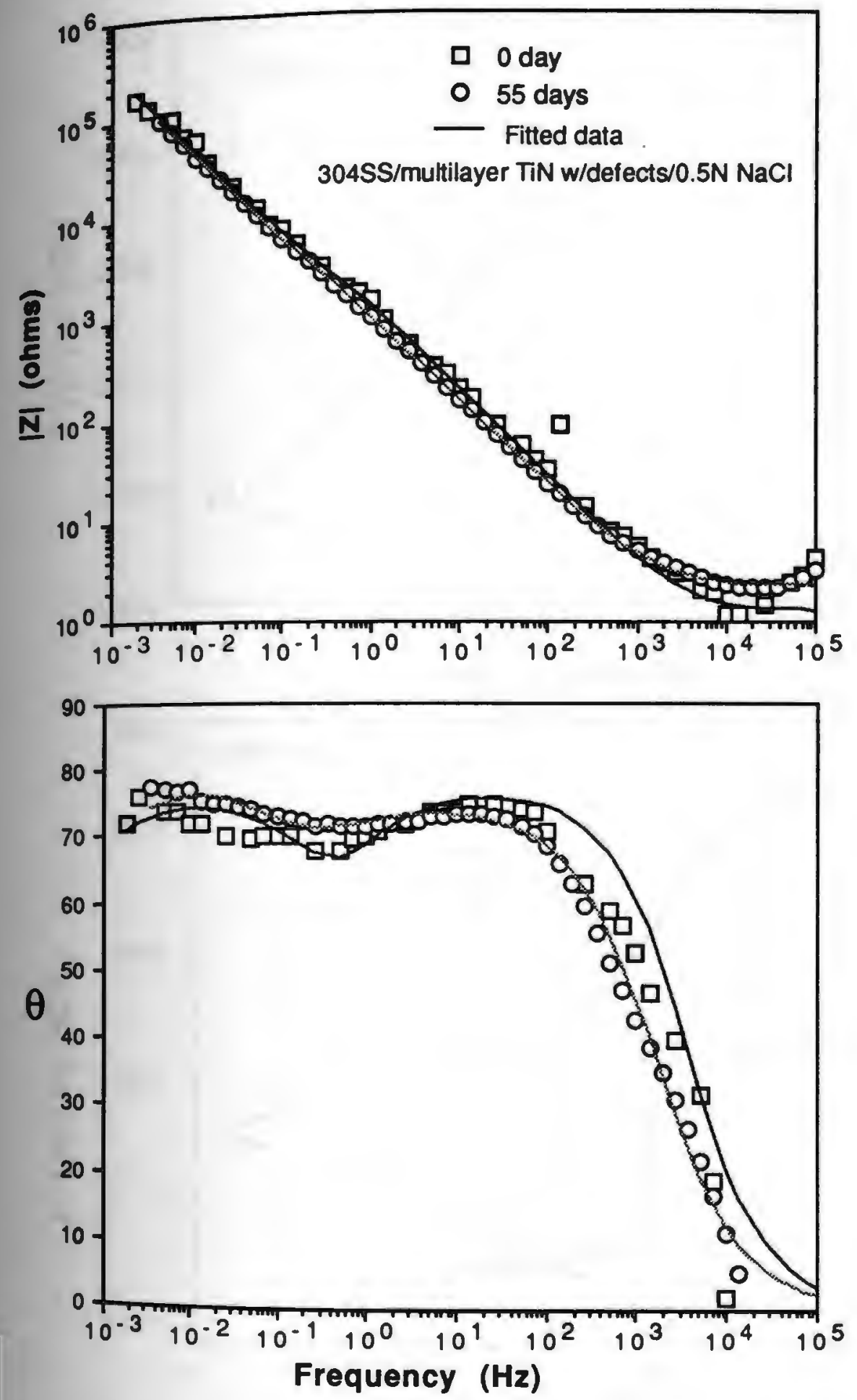

Figure 6. Bode plots for TiN with Ti interlayer \#6 with large defects on 304 SS. 

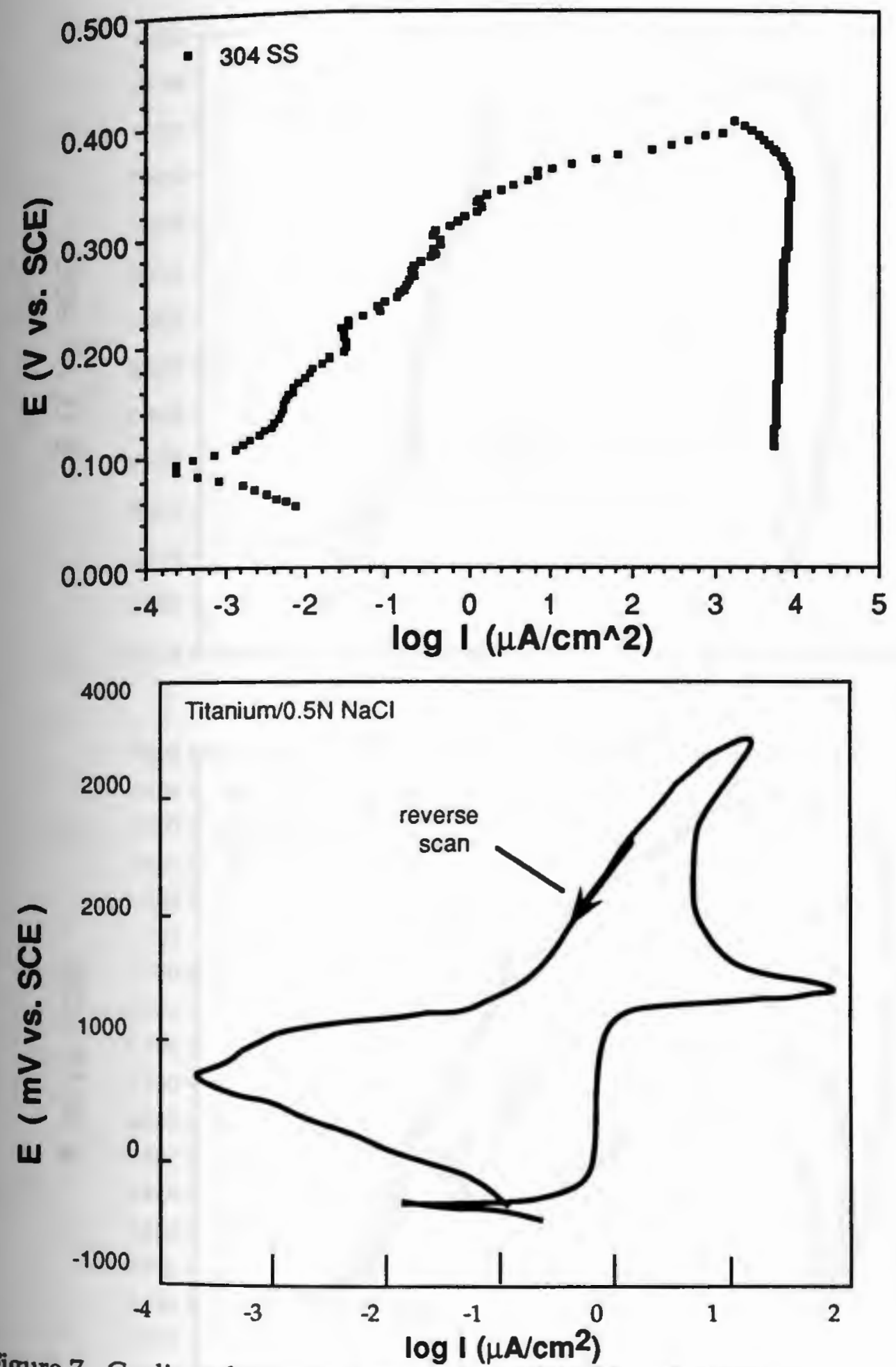

Figure 7. Cyclic polarization scans plot of 304 SS and titanium. 

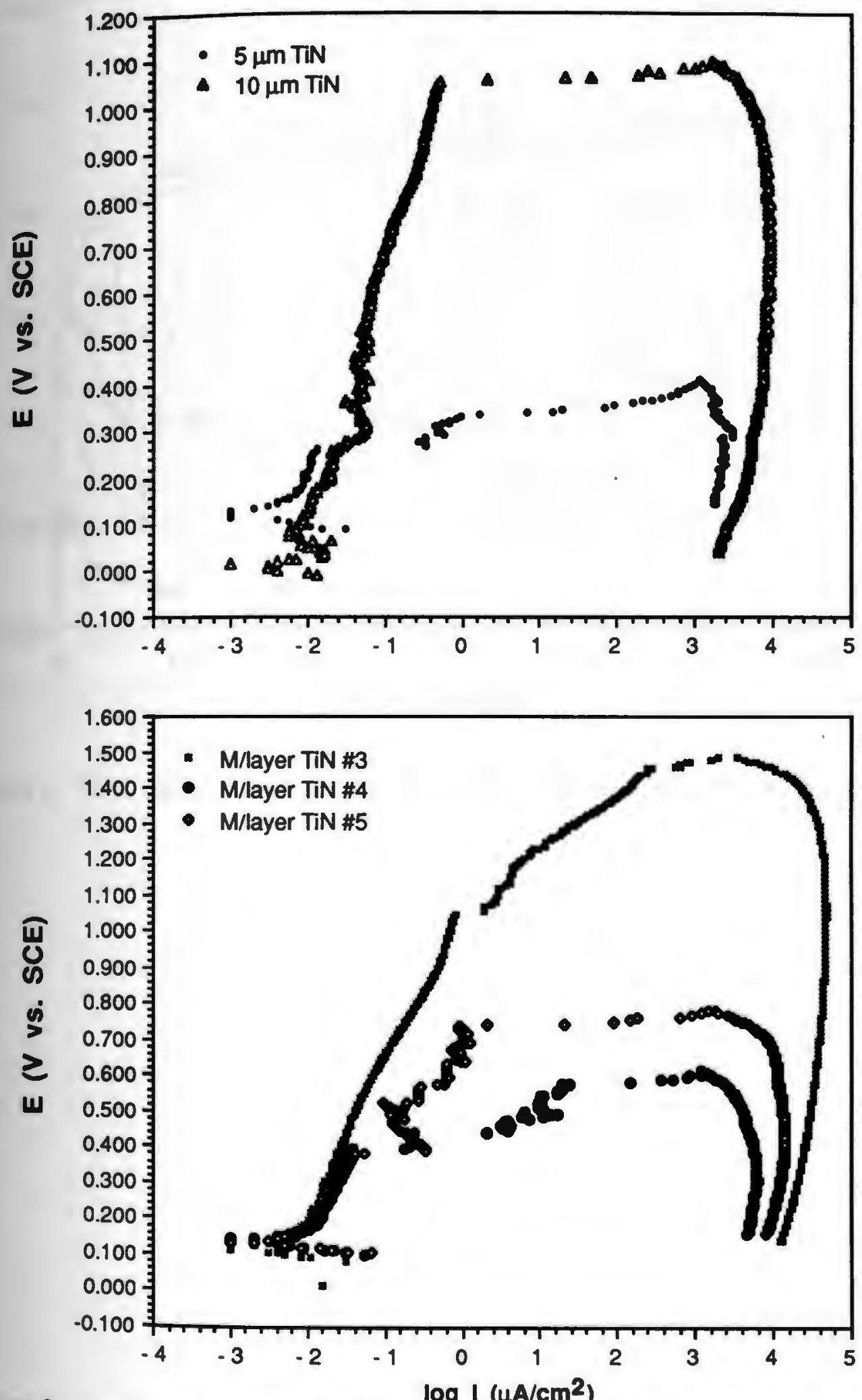

$\log \left(\frac{\log }{\left(\mu \mathrm{A} / \mathrm{cm}^{2}\right)}\right.$
8. Cyclic polarization scans plot of $\mathrm{TiN}$ coated 304 stainless steels. 


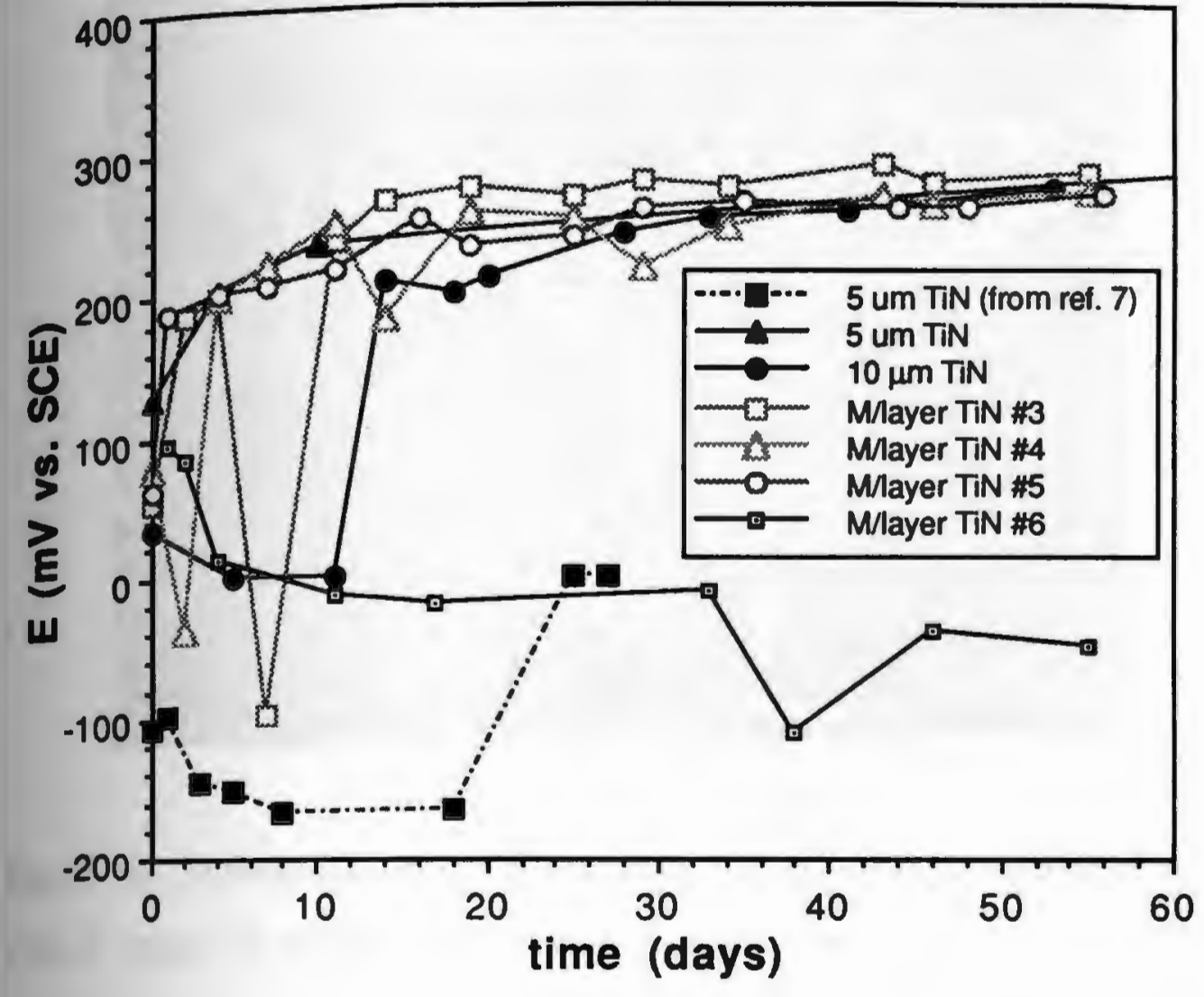

Figure 9. Free corrosion potential of various TiN coated stainless steels. 


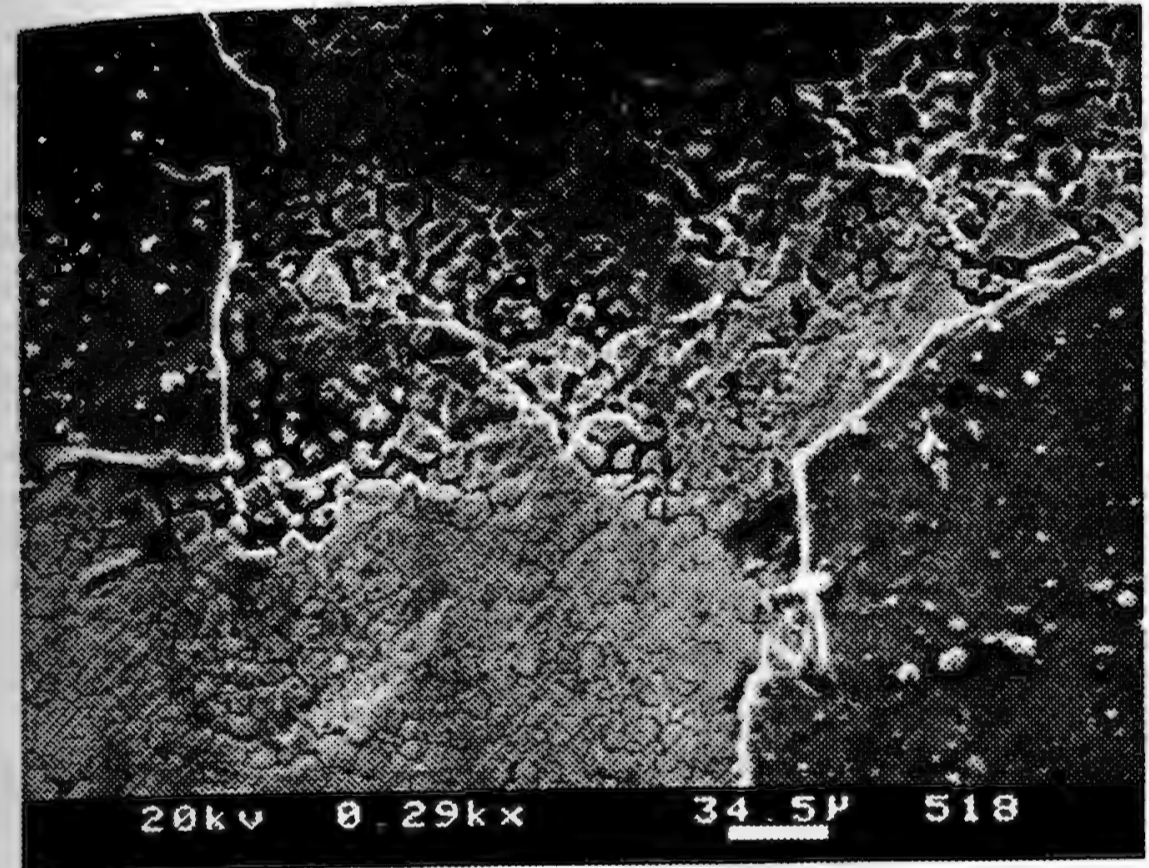

Figure 10. Scanning electron micrograph of TiN with Ti interlayer \#31 shown region of coating peeled from the substrate. 

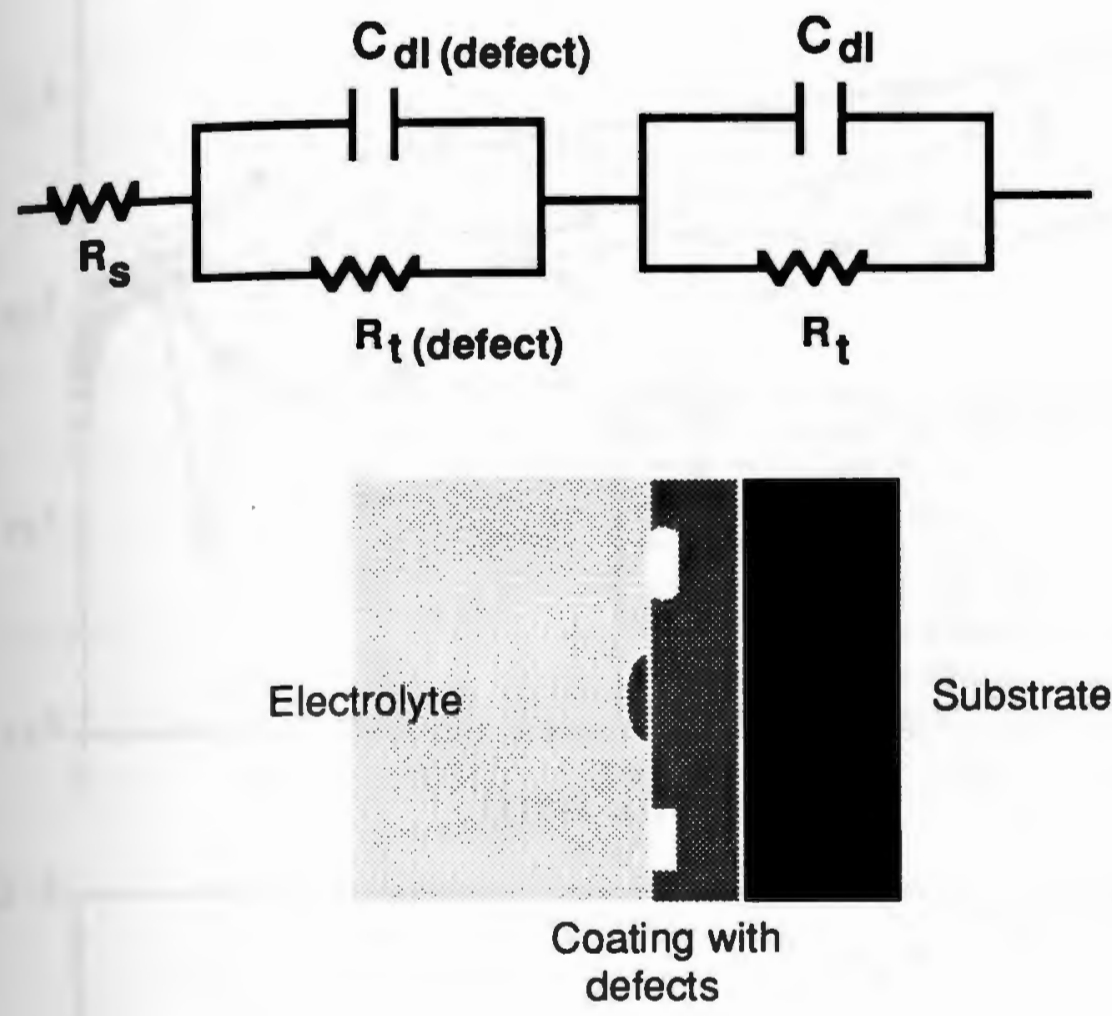

Figure 11. Equivalent circuit models employed to simulate impedance data. 

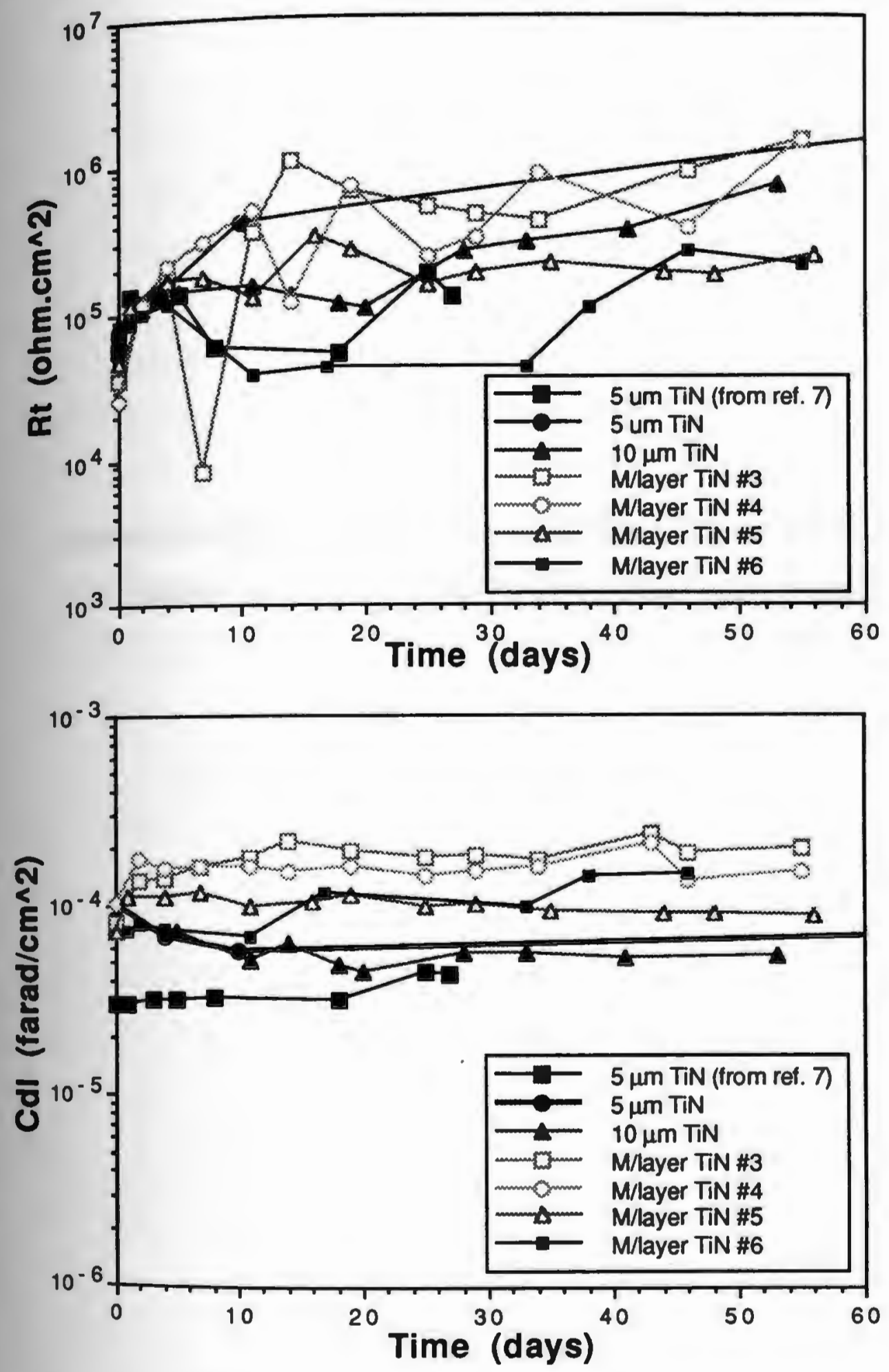

Figure 12. Charge transfer resistance and double layer capacitance plots of titanium nitride coatings on 304 SS. 
CHAPTER III

\section{EFFECT OF THICKNESS AND AN INTERLAYER ON CORROSION}

BEHAVIOR OF ION PLATED ZrN COATINGS ON 304 SS 


\section{ABSTRACT}

A study was conducted in sodium chloride environment utilizing mentiodynamic and ac impedance techniques to investigate the effect of $\mathrm{Zr}$ intermediate layer on $\mathrm{ZrN}$ coatings and different thicknesses of single layer $\mathrm{ZrN}$ on corrosion behavior of 304 stainless steel. Higher corrosion resistance of this coating in comparison to bare 304 SS and TiN coated 304 SS was confirmed and attributed to formation of oxide film $\mathrm{ZrO}_{2} \cdot 2 \mathrm{H}_{2} \mathrm{O}$. Passive films on this coating formed at lower current density than on 304 SS. The passive region extended over several hundreds $\mathrm{mV}$ greater than the bare stainless steel with higher breakdown potential. Increased the coating thickness and $\mathrm{Zr}$ interlayer increased the breakdown potential. 


\section{INTRODUCTION}

Hard ceramic coatings like TiN and $\mathrm{ZrN}$ has been known to improve wear resistance of steel 1,2. The former is amenable to substitution for gold due to its color similarity, however its application as corrosion resistance coatings was questioned 3 . Several studies on TiN coatings reported it to be actrochemically active 4,5 due to the porosity nature of this coating when applied to substrates like 304 stainless steel contributes to extensive localized corrosion and also possible for galvanic corrosion between the exposed substrate and the coating 6-8. Presence of microdefects and columnar structures in TiN coatings are common and also contribute to poor protection of the substrate.

Previous study of $5 \mu \mathrm{m}$ thick ion plated PVD coatings on 304 stainless steel shown higher corrosion resistance can be achieved through $\mathrm{ZrN}$ coating compared to TiN coating and TiN implanted with $\mathrm{Ti}$ or $\mathrm{Au}{ }^{9}$. Spontaneous protective surface film formation on $\mathrm{ZrN}$ coated substrate was suggested as contributing to higher corrosion resistance.

Further study was conducted to investigate the electrochemistry which lead to a higher corrosion resistance of $\mathrm{ZrN}$ coated stainless steels. Zirconium nitride coating of different thicknesses and coatings with $\mathrm{Zr}$ intermediate layer were studied employing $\mathrm{dc}$ and ac electrochemical techniques. Studies shown that thicker and more dense coatings lead to less porosity and therefore provide a better protection of the substrates 1,4,5. Also increased of corrosion resistance was found for coatings with noble metal interlayer between substrate and coating 6-8. The purpose of this paper is to present the 
effect of coating thickness and $\mathrm{Zr}$ intermediate layer on corrosion behavior of $\mathrm{ZrN}$ coated stainless steel in chloride media.

\section{EXPERIMENTAL PROCEDURES}

\section{Materials}

Substrates used were 304 SS of composition described elsewhere 9 . Substrates were $3.2 \mathrm{~cm}$ diameter and $0.2 \mathrm{~cm}$ thick. Coating were applied by PVD ion plating technique by Multi Arc Scientific Coatings, New Jersey. Precleaning of the substrates were carried out by degreasing with non-freon degrease (NFD), rinsing with tap water, spraying with deionized water, and drying. Different thicknesses of coating of single and multilayer were applied and their composition are shown below in table 1. 304 SS and zirconium were tested for comparison.

\section{TABLE I : COATINGS' DESCRIPTION}

Single layer

\#1 $5 \mu \mathrm{m} \mathrm{ZrN}$

\#2 $10 \mu \mathrm{m} \mathrm{ZrN}$

Multi layer

\#3 $2.1 \mu \mathrm{m} \mathrm{ZrN} / 0.7 \mu \mathrm{m} \mathrm{Zr} / 2.0 \mu \mathrm{m} \mathrm{ZrN}$

\#4 $3.8 \mu \mathrm{m} \mathrm{ZrN} / 0.7 \mu \mathrm{m} \mathrm{Zr} / 2.9 \mu \mathrm{m} \mathrm{ZrN}$

(large defects are visible on coating) 
experimental techniques

Pre-exposure surface characterization of the samples were conducted using SEM. Samples were examined again after exposed to electrolyte.

Corrosion experiments were conducted in $0.5 \mathrm{~N} \mathrm{NaCl}$, naturally aerated. Three different electrochemical techniques employed were ac impedance, cyclic polarization and linear polarization. Ac impedance measurements were conducted employing a three electrode cell shown elsewhere 9. Samples were exposed to electrolyte up to 60 days. Applied ac voltage amplitude was $5 \mathrm{mV}$, over bandwidth of $0.001 \mathrm{~Hz}$ to $100 \mathrm{kHz}$, and at open circuit potential. Area exposed was $6 \mathrm{~cm}^{2}$. Non-linear least squares fitting procedure EQUIVCRT was employed to simulate the experimental data 10. Corrosion behavior of coatings are discussed in terms of parameters from equivalent circuit model that give a best fit to the experimental data.

Potentiodynamic cyclic polarization and linear polarization were conducted in naturally aerated $0.5 \mathrm{~N} \mathrm{NaCl}$ solution over $1 \mathrm{~cm}^{2}$ area. Stable free corrosion potential was achieved before experiments were conducted. In cyclic polarization, the potential was scanned from $-50 \mathrm{mV}$ of the free corrosion potential in the noble direction, and reversed once the current density reached $1000 \mu \mathrm{A} / \mathrm{cm}^{2}$. The linear polarization measurements were conducted at three potential ranges; $+/-10,15$, and $20 \mathrm{mV}$ from the free corrosion potential, to show the effect of potential on the polarization tesistance. These values were then compared to those extracted from equivalent circuit modelling of impedance data. 


\section{EXPERIMENTAL RESULTS}

Pre-exposure characterization

Typical surface of coated ZrN samples shown two types of defects; type I defect appears as depression below the average coating thickness, and type II defect appears as microdroplets over the average coating thickness with a hemispherical shape. Average size of these defects are approximately $5 \mu \mathrm{m}$ which do not expose the substrate, see figure 1a. The thick multilayer coating \#4 has larger circular defects approximately $100 \mu \mathrm{m}$ in diameter, figure $1 \mathrm{~b}$, but do not exposed the substrate.

\section{Electrochemical Impedance Spectroscopy}

\section{a. Single layer coatings}

Initial impedance behavior of the $5 \mu \mathrm{m}$ and 10 samples shown a high impedance and phase angle behavior over wide frequency range, figures 2 and 3. The impedance approached $10^{6} \mathrm{ohms}$ at $1 \mathrm{mHz}$. Phase angle at frequencies less than $1 \mathrm{~Hz}$ increased with time along with increased in impedance. Phase angle at frequencies higher than $1 \mathrm{~Hz}$ decreased with time, approaching $65^{\circ}$ for the $10 \mu \mathrm{m}$ and $45^{\circ}$ for the $5 \mu \mathrm{m}$ coatings. No corrosion was observed on both samples over 60 days exposure, however a decoloration of the exposed surface was observed from a yellow gold color of $\mathrm{ZrN}$ to a silver gray color.

\section{b. Multi layers coatings}

Impedance behavior of coating \#3 shown high impedance and phase angle behavior over wide frequency range with the impedance at $1 \mathrm{mHz}$ approaching $10^{6} \mathrm{ohms,}$ figure 4 . With increased exposure, the impedance did 
not change significantly. Phase angle at frequencies higher than $1 \mathrm{~Hz}$ decreased. No corrosion of sample was observed, and only slight color changed of exposed surface was observed.

Coating with larger defects \#4 shown a high phase angle at high frequencies and decreasing phase angle with frequencies below $10 \mathrm{~Hz}$, figure 5. With increasing exposure, two maxima were very distinctive and the impedance decreased. No corrrosion was observed even at defects.

\section{Dotentiodynamic Behavior}

Cyclic polarization scans of 304 SS and zirconium are shown in figure 6. The bare 304 SS shown a typical anodic Tafel behavior followed by a passive region with the critical current density for film formation ( $\mathrm{I}_{\mathrm{crit}}$ ) of $.005 \mu \mathrm{A} / \mathrm{cm}^{2}$ and primary passivation potential (Epp) at $120 \mathrm{mV}$ (SCE). The corrosion potential ( $E_{\text {corr }}$ ) is at $90 \mathrm{mV}$ vs. SCE. The passive region shown small increased in current density with increasing potential until the breakdown potential was reached. The breakdown potential of the passive film $\left(E_{b}\right)$ is approximately $340 \mathrm{mV}$ vs. SCE. The zirconium sample also shown a typical anodic Tafel behavior followed by a passive region, similar to those found in other studies 11,12 . Ecorr, $I_{c r i t}, E_{p p}$, and $E_{b}$ for zirconium are approximately $-420 \mathrm{mV}(\mathrm{SCE}), 0.1 \mu \mathrm{A} / \mathrm{cm}^{2},-370 \mathrm{mV}(\mathrm{SCE})$, and 240 $\mathrm{mV}(\mathrm{SCE})$, respectively. The passive region of zirconium has a limiting current density or passive film current density (Ipass) at $0.6 \mu \mathrm{A} / \mathrm{cm}^{2}$.

The cyclic polarization scans for $\mathrm{ZrN}$ coated $304 \mathrm{SS}$ are shown in figure 7. Their corrosion potentials are more negative than that for bare 304SS; -176 $\mathrm{mV},-96 \mathrm{mV}$, and $6 \mathrm{mV}$ vs. SCE for coatings \#1, \#2, and \#3, respectively. 
They did not show the typical anodic Tafel behavior but are characterized by a limiting current density at $0.001 \mu \mathrm{A} / \mathrm{cm}^{2}$ followed by a passive region. The passive region for the $5 \mu \mathrm{m}$ sample shown small increased of current density with increasing potential until the potential reached the breakdown potential (Eb) at approximately $300 \mathrm{mV}$ vs. SCE. The passive regions for the $10 \mu \mathrm{m}$ and multi layer coating \#3 reached a limiting current density at approximately 0.2 $\mu \mathrm{A} / \mathrm{cm}^{2}$. The breakdown potential for these coatings are approximately 400 $\mathrm{mV}$, and $850 \mathrm{mV}$ vs. SCE, respectively.

Polarization resistances calculated from least squares analysis are tabulated in table 2. The polarization resistance increased slightly with an increasing polarization potential.

\section{BIE 2 : POLARIZATION RESISTANCE OF ZrN (ohms.cm²)}

$+/-10 \mathrm{mV}+/-15 \mathrm{mV}$

$+/-20 \mathrm{mV}$

\begin{tabular}{llll} 
& $+1-10 \mathrm{mV}$ & $+/-15 \mathrm{mV}$ & $+/-20 \mathrm{mV}$ \\
a. $5 \mu \mathrm{m} \mathrm{ZrN}$ & & & \\
b. $10 \mu \mathrm{m} \mathrm{ZrN}$ & $1.62 \mathrm{E}+6$ & $1.21 \mathrm{E}+6$ & $1.40 \mathrm{E}+6$ \\
& - & $1.62 \mathrm{E}+6$ & - \\
$\mathrm{nZ \textrm {ZrN }} / 0.7 \mathrm{Zr} / 2.0 \mathrm{ZrN}$ & - & $1.62 \mathrm{E}+6$ & $1.94 \mathrm{E}+6$ \\
\hline
\end{tabular}

\section{Free Corrosion Potential}

All except the zirconium nitride with $\mathrm{Zr}$ interlayer with large defects shown initially an increased of $\mathrm{E}_{\text {corr }}$ during the first ten days, figure 8 . Further exposure resulted in decreased of potential. 
Post-Exposure Characterization

SEM study shown no significant changes in the surface microstructure of coated surfaces due to exposure.

\section{DISCUSSION}

Impedance Analysis

All impedance data in this study were succesfully modelled by equivalent circuit in figure 9. $\mathbf{R}_{\mathbf{S}}$ is the solution resistance, $\mathbf{R}_{\mathbf{t}}$ (defect)Cdl(defect) parallel sub-circuit is to describe the interfacial processes at the defect regions, and the $R_{t}-C_{d l}$ parallel sub-circuit is to describe the processes at other regions of the coatings. These sub-circuits are built in series since the defects did not expose the substrate to the environment. This is similar to the model proposed for oxide film on aluminum 13. Differences in the charge transfer current and capacitive charging at defects and other coated regions would indicate the separatibility of the two maxima, ie. shown for the $\mathrm{ZrN}$ with $\mathrm{Zr}$ interlayer \#4 with larger defects, figure 5.

The charge transfer resistance $\left(R_{t}\right)$ and double layer capacitance $\left(C_{\mathrm{dl}}\right)$ are shown in figure 10. $R_{t}$ of the $5 \mu \mathrm{m} \mathrm{ZrN}, 10 \mu \mathrm{m} \mathrm{ZrN}$, and multilayer $\mathrm{ZrN}$

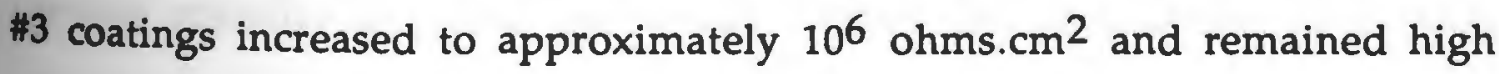
throughout the test period. $R_{t}$ of the multilayer $\mathrm{ZrN} \# 4$ remained at $10^{5}$ ohms.cm ${ }^{2}$ indicated significant effect of large defects on the overall charge transfer resistance.

Increased in the phase angle at low frequency during first ten days was due to formation of passive oxide films on the surface. This is suggested by 
the corresponding increased of the corrosion potential into the passive region as shown in the cyclic polarization scans. Increased of the charge transfer resistance $\left(R_{t}\right)$ and decreased in the double layer capacitance $\left(C_{\mathrm{dl}}\right)$ during this period supported the formation and thickening of oxide films 14-16.

\section{Potentiodynamic Behavior}

The cyclic polarization scans of the $\mathrm{ZrN}$ coated 304 SS shown a limiting current density at $0.001 \mu \mathrm{A} / \mathrm{cm}^{2}$ which is near the sensitivity limit of the equipment used in this study. This suggested a very low current density of at least $0.001 \mu \mathrm{A} / \mathrm{cm}^{2}$ for the formation of passive film on these coatings. This is one-half order of magnitude lower than that for bare 304 SS. The passive film is suggested as $\mathrm{ZrO}_{2} \cdot 2 \mathrm{H}_{2} \mathrm{O}$ which is thermodynamically favorable to form from $\mathrm{ZrN}$ under the experimental condition in this study 17. The passive film on $\mathrm{ZrN}$ coatings is stable over a wider range of potential than that of 304 SS. The breakdown potential can be extended higher than that for $304 \mathrm{SS}$ and the $5 \mu \mathrm{m} \mathrm{ZrN} \mathrm{sample} \mathrm{by} \mathrm{plating} \mathrm{a} \mathrm{thicker} \mathrm{single} \mathrm{layer} 10 \mu \mathrm{m} \mathrm{ZrN}$ coating or a multilayer $\mathrm{ZrN}$ coating of approximately $5 \mu \mathrm{m}$ thick. More zirconium was available for for further oxidation of the thicker coating and multilayer $\mathrm{ZrN}$ coating allowing it to thicken the oxide film at higher anodic potential. Higher breakdown potential could also be contributed to the greater stability of oxide formation during the breakdown and repair processes. This is related to variation in stress distributions in the coatings from compressive everywhere in thinner coating to a variation from compressive at substrate/coating interface to tensile at the surface in thicker coating 18,19 . 
The passive range on the $10 \mu \mathrm{m} \mathrm{ZrN}$ and multilayer $\mathrm{ZrN} \# 3$ were also greater than that for zirconium with a lower passive film current density, and more noble breakdown potential than zirconium.

The charge transfer resistance from polarization resistance experiments corresponds well to the values extracted from equivalent circuit modelling of the impedance data.

\section{Overall Discussions}

Charge transfer resistance values obtained for $\mathrm{ZrN}$ coatings of different thickness and with $\mathrm{Zr}$ interlayer agreed to that was previously obtained ${ }^{9}$, Pproximately $10^{6} \mathrm{ohms. \textrm {cm } ^ { 2 }}$. This is higher than those for bare 304 SS and TiN coated 304 SS. Higher resistance of this coating was due to formation of passive oxide film. XPS analysis of the $5 \mu \mathrm{m} \mathrm{ZrN} \mathrm{sample} \mathrm{after} 50$ days exposure indicated a region of $0.1 \mu \mathrm{m}$ thick with high oxygen content 20 , suggested formation of oxide layer.

The $\mathrm{ZrN}$ coated 304 SS formed passive film at lower current density, has wider range of passive region, and higher breakdown potential than the bare 304 SS. These properties contributed to the higher corrosion resistance of this coating than the bare steel. This coating can find useful application where high corrosion resistance to pitting is needed and as a substitute for tirconium. 


\section{CONCLUSIONS}

Rlectrochemical studies of $\mathrm{ZrN}$ coated stainless steels shown a nontypical behavior of anodic oxidation which lead to formation of protective oxide film of $\mathrm{ZrO}_{2} \cdot 2 \mathrm{H}_{2} \mathrm{O}$. Excellent corrosion resistance was achieved with $\mathrm{ZrN}$ coating with a charge transfer resistance value in the range of 106 ehms. $\mathrm{cm}^{2}$ for coating with different thicknesses and with a $\mathrm{Zr}$ intermediate layer. The role of thicker coating and interlayer was to allow further formation of oxide layer to thicken this layer and raised the breakdown potential higher than that of zirconium.

\section{ACKNOWLEDGEMENT}

Authors would like to thank Ray Fontana of Multi Arc Coatings of New Jersey for providing PVD coatings.

\section{REFERENCES}

1. E. I. Meletis, A. Erdemir, and R. F. Hochman, L. of Materials Fingineering, v7 (1985), p.173

2. P. C. Johnson, and H. Randhawa, Surface and Coatings Technology v33 (1987), p.53

3. Y. Massiani, J. Crousier, L. Fedrizzi, A. Cavalleri, and P. L. Bonora, ce and Coatings Technology v33 (1987), p.309

4. A. Erdemir, W. B. Carter, E. I. Meletis, and R. F. Hochman, Materials ce and Engineering, v69 (1985), p89 
E. I. Meletis, W. B. Carter, and R. F. Hochman, Microstructural science v13 (1986), p.417

6.

M. J. Park, A. Leyland, A. Matthews, Surface and Coatings Technology v43/44 (1990), p.481

7.

P. V. Nazarenko, A. G. Molyar, I. E. Polishchuk, O. G. Yachinskaya, and A. A. Il'in, Translated from Metallovedenie i Termicheskaya Obrabotka Metallov No. 4 (April 1990), p.61

8.

V. A. Dmitriev, L. A. Khvorostukhin, M. A. Tolstaya, Yu. I. Pavlov,

A. E. Bolmanenkov, and A. A. Emel'yanov, Translated from Zaschita Metallov, v26 (1990), p.151

9. L. van Leaven, M. N. Alias, and R. Brown, Surface and Coatings Technology v53 (1992), p.25

10. B. A. Boukamp, EOUIVCRT-Users Manual, 2nd ed., revised, University of Twente, Netherlands, 1989

11. G. C. palit, H. S. Gadiyar, Corrosion, v43 (1987), p.140

12. D. R. Knittel, A. Bronson, Corrosion, v40 (1984), p.9

13. J. Hitzig, K. Juttner, W. J. Lorenz, and W. Paatsch, I. Electrochemical Society v133 (1986), p.887

14. J. A. Bardwell, and M. C. H. McKubre, Electrochimica Acta, v36 (1991), p. 647

15. M. G. S. Ferreira, and J. L. Dawson, L. Electrochemical Society v132 (1985), p.760

16. M. E. Curly-Fiorino, and G. M. Schmid, Corrosion Science, v20 (1980), p.313

17. W. M. Latimer, Oxidation Potentials, 2nd. ed., Prentice Hall, New Jersey, 1956 
18. S. J. Bull, P. R. Chalker, C. F. Ayres, and D. S. Rickerby, Materilas ance and Engineering, vA139 (1991), p.71

19. D. S. Rickerby, G. Eckold, K. T. Scott, and I. M. Buckley-Goldner, Thin Solid Films, v154 (1987), p.125

20. R. Brown, M. N. Alias, R. G. Fontana, Surface and Coatings Technology, v62 (1993), p.467 

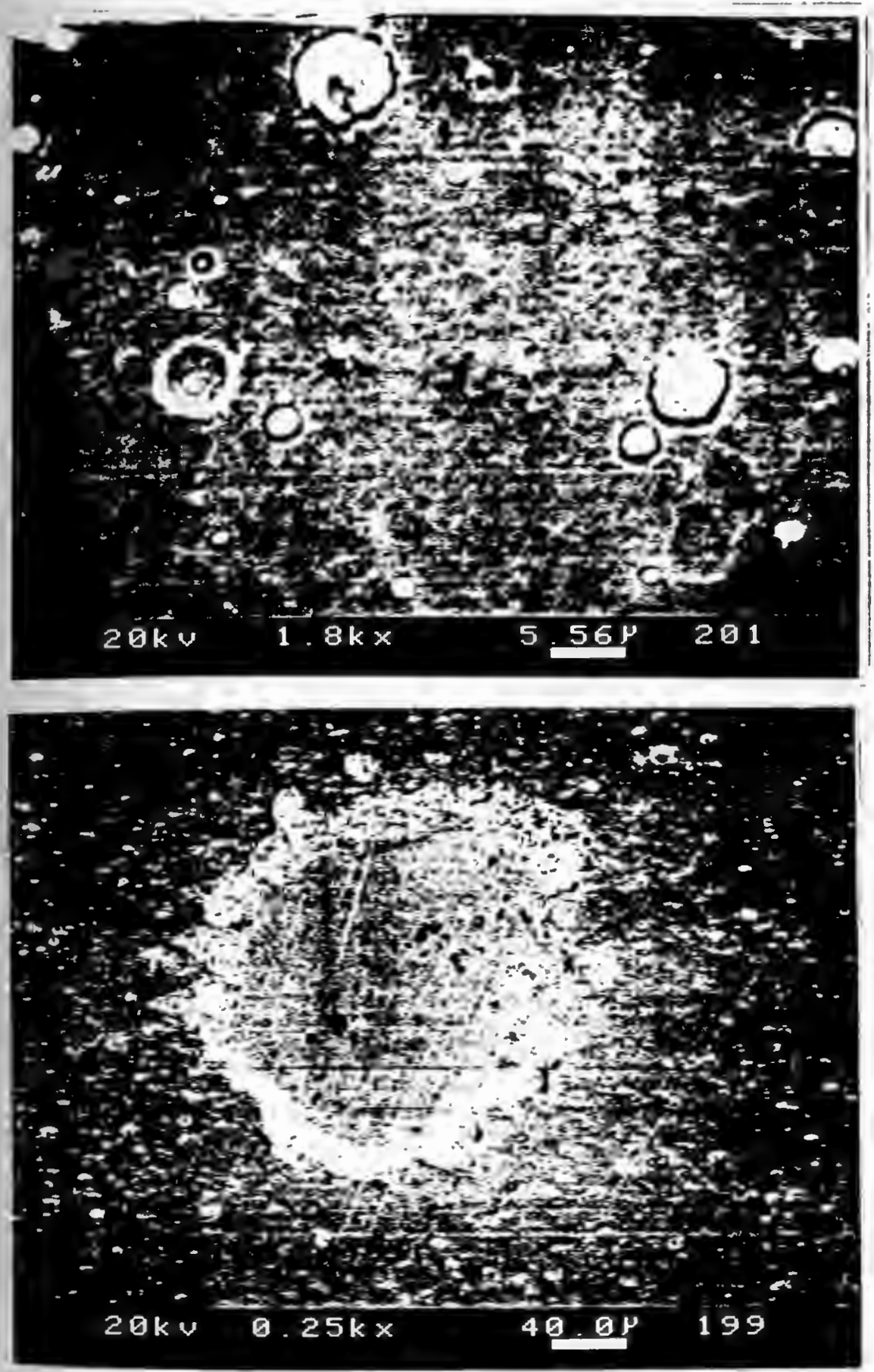

Figure 1. SEM micrographs of $\mathrm{ZrN}$ coatings by PVD technique on stainless steel shown (a). a typical surface with two types of defects approximately $5 \mu \mathrm{m}$ in diameter, and (b). a coating with large defects approximately $100 \mu \mathrm{m}$ in diameter for the $\mathrm{ZrN}$ with $\mathrm{Zr}$ interlayer \#4. 

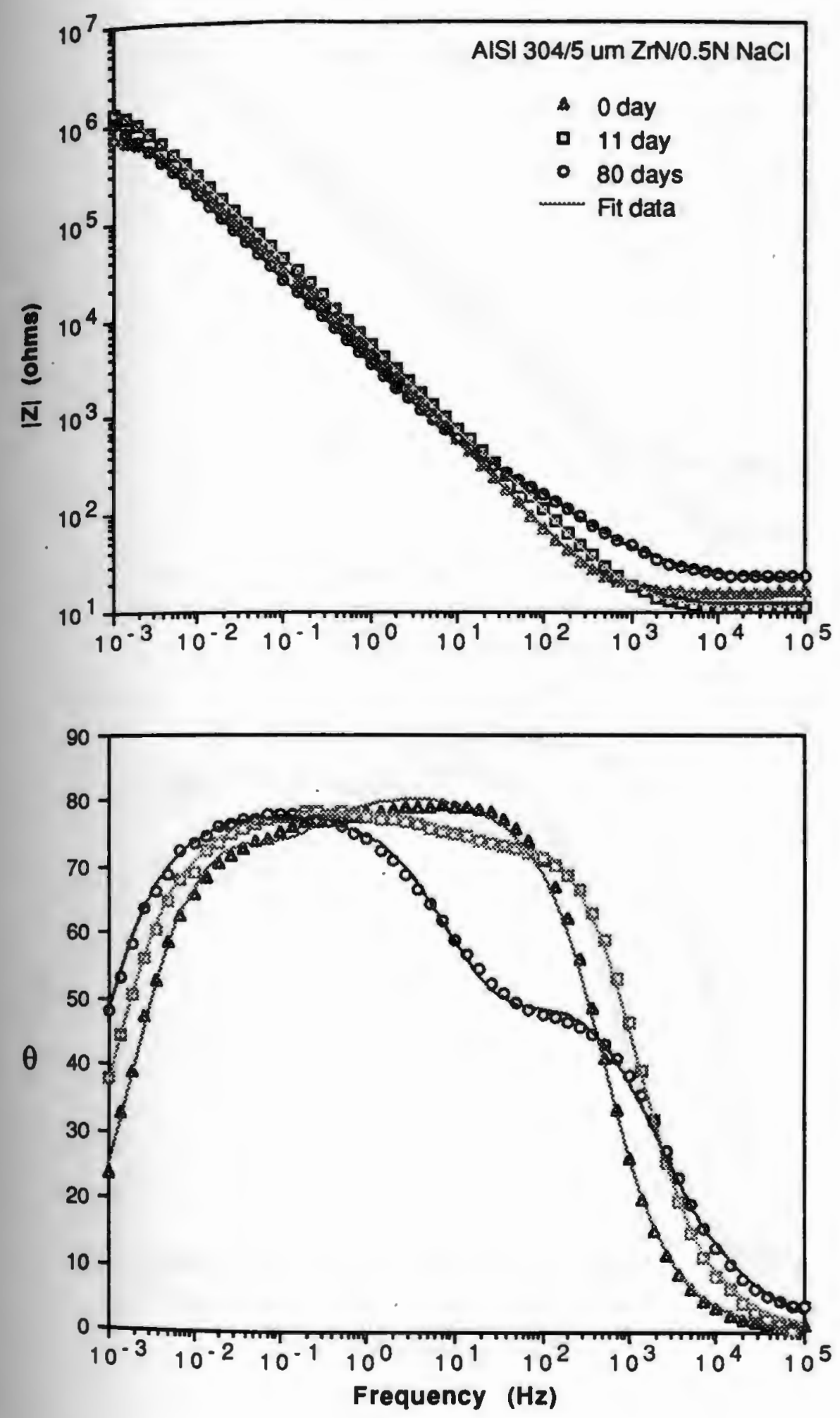

Figure 2. Impedance and phase angle plots of $5 \mu \mathrm{m} \mathrm{ZrN}$ coated $304 \mathrm{SS}$. 

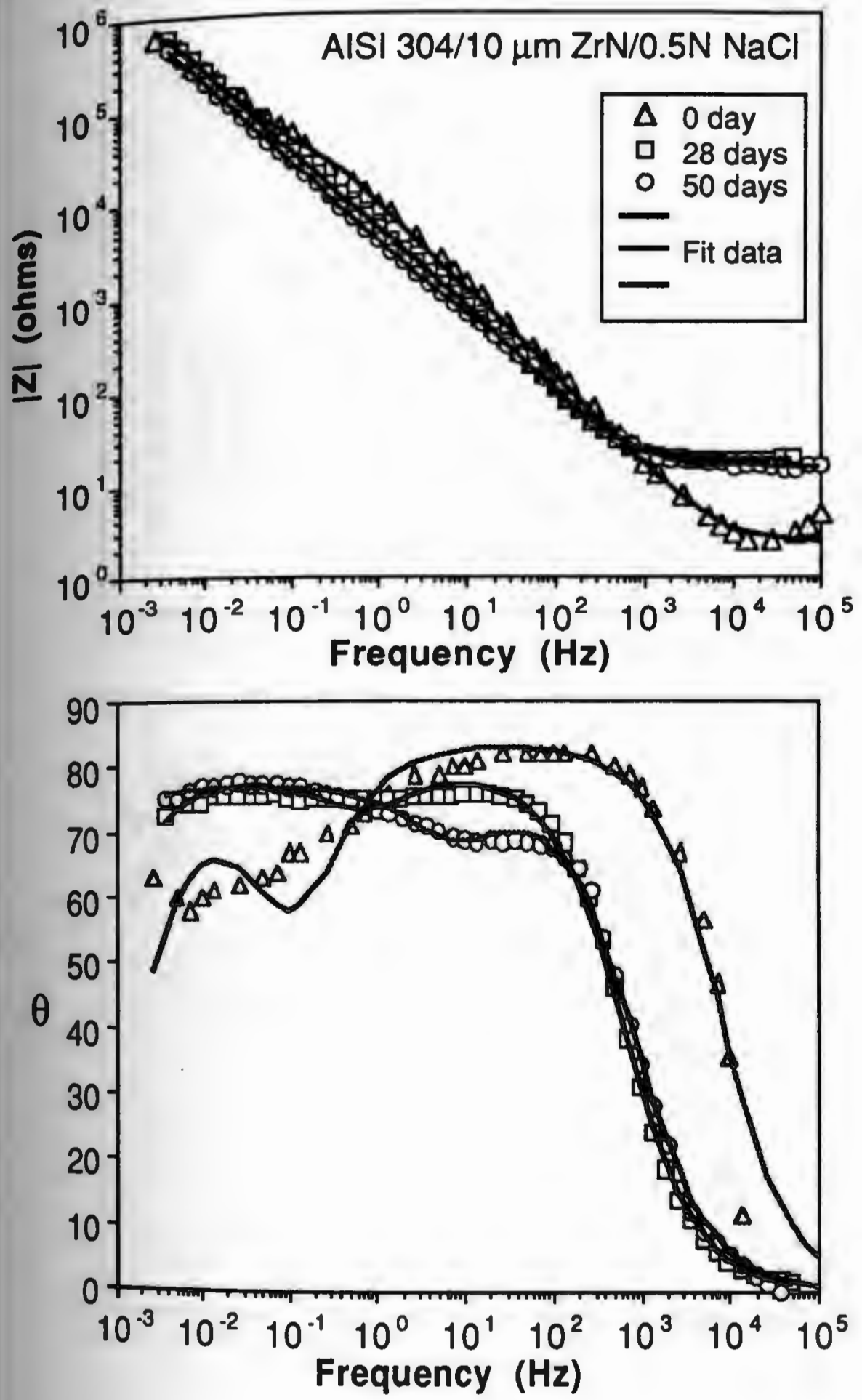

Figure 3. Impedance and phase angle plots of $10 \mu \mathrm{m} \mathrm{ZrN}$ coated $304 \mathrm{SS}$. 

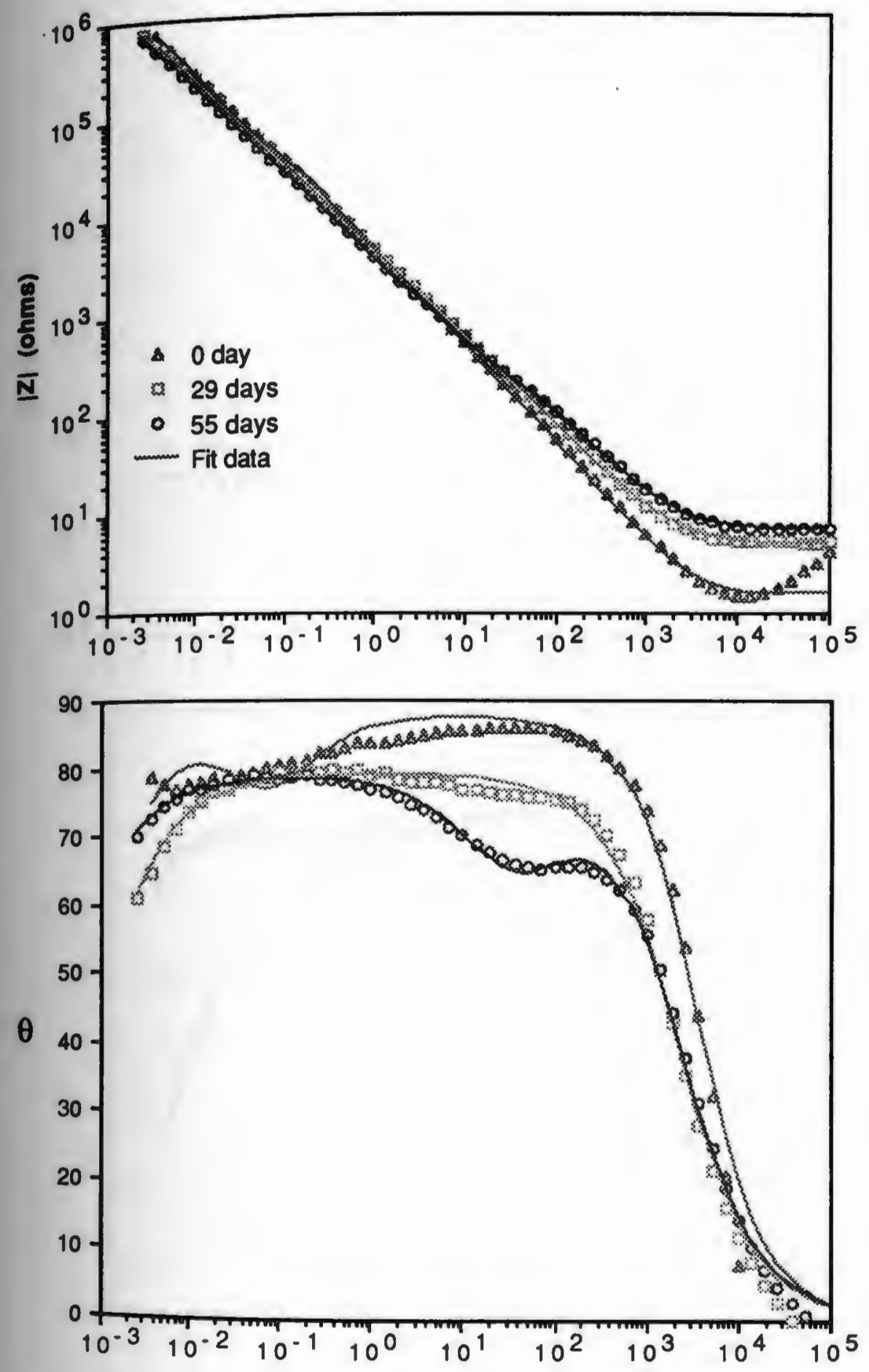

Figure 4. Impedance and phase angle plots of $\mathrm{ZrN}$ with $\mathrm{Zr}$ interlayer coating \#3 on 304 SS. 

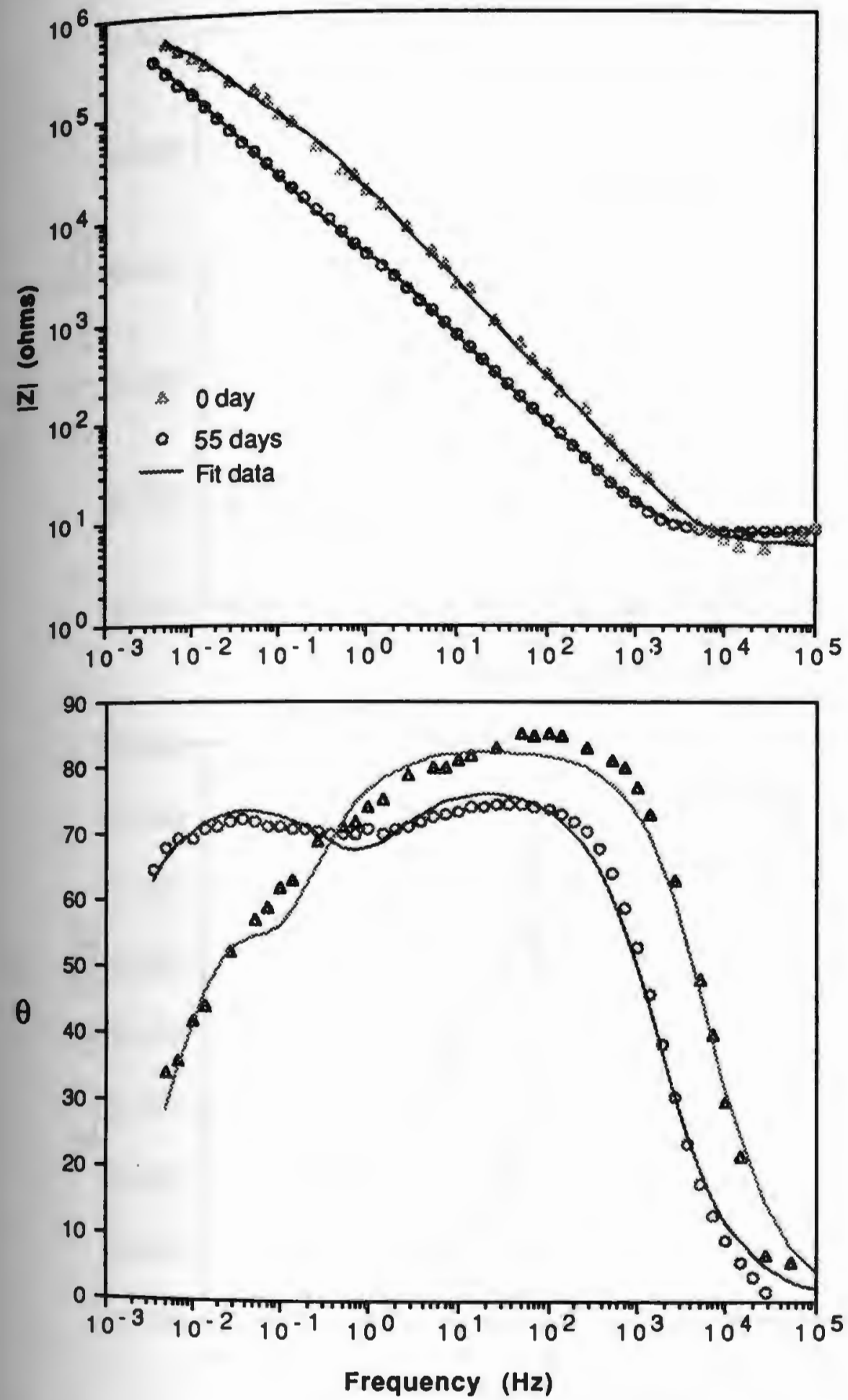

Figure 5. Impedance and phase angle plots of $\mathrm{ZrN}$ with $\mathrm{Zr}$ interlayer coating \#4 on 304 SS, with large defects approximately $100 \mu \mathrm{m}$ in diameter. 

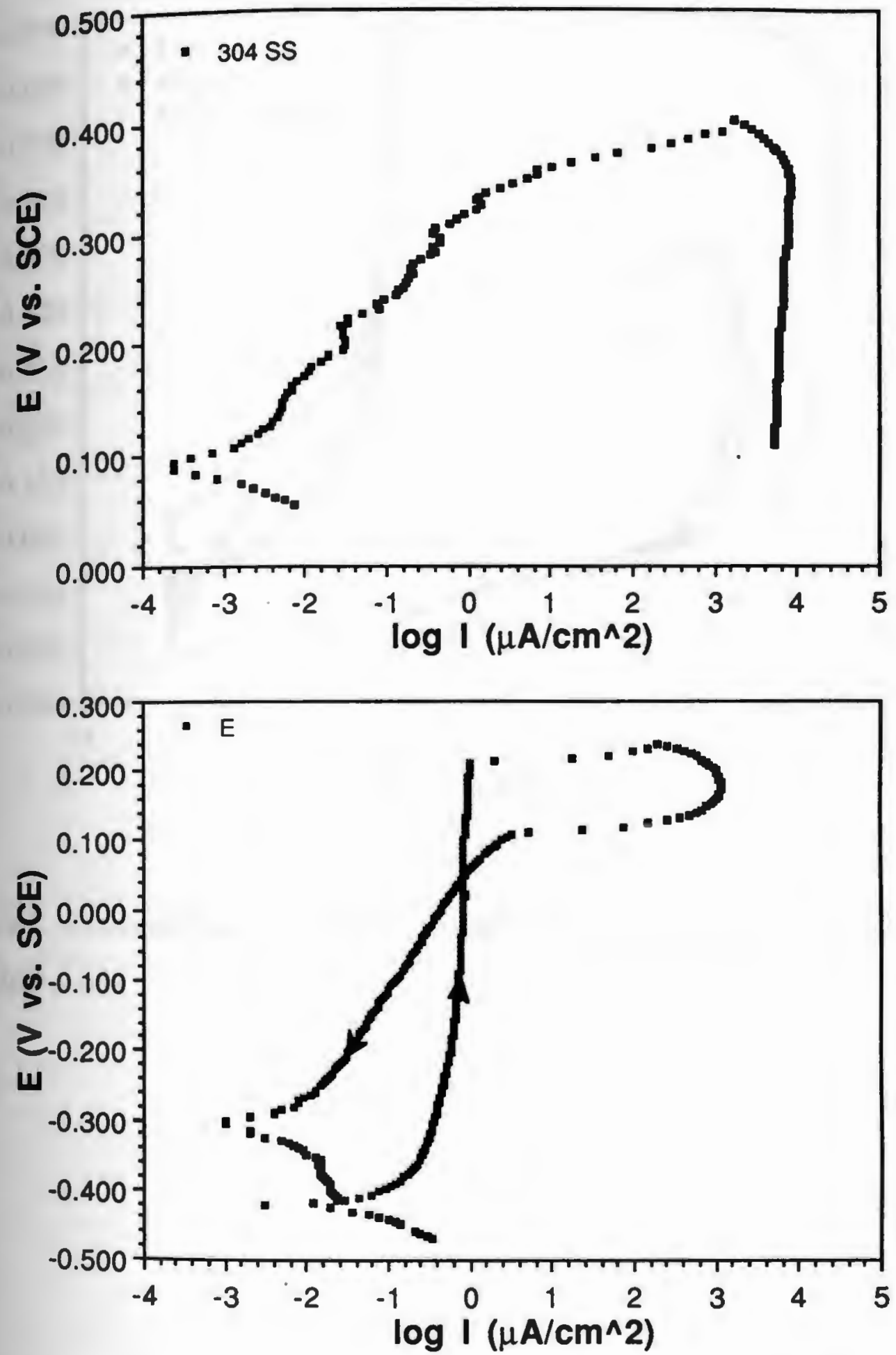

Figure 6. Potentiodynamic cyclic polarization behavior of 304 SS and Irconium. 


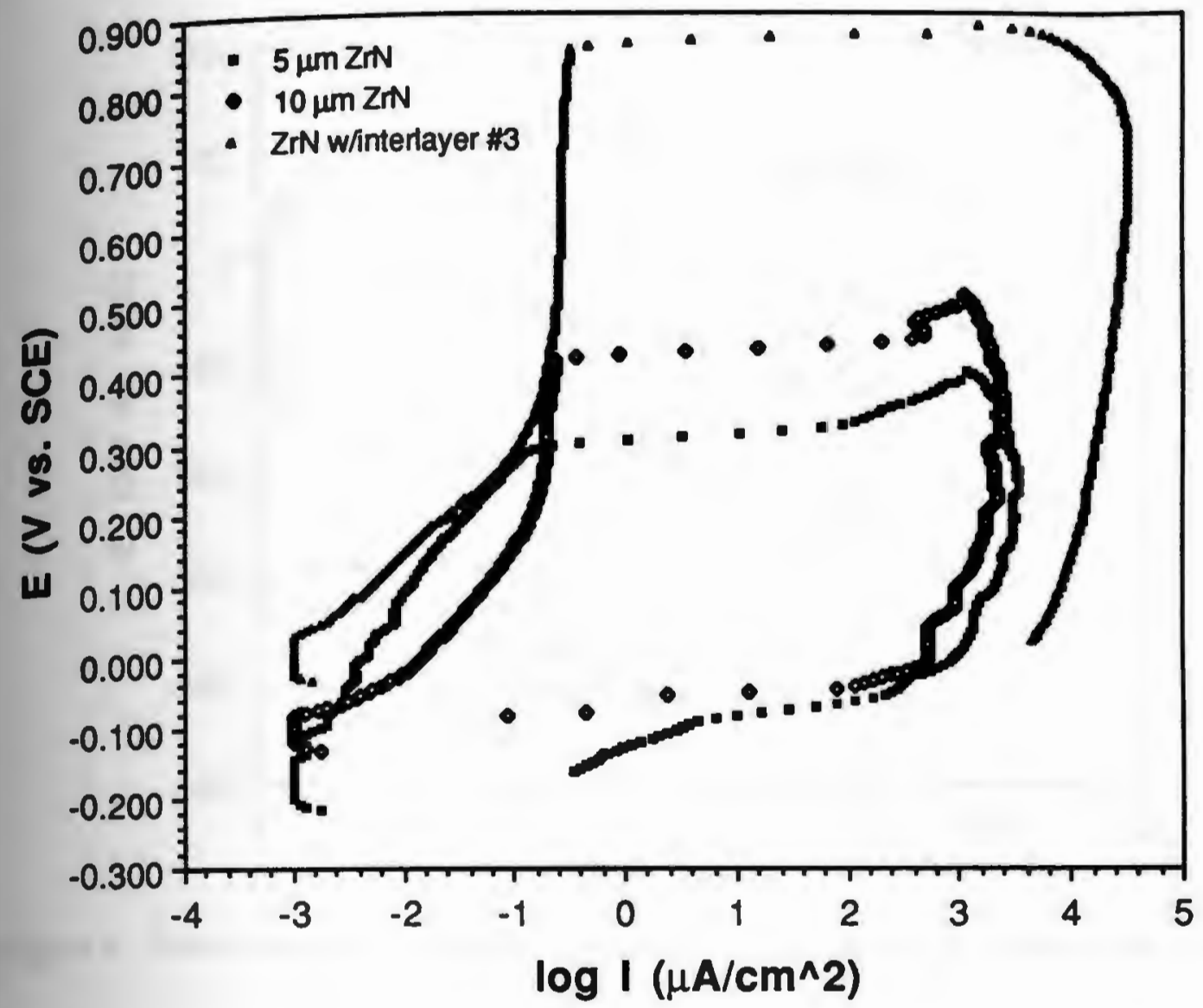

Figure 7. Potentiodynamic cyclic polarization scans plot of $\mathrm{ZrN}$ coated 304 stainless steels. 


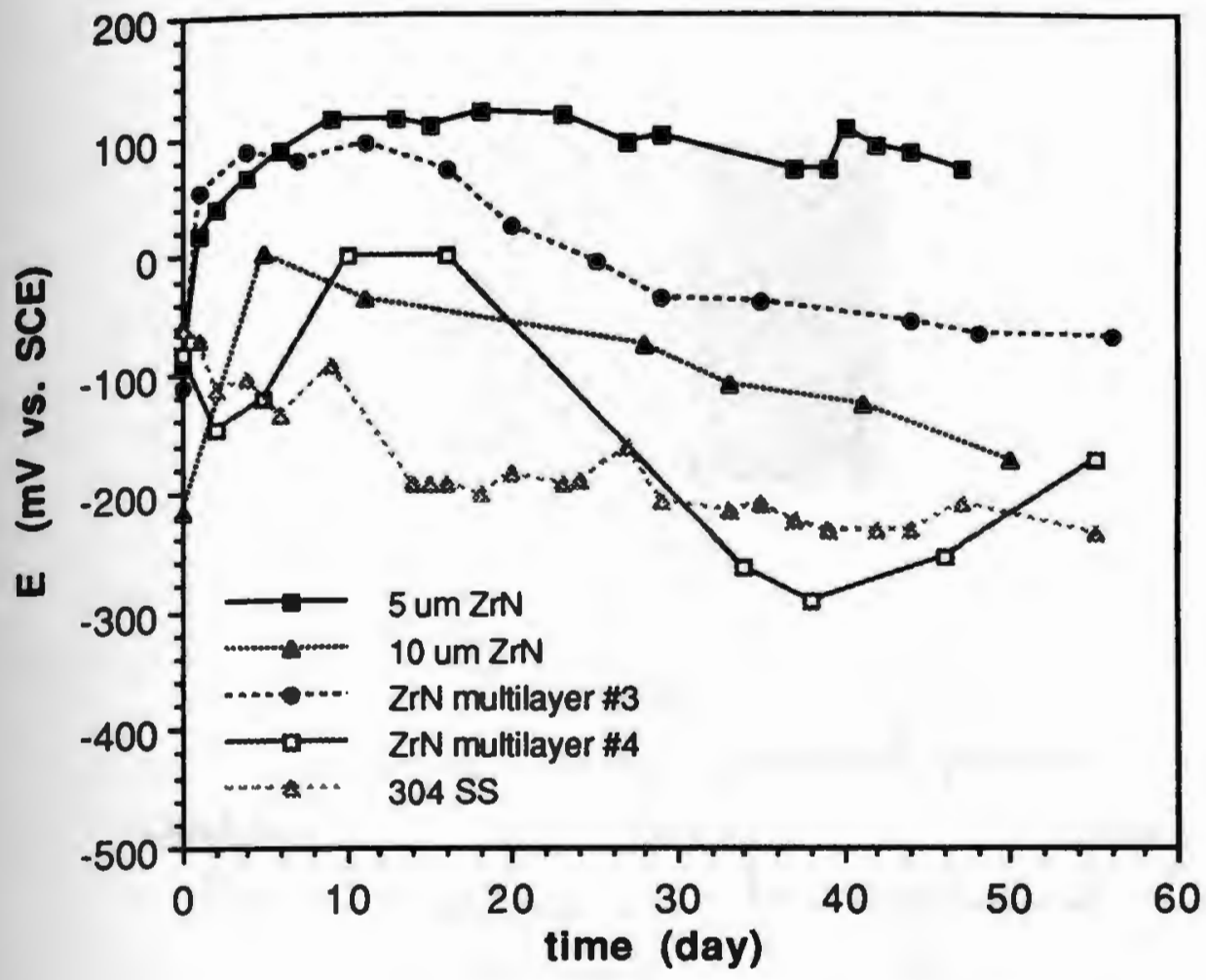

Figure 8. Free corrosion potential variation of $\mathrm{ZrN}$ coated 304 stainless steels. 

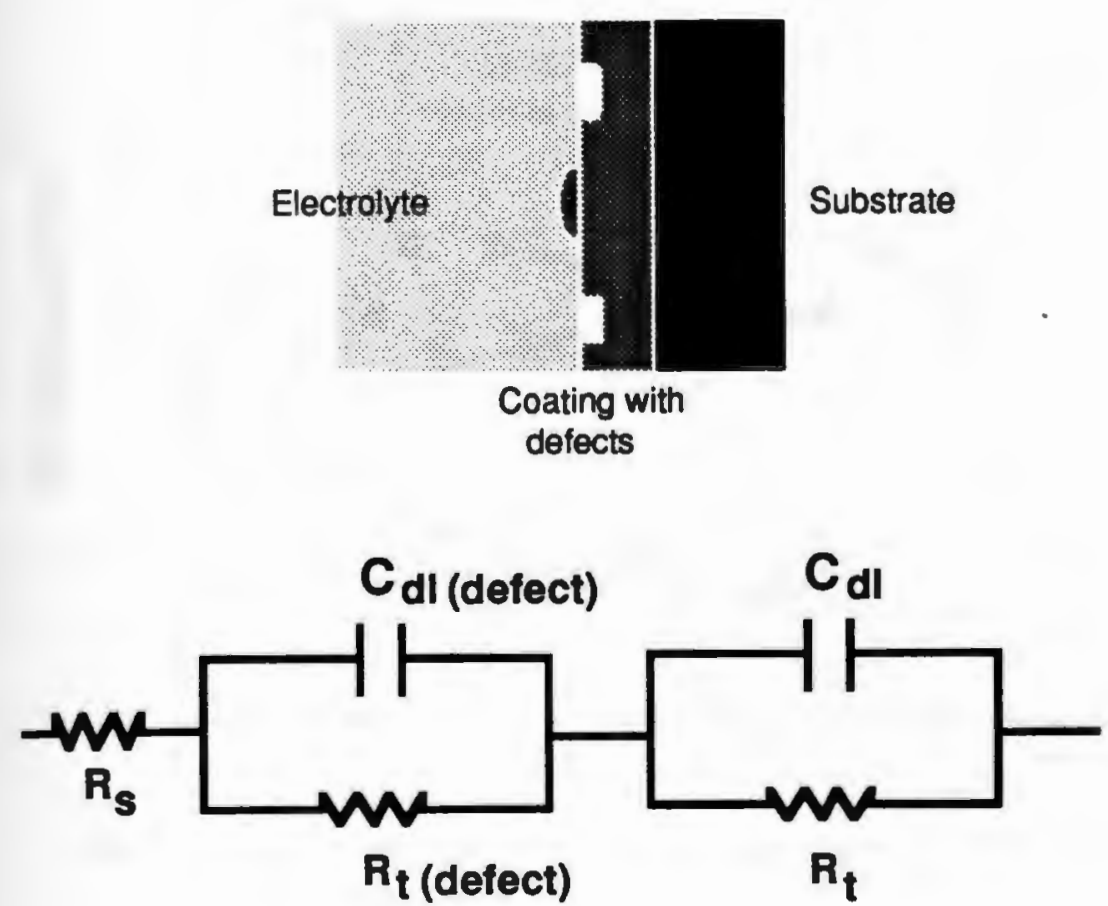

Figure 9. Equivalent circuit model employed to simulate impedance data. $\mathbf{R}_{\mathbf{S}}$ is the solution resistance, $R_{t}$ and $C_{d l}$ are representing processes on coating surfaces, and $R_{t}$ (defect) and $C_{\mathrm{dl}}$ (defect) are representing the processes at the defects. 

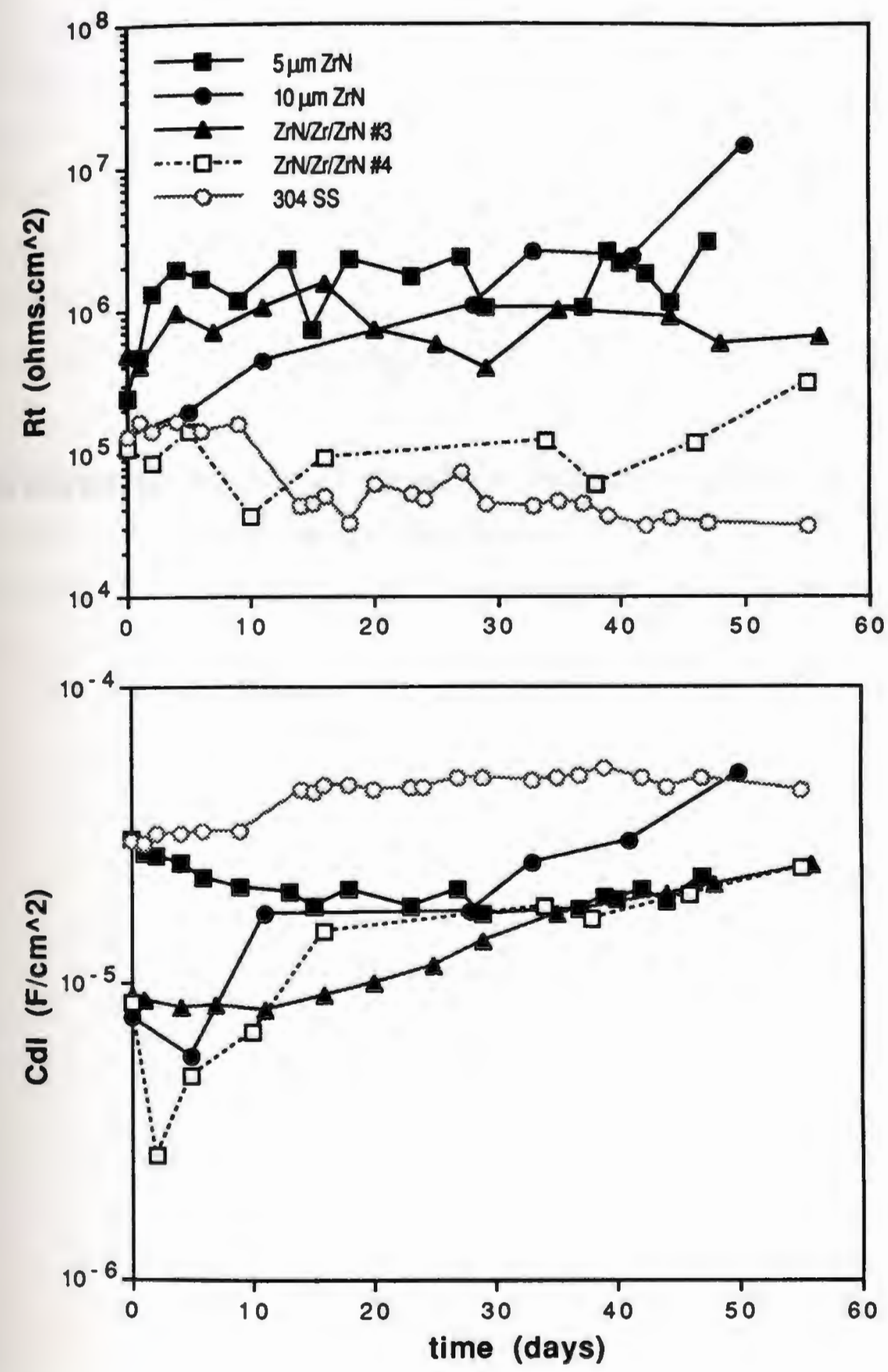

Figure 10. $R_{t}$ and $C_{d l}$ variation for $\mathrm{ZrN}$ coated stainless steels. 


\section{CHAPTER IV}

AN ESCA INVESTIGATION ON OXIDATION OF NITRIDE FILMS IN AQUEOUS SOLUTION 


\section{ABSTRACT}

ESCA was utilized to investigate the oxidation of TiN and $\mathrm{ZrN}$ thin films on $304 \mathrm{SS}$ when exposed to $\mathrm{NaCl}$ solution. Ac impedance and dc polarization tests were conducted to determine the time dependent behavior and stive-to-passive transition behavior, respectively. These tests suggested passive oxide films were formed on the nitride coatings. Depth profile analysis of fresh samples and samples exposed during impedance tests indicated a layer rich in oxygen over the $\mathrm{ZrN}$ coating after exposure but not over TiN coating. Chemical shifts in the $\mathrm{Zr} 3 \mathrm{~d}_{5 / 2}$ core electrons indicate transformation from $\mathrm{ZrN}$ to its oxide; the shifts in $\mathrm{Ti} 2 \mathrm{p}_{3} / 2$ did not support the change from TiN to its oxide. The influence of these shifts on corrosion protection is documented and the mechanism for corrosion protection is proposed. 


\section{INTRODUCTION}

Analysis of corrosion surface ex-situ or in-situ is a tool to further understand the electrochemical processes occuring at the solution/solid interface. Ex-situ techniques such as ESCA, and Auger can provide information on surface composition within several hundreds angstroms depth 1,2. Etching of the surface during ESCA analysis make it possible to gather a depth profile of atomic composition up to several $\mu \mathrm{m}$ depth of the sample. Changes in the surface composition and in depth below the surface due to electrochemical processes are detectable. This information is useful in explaining the findings from electrochemical tests such as impedance spectroscopy and dc polarization.

ESCA was used to analyze the surface and bulk composition of various steels in different environments to determine the effect of alloying elements such as $\mathrm{Cr}$ and Mo on the passive film and its composition 3,4.

In this paper, attempts are made to discuss the findings from ESCA analysis of $\mathrm{ZrN}$ and $\mathrm{TiN}$ coated 304 stainless steels after exposure to $\mathrm{NaCl}$ environment. Earlier cyclic polarization studies suggested passivation of the nitride coatings to form hydrated oxide films when they are anodically polarized 5. These films possibly existed as $\mathrm{ZrO}_{2} \cdot 2 \mathrm{H}_{2} \mathrm{O}$ and $\mathrm{TiO}_{2} \cdot \mathrm{H}_{2} \mathrm{O}$, respectively on the $\mathrm{ZrN}$ and TiN coatings. Formation of these passive films, which is thermodynamically possible, is also believed to contribute to increased charge transfer resistance of the coated 304 steels in comparison to the uncoated steel 6. A depth profile analysis of the exposed and fresh TiN and $\mathrm{ZrN}$ coated steels was conducted and changes in the oxygen composition 
were observed. The chemical shifts in the $\mathrm{Zr}$ and $\mathrm{Ti}$ core level electrons indicated transformation from nitride to oxide. These are discussed in detail here.

\section{EXPERIMENTAL PROCEDURES}

\section{Materials}

AISI 304 stainless steel discs of $3.75 \mathrm{~cm}$ diameter and $0.2 \mathrm{~cm}$ thick were employed as substrate material. TiN and $\mathrm{ZrN}$ coatings of $5 \mu \mathrm{m}$ were deposited by cathodic arc ion plating (plasma deposition).

\section{Dectrochemical Testing}

Ac impedance tests were conducted to analyze the corrosion behavior of the coatings for up to 50 days in a three electrode cell configuration. All tests were done utilizing $0.5 \mathrm{~N} \mathrm{NaCl}$ solution. PARC M388 software was used to perform impedance data collection. A frequency range of $100 \mathrm{kHz}$ to $3 \mathrm{mHz}$ and a $5 \mathrm{mV}$ perturbation amplitude were employed. Data analysis and circuit modeling were performed using a commercial software. The charge transfer resistance, $R_{t}$, from the best data fit circuit model of the impedance data was the parameter utilized to evaluate the corrosion performance. Cyclic polarization tests were employed to study the anodic polarization behavior of the coated steels in a similar environment.

\section{Surface Analysis}

ESCA depth profiling was performed on fresh $\mathrm{TiN}$ and $\mathrm{ZrN}$ coated samples, and on exposed TiN and $\mathrm{ZrN}$ coated samples. Changes in the metal, oxygen and nitrogen composition with depth were determined. Shifts 
in the $\mathrm{Zr} 3 \mathrm{~d}_{5 / 2}$ and $\mathrm{Ti} 2 \mathrm{p}_{3 / 2}$ core electrons were analyzed. The ESCA data was taken using a Perkin Elmer PHI 5500 Multi-Technique Surface Analyzer with a $\mathrm{Mg} \mathrm{Ka} x$-ray at a fixed take-off angle of $45^{\circ}$, a beam voltage of $4.7 \mathrm{kV}$ and 5 $\mu$ A sputter current over $4 \mathrm{~mm}^{2}$ area of the sample. Calibration for the sputtering rate was done using $0.5 \mu \mathrm{m}$ TiN and $\mathrm{ZrN}$ films on similar substrate. These samples were sputter-etched at different current rate until the substrate (or iron) was detected. A sputter rate of 32.7 angstroms per minutes was found to give the best correlation between sputtering time and depth and was used in depth analysis.

\section{EXPERIMENTAL RESULTS}

Electrochemical Tests

Impedance data on both $\mathrm{TiN}$ and $\mathrm{ZrN}$ coated stainless steels indicated higher impedance of the latter than the former $(6,7)$. The charge transfer resistance extracted from the modeling procedure was found to be higher for the $\mathrm{ZrN}$ coated steels than the uncoated steel and the TiN coated steels, figure 1.

Cyclic polarization scans of bare 304 SS and of TiN coated 304 stainless steels shown an anodic Tafel region followed by a passive region and a rapid increase in current to indicate coating breakdown (6), figure 2. The latter has a corrosion potential higher than the former. The cyclic polarization scan of ZrN coated 304 SS shown a lower corrosion potential than the 304 SS. The critical current density for film formation on the former was lower than the other two samples. The passive range on the $\mathrm{ZrN}$ coated $304 \mathrm{SS}$ was also greater than the other two samples. 
Surface Analysis

XPS Zr 3d5/2 spectra of bulk $\mathrm{ZrN}$ on 304 stainless steel appeared at 178.9 $\mathrm{eV}$, figure 3. The $\mathrm{N}$ 1s peak for $\mathrm{ZrN}$ was found at $396.0 \mathrm{eV}$. The XPS Ti $2 \mathrm{p}_{3 / 2}$ spectra of bulk TiN on 304 stainless steel appeared at $454.0 \mathrm{eV}$, figure 4. The TiN N 1s peak occurred at $396.4 \mathrm{eV}$.

The depth profile of $\mathrm{ZrN}$ coated sample after more than 50 days exposure was found to have increased in the O1s content in comparison to the unexposed material, except for the immediate surface, figure 5. Small amounts of oxygen were found very near the surface in the unexposed sample. The thickness of the oxygen containing layer, ie. above the bulk level, in the un-exposed sample was 392 Angstroms. This increased to 1635 Angstroms after more than 50 days exposure in the $\mathrm{NaCl}$ solution.

The $\mathrm{Zr} 3 \mathrm{~d}_{5 / 2}$ spectra of the exposed $\mathrm{ZrN}$ near the surface showed a peak at $182.8 \mathrm{eV}$, figure 6. After 50 minutes of sputtering below the oxygen rich layer, the $3 d_{5 / 2}$ peak was found to be similar to the unexposed material.

The depth profile of the TiN coated sample before and after exposure showed insignificant change in the oxygen content, figure 7. The TiN 2p3/2 spectra near the surface showed its peak at $455.4 \mathrm{eV}$. After 20 minutes sputtering into the bulk TiN coating no significant change in the binding energy was found, figure 8. 


\section{DISCUSSION}

The charge transfer resistance of the $\mathrm{ZrN}$ coated steel was higher than the TiN coated steel and bare stainless steel in $\mathrm{NaCl}$ solution. The increased in $R_{t}$ value for the $\mathrm{ZrN}$ during the first ten days was accompanied by an increase in the phase angle at the low frequency region during impedance testing 5 . This suggested formation of a passive film on $\mathrm{ZrN}$ and its formation was more spontaneous than for TiN 7. The cyclic polarization behavior of both coatings in a similar environment indicated both were capable of forming passive films. The passive regions indicated the possible formation of hydrated $\mathrm{TiO}_{2}$ and $\mathrm{ZrO}_{2}$ on $\mathrm{TiN}$ and $\mathrm{ZrN}$ respectively. Formation of both types of films are thermodynamically possible under the conditions of testing 8,9. As compared to TiN, the passive film on $\mathrm{ZrN}$ formed at a lower current density due to a lower energy of transformation from $\mathrm{ZrN}$ to the hydrated oxide.

The formation of oxides on the nitride coatings was confirmed through ESCA analysis. Depth profile analysis of $\mathrm{ZrN}$ coated samples showed presence of an oxygen rich layer near the surface of the coating after exposure to aqueous solutions. It has been postulated that oxygen replaced the nitrogen through the oxidation reaction of the nitrides to hydrated oxides 7 . This is believed to occur as the $\mathrm{Zr} 3 \mathrm{~d}_{5 / 2}$ spectra indicated a shift from $178.9 \mathrm{eV}$ to 182.8 $\mathrm{eV}$. The $\mathrm{Zr} 3 \mathrm{~d}_{5 / 2}$ peak for $\mathrm{ZrN}$ found in this study agrees quite well with other findings in literature reported at $180.9 \mathrm{eV} 10$. Shifts in this spectra to a higher energy value of $182.8 \mathrm{eV}$ indicated oxidation of the $\mathrm{Zr}$ from an oxidation state in $\mathrm{ZrN}$ to a +4 oxidation state. This is consistent with a value in literature for a $\mathrm{ZrO}_{2}$ compound which has the $\mathrm{Zr} 3 \mathrm{~d}_{5 / 2}$ peak at $182.2 \mathrm{eV} 11$. 
The $O$ is spectra very near the surface of the exposed $\mathrm{ZrN}$ sample has a very broad peak which could indicate contributions of various types of oxygen bonds to metal ions such as $\mathrm{M}-\mathrm{O}, \mathrm{M}-\mathrm{H}_{2} \mathrm{O}$ and $\mathrm{M}-\mathrm{OH}$ 12. The oxides may initially exist in its hydrated form of $\mathrm{ZrO}_{2} \cdot 2 \mathrm{H}_{2} \mathrm{O}$ or $\mathrm{Zr}(\mathrm{OH})_{4}$ but with time may undergo de-protonation to anhydrous $\mathrm{ZrO}_{2}{ }^{13}$. Initial oxides of this type on the surface of the as-received sample can also contribute to the broad $O$ is peak.

The chemical shifts in the $\mathrm{Zr} 3 \mathrm{~d}_{5 / 2}$ spectra from that of $\mathrm{ZrN}$ to $\mathrm{ZrO}_{2}$ eliminated the possibility of formation of $\mathrm{Zr}-\mathrm{N}-\mathrm{O}$ type layer due to incorporation of oxygen into the $\mathrm{ZrN}$ lattice when exposed to $\mathrm{NaCl}$ solution 7. An insignificant change of oxygen content was found on the exposed TiN compared to the unexposed sample. This may indicate very little or nonexistence oxidation of TiN to its oxide as was shown even though it is thermodynamically possible. The very slight shift in the $\mathrm{Ti} 2 \mathrm{p}_{3} / 2$ indicated that transformation from $\mathrm{TiN}$ to $\mathrm{TiO}_{2}$ did not occur. TiN Ti $2 \mathrm{p}_{3 / 2}$ spectra appears in the range of 454.4 to $455.6 \mathrm{eV}$, while that of $\mathrm{TiO}_{2}$ at $458.5 \mathrm{eV} 11$.

It is suspected that oxidation of $\mathrm{ZrN}$ coating on stainless steel exposed to $\mathrm{NaCl}$ solution is kinetically driven by the potential driven between the coating and substrate. The corrosion potential of $\mathrm{ZrN}$ coated $304 \mathrm{SS}$ is anodic to that of bare 304 SS suggesting that the coating itself has an equilibrium potential anodic to the steel. A thermodynamic calculation for the redox reaction of $\mathrm{ZrN}$ to its oxide $\mathrm{ZrO}_{2} .2 \mathrm{H}_{2} \mathrm{O}$ indicated equilibrium potential of $-1322 \mathrm{mV}$ (SCE) at $\mathrm{pH}$ of 6 , similar to the condition used in this study. In practical application, it is expected that some defects on the coating to directly expose the substrate to the solution. This will develop a galvanic couple, 
figure 9. Since the coating is anodic, oxidation of $\mathrm{ZrN}$ to its oxide will provide the passive film to protect the substrate.

In the case of TiN coated 304 SS, the corrosion potential is higher than that of bare 304 SS. This is inconsistent to the predicted equilibrium potential for TiN oxidation to $\mathrm{TiO}_{2} \cdot \mathrm{H}_{2} \mathrm{O}$ at $-742 \mathrm{mV}(\mathrm{SCE})$. Nevertheless, this suggested a more noble potential of the coating than the substrate in $0.5 \mathrm{~N}$ $\mathrm{NaCl}$ solution, figure 10 . The protective ability of this system is dependent on the defect coverage of the TiN coating and the properties of the passive film on the substrate. If the passive film is weak or thin, consequent localized corrosion like pitting of the substrate would occur. Similarly, an active substrate like mild steel or aluminum will corrode more rapidly than without coating due to the galavanic couple between the sustrate and coating.

The formation of an oxide layer on $\mathrm{ZrN}$, as schematically shown in figure 11, is a good protective passive film against chloride attack on 304 stainless steel. It was shown that this film can be formed on $\mathrm{ZrN}$ at lower current density than on zirconium metal in a similar chloride environment 5. The passive current density of the film formed on $\mathrm{ZrN}$ was also found to be lower than on zirconium. The passive range can be extended to a more noble potential than the pitting nucleation potential of zirconium in similar chloride solution by laying $\mathrm{ZrN}$ coating thicker than $5 \mu \mathrm{m}$ or a metal interlayer between $\mathrm{ZrN}$ layers. These may indicate the potential of $\mathrm{ZrN}$ coating as an alternative corrosion resistant coating especially in severe chloride environments. 
The lower charge transfer resistance of the exposed TiN coated sample than the $\mathrm{ZrN}$ coated sample was due to lack of oxidation of the TiN. In this case, TiN acts only as an inert layer in the chloride solution. The protective ability of TiN is then dependent on the defect-free coverage of this coating on the substrate. Defects on TiN coatings can cause very severe corrosion of the substrate 14,15 . However, improved TiN coatings with a lower defect density and better adherence has been achieved by laying a thicker coating or a metal interlayer between $\mathrm{TiN}$ layers 5 .

\section{CONCLUSIONS}

On the basis of the present study the following conclusions can be drawn:

(1). The $\mathrm{ZrN}$ film on $304 \mathrm{SS}$ is transformed to its oxide after exposure to $\mathrm{NaCl}$ solution.

(2). The TiN film on 304 SS does not undergo a similar Hansformation.

(3). The higher corrosion resistance of the $\mathrm{ZrN}$ coated 304 stainless steel can be attributed to the formation of hydrated $\mathrm{ZrO}_{2}$ film which is driven by the potential difference between the anodic coating and the cathodic substrate.

\section{ACKNOWLEDGMENTS}

Authors would like to thank Ray Fontana, Multi Arc Scientific Coatings, New Jersey for the ion plating, and Mike Platek, Rhode Island 
Thin Films and Interface Laboratory, Kingston, Rhode Island for ESCA gurements.

\section{REFERENCES}

1. D. Briggs and M. P. Seah, Practical Surface Analysis by Auger and XPS, Wiley, New York, 1982

2. C. R. Brundle, "Electron Spectroscopy Studies of Adsorption and Oxidation Processes at Metal Surfaces", Journal of Electron Spectroscopy and Related Phenomena, v5 (1974), p.291-319

3. K. Asami, K. Hashimoto, T. Masumoto and S. Shimodaira, "ESCA Study of the Passive Film on an Extremely Corrosion-Resistant Amorphous Iron Alloys", Corrosion Science, v16 (1976), p.909-914

4. K. Asami, K. Hashimoto and S. Shimodaira, "XPS Determination of Rompositions of Alloy Surfaces and Surface Oxides on Mechanically Polished Iron-Chromium Alloys", Corrosion Science, v17 (1977), p.713-723

5. M. N. Alias and R. Brown, "The Effect of Thickness and Process Parameters on Corrosion Behavior of $\mathrm{ZrN}$ and TiN Coatings in the Marine invironment", Paper No. 30, NACE CORROSION '93, New Orleans, Louisiana, March 1993

6. L. van Leaven, M. N. Alias and R. Brown, "Corrosion Behavior of Ion Plated and Implanted Films", Surface and Coatings Technology, v53 (1992), p.25-34

7. R. Brown, M. N. Alias and R. Fontana, "The Effect of Composition and Thickness on Corrosion Behavior of TiN and ZrN Thin Films", Surface and Coatings Technology, accepted for publication 1993 
8. A. K. Gorbachev, "Thermodynamics of Oxidation-Reduction Equilibria in the TiN-H2O System", Translated from Zashchita Metallov, v19 no. 2 (1983), p. 253-257

9. R. Brown and M. N. Alias, "Potential-pH Equilibrium Diagrams of $\mathrm{ZrN}-$ H2O System", in preparation

10. M. Azuma, Y. Nakato and H. Tsubomura, "Oxygen and Chlorine Evolution on Niobium, Zirconium and Other Metal-Nitride Amorphous Thin Film Electrodes Prepared by the Reactive RF Sputtering Technique", Journal of Electroanalytical Chemistry, v255 (1988), p.179-198

11. C. D. Wagner, W. M. Riggs, L. E. Davis, J. F. Moulder and G. E. Muilenberg, Handbook of X-ray Photoelectron Spectroscopy, Perkin Elmer Corporation, Physical Electronics Division, Eden Prairie, Minnesota, 1979

12. K. Asami and K. Hashimoto, "The X-Ray Photoelectron Spectra of Several Oxides of Iron and Chromium", Corrosion Science, v17 (1977), p.559-570

13. G. Okamoto and T. Shibata, "Passivity and the Breakdown of Passivity of Stainless Steel", in Passivity of Metals, R. P. Frankenthal and J. Kruger editors, The Electrochemical Society, Pennington, New Jersey, 1977, p.646677

14. A. Erdemir and R. F. Hochman, "Corrosion Behavior of TiN Ion Plated M-50 Bearing Steel", Journal of Materials for Energy Systems, v7 (1985), p.265-268

15. M. J. Park, A. Leyland and A. Matthews, "Corrosion Performance of Layered Coatings Produced by Physical Vapour Deposition", Surface and Coatings Technology, v43/44 (1990), p.481-492 


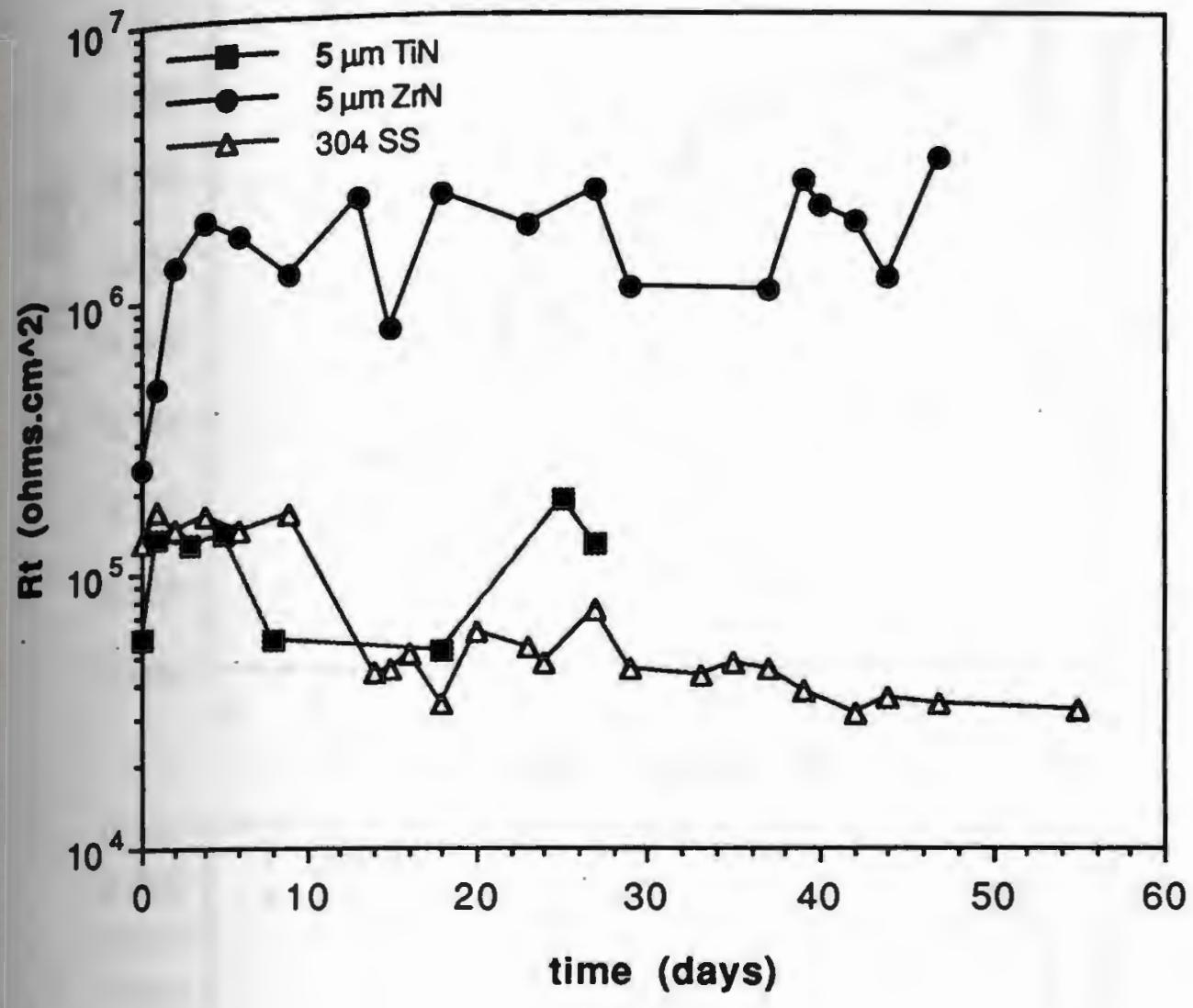

Figure 1. Charge transfer resistance of uncoated, $5 \mu \mathrm{m}$ TiN and $\mathrm{ZrN}$ coated $304 \mathrm{SS}$ exposed to $\mathrm{NaCl}$ as obtained from impedance data. 

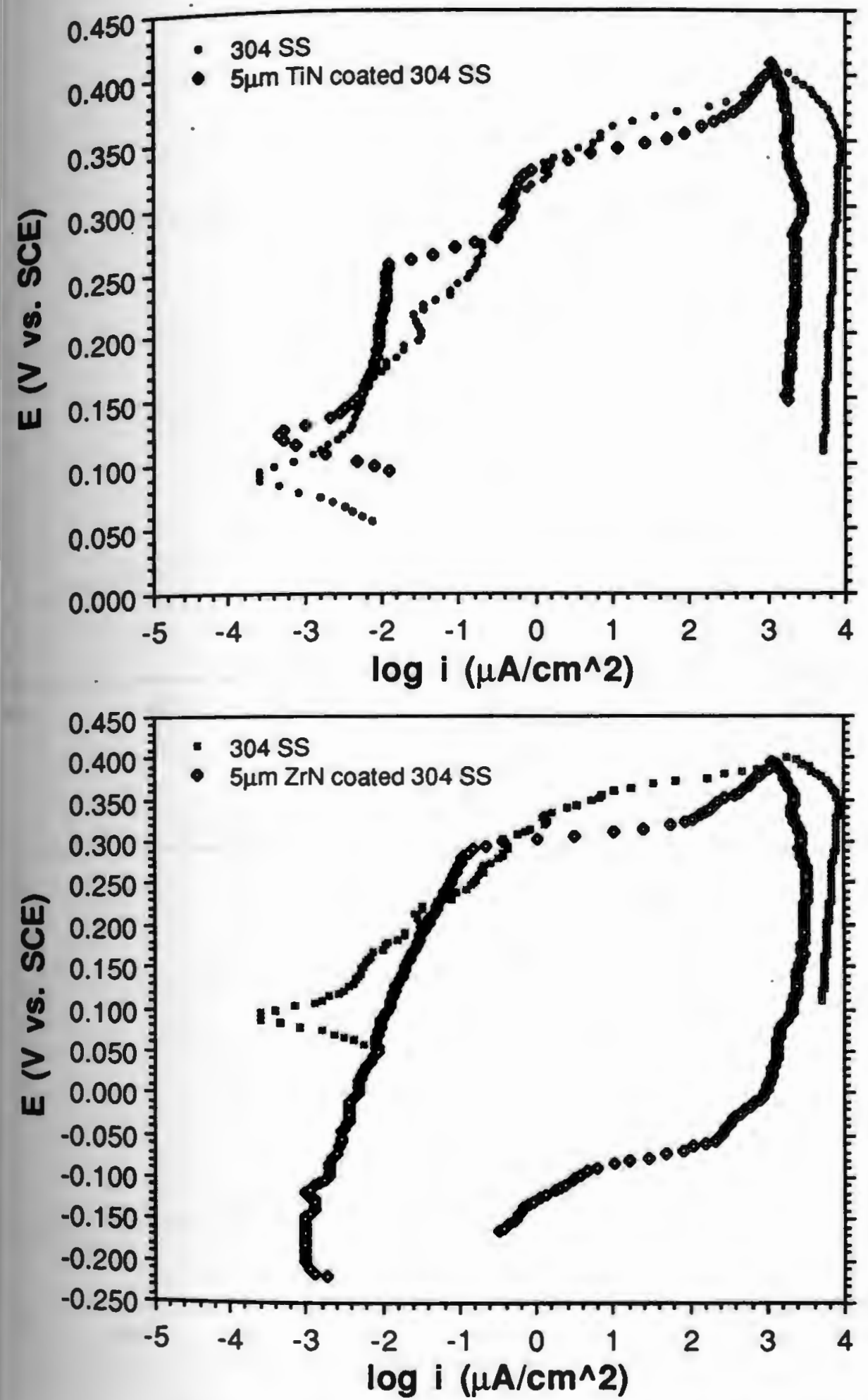

Figure 2. Cyclic polarization scans plot of $\mathrm{TiN}$ and $\mathrm{ZrN}$ coated $304 \mathrm{SS}$, and bare $304 \mathrm{SS}$ in $0.5 \mathrm{~N} \mathrm{NaCl}$ solution. 

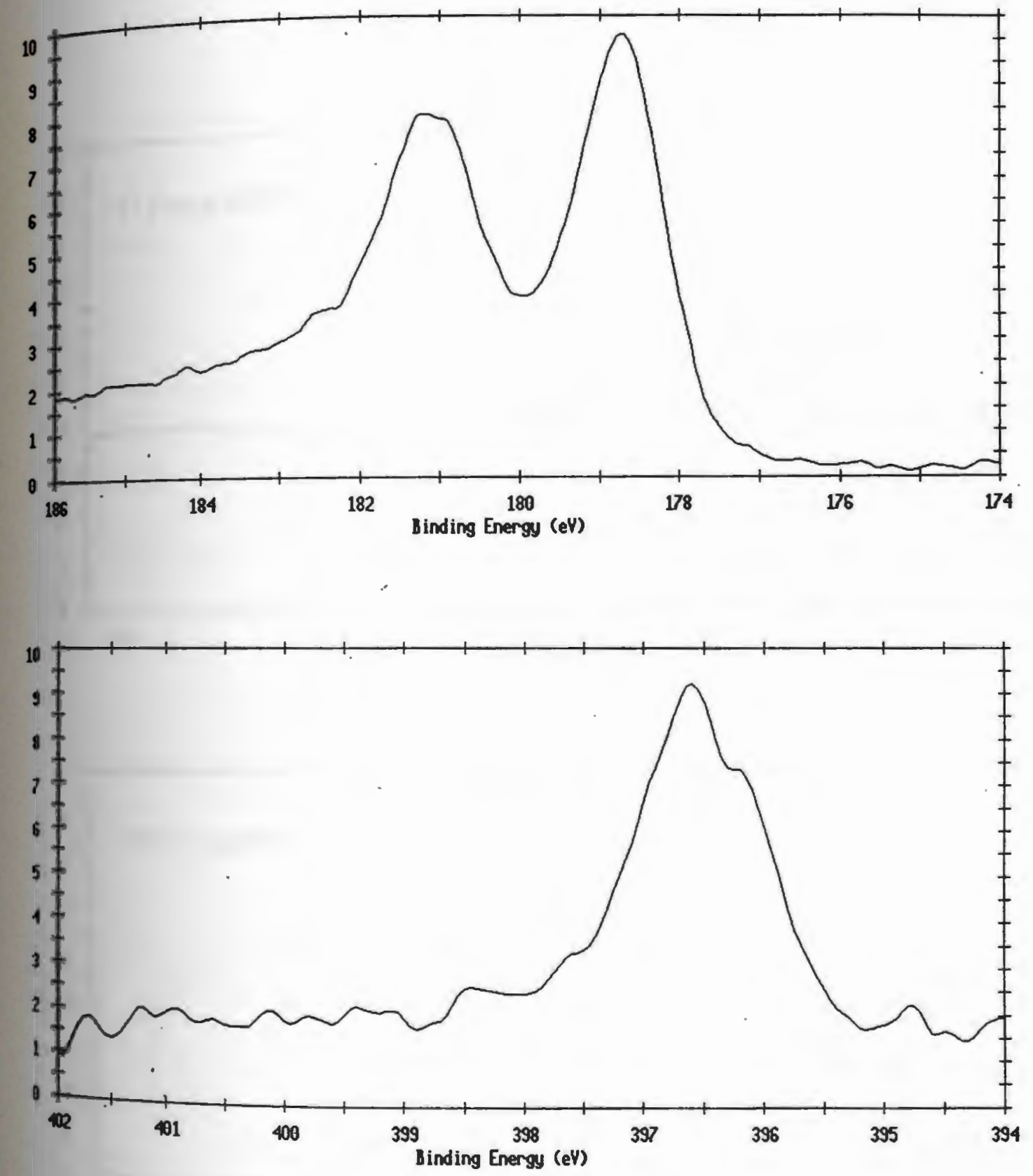

Figure 3. $\mathrm{Zr}_{3} \mathrm{~d}_{5 / 2}$ and $\mathrm{N}$ 1s ESCA spectra of bulk $\mathrm{ZrN}$ on 304 stainless steel. 

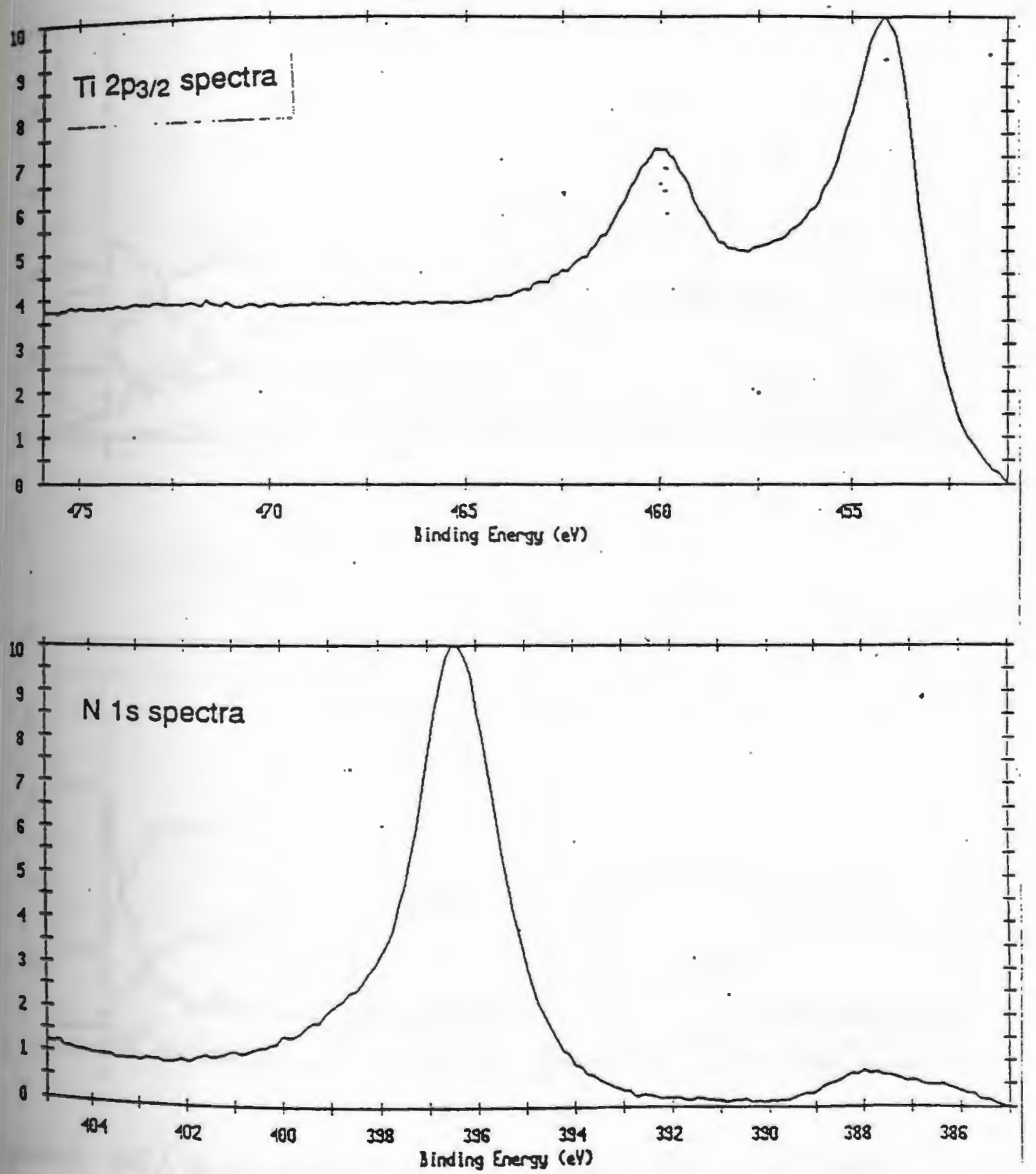

Figure 4. Ti $2 p_{3 / 2}$ and N 1s ESCA specra of bulk TiN on 304 stainless steel. 

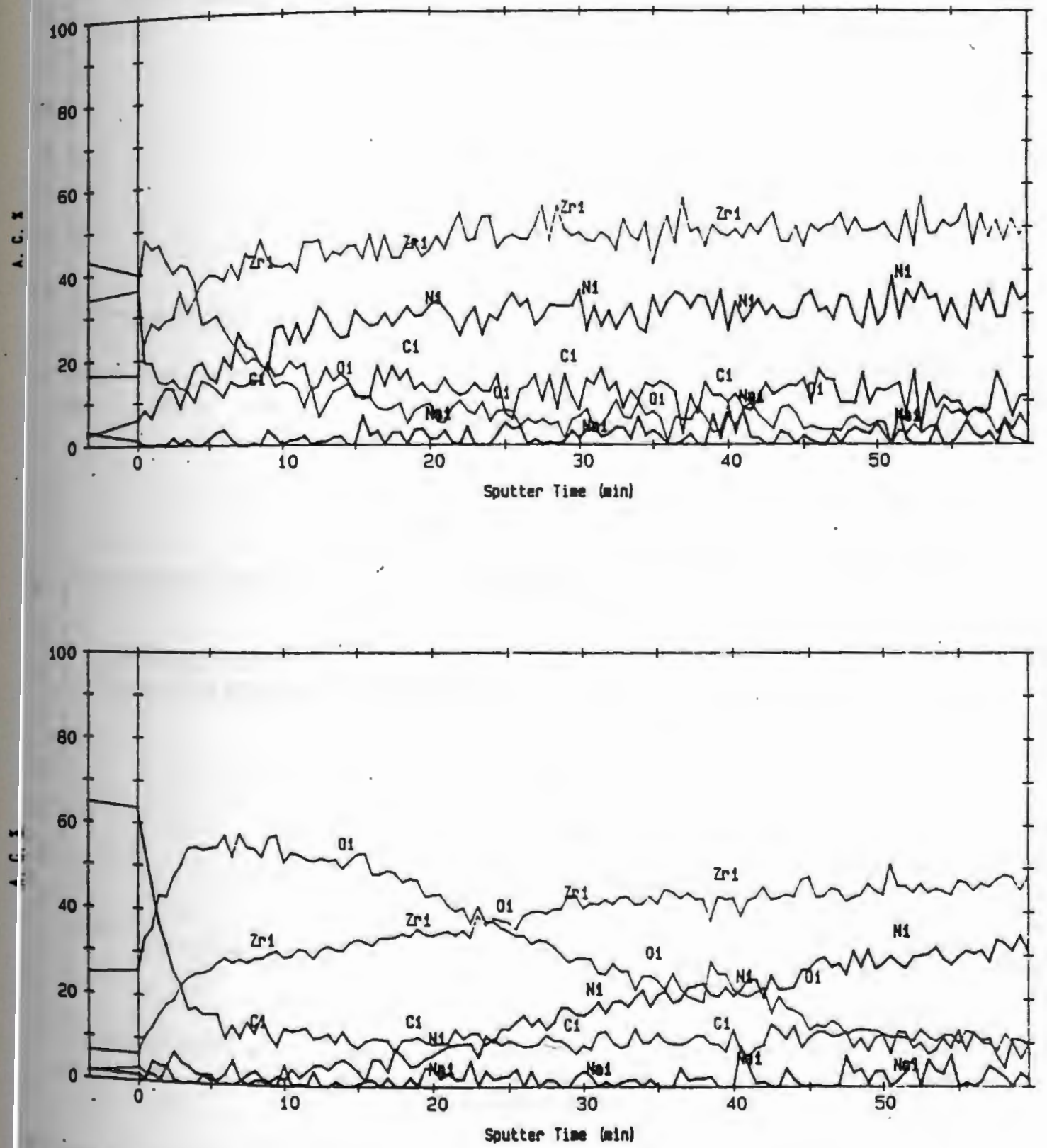

Figure 5. ESCA depth profile of fresh and exposed $\mathrm{ZrN}$ coated 304 SS. 

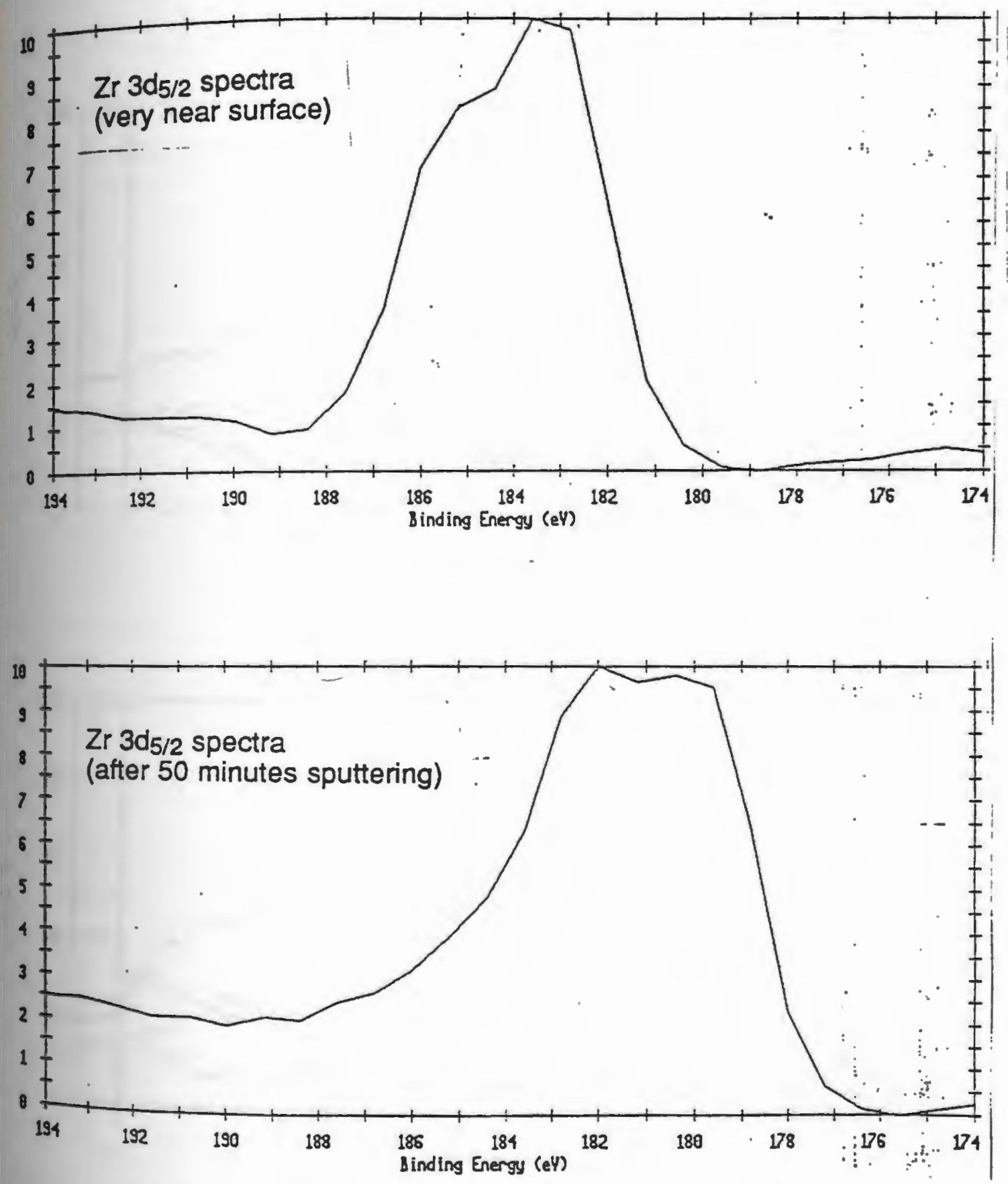

Figure 6. $\mathrm{Zr} 3 \mathrm{~d}_{5 / 2}$ ESCA spectra of the exposed $\mathrm{ZrN}$ coated $304 \mathrm{SS}$ at very near the surface and after 50 minutes sputtering. 

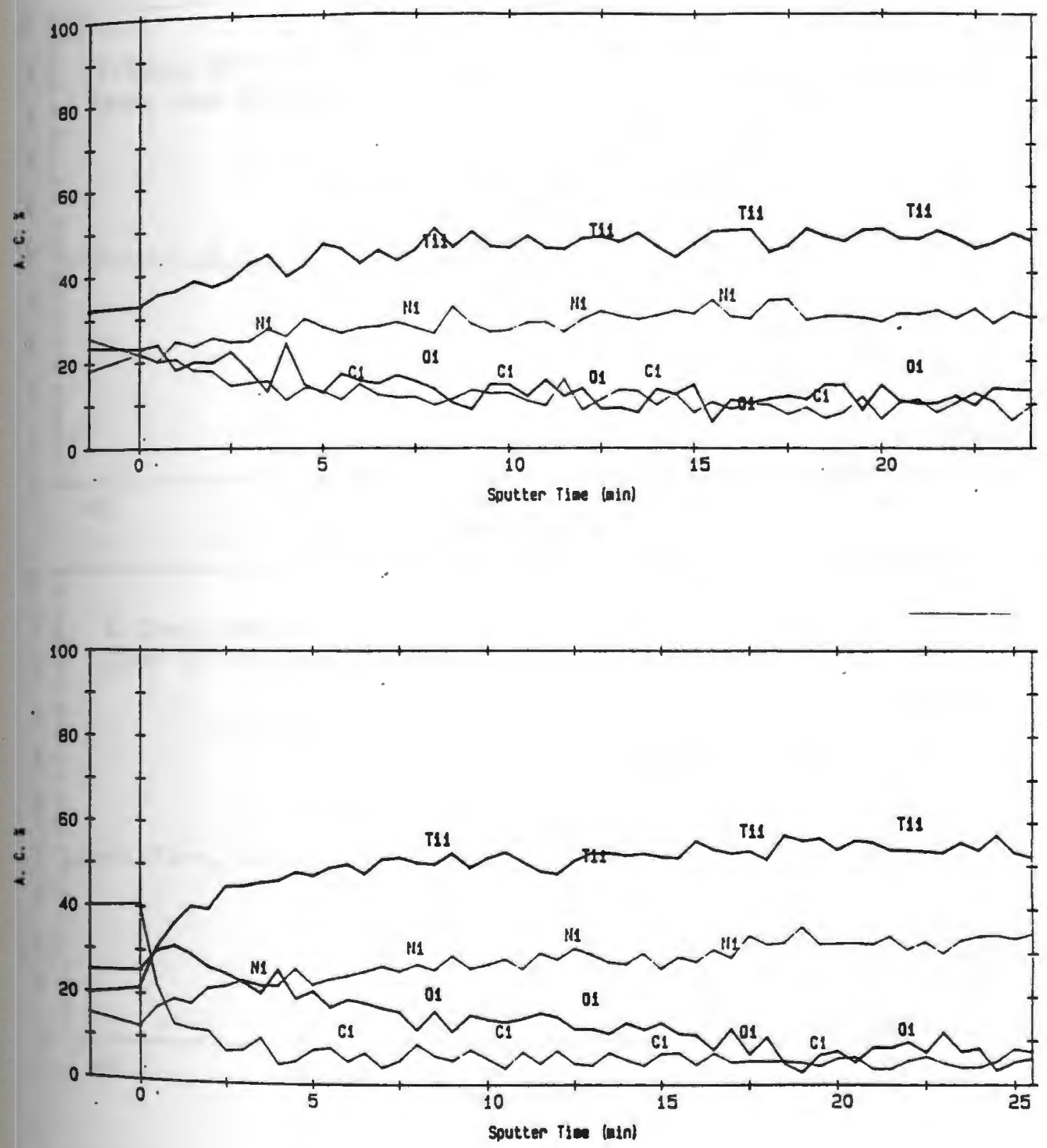

Figure 7. ESCA depth profile of fresh and exposed TiN coated 304 SS. 

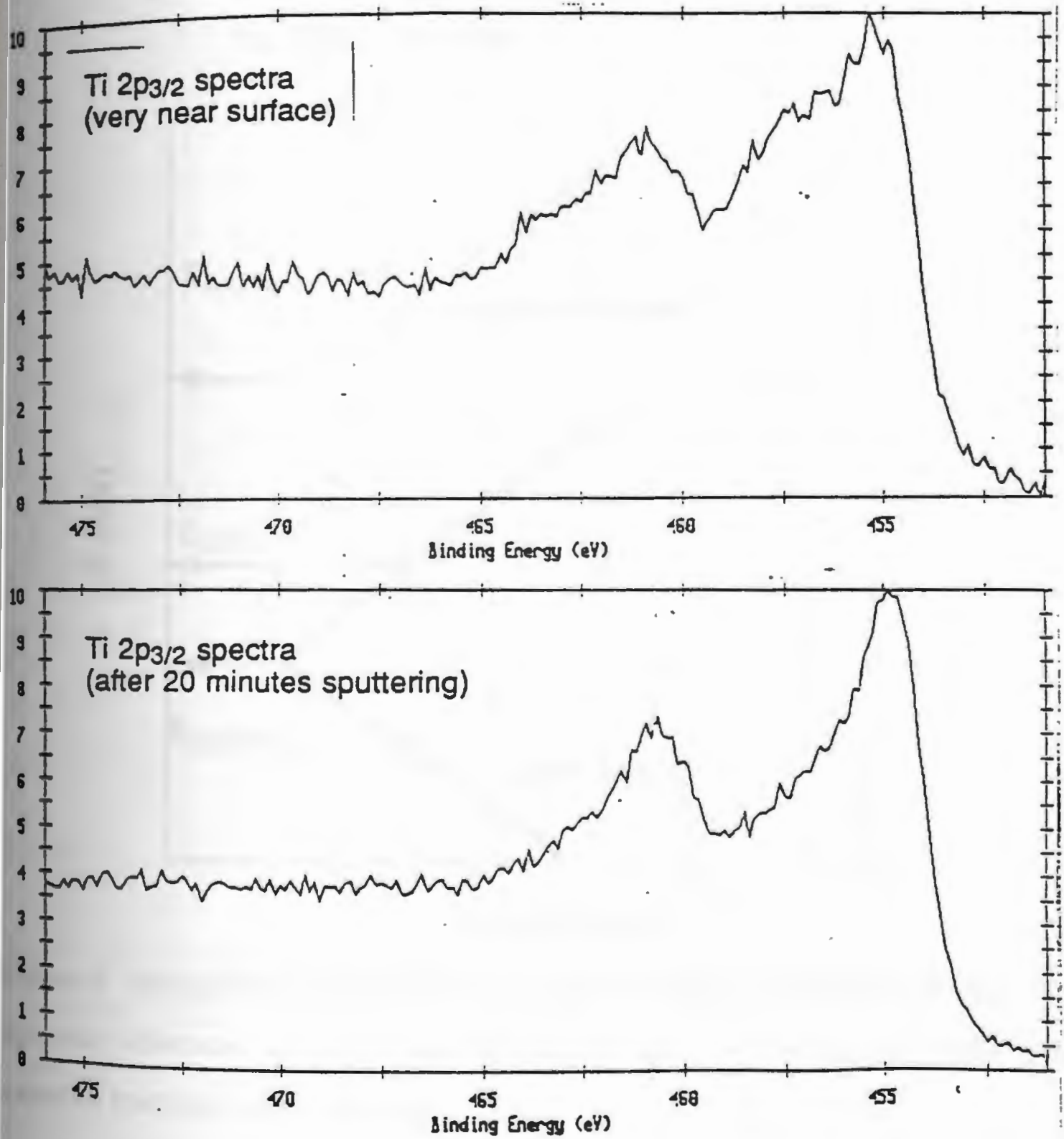

Figure 8. Ti $2 p_{3 / 2}$ ESCA spectra of the exposed TiN coated 304 SS at very near the surface and after 20 minutes sputtering. 

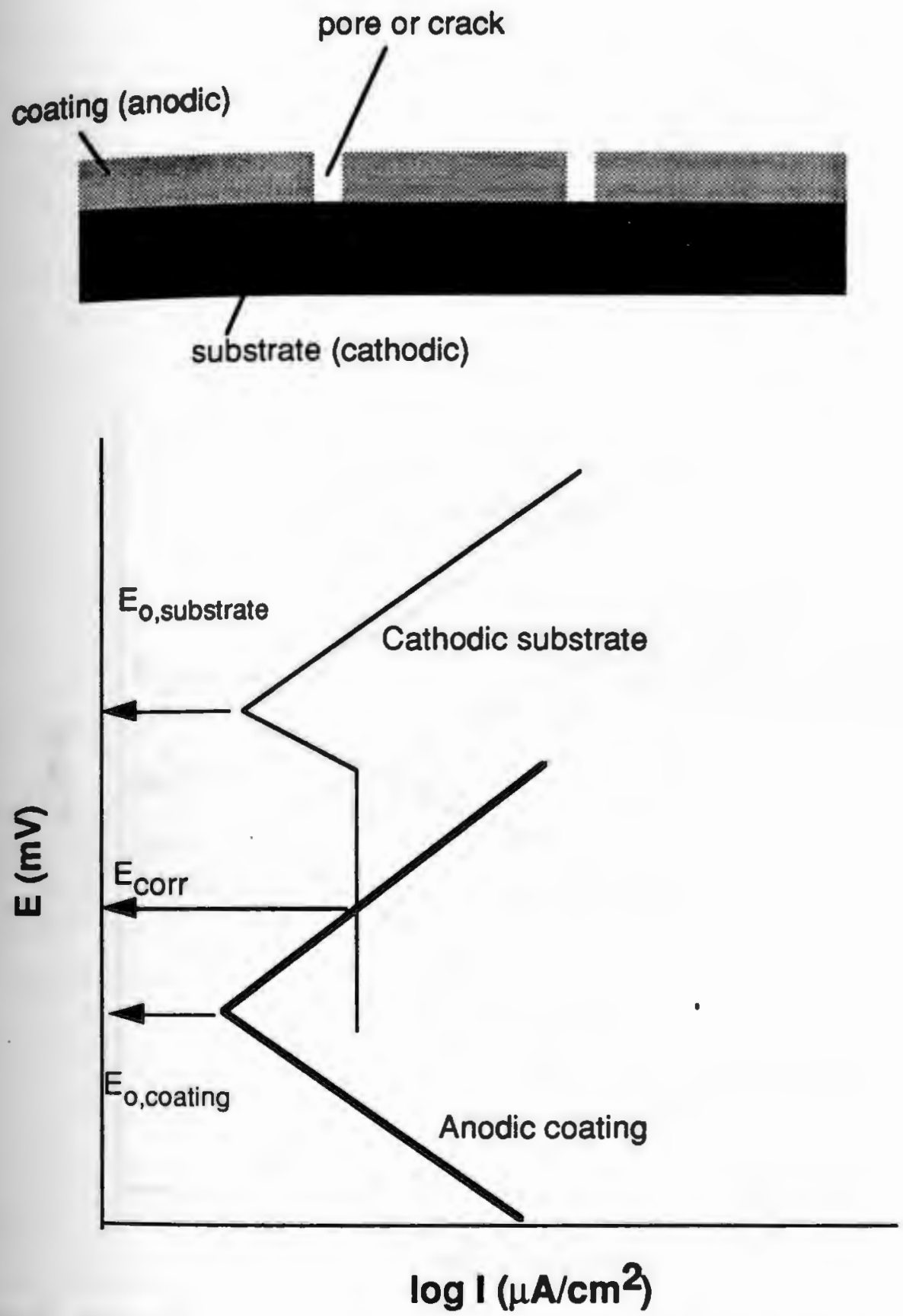

Figure 9. Schematic representation of anodic coating with pores exposing the cathodic substrate, and hypothetical Evans diagram showing the anodic and cathodic reactions in the system. 

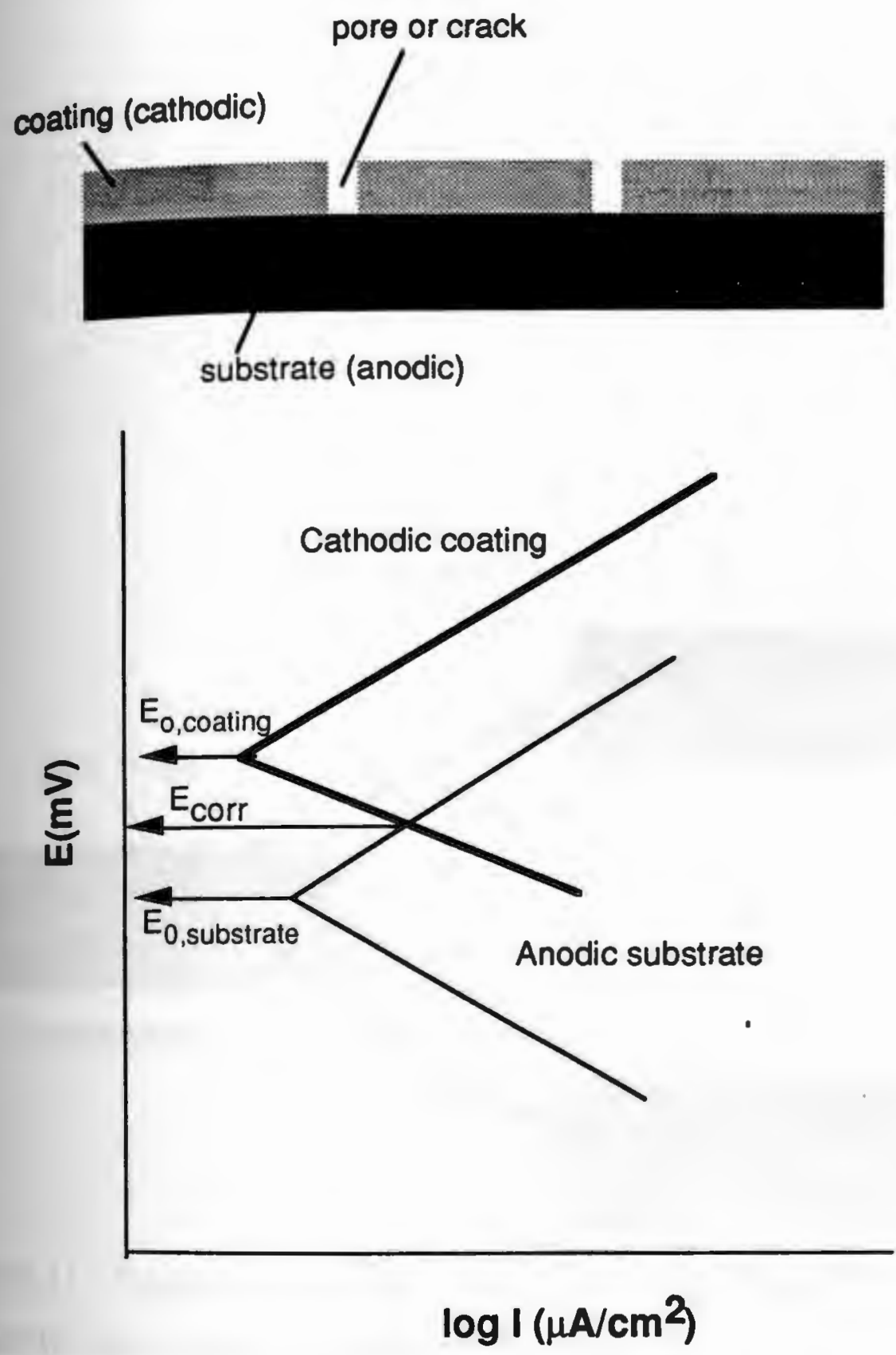

Figure 10. Schematic representation of cathodic coating with pores exposing the anodic substrate, and hypothetical Evans diagram showing the aanodic cathodic reactions in the system. 


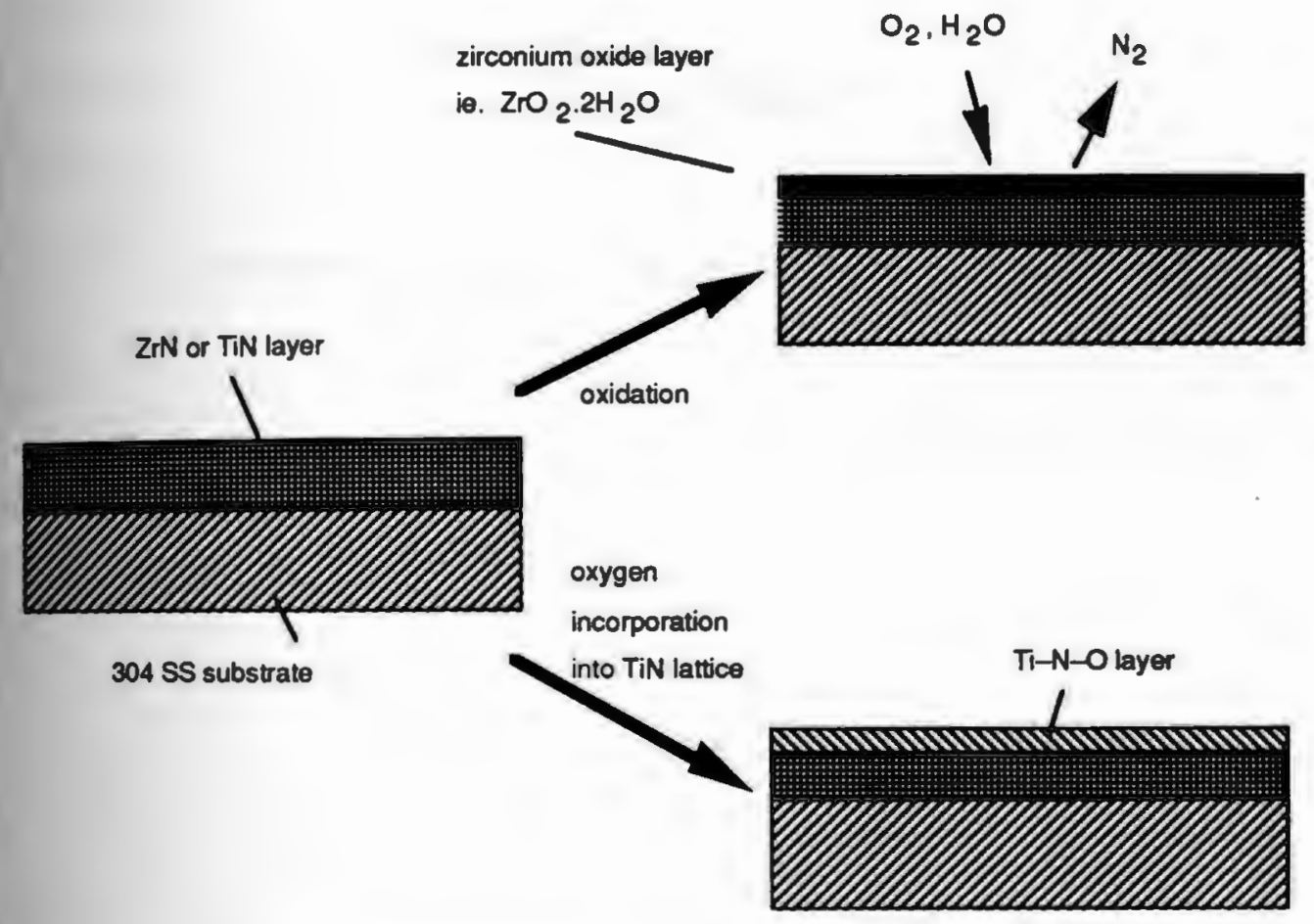

Figure 11. Schematic representation of formation of oxide layer on $\mathrm{ZrN}$ as protective film against chloride attack on 304 SS. 


\section{CHAPTER V}

THERMODYNAMIC EQUILIBRIA OF ZrN IN WATER 


\section{ABSTRACT}

pH-potential diagram for $\mathrm{ZrN}$ in water was constructed. The immunity, passivity and corrosion regions nearly followed that for zirconium. The equilibrium potentials for oxidation to solid and dissolved compounds are higher for $\mathrm{ZrN}$ than zirconium. Oxidation to $\mathrm{ZrO}_{2} \cdot 2 \mathrm{H}_{2} \mathrm{O}$ occurs at lower potential than oxidation of $\mathrm{TiN}$ to its hydrated oxide indicating lesser stability of $\mathrm{ZrN}$ than $\mathrm{TiN}$. This diagram can be useful for selecting potential protective coating for metals or alloys at any $\mathrm{pH}$ and potential. 


\section{INTRODUCTION}

Electrochemical studies on steels coated with TiN have been widely conducted (1-7). In acidic environment as in sulfuric acid solution it was shown that this nitride coating has excellent corrosion protection properties. Inertness and/or passivation of this coating in the acidic environment were reasons for its high corrosion resistance. Surface coverage of coating over the based substrate is one of the important factors of a succesful coating. It was found that defects and cracks in the coatings over an active substrate can cause severe corrosion of the substrate.

Some studies were conducted to test the corrosion protection ability of $\mathrm{ZrN}$ coatings compared to TiN coatings on stainless steel in chloride environment (8-9). Higher corrosion resistance of stainless steel coated with $\mathrm{ZrN}$ was found, and was suggested due to more spontaneous formation of passive film on ZrN. That was supported by potentiodynamic polarization scan tests which shown a lower current density for formation of passive film on $\mathrm{ZrN}$ coated stainless steel than on TiN coated stainless steel, and by XPS analysis of samples exposed over a period of time which shown existence of zirconium oxide of few hundreds angstrom thick in the original layer of deposited $\mathrm{ZrN}$ coating (10). Transformation of $\mathrm{ZrN}$ to possibly the hydrated form of zirconium oxide, $\mathrm{ZrO}_{2} \cdot 2 \mathrm{H}_{2} \mathrm{O}$, occurred by electrochemical reaction. This transformation did not take place for the case of TiN coated stainless steel exposed in similar environment at open circuit condition. This is hiconsistent to the predicted electrochemical equilibrium diagram of TiNwater system which suggested passivation of $\mathrm{TiN}$ to $\mathrm{TiO}_{2} \cdot \mathrm{H}_{2} \mathrm{O}$ in that condition (11). 
The formation of passive oxide film on $\mathrm{ZrN}$ over stainless steel was suggested as driven by potential difference between the coating and the stainless steel. The free corrosion potential of the $\mathrm{ZrN}$ coated stainless steel was lower than the bare stainless steel, but that of the TiN coated stainless steel was higher than the bare stainless steel. Accordingly, oxidation of $\mathrm{ZrN}$ will take place since it is anodic to the substrate and protect the substrate. In the TiN case, the oxidation of the substrate will occur. If the substrate is active it will corrode, but if it is passive the corrosion behavior will depend only on the protective ability of the passive films of both the coating and the substrate. Passive films on stainless steel are susceptible to pitting in chloride environment. Passive films on $\mathrm{ZrN}$ coatings was found to provide higher corrosion resistance of the stainless steel. Thermodynamic calculation and surface analysis indicated transformation of $\mathrm{ZrN}$ to zirconium oxide by anodic oxidation involving electron transfer (10). In this case, the substrate is protected by the passive oxide films over the $\mathrm{ZrN}$ coating. It is also possible that other nitrides with potential more anodic than the substrate can be used to form more stable passive films to protect corrosion of the underlaying substrate.

Thermodynamic prediction for electrochemical behavior of $\mathrm{ZrN}$ in water at any $\mathrm{pH}$ and potential can be made possible by construction of its Pourbaix diagram. Only TiN-water Pourbaix diagram is available in the literature for nitride (11). It is then desirable to construct $\mathrm{ZrN}$-water Pourbaix diagram, discuss the thermodynamic stability of $\mathrm{ZrN}$ in water, and compare it to the TiN-water thermodynamic diagram with respect to their application for selection of protective coating. 


\section{THEORY}

Electrochemical equilibria for reaction involving electrons transfer like

$(13,14)$

$$
\mathrm{aA}+\mathrm{cH}_{2} \mathrm{O}=\mathrm{bB}+\mathrm{mH}^{+}+\mathrm{ne}^{-}
$$

is considered by calculating the sum of free energy given as

$$
\Sigma \Delta G_{0}^{*}=E_{0}(23.060 \mathrm{n}) \text { for } \Delta G_{0}^{\circ} \text { in } \mathrm{kcal} / \mathrm{mole}
$$

where $\Delta G^{*}{ }_{0}$ is the sum of all free energies of all components in the reaction at $298 \mathrm{~K}$ in $\mathrm{kcal} / \mathrm{mole}, \mathrm{n}$ is the number of electron transfer involved, and $\mathrm{E}_{\mathrm{O}}$ is the standard equilibrium reduction potential, in volts vs. SHE, where all the components of the reaction are in standard state where the activity and fugacity of the dissolved and gaseous bodies, respectively, equals to 1 .

The equilibrium reduction potential at any given condition is given as

$$
\mathrm{E}=\mathrm{E}_{\mathrm{o}}+(0.0591 / \mathrm{n}) \Sigma \mathrm{v} \log [\mathrm{M}]-(0.0591 \mathrm{~m} / \mathrm{n}) \mathrm{pH}
$$

where $\mathrm{M}$ is the activity or corrected concentration for a dissolved state or the fugacity or corrected partial pressure for gaseous state, and

$$
\sum \mathrm{v} \log [\mathrm{M}]=\log \{[\mathrm{B}] \mathrm{b} /[\mathrm{A}] \mathrm{a}\}
$$

The chemical equilibria for chemical reaction type

$$
\mathrm{aA}+\mathrm{cH}_{2} \mathrm{O}=\mathrm{bB}+\mathrm{mH}^{+}
$$

where there is no electron transfer, in which B is in the alkaline form and A is in the acid form, the equilibrium is given as

$$
\Sigma \mathrm{v} \log [\mathrm{M}]=\log \mathrm{K}+\mathrm{mpH}
$$

where

$$
\sum \mathrm{v} \log [\mathrm{M}]=\log \{[\mathrm{B}] \mathrm{b} /[\mathrm{A}] \mathrm{a}\}
$$


and

$$
\log K=-\left(\Sigma \Delta G_{0}^{\circ}\right) / 1.363
$$

\section{CONSIDERATION OF SUBSTANCES}

Solid and dissolved substances must be considered to construct $\mathrm{ZrN}$ water diagram similar to those considerations for $\mathrm{Zr}$-water equilibrium diagram $(13,14)$. An assumption taken is that the oxidation state of metal of nitride; assumed at 0 oxidation state. Listed below are substances considered and their descriptions for the construction of $\mathrm{ZrN}$-water diagram :

Oxidation No. Considered Substances Descriptions

(z)

0

0

$+$

$+4$

$+4$

$+4$

$+4$

$+4$
Solid Substances

$\mathrm{Zr}$

$\mathrm{ZrN}$

$\mathrm{ZrO}_{2} .2 \mathrm{H}_{2} \mathrm{O}$ or $\mathrm{Zr}(\mathrm{OH})_{4}$

$\mathrm{ZrO}_{2} \cdot \mathrm{H}_{2} \mathrm{O}$ or $\mathrm{ZrO}(\mathrm{OH})_{2}$

$\mathrm{ZrO}_{2}$ anhydrated

Dissolved Substances

$\mathrm{Zr}^{4+}$

$\mathrm{ZrO}^{2+}$

$\mathrm{HZrO}_{3}^{-}$ grey-white, cubic

golden, $\mathrm{NaCl}$

hydrated oxide, white, amorphous

hydrated oxide, white

anhydrous oxide or zirconia, white,

monoclinic

zirconic ion, colourless

zirconyl ion, colourless

zirconate ion, colourless

\section{FREE ENERGY VALUES}

Free energy values at $298 \mathrm{~K}$ used in calculation of equilibrium reduction potential and stability regions of dissolved species are given in tables below. All values are taken from reference (15) unless noted otherwise: 
Table I : Compounds of Zirconium, water and gas components

\begin{tabular}{|c|c|}
\hline Formula & $\Delta \mathrm{G}_{0}^{\circ}$ (Kcal/mole $)$ \\
\hline $\mathrm{H}^{+}(\mathrm{aq})$ & 0 \\
\hline $\mathrm{OH}^{-}(\mathrm{aq})$ & -37.595 \\
\hline $\mathrm{H}_{2} \mathrm{O}(\mathrm{l})$ & -56.72 \\
\hline $\mathrm{H}_{2}(\mathrm{~g})$ & 0 \\
\hline $\mathrm{N}_{2}(\mathrm{~g})$ & 0 \\
\hline $\mathrm{O}_{2}(\mathrm{~g})$ & 0 \\
\hline $\mathrm{Zr}(\mathrm{c})$ & 0 \\
\hline $\mathrm{ZrN}(\mathrm{c})$ & -75.4 \\
\hline $\mathrm{Zr}^{4+}(\mathrm{ag})$ & $-142.0(13)$ \\
\hline $\mathrm{ZrO}^{2+}(\mathrm{aq})$ & $-201.5(13)$ \\
\hline $\mathrm{ZrO}_{2}(\mathrm{c})$ & $-247.7(13)$ \\
\hline $\begin{array}{l}\mathrm{ZrO}_{2} .2 \mathrm{H}_{2} \mathrm{O}(\mathrm{c}) \\
\text { or } \mathrm{Zr}(\mathrm{OH})_{4}(\mathrm{c})\end{array}$ & -370.0 \\
\hline $\begin{array}{l}\mathrm{ZrO}_{2} \cdot \mathrm{H}_{2} \mathrm{O}(\mathrm{c}) \\
\text { or } \mathrm{ZrO}(\mathrm{OH})_{2}(\mathrm{c})\end{array}$ & -311.5 \\
\hline $\mathrm{HZrO}_{3}^{-}$(aq) & -287.7 \\
\hline
\end{tabular}

\section{REACTIONS AND EQUILIBRIUM FORMULAE}

The equilibrium potentials for oxidation and reduction reactions are calculated as shown below :

2 dissolved substances (13)

$Z=+4$

(1) $\mathrm{ZN}^{4+}+\mathrm{H}_{2} \mathrm{O}=\mathrm{ZrO}^{2+}+2 \mathrm{H}^{+}$

By employing equation (iv) :

$\log \left(\mathrm{ZrO}^{2+} / \mathrm{Zr}^{4+}\right)=-\Sigma \Delta \mathrm{G}_{\mathrm{o}}^{\mathrm{O}} / 1.363+2 \mathrm{pH}$

$\log \left(\mathrm{ZrO}^{2+} / \mathrm{Zr}^{4+}\right)=2.06+2 \mathrm{pH}$

(2). $\mathrm{ZrO}^{2+}+2 \mathrm{H}_{2} \mathrm{O}=\mathrm{HZrO}_{3}^{-}+3 \mathrm{H}^{+}$

$\log \left(\mathrm{HZO}_{3}^{-} / \mathrm{ZrO}^{2+}\right)=-19.95+3 \mathrm{pH}$ 
Limits of the domains of relative predominance of the dissolved substances :

(1). $\mathrm{zr}^{4+} / \mathrm{ZrO}^{2+}$

$$
\begin{aligned}
& \mathrm{pH}=-1.03 \\
& \mathrm{pH}=6.65
\end{aligned}
$$

(2'). $\mathrm{ZO}^{2+} / \mathrm{HZrO}_{3}^{-}$

\section{2 solid substances, and 1 gaseous substance}

$Z: 0$ to +4

(3a). $\mathrm{ZNN}+2 \mathrm{H}_{2} \mathrm{O}=\mathrm{ZrO}_{2}+4 \mathrm{H}^{+}+1 / 2 \mathrm{~N}_{2}+4 \mathrm{e}^{-}$

By employing equations (i), (ii), and (iii) :

$$
E=-0.6381-0.0591 \mathrm{pH}+0.0074 \log \mathrm{P}_{\mathrm{N} 2}
$$

(3b). $\mathrm{ZrN}+3 \mathrm{H}_{2} \mathrm{O}=\mathrm{ZrO}_{2} \cdot \mathrm{H}_{2} \mathrm{O}+4 \mathrm{H}^{+}+1 / 2 \mathrm{~N}_{2}+4 \mathrm{e}^{-}$

$E=-0.7149-0.0591 p H+0.0074 \log P_{\mathrm{N} 2}$

(3c). $\mathrm{ZrN}+4 \mathrm{H}_{2} \mathrm{O}=\mathrm{ZrO}_{2} \cdot 2 \mathrm{H}_{2} \mathrm{O}+4 \mathrm{H}^{+}+1 / 2 \mathrm{~N}_{2}+4 \mathrm{e}^{-}$

$$
E=-0.7342-0.0591 \mathrm{pH}+0.0074 \log P_{\mathrm{N} 2}
$$

\section{1 solid substance, and 1 dissolved substance (13)}

$Z=+4$

(4a). $\mathrm{Zr}^{4+}+2 \mathrm{H}_{2} \mathrm{O}=\mathrm{ZrO}_{2}+4 \mathrm{H}^{+}$

By employing equation (iv) :

$$
\log \left(\mathrm{Zr}^{4+}\right)=5.64-4 \mathrm{pH}
$$

(4b). $\mathrm{ZH}^{4+}+3 \mathrm{H}_{2} \mathrm{O}=\mathrm{ZrO}_{2} \cdot \mathrm{H}_{2} \mathrm{O}+4 \mathrm{H}^{+}$

$\log \left(\mathrm{Zr}^{4+}\right)=0.79-4 \mathrm{pH}$

(4c). $\mathrm{Z}^{4+}+4 \mathrm{H}_{2} \mathrm{O}=\mathrm{ZrO}_{2} \cdot 2 \mathrm{H}_{2} \mathrm{O}+4 \mathrm{H}^{+}$

$\log \left(\mathrm{Zr}^{4+}\right)=-0.91-4 \mathrm{pH}$

(5a). $\mathrm{ZrO}^{2+}+\mathrm{H}_{2} \mathrm{O}=\mathrm{ZrO}_{2}+2 \mathrm{H}^{+}$

$\log \left(\mathrm{ZrO}^{2+}\right)=7.70-2 \mathrm{pH}$

(5b). $\mathrm{ZrO}^{2+}+2 \mathrm{H}_{2} \mathrm{O}=\mathrm{ZrO}_{2} \cdot \mathrm{H}_{2} \mathrm{O}+2 \mathrm{H}^{+}$

$\log \left(\mathrm{ZrO}^{2+}\right)=2.48-2 \mathrm{pH}$

(5c). $2 \mathrm{ZO}^{2+}+3 \mathrm{H}_{2} \mathrm{O}=\mathrm{ZrO}_{2} \cdot 2 \mathrm{H}_{2} \mathrm{O}+2 \mathrm{H}^{+}$

$\log \left(\mathrm{ZrO}^{2+}\right)=1.15-2 \mathrm{pH}$

(6a). $\mathrm{ZrO}_{2}+\mathrm{H}_{2} \mathrm{O}=\mathrm{HZrO}_{3}^{-}+\mathrm{H}^{+}$

$\log \left(\mathrm{HZrO}_{3}^{-}\right)=-12.25+\mathrm{pH}$

(6b). $\quad \mathrm{ZrO}_{2} \cdot \mathrm{H}_{2} \mathrm{O}=\mathrm{HZ}_{\mathrm{rO}_{3}^{-}}^{-}+\mathrm{H}^{+}$

$\log \left(\mathrm{HZrO}_{3}{ }^{-}\right)=-17.46+\mathrm{pH}$

(6c). $\mathrm{ZrO}_{2} \cdot 2 \mathrm{H}_{2} \mathrm{O}-\mathrm{H}_{2} \mathrm{O}=\mathrm{HZrO}_{3}^{-}+\mathrm{H}^{+}$

$\log \left(\mathrm{HZrO}_{3}^{-}\right)=-18.78+\mathrm{pH}$ 
(2) : 0 to +4

(7). $\mathrm{ZrN}=\mathrm{Zr}^{4+}+1 / 2 \mathrm{~N}_{2}+4 \mathrm{e}^{-}$

By equations (i), (ii), and (iii) :

$$
E=-0.7220+0.0074 \log P_{N 2}+0.0148 \log \left[Z^{4+}\right]
$$

(8). $\mathrm{ZrN}+\mathrm{H}_{2} \mathrm{O}=\mathrm{ZrO}^{2+}+2 \mathrm{H}^{+}+1 / 2 \mathrm{~N}_{2}+4 \mathrm{e}^{-}$

$E=-0.7522-0.0295 \mathrm{pH}+0.0074 \log \mathrm{PN}_{2}+0.0148 \log \left[\mathrm{Zr}^{2+}\right]$

(9). $\mathrm{ZrN}+3 \mathrm{H}_{2} \mathrm{O}=\mathrm{HZrO}_{3}^{-}+5 \mathrm{H}^{+}+1 / 2 \mathrm{~N}_{2}+4 \mathrm{e}^{-}$

$E=-0.4569-0.0739 \mathrm{pH}+0.0074 \log \mathrm{P}_{\mathrm{N} 2}+0.0148 \log \left[\mathrm{HZrO}_{3}{ }^{-}\right]$

(V) Hydrogen and Oxygen Equilibrium Lines (13)

(a). $\mathrm{H}_{2}=2 \mathrm{H}^{+}+2 \mathrm{e}^{-}$

$E=-0.0591 \mathrm{pH}-0.0295 \log \mathrm{pH}_{2}$

(b). In alkaline media: $\quad 4\left(\mathrm{OH}^{-}\right)=\mathrm{O}_{2}+2 \mathrm{H}_{2} \mathrm{O}+4 \mathrm{e}^{-}$

In acidic media : $\quad 2 \mathrm{H}_{2} \mathrm{O}=\mathrm{O}_{2}+4 \mathrm{H}^{+}+4 \mathrm{e}^{-}$

$$
E=1.228-0.0591 \mathrm{pH}+0.0148 \log \mathrm{pO}_{2}
$$

\section{CONSTRUCTION OF DIAGRAMS}

The solubility limits of predominance substances are calculated using activities of $10^{0}, 10^{-2}, 10^{-4}$, and $10^{-6} . \mathrm{ZrN}$ is assumed to exist in its ground state ; 0 oxidation state. Oxidation of nitride is assumed to produce dissolved $\mathrm{N}_{2}$ in the solution. The partial pressure of $\mathrm{N}_{2}$ of 1 atmosphere is used to construct this diagram. 
$\mathrm{ZrN}$-water diagram considering formation of $\mathrm{ZrO}_{2} .2 \mathrm{H}_{2} \mathrm{O}$ solid is shown in figure 1. Hydrated zirconium oxide is formed at approximately 800 $\mathrm{mV}$ higher from $\mathrm{ZrN}$ than from pure $\mathrm{Zr}$. Oxidation of $\mathrm{Zr}$ to its hydrated oxide follows the reaction given by

$$
\mathrm{Zr}+4 \mathrm{H}_{2} \mathrm{O}=\mathrm{ZrO}_{2} \cdot 2 \mathrm{H}_{2} \mathrm{O}+4 \mathrm{H}^{+}+4 \mathrm{e}^{-}
$$

and its equilibrium potential is given by

$$
\mathrm{E}=-1.553-0.0591 \mathrm{pH}
$$

This hydrated oxide is stable between $\mathrm{pH} 4$ and 13 for the activity of dissolved ions at $10^{-6}$. This is a passive region for $\mathrm{ZrN}$. In comparison to the TiNwater system (11), the oxide is more favorably formed at lower potentials, much below the water stability region. This oxidation reaction releases nitrogen gas into the solution. The oxidation potential for TiN to the hydrated titanium oxide, $\mathrm{TiO}_{2} \cdot \mathrm{H}_{2} \mathrm{O}$, is given by

$$
\mathrm{TiN}+3 \mathrm{H}_{2} \mathrm{O}=\mathrm{TiO}_{2} \cdot \mathrm{H}_{2} \mathrm{O}+4 \mathrm{H}^{+}+1 / 2 \mathrm{~N}_{2}+4 \mathrm{e}^{-}
$$

and its equilibrium potential is given by

$$
E=-0.098-0.0591 \mathrm{pH}+0.0074 \log \mathrm{PN} 2
$$

By considering formation of the anhydrated zirconium oxide film, $\mathrm{ZrO}_{2}$, the regions of ionic stability of $\mathrm{Zr}^{+4}, \mathrm{ZrO}^{+2}$ and $\mathrm{HZrO}^{-3}$ overlapping one another. This suggested formation of this anhydrous solid is rmodynamically impossible under this condition. It is unstable and is readily to form dissolved ions in the solution. It is also undesirable since it promotes corrosion of $\mathrm{ZrN}$. 


\section{DISCUSSIONS}

In comparison to the $\mathrm{Zr}$-water Pourbaix diagram, the diagram for $\mathrm{ZrN}$ shown higher potential for formation of its metal oxide or hydroxide (13). The regions of immunity, passivity and corrosion of $\mathrm{ZrN}$-water diagram is nearly similar in shape to the zirconium-water diagram. The passive film is stable over wide $\mathrm{pH}$ range.

Construction of Pourbaix diagrams can be very helpful in prediction of corrosion behavior of nitride coatings when deposited over steel or aluminum alloys. In practical applications, it is very unlikely that the deposited coatings are perfectly covering the substrate. Defects or pores on these thin coatings usually of less than $10 \mu \mathrm{m}$ thick can directly expose the substrate to the environment, figure 2. A galvanic couple between the substrate and the coating can occur. For steel in seawater, where the $\mathrm{pH}$ is nearly 8 , the free corrosion potential is between -0.6 and $-0.45 \mathrm{~V}$ (SCE) when active, and is between 0 and $200 \mathrm{mV}$ (SCE) when passive. Previously it was shown that $\mathrm{ZrN}$ on stainless steel oxidized to its oxide after exposure to $\mathrm{Cl}^{-}$ containing environment of $\mathrm{pH} 6$ (10). However, oxidation of TiN to its hydrated oxide did not occur after similar exposure although it was shown as modynamically possible under the particular condition (11). This was suggested as due to potential difference between the substrate and coating.

The free corrosion potential of $\mathrm{ZrN}$ coated steel was much lower than that of bare steel due to lower potential of the coating than the substrate. This formed a galvanic couple between the coating and the substrate and promoted pxidation of $\mathrm{ZrN}$ to its oxide, figure 2. Oxide film on $\mathrm{ZrN}$ acts as corrosion 
rotection layer to chloride attack. The free corrosion potential of TiN coated steel is slightly higher than that of bare steel. Oxidation of TiN was not promoted since its potential was higher than the substrate, figure 3 . In this case the corrosion protection of the steel will only depend on the passive film formed from its anodic oxidation. If the passive film is weak or thin then it is more susceptible to chloride attack and consequent pitting corrosion.

Under the condition employed in that study $\mathrm{ZrN}$ was less stable than TiN and more readily to oxidize to its passive hydrated oxide film. This was measured as lower critical current density for passive film formation in the potentiodynamic cyclic polarization test (16).

$\mathrm{ZrN}$ coating can also be considered as a potential protective coating on aluminum alloys like $\mathrm{Al} 6061$ and $\mathrm{Al} 7075$ which are susceptible to pitting in $\mathrm{Cl}^{-}$containing environment. Typical corrosion potential of these alloys in $0.5 \mathrm{~N} \mathrm{NaCl}$ solution of $\mathrm{pH}$ approximately 6 is between -0.7 and $-0.85 \mathrm{~V}$ (SCE), which is cathodic to the equilibrium potential for $\mathrm{ZrN}$ oxidation to its hydrated oxide. This hydrated oxide is a good passive film for protection in $\mathrm{Cl}^{-}$containing solution. Large potential difference between the coating and substrate act as driving force for the oxidation of the anodic coating. This will once again protect the cathodic substrate.

Application of TiN may not protect the particular aluminum alloys in fiscussion. Equilibrium potential of this coatings at $\mathrm{pH} 6$ is approximately $-0.742 \mathrm{~V}$ (SCE) which is slightly cathodic to the corrosion potential of the alloys. The actual potential of this nitride can be higher than the equilibrium potential due to the native oxide on the surface from oxidation with air and 
stoichiometric nature of the coating. The substrate is anodic to the coating and will corrode. Corrosion of the substrate under this condition could be worse than pitting on uncoated aluminum alloys.

A successful corrosion protection scheme using nitride coatings is very much dependent on the thermodynamically favorable formation of protective passive oxide film on nitride coatings, more anodic potential of the coating than the substrate, and the large potential difference between the substrate and the coating to kinetically drive the oxidation of coating. The greater potential difference between the coating and substrate, subjected to the fact that the coating is anodic to the substrate, the greater the driving force for the oxidation to occur. Low current density for formation of oxide from the nitride is favorable since it does not require large amount of metal dissolves to the solution. It also means more spontaneous formation of the passive film.

Through the establishment of other metal nitride-water diagrams, considerations can be made before applying specific coatings on aluminum alloys or steels for applications in severe environments. At different $\mathrm{pH}$ and potentials, some oxides are more stable than the others. These diagrams can be used as guidelines for choosing a coating for protecting any substrates.

\section{CONCLUSIONS}

$\mathrm{ZrN}$-water thermodynamic diagram was constructed from rmodynamic data of $\mathrm{ZrN}$ and other compounds of zirconium. The regions of immunity, passivity and corrosion of $\mathrm{ZrN}$ is similar in shape to 
those for zirconium. Equilibrium potentials for oxidation of $\mathrm{ZrN}$ to dissolved and solid compounds are higher than for zirconium. This diagram is very helpful for selection of good protective coating for metals or alloys and for predicting the possible reactions to occur underspecific $\mathrm{pH}$ and poteritial.

\section{REFERENCES}

1. E. I. Meletis, A. Erdemir, R. F. Hochman, J. of Materials Engineering, v7 (1985), p.173

2. A. Erdemir, W. B. Carter, E. I. Meletis, R. F. Hochman, Materials Science and Engineering, v69 (1985), p.89

3. E. I. Meletis, W. B. Carter, R. F. Hochman, Microstructural Science, v13 (1986), p.147

4. Y. Massiani, J. Crousier, L. Fredrizzi, A. Cavalleri, P. L. Bonora, Surface and Coatings Technology, v33 (1987), p.309

5. M. J. Park, A. Leyland, A. Matthews, Surface and Coatings Technology, v43/44 (1990), p.481

6. P. V. Nazarenko, A. G. Molyar, I. E. Polishchuk, O. G. Yachinskaya, A. A. Il'in, Translated from Metallovedenie i Termicheskaya Obrabotka Metallov, No. 4 (April 1990), p.61

7. V. A. Dmitriev, L. A. Khvorostukhin. M. A. Tolstaya, Yu. I. Pavlov, A. E. Bolmanenkov, A. A. Emel'yanov, Translated from Zaschita Metallov, v26 (1990), p.151

8. L. van Leaven, M. N. Alias, R. Brown, Surface and Coatings Technology, v53 (1992), p.25

9. R. Brown, M. N. Alias, R. Fontana, Surface and Coatings Technology, v62 (1993), p.467 
10. R. Brown, M. N. Alias, "Oxidation of Nitride Films in Aqueous Solutions : Correlation Between Surface Analysis and Electrochemical Studies", NACE Corrosion/94 Conference, Paper no. 322, NACE, Houston, Texas, 1994

11. A. K. Gorbachev, Translated from Zaschita Metallov, v19 (1983), p.253

12. L. E. Toth, Transition Metal Carbides and Nitrides, Academic Press, NY, 1971

13. M. Pourbaix, Atlas of Electrochemical Equilibria, Pergamon Press, NY, 1966

14. M. Pourbaix, Lectures on Electrochemical Corrosion, Plenum Press, NY, 1973

15. W. M. Latimer, Oxidation Potentials, 2nd edn., Prentice-Hall, NY, 1952 16. M. N. Alias, R. Brown, "Effect of Thickness and Process Parameters on Corrosion Behavior of $\mathrm{ZrN}$ and TiN Coatings in the Marine Environment", NACE Corrosion 93 Paper No. 30, NACE, Houston, Texas, 1993 


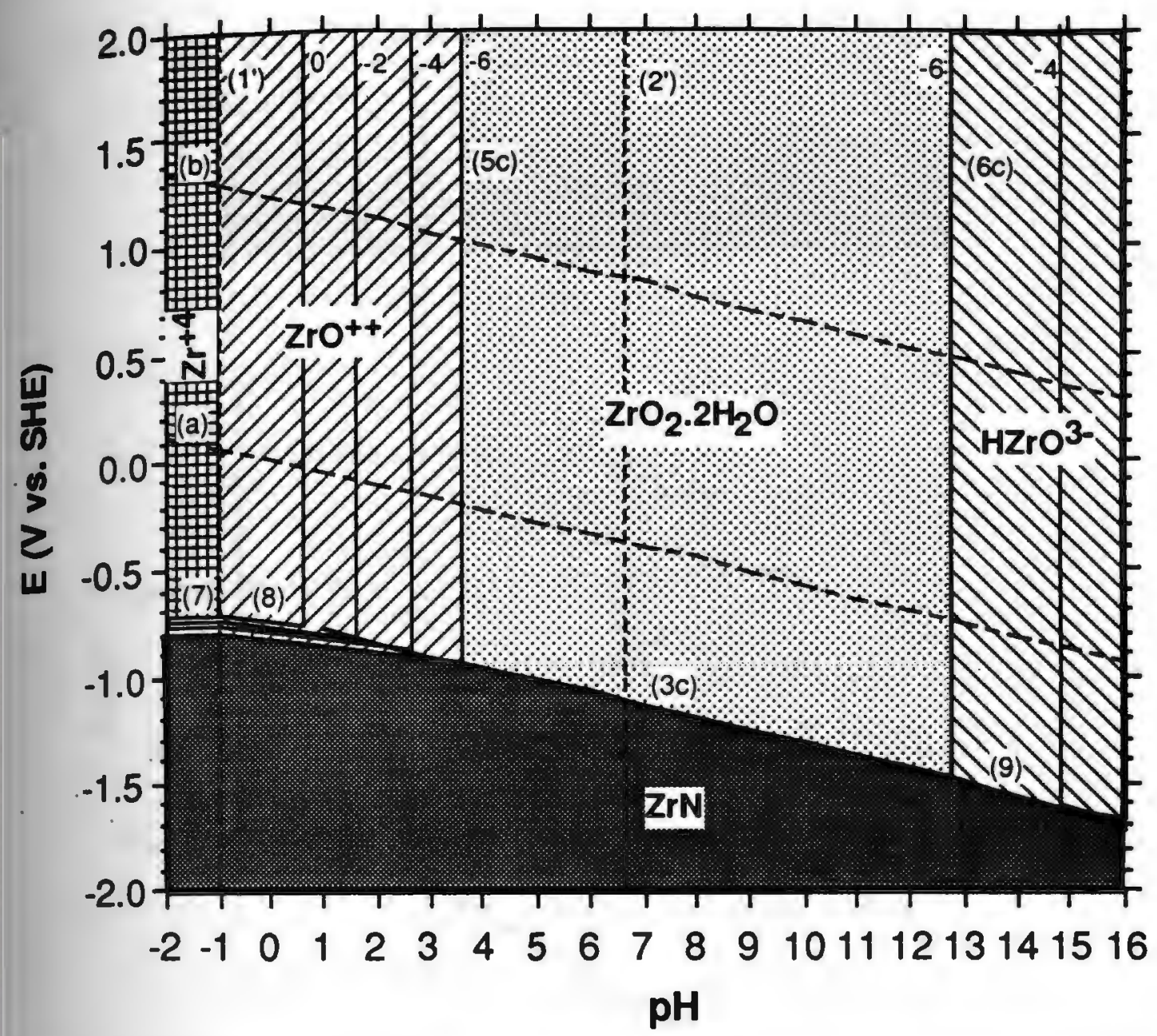

Figure 1. $\mathrm{ZrN}$-water thermodynamic diagram considering $\mathrm{ZrO}_{2} \cdot 2 \mathrm{H}_{2} \mathrm{O}$ solid. 

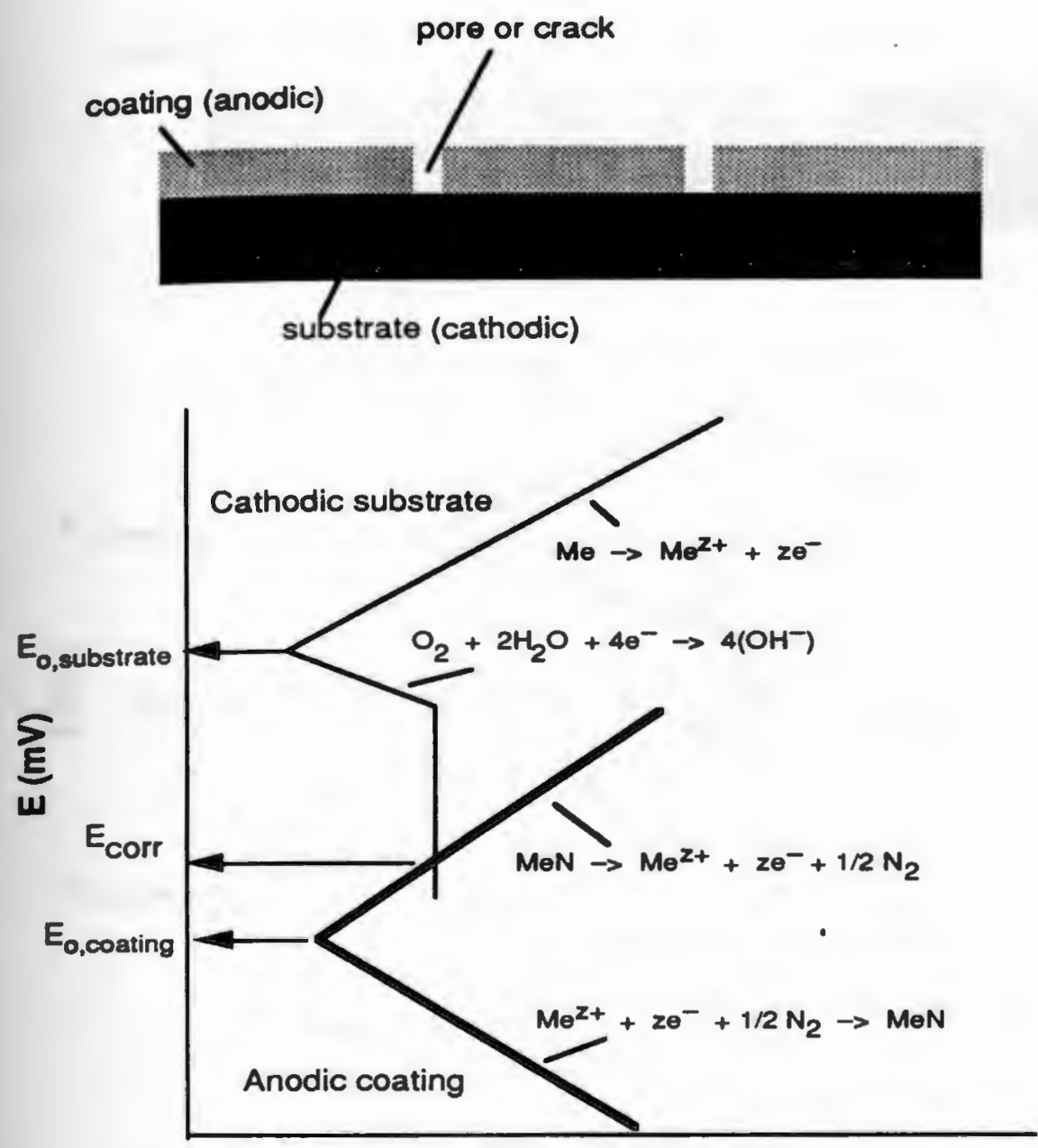

$\log I\left(\mu \mathrm{A} / \mathrm{cm}^{2}\right)$

Figure 2. Schematic diagram of anodic coating with defects exposing the cathodic substrate and the hypothetical Evans diagram showing the possible anodic and cathodic reactions. 


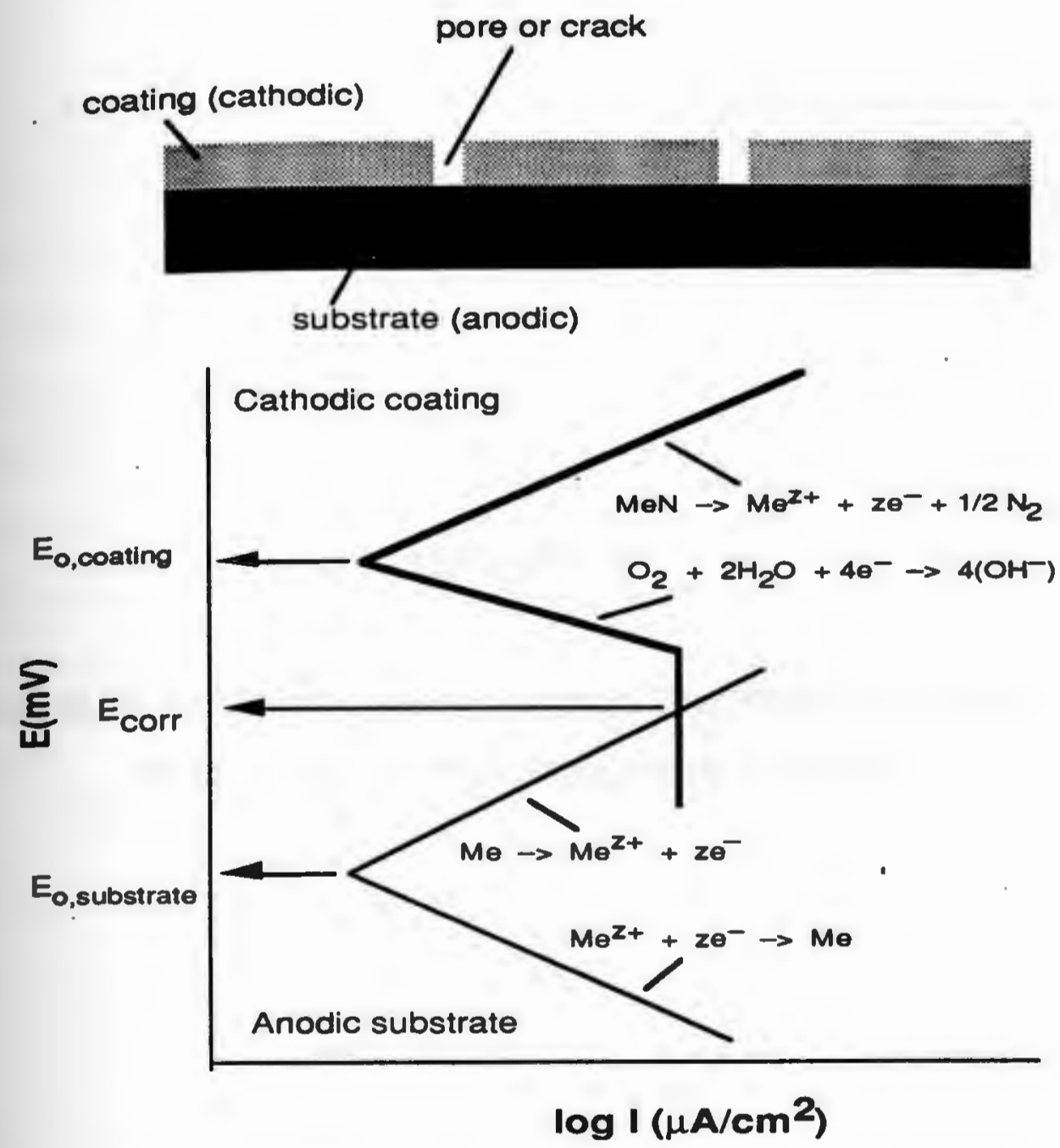

Figure 3. Schematic diagram of cathodic coating with defects exposing the anodic substrate and the hypothetical Evans diagram showing the possible anodic and cathodic reactions. 
CHAPTER VI

LOCAL ELECTROCHEMICAL IMPEDANCE SPECTROSCOPY STUDY ON CORROSION OF NITRIDE COATED ALLOYS 


\section{ABSTRACT}

The local impedance of pit and passive areas on stainless steels and aluminum alloys were measured utilizing the local electrochemical impedance spectroscopy (LEIS) technique. Separate contributions of active and passive area to the overall impedance measured by conventional Sectrochemical impedance spectroscopy (EIS) were identified. The overall impedance may not show the contribution of pit to the impedance behavior because it was masked by the higher impedance of the passive area. Local corrosion rate and growth behavior of pit was measured by this local impedance technique. 


\section{INTRODUCTION}

Electrochemical impedance spectroscopy was proven to be a powerful tool to non-destructively monitor the corrosion rate of various systems in various environments 1-5. In addition, time dependent mechanistic information can be extracted through this small ac perturbation non-steady state technique with some electrical circuit modeling of the interface in interest. However, this technique provides surface averaged information and causes problems in determination of the accurate physical attributions to the measured response. In particular, detection of small pit in a relatively larger passive system was not directly obtainable from the impedance measurement. Various different equivalent circuit models to represent passive systems undergoing pitting were introduced 6-8. Electrical properties of the passive film, total pit area and corrosion rate of the pit can be obtained from the parameters in the equivalent circuit models.

An active pit in a passive matrix can be equivalently modelled 6 by simple parallel $\mathrm{R}_{\text {pit }} \mathrm{C}_{\text {pit }}$ representing the faradaic and capacitive processes at the pit in series to the electrolyte resistance, $R_{\text {pore }}$ in the pore of the pit built in parallel with another parallel $R_{t} C_{d l}$ of the passive film, figure 1 . The solution resistance of the bulk electrolyte is represented by $R_{S}$, and the fraction of passive area is given by $\theta$. Impedance plots of this system may indicate a single or two maxima behavior dependent on the ratio of the two time constants of the pit and the passive film. The two maxima may overlap to show only a single maxima behavior over the measured frequency range. The frequency response of the pit may be masked by the larger response of the passive system. Fitting the data to the particular model may become time 
consuming and produce undesirable results. It is then desirable to separately measure the response at the pit and over the passive film. A local electrochemical impedance spectroscopy (LEIS) can be utilized as it was proven to measure the local properties of chemically and physically heterogeneous surface $9-11$.

The objectives of this study were to construct a LEIS apparatus, measure the local impedance of pit and passive film in bare and coated stainless steels or aluminum alloys to compare to the overall impedance measured by the conventional EIS technique. The apparatus was first calibrated with model homogeneous and heterogeneous electrodes. Local EIS data was fitted to an equivalent circuit model and its parameters were backfitted to the active pit model. Results of this investigation are detailed in this paper.

\section{EXPERIMENTAL PROCEDURES}

\section{Materials}

Model homogeneous electrodes were prepared from $1.1684 \mathrm{~cm}^{2}$ of 304 stainless steel and $0.0962 \mathrm{~cm}^{2} \mathrm{~Pb} / \mathrm{Sn}$ solder in epoxy resin, figure 2 . The iterogeneous electrode was made of $0.0962 \mathrm{~cm}^{2} \mathrm{~Pb} / \mathrm{Sn}$ solder in 304 stainless steel matrix with a total area of $1.1684 \mathrm{~cm}^{2}$. All electrodes were polished to 600 grit surface immediately before exposed to solution for testing.

A model passive electrode with an artificial pit was made by drilling a 1 $\mathrm{mm}$ diameter hole in the center of approximately $1 \mathrm{~cm}^{2}$ of 304 stainless steel mounted in epoxy. TiN coated 304 stainless steel with pits formed during 
cyclic polarization was tested 12. Al6061-T6 and Al7075-T6 coated with $5 \mu \mathrm{m}$ $\mathrm{CrN}$ were used to monitor time dependent impedance behavior by both LEIS and EIS.

All experiments were conducted in $0.5 \mathrm{~N} \mathrm{NaCl}$ solution prepared from double distilled deionized water. The bulk solution conductivity was 0.063 (ohm.cm) ${ }^{-1}$.

Bxperimental Techniques

All EIS measurements were conducted utilizing EG\&G M388 software with a 3-electrode cell system. A $5 \mathrm{mV}$ potential perturbation was maintained between the sample and a saturated calomel electrode (SCE) and the current response measured between the sample and the $\mathrm{Pt}$ counter electrode. Measurements were made through a Solartron 1255 FRA high frequency response analyzer and a EG\&G 273 potentiostat interfaced to the lectrochemical cell and a personal computer. 7 data points per frequency decade were taken between $100 \mathrm{kHz}$ and $0.01 \mathrm{~Hz}$. The impedance was measured in ohms and area-normalized to ohm. $\mathrm{cm}^{2}$ by multiply with the total area exposed.

A LEIS apparatus was designed and consisted of a xy-stage with movement resolution of $2.5 \mu \mathrm{m} / \mathrm{step}$ and $\mathrm{z}$-motor to adjust the probe height with a resolution of $5 \mu \mathrm{m} / \mathrm{step}$. Sample and glass container were clamped to the stage. The container was filled with $0.5 \mathrm{~N} \mathrm{NaCl}$ solution. A Pt counter electrode and SCE reference electrode complete the cell. A Pt bi-probe was placed with the bottom of the probe $100 \mu \mathrm{m}$ vertically above the surface. In the LEIS experiments the probe was kept at constant height above the surface. 
pasurements were made by applying $5 \mathrm{mV}$ perturbation between the sample and the reference electrode utilizing the FRA and potentiostat over a frequency range between $100 \mathrm{kHz}$ and $1 \mathrm{~Hz}$ at 7 frequency points per decade. Local current were calculated from the measured potential difference at the two tips. The measured potential difference was amplified by an strumentation amplifier and send to the input current channel of the FRA. The ratio of the output potential and input potential diference was multiply with the ratio of tip separation distance and solution conductivity to produce the local impedance. A solution conductivity of 0.063 (ohm.cm)-1 was used in all calculation. The measured local impedance was the normal impedance of the surface due to the design of the bi-probe which allowed measurement of ac potential difference in the solution between two potential lines parallel to the surface.

The Pt tips were made from $125 \mu \mathrm{m}$ diameter $\mathrm{Pt}$ wire inserted into glass capillaries with initial ID of $0.8 \mathrm{~mm}$ and $9 \mathrm{~cm}$ long, figure 3 . One end of the capillary was flame sealed and polished to expose the tip. The tip was platinized using chloroplatinic acid solution to produce large surface area and low interfacial impedance of the probe 9,13. Two identical tips were produced, sealed together and bent to allow only the potential drop normal to the surface being measured in LEIS tests. The tips have separation distance of $500 \mu \mathrm{m}$ vertically. 


\section{EXPERIMENTAL RESULTS}

\section{Calibration}

EIS and LEIS spectra on 304 SS electrode are identical between $10 \mathrm{kHz}$ and $10 \mathrm{~Hz}$ in both the impedance and phase angle behavior, figure 4. No pits were observed throughout the test and the free corrosion potential was stable at $-250 \mathrm{mV}$ (SCE). The EIS and LEIS spectra of $\mathrm{Pb} / \mathrm{Sn}$ solder are also identical over the frequency range but lower to the stainless steel. The solder was more anodic to the steel with free corrosion potential stable at $-580 \mathrm{mV}$ (SCE) throughout the test.

Oxidation of the $\mathrm{Pb} / \mathrm{Sn}$ electrode was observed when the model heterogeneous electrode was exposed after some time to the solution. The solder area became black and solution in this vicinity turned cloudy. No corrosion of the stainless steel was observed. LEIS spectra of the model heterogeneous electrode indicate lower local impedance and phase angle behavior at the solder than at the stainless steel region, figure 5. The overall impedance and phase angle behavior nearly match the local impedance and local phase angle of the stainless steel. The local impedance measured at both solder and steel regions are similar to the local impedance measured over the bomogeneous electrodes.

\section{Model Pit on Stainless Steel}

Local and overall impedance and phase angle behavior of stainless steel with an artificial pit are shown in figure 6. No corrosion product was 
observed at the pit. Local impedance of flat passive area is identical to the local impedance of the pit. The overall impedance is higher than the local impedance. The overall phase angle behavior matched the phase angle of the flat passive area between $500 \mathrm{~Hz}$ and $50 \mathrm{~Hz}$ but matched the phase angle of the pit between $50 \mathrm{~Hz}$ and $1 \mathrm{~Hz}$. The overall impedance is dominated by diffusion behavior at low frequency region.

\section{Pits on TiN Coated Stainless Steel}

Local impedance at both pit and TiN coating region are identical but lower than the overall impedance, figure 7. The local phase angle behavior of the coated area and pit match the overall phase angle behavior between 300 $\mathrm{Hz}$ and $3 \mathrm{~Hz}$. No corrosion of the pit was observed.

\section{Pitting on CrN Coated Al Alloys}

Pits were observed on Al6061-T6 coated with $5 \mu \mathrm{m}$ CrN within 24 hours exposure in $0.5 \mathrm{~N} \mathrm{NaCl}$ solution. White corrosion product was observed over the pits. The overall impedance and phase angle decrease after more than a day exposure, figure 8. Local impedance at various location before pits were observed are nearly identical but lower than the overall Impedance by conventional EIS. Local impedance of the pit is lower than the coated area which remains high throughout the test. The phase angle pehavior of the pit indicates a single maxima with lower phase angle than that of the coated area. The phase angle over other coating area is identical to the overall phase angle behavior. The high frequency impedance arrest is higher for the pit than the coated area. 
EIS and LEIS spectra of Al7075-T6 coated with $5 \mu \mathrm{m}$ CrN also indicated lower impedance over the pits than over other coating area, figure 9. Pits were observed on the surface after several hours exposure. The phase angle of the pit was lower than other coating area with the latter nearly close to the overall phase angle behavior.

\section{DISCUSSIONS}

The local EIS technique was used to monitor pitting corrosion on stainless steels and aluminum alloys. Local impedance behavior of pit and passive area was monitored and the individual corrosion rate was determined. Calibration of this technique to monitor physical and chemical tterogeneities on corroding surface was conducted on a model active $\mathrm{Pb} / \mathrm{Sn}$ solder in passive 304 stainless steel matrix. LEIS was able to monitor differences in impedance behavior of the anodic and passive regions. This was not available from the surface averaged response of conventional EIS pechnique. The overall impedance behavior was dominated by the higher impedance behavior of the passive steel area because the current from the smaller anodic region spread out laterally to the larger passive area.

The local impedance of a model pit on stainless steel is identical to local impedance of the passive area. The reason for this is that the pits are passive and do not corrode. The overall phase angle behavior is dominated by the flat passive area at high frequency but is dominated by the pit response at lower frequency. The pit causes the phase angle to decrease at frequency less than $50 \mathrm{~Hz}$. Contributions of the pit and passive area to the overall 
impedance and phase angle are easily identified from the overall impedance and phase angle behavior. In the case of pits on TiN coated stainless steel, both local impedance and phase angle at the pit and coated area are identical therefore not easily identified from the overall impedance and phase angle behavior.

Local impedance on $\mathrm{CrN}$ coated aluminum alloys show lower Impedance at pits than at passive coating area. The overall impedance is again dominated by the impedance of the passive coating area. This can be shown using the active pit model from which the fraction of pit area was usually determined, figure 1. An attempt is made to justify this model using the charge transfer resistance and capacitance values obtained from the local impedance of the pit and passive region. The local charge transfer resistance and capacitance are obtained from a simple Randle's circuit, figure 10. These values are used to generate the overall impedance and compare to the measured overall impedance.

The exposed $5 \mu \mathrm{m} \mathrm{CrN}$ coated Al6061-T6 have a fraction pit area of 0.0086. The calculated overall impedance was slightly lower than the measured overall impedance, figure 11 . This is because the calculated impedance was generated from the normal impedance measured locally. Impedance lateral to the surface was not measured by this technique and may contribute to the higher overall impedance measured by conventional EIS pechnique. The calculated phase angle shown a single maxima and followed closely the phase angle of other coating area at high frequencies. The lower response of the pit was masked by the higher response of the coated area. Also it was obvious that the time constants for the response of the pit and 
other coating area were identical and overlapped one another. As a result a single maxima behavior was observed in the overall impedance behavior.

The corrosion rate of pits and coated area are obtained from fitting procedure of local impedance data, figure 12. The charge transfer resistance of the pits was lower than the coated area. Difference in the corrosion behavior of the pits can be monitored as shown for both coated Al6061-T6 and Al7075-T6 alloys. The former shown a constant charge transfer resistance value after pit formation suggesting a stable pit and the latter shown continually decreasing charge transfer resistance suggesting a progessive pit growth behavior. The total charge transfer resistance from overall EIS may or not decrease due to pitting. The higher fraction of pit area for the coated Al7075-T6 than the coated Al6061-T6 may contribute to decreasing of its overall charge tranfer resistance.

In summary, LEIS technique was shown as able to monitor differences of local impedance of pit and passive which most of the time was not monitored in the surface averaged impedance response by conventional EIS technique. Separate contributions of active pit and passive area to the overall impedance are identified. Information on local corrosion rate of pit, pit growth behavior, and changes in local properties of passive film are available by this technique.

\section{CONCLUSIONS}

1. Local electrochemical impedance spectroscopy was found useful to monitor local corrosion rate of pit and passive area. 
2. This technique can be used to justify equivalent circuit model of overall impedance behavior and identify contribution of local sites to the overall impedance. 


\section{REFERENCES}

1. Macdonald, J. R., Impedance Spectroscopy: Emphasizing Solid Materials and Systems, Wiley, New York, 1987

2. Gabrielli, C., Identification of Electrochemical Processes by Frequency Response Analysis, Solartron Instrumentation Group, 1980

3. Oltra, R., M. Keddam, "Application of Impedance Technique to Localized Corrosion", Corrosion Science, v28 (1988), p.1

4. Juttner, K., "Electrochemical Impedance Spectroscopy (EIS) of Corrosion Proceses on Inhomogeneous Surfaces", Elcetrochimica Acta, v35 (1990), p.1501

5. Walter, G. W., "A Review of Impedance Plot Methods Used for Corrosion Performance Analysis of Painted Metals", Corrosion Science, v26 (1986), p.681

6. Hitzig, j., K. Juttner, W. J. Lorenz, W. Paatsch, "AC Impedance Measurements on Corroded Porous Aluminum Oxide Films", Journal of the Electrochemical Society, v133 (1986), p.887

7. Juttner, K., W. J. Lorenz, M. W. Kendig, F. Mansfeld, "Electrochemical Impedance Spectroscopy on 3-D Inhomogeneous Surfaces: Corrosion in Nuetral Aerated Solutions", Journal of the Electrochemical Society, v135 (1988), p.332

8. Shih, H., F. Mansfeld, "A Fitting Procedure for Impedance Spectra Obtained for Cases of Localized Corrosion", Corrosion, v45 (1989), p.610 9. Lillard, R. S., P. J. Moran, H. S. Isaacs, "A Novel Method for Generating Quantitative Local Electrochemical Impedance Spectrocsopy", Journal of the Plectrochemical Society, v139 (1992), p.1007 
10. Isaacs, H. S., M. W. Kendig, “Determination of Surface Inhomogeneities Using a Scanning Probe Impedance Technique", Corrosion, v36 (1980), p.269 11. Isaacs, H. S., "Detectionof Defects and Metallurgical Variations inMetal Surfaces", in Novel NDE Methods for Materials, B. K. Rath editor, The Metallurgical Society of AIME, 1983, p.63

12. Brown, R., M. N. Alias, "Effect of Film Thickness and An Interlayer on Corrosion Behavior of Ion Plated TiN on 304 SS", prepared for submission to Corrosion

13. Hills, G. J., D. J. G. Ives, "The Hydrogen Electrode", in Reference Electrodes: Theory and Practices, D. J. G. Ives and G. J. Janz editors, Academic Press, New York, 1961, p.71 


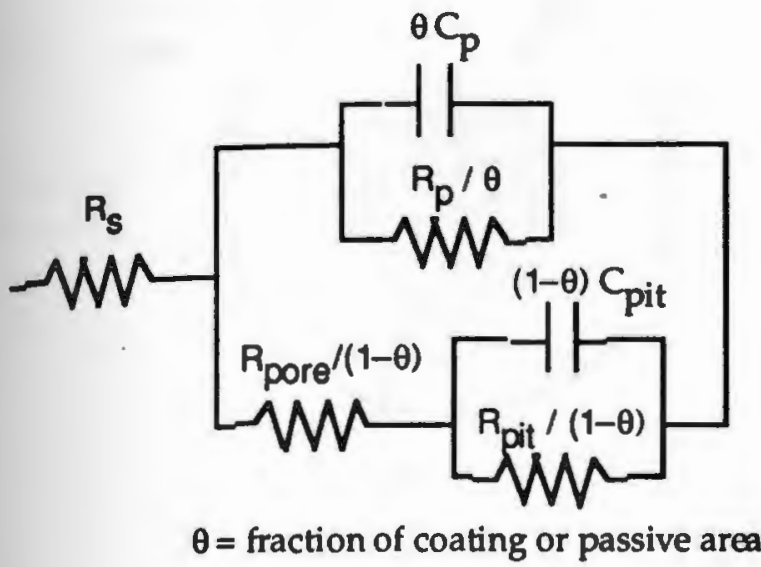

$\theta=$ fraction of coating or passive area

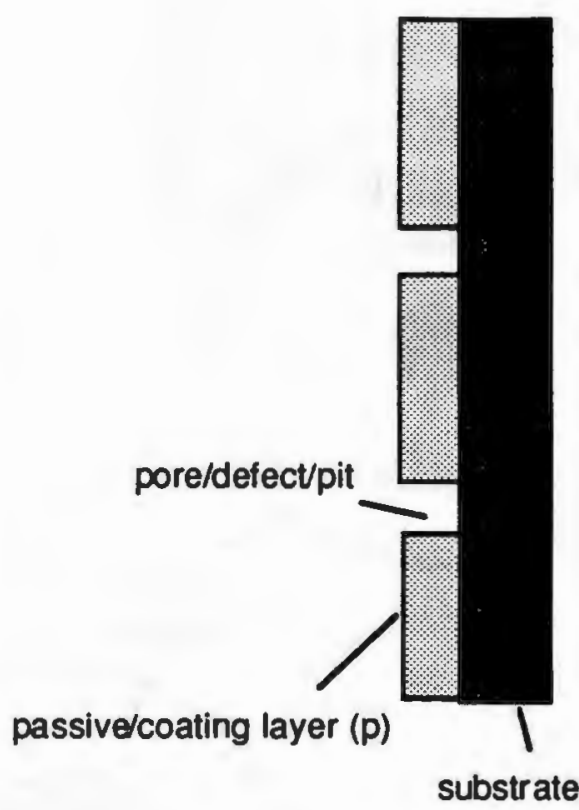

Figure 1. Schematic diagram of pits in passive electrode and its equivalent circuit model to represent the faradaic and capacitive processes at the pit and the passive surface. 
(a).

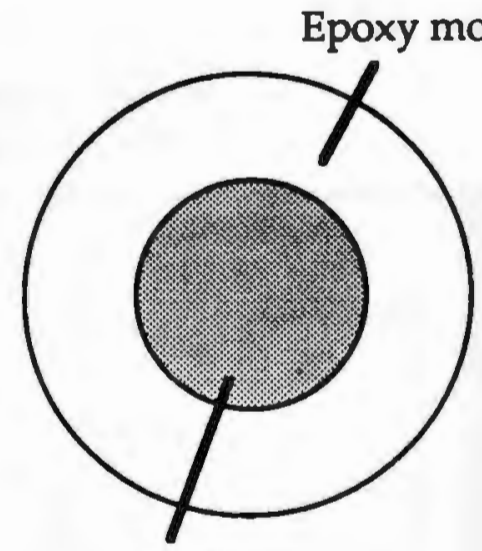

(b).

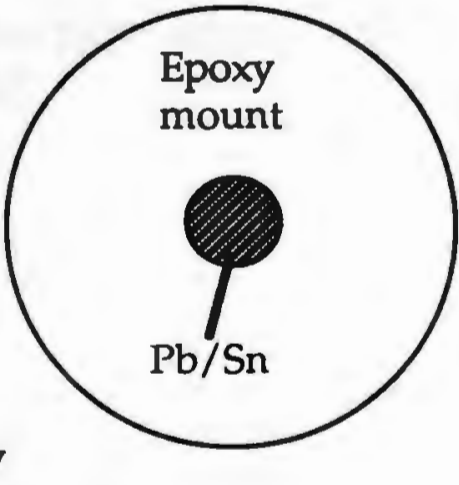

\section{SS}

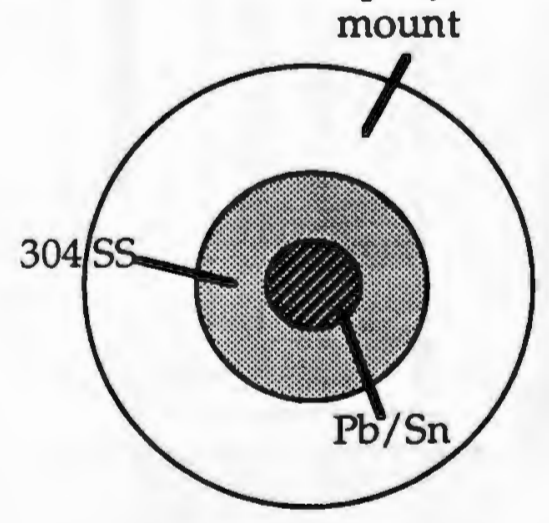

(c).

Figure 2. Schematic representation of model electrodes used for calibration of LEIS technique. 


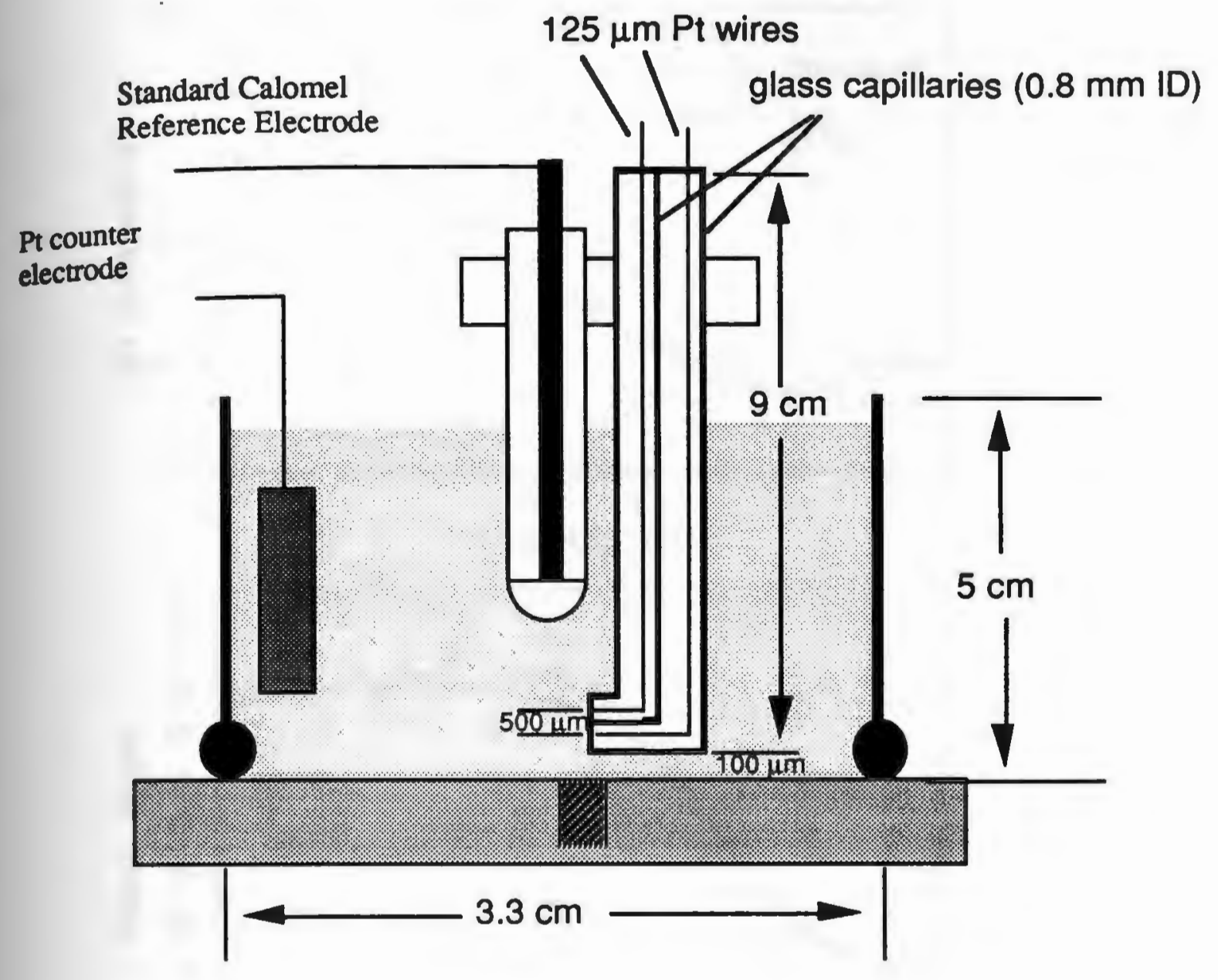

Working electrode

Figure 3. Schematic representation of bi-probe used in LEIS experiments. 

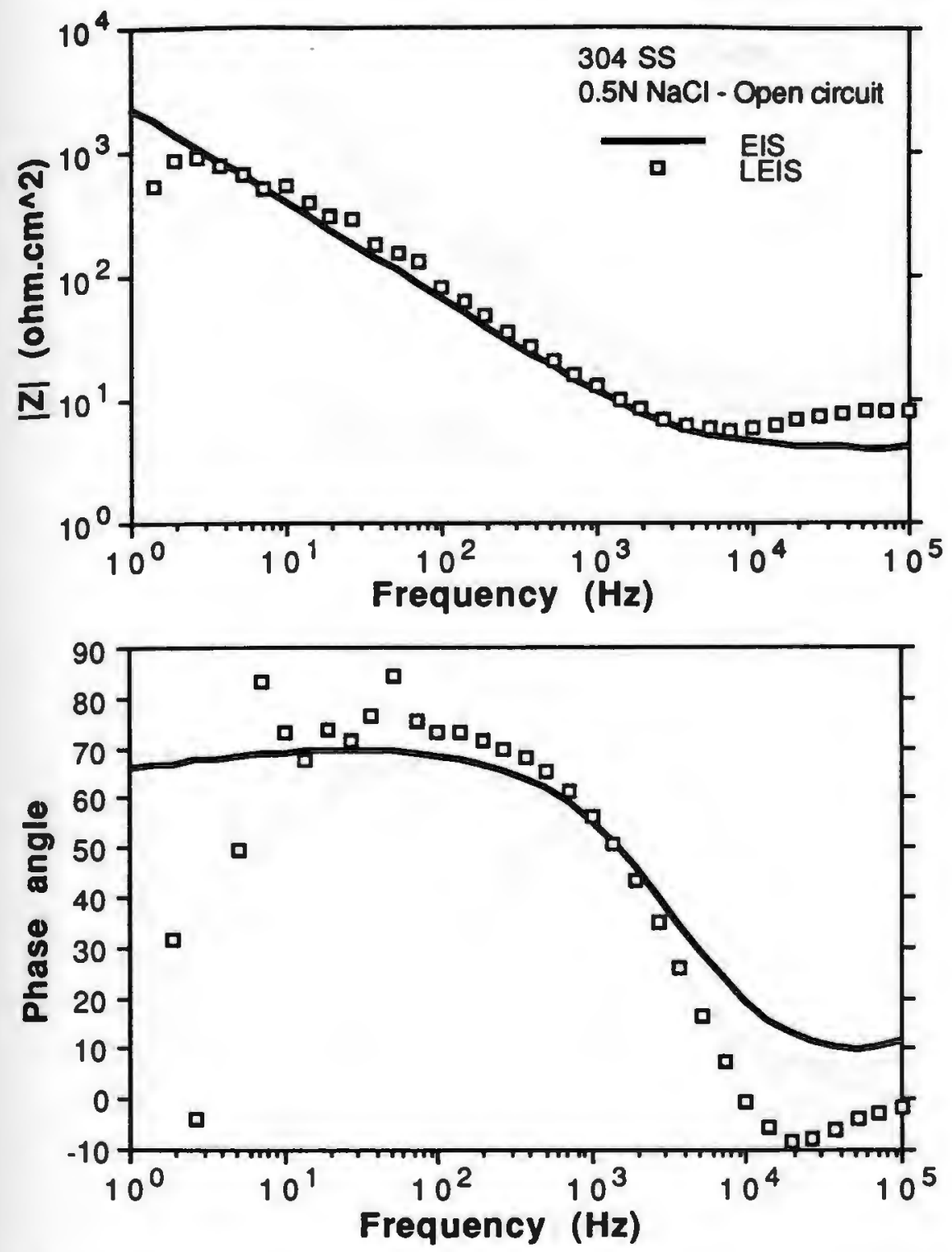

Figure 4. Impedance and phase angle plots of EIS and LEIS of 304 stainless steel electrode. 

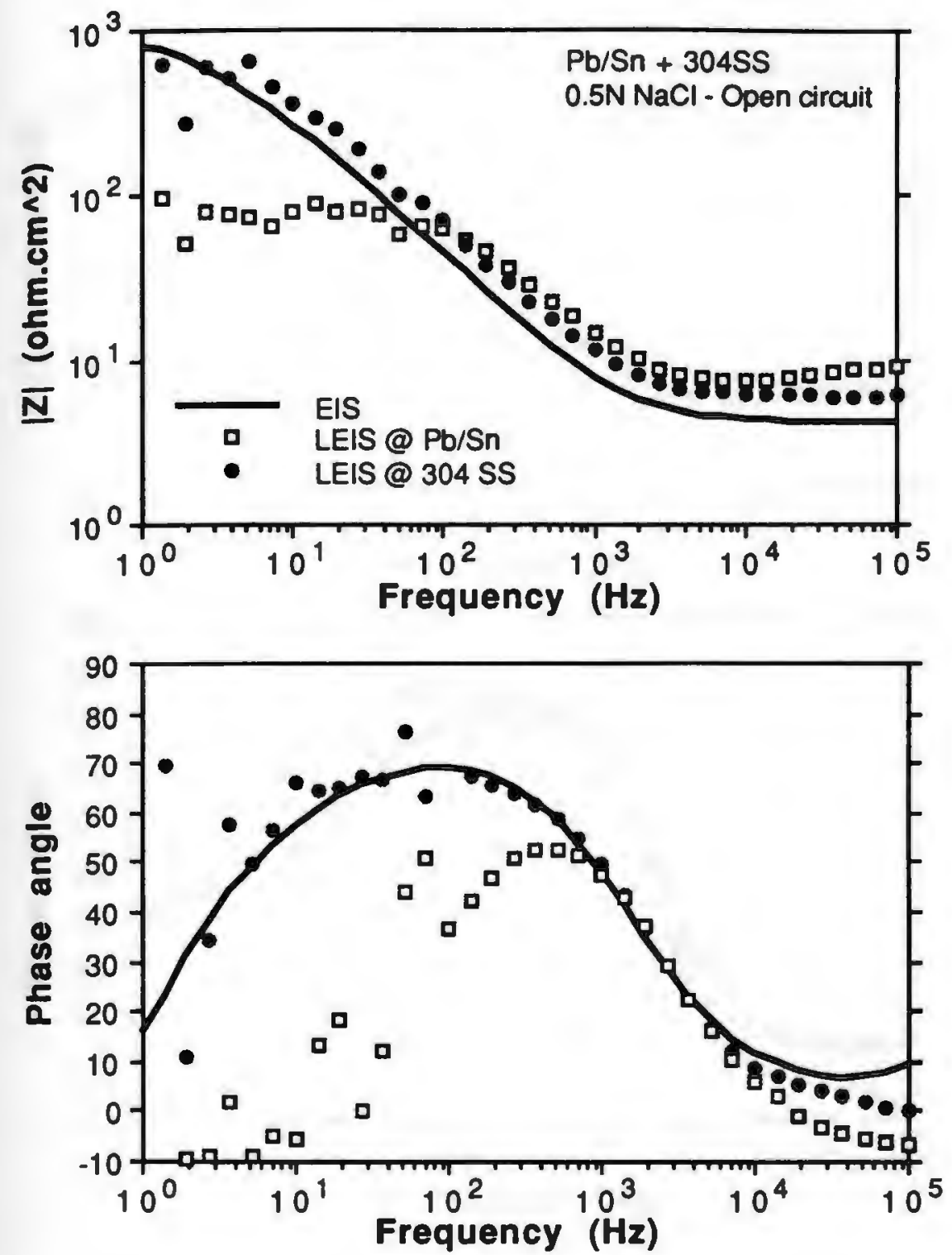

Figure 5. Impedance and phase angle plots of EIS and LEIS of $\mathrm{Pb} / \mathrm{Sn}$ solder coupled to 304 stainless steel. 

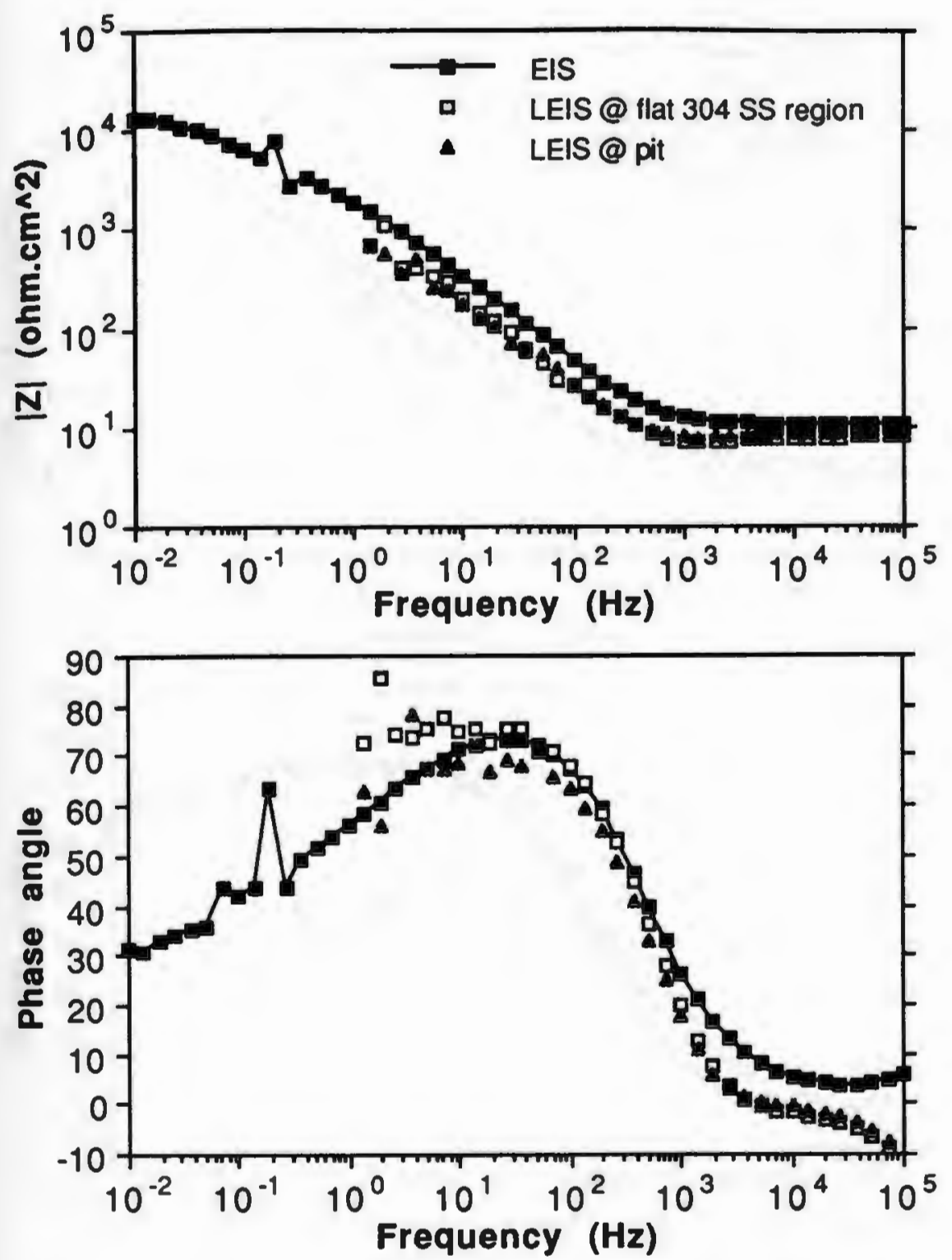

Figure 6. Impedance and phase angle plot of EIS and LEIS of 304 stainless steel with an artificial pit. 

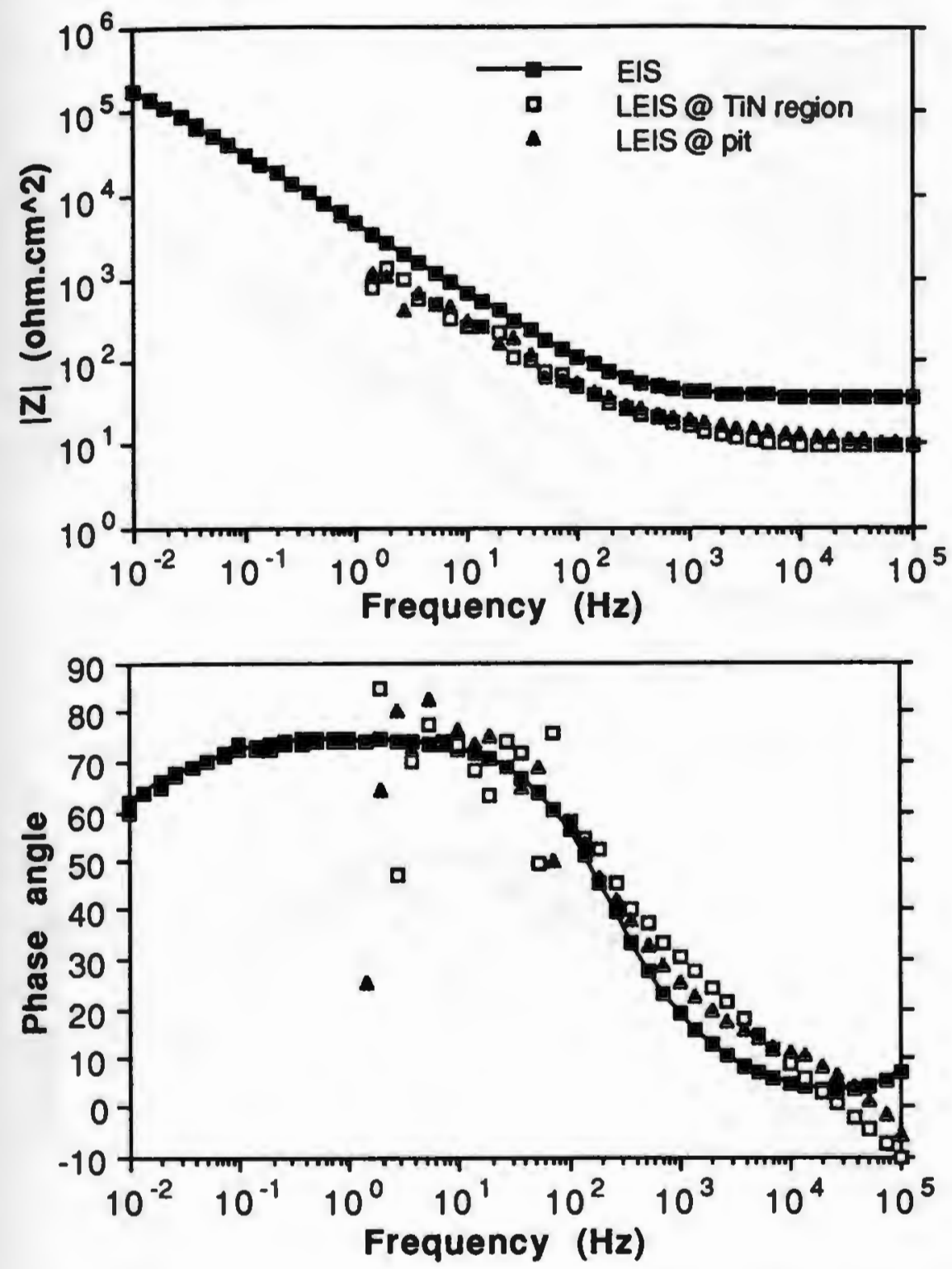

Figure 7. Impedance and phase angle plots of EIS and LEIS of $5 \mu \mathrm{m}$ TiN coated 304 stainless steel with pits from cyclic polarization test. 

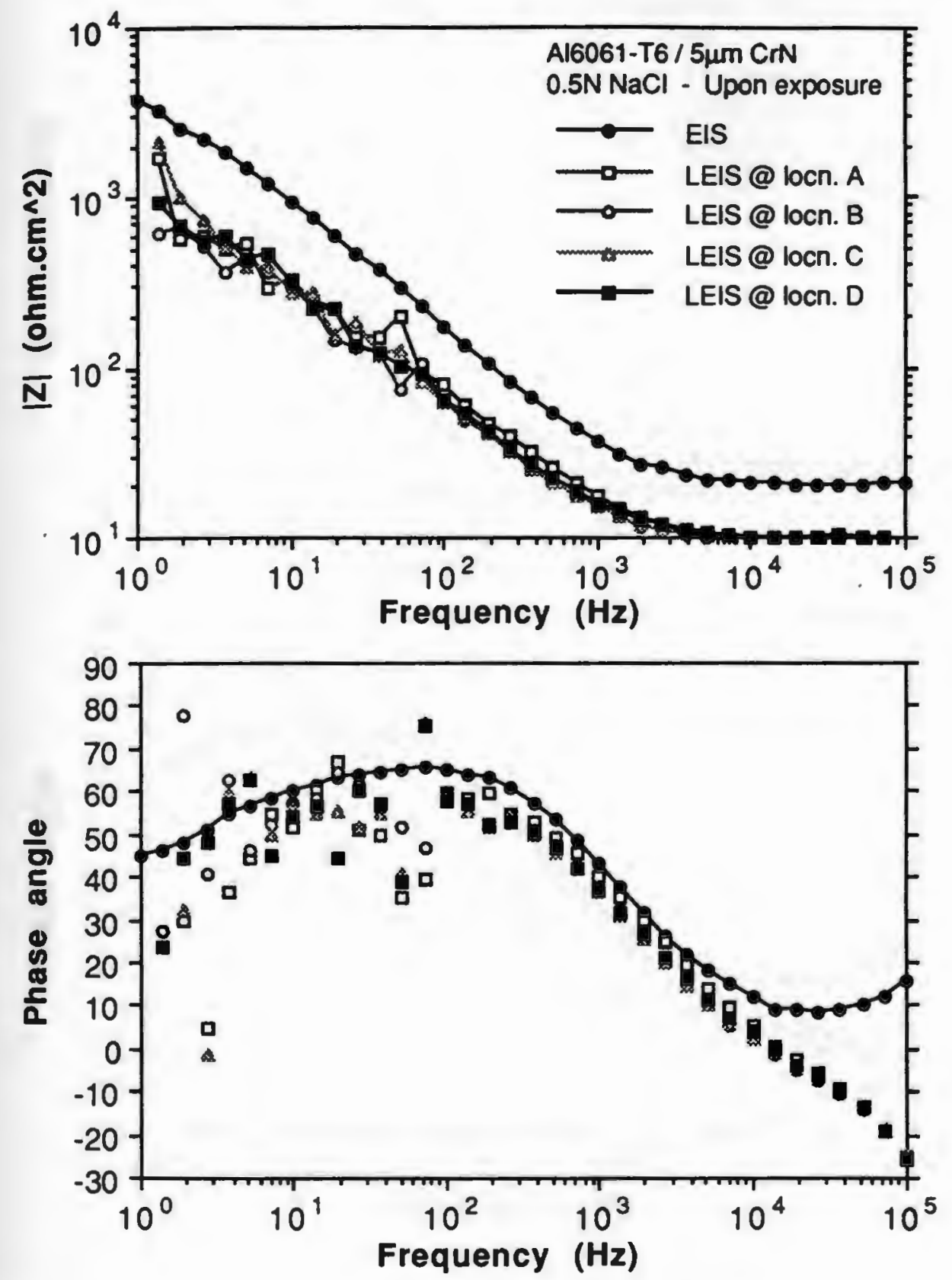

Figure 8. (a). Impedance and phase angle plots of EIS and LEIS of Al6061-T6 coated with $5 \mu \mathrm{m} \mathrm{CrN}$ upon exposure. 

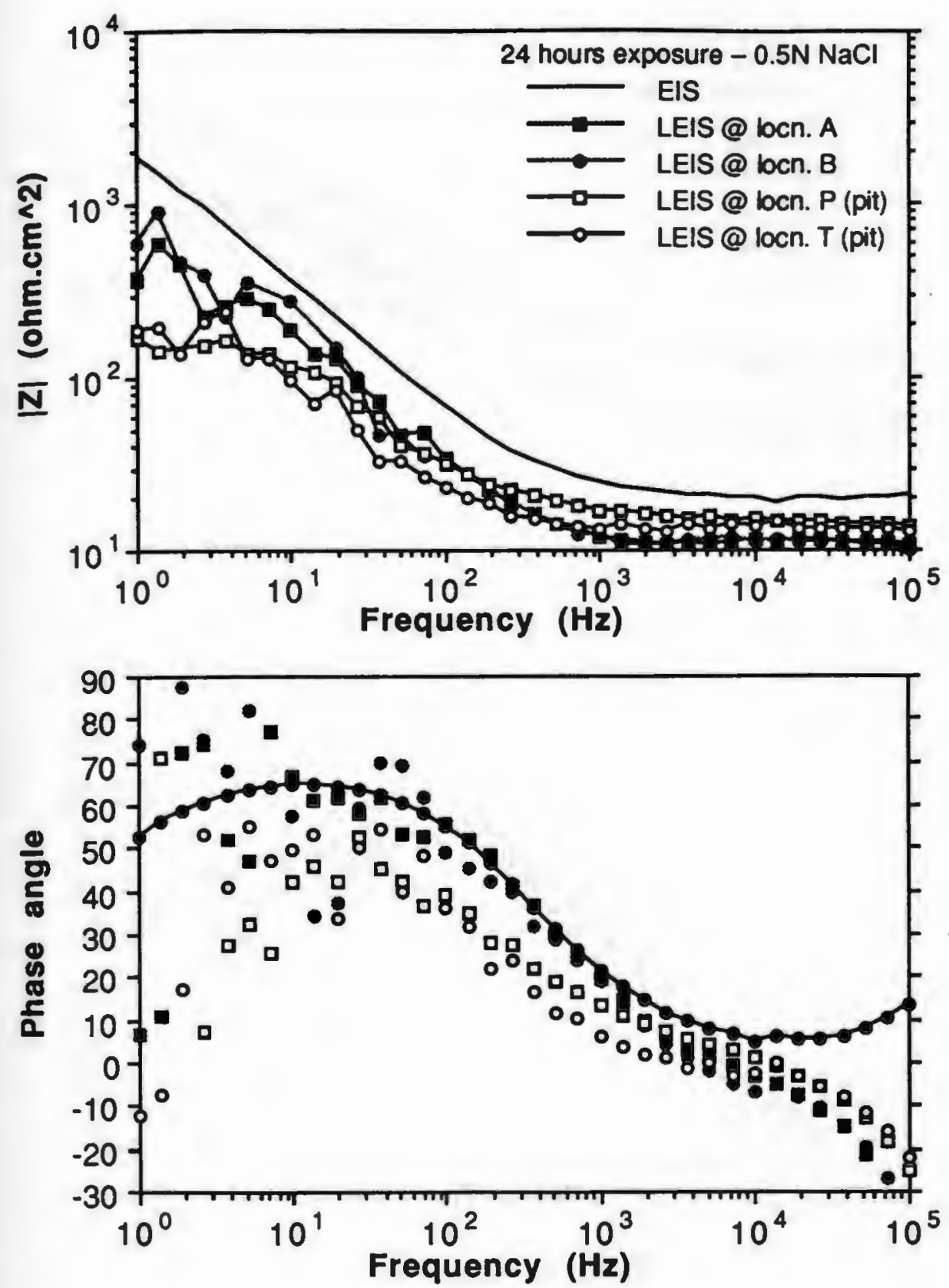

Figure 8. (b). Impedance and phase angle plots of EIS and LEIS of Al6061-T6 coated with $5 \mu \mathrm{m} \mathrm{CrN}$ after 24 hours exposure. 

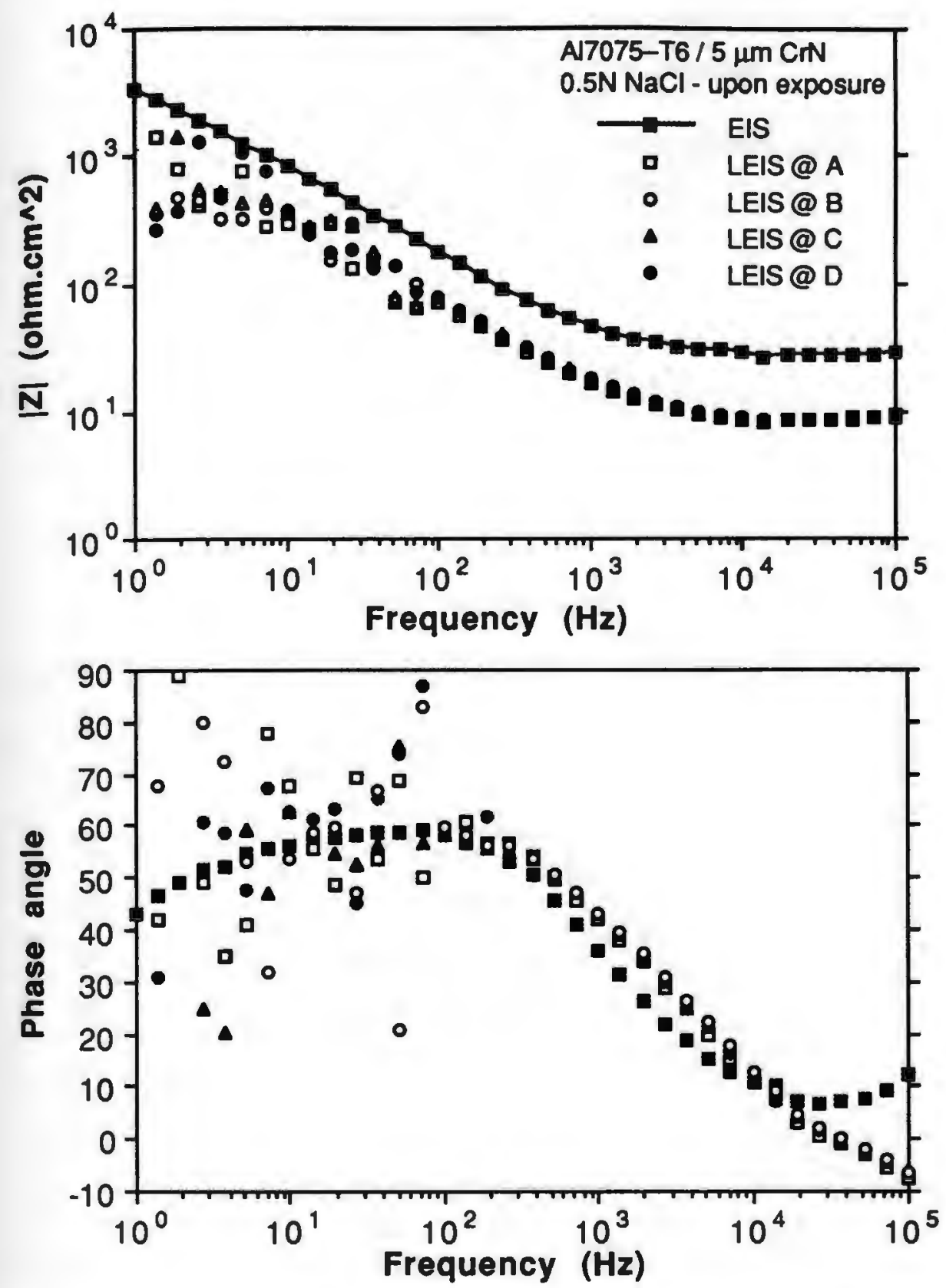

Figure 9. (a). Impedance and phase angle plots of EIS and LEIS of Al7075-T6 coated with $5 \mu \mathrm{m} \mathrm{CrN}$ upon exposure. 

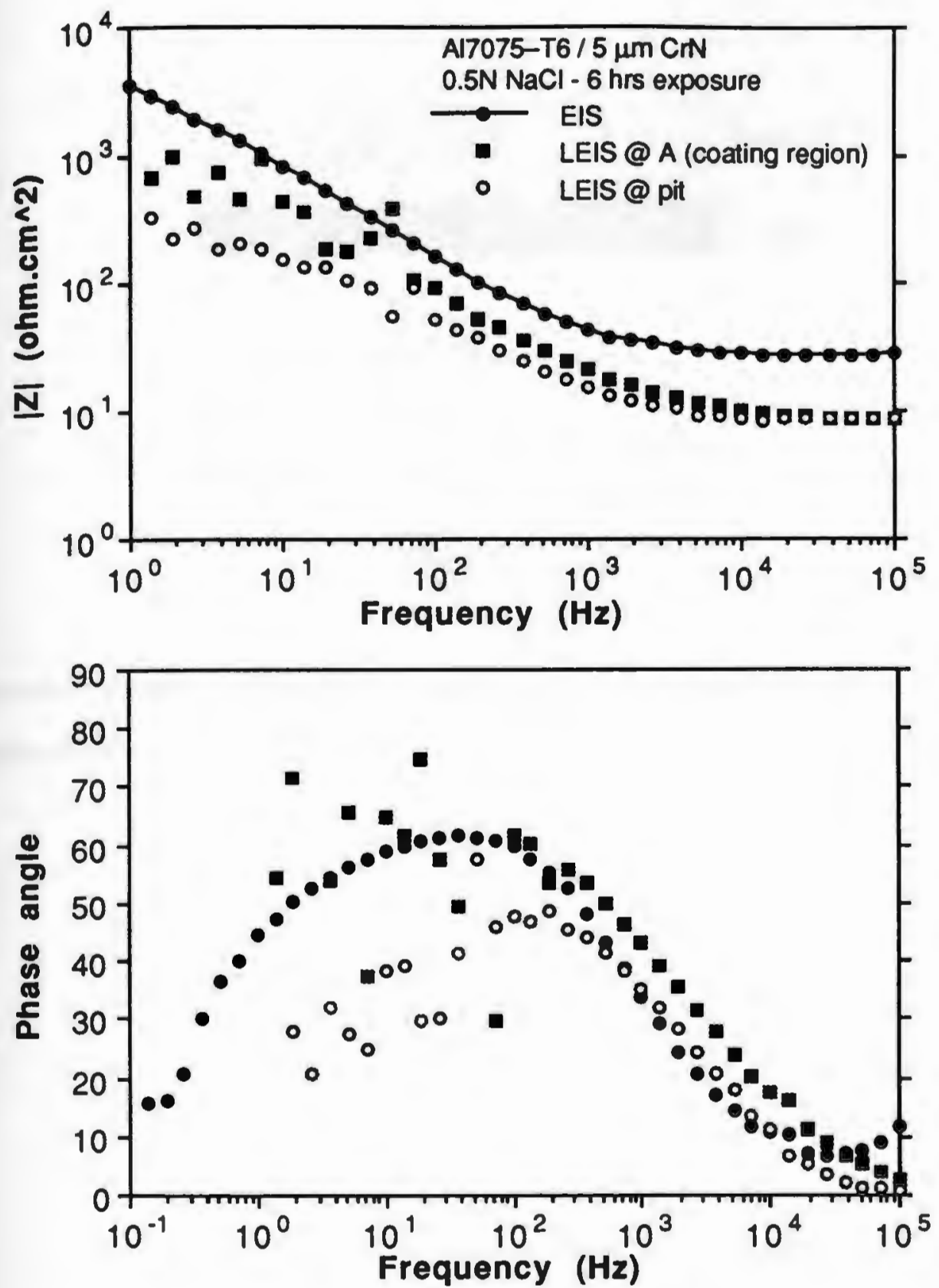

Figure 9. (b). Impedance and phase angle plots of EIS and LEIS of Al7075-T6 coated with $5 \mu \mathrm{m} \mathrm{CrN} \mathrm{after} 6$ hours exposure. 


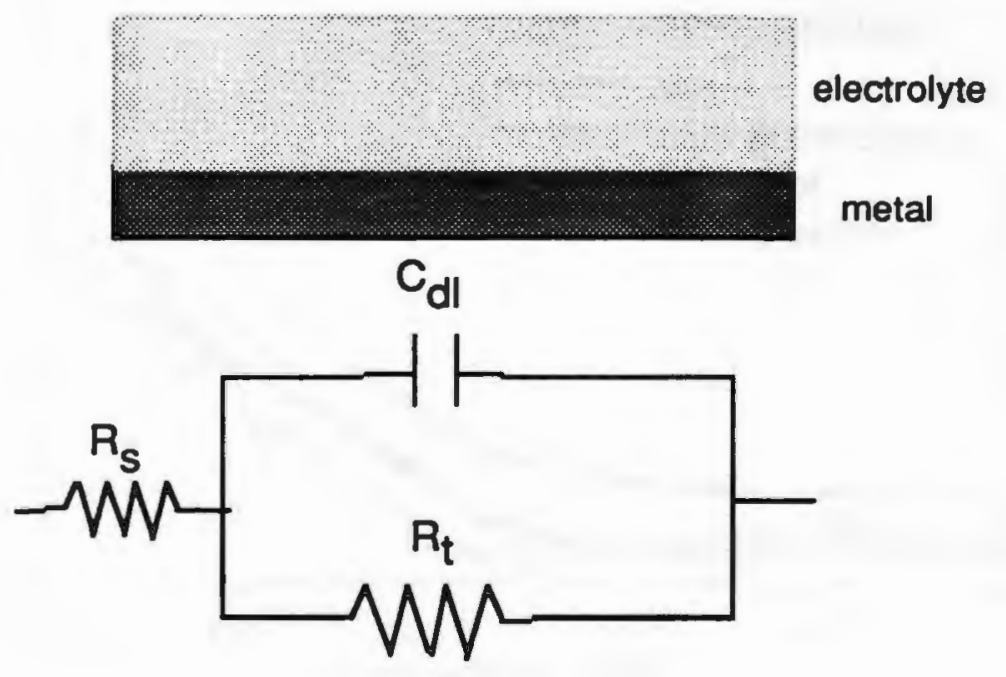

Figure 10. Schematic diagram of equivalent circuit model used to fit the local impedance data. 

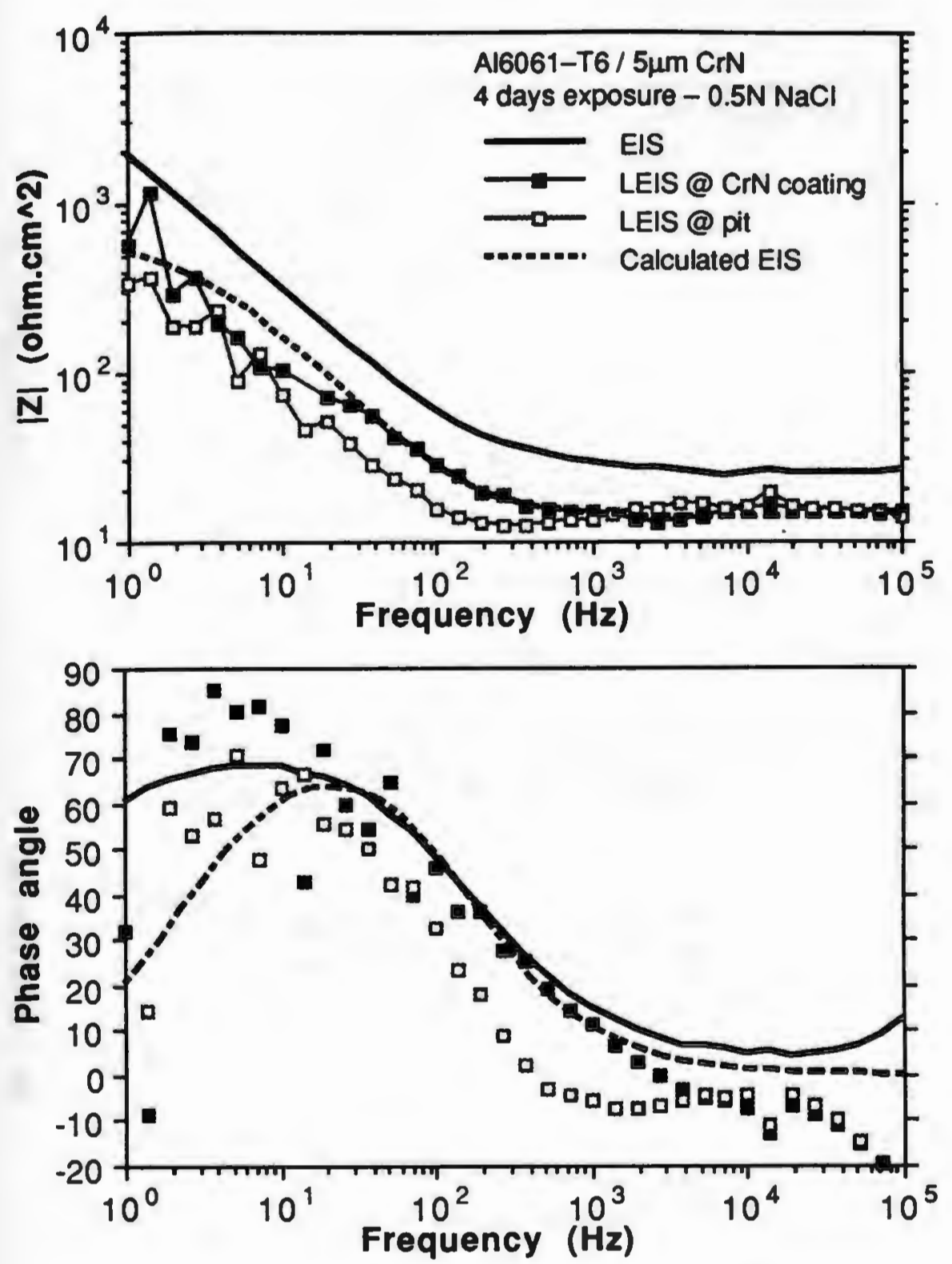

Figure 11. Comparison between the calculated overall impedance employing the active pit model and the measured impedance from EIS for A16061-T6 coated with $5 \mu \mathrm{m} \mathrm{CrN.}$ 

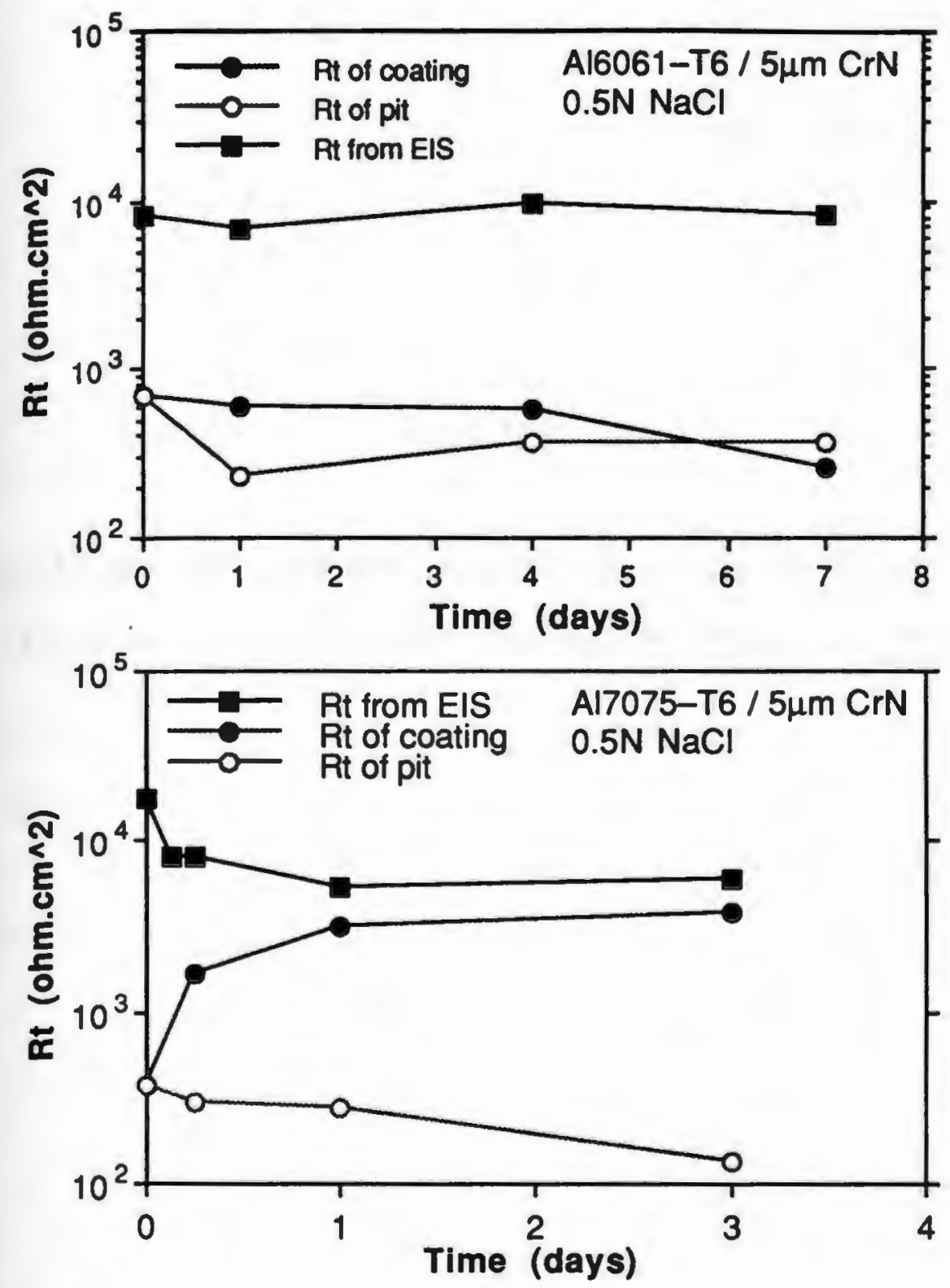

Figure 12. Comparison of the individual and overall charge transfer resistance for both aluminum alloys coated with $5 \mu \mathrm{m} \mathrm{CrN}$. 


\section{CHAPTER VII}

\section{APPLICATION OF SCANNING POTENTIAL MICRO-PROBE TECHNIQUES}

TO MONITOR DAMAGE IN FIBER REINFORCED COMPOSITES 


\section{ABSTRACT}

Scanning reference electrode technique (SRET) and local lectrochemical impedance spectroscopy (LEIS) were utilized to monitor damages in carbon/glass/vinyl ester composites subjected to simulated galvanic coupling condition in $0.5 \mathrm{~N} \mathrm{NaCl}$ solution. Potential difference between the damaged polymer regions over carbon fibers closest to the surface and the blistered polymer regions over glass fibers closest to the surface were found by SRET only under applied cathodic potential conditions due to net current flowing out from the carbon fibers to the solution. Time dependent LEIS measurement able to monitor differences in impedance at both regions under unbiased and biased conditions. Additional information on damage mechanism in this type of polymer composite was obtained and discussed in comparison to data gathered from conventional electrochemical impedance spectroscopy (EIS). 


\section{INTRODUCTION}

Electrochemical impedance spectroscopy was proven to be a powerful technique to monitor corrosion of polymer coated metals 1 . Studies were conducted extending this technique to monitor damage processes in fiber reinforced composites such as blistering in carbon/glass/vinyl ester (CGVE) composite and polymer degradation in carbon/epoxy (CE) composite 2-4. Since the EIS technique provided an average measurement of the corroding surface, any particular data trend measured for damaged composite cannot be used to indicate specific type of damages or separate concurrently operating mechanisms. The location of degradation processes with respect to microstructural features cannot be indicated by traditional EIS techniques. A surface potential mapping technique and local measurements of impedance technique like the scanning reference electrode technique (SRET) and local electrochemical impedance spectroscopy (LEIS) could be used to separate out and provide a quantitative information on individual damage processes as well as indicate their locations $5-7$.

Blistering in CGVE composite is very apparent over regions where the glass fibers are closest to the exposed surface, figure 1. Cracking occurs over regions where the carbon fibers closest to the exposed surface. This situation will produce a large potential variation in the solution very near the exposed surface between the glass fiber and carbon fiber regions. It was suspected that a scanning reference electrode technique could be employed to monitor the potential variation over the damaged composite. 
The potential distribution very near the corroding surface can be scanned by placing a micrometer size inert wire, ie. platinum, exposed only at its tip at a distance approximately the diameter of the tip from the surface. Potential at any point over the corroding surface is measured relative to a similar electrode placed at some distance away. The current density at any point can also be calculated using Ohm's law 6 such that

$$
\mathfrak{i}=-\mathbf{k} \Delta \mathrm{E}
$$

where $\mathrm{k}$ is the solution conductivity (ohm.cm) ${ }^{-1}$, and $\Delta \mathrm{E}$ is the potential field given by the potential difference between the two platinum electrodes divided by the separation distance.

Local EIS is a promising technique to monitor impedance at specific sites on the corroding surface due to physical and chemical heterogeneities 7 . A similar apparatus was developed to test the applicability of this technique to monitor damage in CGVE composites. Local impedance was measured utilizing a platinum bi-probe placed very near the surface to measure the solution current density normal to the electrode surface. A voltage perturbation amplitude was maintained between a standard calomel reference electrode and the working electrode over the frequency range of $100 \mathrm{kHz}$ to $1 \mathrm{~Hz}$. Current response of the system at a specific site was measured as the potential difference at the tips of the bi-probe which was then converted to current at each frequency. The local impedance $\left(0 \mathrm{hm} . \mathrm{cm}^{2}\right)$ can be calculated from a modified Ohm's law

$$
|\mathrm{Z}(\omega)|_{\text {local }}=\mathrm{V}(\omega)_{\text {applied }} / \mathrm{i}(\omega)_{\text {local }}
$$




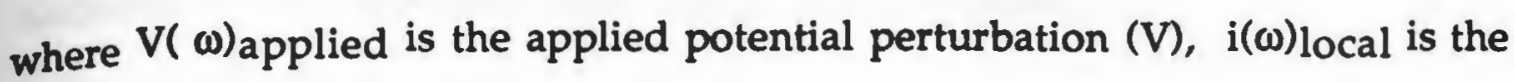
local current density $\left(\mathrm{A} / \mathrm{cm}^{2}\right)$ given as

$$
\mathrm{i}(\omega)_{\text {local }}=\Delta \mathrm{V}(\omega)_{\text {tip }} \mathrm{k} / \mathrm{l}
$$

where $\Delta \mathrm{V}(\omega)$ tip is the potential difference measured at the tips of bi-probe (V), $\mathrm{k}$ is the solution conductivity (ohm.cm) ${ }^{-1}$, and 1 is the separation distance of the bi-probe tips $(\mathrm{cm})$.

The applicability of the scanning reference electrode technique to monitor damages in CGVE composite was tested on a pre-damaged sample with blisters and polymer crackings under a simulated galvanic coupling condition in $0.5 \mathrm{~N} \mathrm{NaCl}$. The applicability of LEIS technique to monitor impedance variation over different locations of the glass fibers and the carbon fibers during degradation under applied cathodic potential was also tested. The applicability and sensitivity of both techniques to specifically monitoring electrochemical variations in the system will be discussed.

\section{EXPERIMENTAL PROCEDURES}

Materials

Model homogeneous and heterogeneous were prepared to test the applicability of LEIS technique. A 304 stainless steel and a commercial $\mathrm{Pb} / \mathrm{Sn}$ solder electrodes were mounted in epoxy and polished using 600 grit carbide paper, figure 2. Total active area of the former was $1.1684 \mathrm{~cm}^{2}$ and of the latter was $0.0962 \mathrm{~cm}^{2}$. A heterogeneous electrode of $0.0962 \mathrm{~cm}^{2} \mathrm{of} \mathrm{Pb} / \mathrm{Sn}$ 
solder in 304 stainless steel matrix with total area of $1.1684 \mathrm{~cm}^{2}$. This electrode was also polished using 600 grit carbide paper.

A previously damaged CGVE composite with blisters over the glass fibers and polymer cracks over the carbon fibers was used to test the applicability of SRET and LEIS techniques to monitor damages in composite. Three as-received CGVE composites with fiber to polymer ratio of 30:70 were used to study the applicability of both techniques to monitor the time dependent degradation behavior. Total exposed for all composite samples was $22.54 \mathrm{~cm}^{2}$.

All corrosion tests were conducted in $0.5 \mathrm{~N} \mathrm{NaCl}$ solution prepared from double distilled deionized water.

\section{Apparatus}

A SRET apparatus was developed where $X Y Z$ stepping motors were controlled through a DT-2801 A/D board interface to a personal computer. The $X Y$ stage was movable and has a movement resolution of $2.5 \mu \mathrm{m}$ per step. The probe height, $z$ axis, was adjustable with a resolution $5.0 \mu \mathrm{m}$ per step. The sample and open-ended hollow glass tube were mounted on the stage with a clamp. The tube was filled with the test solution. The probe was placed at a specified distance above the surface.

Applied potential was maintained between the sample as a working electrode and the standard calomel (SCE) reference electrode through a PARC 273 potentiostat. A platinum foil was used as a counter electrode to complete the cell. The potential variation very near the surface was measured using a 
platinum bi-probe with tip diameter of $125 \mu \mathrm{m}$. The tips were displaced vertically approximately $2 \mathrm{~mm}$. Potential variation in the solution near the surface was measured between these two tips. During scanning experiments the bi-probe was kept at a constant height of $100 \mu \mathrm{m}$ from the surface. The measured potential difference was input through the analog channel of the $A / D$ board to the computer and saved in a file along with the location of probe. These data can be retrieved for visualization. A BASIC computer program was written to control the probe height, move the sample under the probe, and measure the potential difference at the probe tips. A spatial separation of $50 \mu \mathrm{m}$ per data point was used in all scanning experiments.

Conventional EIS was performed utilizing a EG\&G M388 software with the commonly used 3-electrode cell configuration. The equipments include a Solartron 1255 FRA and a EG\&G 273 potentiostat. A potential perturbation amplitude of $5 \mathrm{mV}, 7$ data points per frequency decade, and a frequency range of $100 \mathrm{kHz}$ to $0.01 \mathrm{~Hz}$ were used in all EIS experiments. The unit of impedance measured by the software was in ohm and was area-normalized to ohm.cm ${ }^{2}$ by multiplying by the total exposed area. The EIS spectra can then be used for comparison with the local EIS (LEIS) spectra.

In LEIS experiments the potential perturbation and applied dc potential were maintained through EG\&G 273 potentiostat between the working electrode and the reference electrode, figure 3. The potential diference measured at the bi-probe tips was amplified through an Analog Devices AD625JN instrumentation amplifier and input to the current input channel of the Solartron 1255 FRA. This allowed very small potential difference measured between the tips to be amplified up to 1000X. An applied 
ac potential perturbation of $20 \mathrm{mV}$ was maintained between a frequency range of $100 \mathrm{kHz}$ and $1 \mathrm{~Hz}$ with a data frequency of 7 points per decade. The measured impedance was area-normalized in units of ohm. $\mathrm{cm}^{2}$. The tips of the bi-probe for the LEIS measurements were displaced $500 \mu \mathrm{m}$ vertically between them. The distance between the bottom of the bi-probe and the surface was kept constant at height of $100 \mu \mathrm{m}$ in all experiments.

Tip Preparation

Pt micro-probes were made using $99.99 \%$ pure platinum wires with diameter of $125 \mu \mathrm{m}$. The wire was inserted into a glass capillary with initial inside diameter of $0.8 \mathrm{~mm}$ and $9 \mathrm{~cm}$ long. One end of the capillary was sealed by heating with propane flame. The other end was left open and the thin wire was soldered to thicker $\mathrm{Pt}$ wire of $250 \mu \mathrm{m}$ inside diameter. The sealed end was polished using 600 grit carbide paper to expose the $\mathrm{Pt}$ at the tip. The tip was cleaned using $\mathrm{HCl}: \mathrm{HNO}_{3}: \mathrm{H}_{2} \mathrm{O}$ solution and $0.1 \mathrm{M} \mathrm{H}_{2} \mathrm{SO}_{4}$ solution and later platinized using choloplatinic acid solution 8 . Two of indentical probes were placed inside a heat shrink tube and heated to produce a Pt bi-probe. 


\section{EXPERIMENTAL RESULTS}

\section{LEIS Calibration}

\section{i. Homogeneous electrode}

Validity of the experimental method on a macroscopically homogeneous electrode was demonstrated using a $\mathrm{Pb} / \mathrm{Sn}$ solder and a $304 \mathrm{SS}$ disk electrodes in $0.5 \mathrm{~N} \mathrm{NaCl}$ solution. The impedance and phase angle from EIS and LEIS of $304 S S$ electrode are nearly identical between $10 \mathrm{kHz}$ and $1 \mathrm{~Hz}$, figure 4. The free corrosion potential of the stainless steel was stable throughout the experiment at $-250 \mathrm{mV}$ (SCE).

The EIS and LEIS spectra of the $\mathrm{Pb} / \mathrm{Sn}$ solder electrode in $0.5 \mathrm{~N} \mathrm{NaCl}$ at open circuit also shown good correlation between $10 \mathrm{kHz}$ and $10 \mathrm{~Hz}$ range. The free corrosion potential was stable throughout experiment at $-580 \mathrm{mV}$ (SCE) which was anodic to the 304 SS electrode.

\section{ii. Heterogeneous electrode}

In $0.5 \mathrm{~N} \mathrm{NaCl}$ solution a galvanic couple was formed with the $\mathrm{Pb} / \mathrm{Sn}$ electrode as the anode and 304SS as cathode. LEIS spectra in figure 5 indicated the impedance spectra at 304SS location similar to that measured on homogeneous stainless steel electrode at open circuit. Oxidation of the $\mathrm{Pb} / \mathrm{Sn}$ electrode was obvious as solution in the vicinity of this electrode became cloudy and the $\mathrm{Pb} / \mathrm{Sn}$ electrode turned black. The LEIS impedance spectra over the $\mathrm{Pb} / \mathrm{Sn}$ shown a typical Randles type circuit with a low charge transfer resistance value typical of a corroding surface. The magnitude of impedance and phase angle measured at a location over the stainless steel followed closely to the overall impedance measured by EIS. This indicates the 
usefullness in separating the individual mechanisms and locations available by LEIS.

SRET and LEIS of composites

\section{i. Pre-damaged sample}

Potential scan over a pre-damaged composite in $0.5 \mathrm{~N} \mathrm{NaCl}$ solution at $-0.9 \mathrm{~V}$ (SCE) shown approximately 10 to $15 \mathrm{mV}$ potential difference between a location over the blistered region on the glass fiber and a location over the damaged polymer over the carbon fiber, figure 6. The potential was more cathodic at the damaged polymer over the carbon fiber than at the blistered polymer over the glass fiber. A similar scan at open circuit condition did not show any potential variation between the damaged region over the carbon fiber and blistered region over the glass fiber.

EIS measurement shown a single maxima at low frequency. The local EIS (LEIS) shown higher magnitude of impedance measured at blistered region over the glass fiber than at damaged polymer region over the carbon fiber, figure 7. The phase angle plot shown higher phase angle for the glass region with a maxima at higher frequency than that for the carbon region.

\section{ii. As received sample at open circuit}

Potential scan over the CGVE composite in $0.5 \mathrm{~N} \mathrm{NaCl}$ at open circuit over a 30 days period did not show any variation in the potential over regions where glass weave is closest to the surface and that of the carbon closest to the surface. 4 days spectra shown very similar local impedance at the glass and carbon regions and that of the overall impedance from EIS, figure 8. At low frequencies below $100 \mathrm{~Hz}$ the local impedance was dominated by noise. The 
local impedance after further exposure decreased at both carbon and glass regions. This was lower at the carbon regions than at the glass regions. The phase angle at carbon regions was lower than at glass regions. The overal impedance and phase angle only indicated slight changes over the exposure period. No visual changes on the exposed surface were observed.

\section{iii. As received samples under applied cathodic potential}

Potential variations in the solution under applied cathodic potential of $-900 \mathrm{mV}(\mathrm{SCE})$ are shown in figure 9. Initial data upon application of potential was dominated by noise. Potential difference of approximately 20 $\mathrm{mV}$ was observed after more than a week exposure when blisters were visually identified by naked eyes. The potential was lower at the carbon regions than at blistered glass regions. Visual inspection of the sample after the test indicated damaged polymer over the carbon regions.

Initial EIS spectra at $-650 \mathrm{mV}$ shown two maxima with the impedance lower than at open circuit condition, figure 10. With increasing exposure the maximum phase angle of the maxima at high frequency decreased along with decreased in the overall impedance. Blisters were visually observed after a week exposure. The initial LEIS spectra at both carbon and glass regions at nearly identical above $10^{4} \mathrm{~Hz}$ but was higher at the glass regions than at carbon regions at lower frequencies. Both were lower than the overall impedance. With increasing exposure the impedance at both regions increased at frequency above $10 \mathrm{kHz}$ but the impedance at the glass regions remained higher than at the carbon regions. Polymer damaged was observed over the carbon regions after removing the sample from solution. 
The overall impedance at $-0.9 \mathrm{~V}$ (SCE) slightly decreased with the phase angle shown two maxima and remained low and slightly changed over the exposure period, figure 11. Blisters were visually observed after a week exposure. Initial local impedance at the glass regions was higher than that carbon fiber regions as shown by the data at 6 days. Both have lower impedance than the overall impedance. The phase angle over the glass regions was higher than that over the carbon regions. The overall phase angle nearly identical to the local phase angle at carbon regions.

The local impedance at both regions increased with increasing exposure and nearly identical after 2 weeks exposure. The phase angle decreased at both regions decreased and also nearly identical after more than 3 weeks exposure. The local impedance at the glass regions remained higher than at the carbon regions at the end of the exposure. Visual inspection at the end of test indicated large blister over the glass fibers and polymer cracks and openings over the carbon fibers.

Line mapping of local impedance over carbon and glass regions under applied condition indicated uniformly lower impedance over the damaged region over carbon fibers than over the blistered region over the glass fibers, figure 12. The difference was greater at lower frequency. 


\section{DISCUSSION}

SRET and LEIS technique were used to monitor damage on carbon/glass/vinyl ester composite subjected to a simulated galvanic coupling in $\mathrm{NaCl}$ solution solution. In this study the dc potential variation between damaged or cracked polymer region over the glass fibers and blistered region over the glass fibers was observed under a simulated galvanic coupling, figures 6 and 9. The potential variation was dependent on the polarization behavior of the carbon. At $-650 \mathrm{mV}$ and $-900 \mathrm{mV}$ (SCE) in $0.5 \mathrm{~N} \mathrm{NaCl}$ solution, a cathodic reduction of oxygen to produce hydroxyl ions occur according to reaction

$$
\mathrm{O}_{2}+2 \mathrm{H}_{2} \mathrm{O}+4 \mathrm{e}^{-} \rightarrow 4 \mathrm{OH}^{-}
$$

Cathodic current flowed from the carbon fiber under the polymer to the secondary platinum electrode acting as the anode. If the blisters over the glass regions did not break open, the current from the carbon just below the glass can only flow out to the solution through the opening paths made by the cracked polymer over the carbon regions. It will appear as that the region over the glass regions had lower cathodic polarization behavior than the carbon region. The cathodic current can easily flow out from the carbon regions where the polymer layers were removed or cracked. This produced variation of the surface potential between the glass and carbon regions as measured by the SRET technique.

Under open circuit condition, SRET technique did not able to resolve any potential variation between the carbon and glass regions for both 
undamaged and damaged composites. At this condition there was no net current flow from the carbon to the bulk solution which did not produce significant variation of potential at locations over the blistered and cracked polymer regions over the glass fibers and carbon fibers, respectively. This technique only indicated the difference in the potential above the carbon and glass regions due to damages from applied cathodic potential. No mechanistic information was obtain from this technique.

The local impedance technique was shown as able to resolve physical and chemical heterogeneities on surface exposed to electrolyte 6,7. A similar technique was constructed to monitor impedance variation in various systems. Calibration of the technique was conducted using two electrochemical different systems; a model homogeneous electrode of 304SS and a model heterogeneous electrode of $304 \mathrm{SS}$ coupled to $\mathrm{Pb} / \mathrm{Sn}$ solder.

In $0.5 \mathrm{~N} \mathrm{NaCl}$ solution the $304 \mathrm{SS}$ electrode was passive and stable over the entire test. No localized corrosion was observed. The local impedance measured at a position over this electrode matched very well to the overall impedance measured by the traditional EIS technique except at the high frequency region which was dominated by artefacts. When the stainless steel was coupled to the $\mathrm{Pb} / \mathrm{Sn}$ electrode in similar solution, anodic oxidation of the $\mathrm{Pb} / \mathrm{Sn}$ electrode occured. The local impedance measured at a location of the $\mathrm{Pb} / \mathrm{Sn}$ electrode was lower than that measured at a location of the stainless steel. The overall impedance was dominated by the higher impedance of the two electrodes; the stainless steel impedance. The large area ratio of stainless steel to solder, $10: 1$, dominated the process. Overlapping time constants of both spectra over the solder and stainless steel, 
approximately at 0.001 and 0.01 seconds, respectively, show only a single maxima in the overall EIS spectra.

The applicability of the LEIS technique to monitor damages in composite was tested on a pre-damaged composite with blisters and polymer cracks. Difference of the impedance and phase angle behavior at the two locations was found. The impedance over the blistered regions was higher than over the carbon regions. The phase angle shown a higher phase angle maxima for the blistered glass regions due to the inertness of the glass fibers. These indicated the higher resistance of the glass regions to penetration of electrolyte in direction normal to the carbon below the glass fibers than that over the carbon regions which were directly exposed to the electrolyte through the cracked polymer layer. The overall impedance nearly followed that measured over the blistered regions over the glass fibers with the phase angle behavior followed nearly that measured over the carbon regions. This indicated that the overall EIS spectra was dominated by the impedance of the undamaged regions as shown previously where only a small area was damaged due to galvanic coupling 2,3 .

Time dependent LEIS measurements over the glass and carbon regions of an as-received CGVE composites under applied potentials indicated higher impedance at the former than at the latter. Significant changes in the local impedance measurements were found but not in the overall EIS measurements. No conclusions can be made regarding the processes occured separately at the carbon and glass regions from the traditional EIS measurements. The higher overall impedance was a reflection of the large surface area not damaged by the processes occurring. 
The time dependent data of local impedance measured at the carbon regions increased approaching that at the glass regions. Increased in the impedance at the carbon regions may be caused by the progression of small blisters along the carbon/polymer interface which increased the exposed area of carbon fibers for cathodic reactions, figure 12. Since in the region of diffusion controlled of the cathodic reduction of oxygen the current density was nearly constant 9 , this resulted in decreasing local current density or increasing in the impedance at the location of measurements over the carbon fiber closest to the surface. Over the glass region, the impedance increased with time and remained higher than at carbon regions could be contributed to increasing in local thickness for diffusion of electrolyte through the blistered polymer over the glass fiber. The blisters formed over the glass fibers may have created nearly identical impedance at both regions.

The phase angle measured over the carbon fibers was lower than at the glass fibers, and nearly resembles that measured by overall EIS. The phase angle of the glass regions decreased after 14 days and continued to decrease below the overall phase angle measured by EIS after 25 days. This can be related to blisters formed over the glass regions and higher content of electrolyte in the blister pockets. These blisters and regions around the glass fibers were saturated with electrolyte and ionic species produced from the cathodic reaction at the carbon. These regions will no longer acted as inert diffusion barrier to electrolyte penetration.

Time dependent impedance data measured by EIS on an as-received composite at open circuit condition shown very insignificant change in the 
impedance and phase angle behavior. The LEIS data shown larger decreased in impedance at the carbon regions than at the glass regions with decreasing phase angle maxima at both sites. Diffusion of electrolyte to the composite was higher at the carbon regions than at the glass regions simply due to a thicker barrier for electrolyte penetration through the latter than the former. The glass fibers acted as additional barrier to the diffusion of electrolyte to the composite. This resulted in lesser decreased in the impedance at the glass sites than at the carbon sites over the exposure period.

This study shown the potential of both SRET and LEIS techniques to monitor the formation and development of damages in CGVE composites. Physical damages were easily identified by both techniques but dependent on the polarization behavior of exposed carbon fibers in the SRET technique. The LEIS technique can detect both physical and electrochemical differences over the composite surfaces even when there is no net current flowing in the system. Information of local properties can be measured by the local impedance technique and mapped for the entire surface of interest.

\section{CONCLUSIONS}

1. SRET and LEIS techniques were very useful to monitor damages in composites. The ac LEIS technique was more sensitive to the physical variations in the composite and able to resolve difference in impedance at carbon and glass regions at open circuit and applied potential conditions. The dc SRET technique was more dependent on the current flow normal to the surface which could not resolve any physical variations on the damaged composite at open circuit conditions. 
2. Local impedance measured at applied cathodic potential conditions suggested damage initiated at regions where carbon fibers were closest to the surface and propagated along the carbon/polymer interface to the glass fibers region to produce large blisters over the glass fibers.

\section{REFERENCES}

1. G. W. Walter, "Application of Impedance Measurements to Study Performance of Painted Metals in Aggressive Solutions", Journal of Electroanalytical Chemistry, v118 (1981), 259-273

2. D. Kaushik, M. N. Alias, R. Brown, "An Impedance Study of a Carbon Fiber/Vinyl Ester Composite", Corrosion, v47(1991), 859-867

3. M. N. Alias, R. Brown, "Damage to Composites from Electrochemical Processes", .Corrosion, v48(1992), 373-378

4. M. N. Alias, R. Brown, "Corrosion Behavior of Carbon Fiber Composites in the Marine Environment", Corrosion Science, v35(1993), 395-402

5. H. S. Isaacs, B. Byas, "Scanning Reference Electrode Techniques in Localized Corrosion", Electrochemical Corrosion Testing, ASTM STP 727, F. Mansfeld, U. Bertocci, eds., American Society for Testing Materials, 1981, 333 
6. H. S. Isaacs, M. W. Kendig, "Determination of Surface Inhomogeneities Using a Scanning Probe Impedance Technique", Corrosion, v36 (1980), 269274

7. R. S. Lillard, P. J. Moran, H. S. Isaacs, "A Novel Method for Generating Quantitative Local Electrochemical Impedance Spectroscopy", Journal of the Electrochemical Society, v139 (1992), 1007-1012

8. Hills, G. J., D. J. G. Ives, "The Hydrogen Electrode", in Reference Electrodes. Theory and Practices, D. J. G. Ives and G. J. Janz, editors, Academic Press, New York, 1961, 71-126

9. Miriyala, S. K., T. J. Rockett, W. C. Tucker, R. Brown, “Corrosion Activated Degradation of Composites in Sea Water", Proceedings of the Annual Tri-Services Conference, Boston, MA, 1992, 441-453 


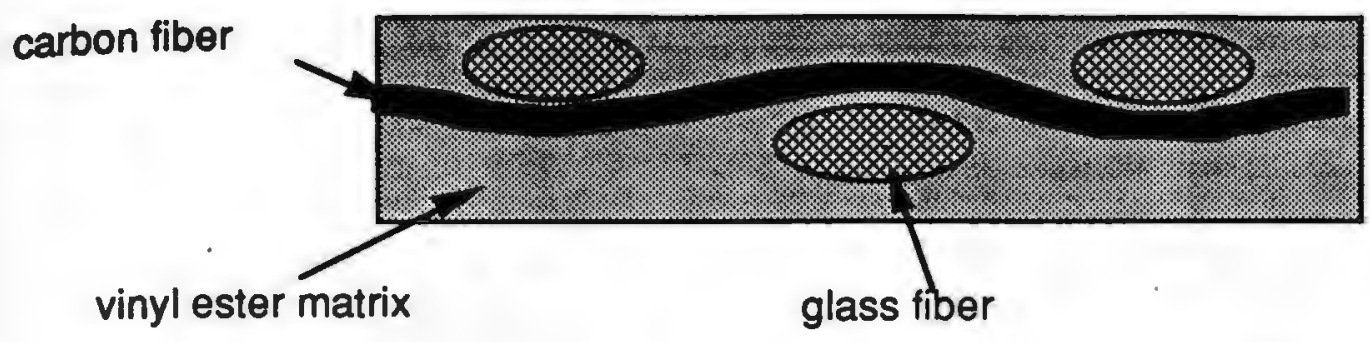

(1) AS-RECEIVED CGVE COMPOSITE

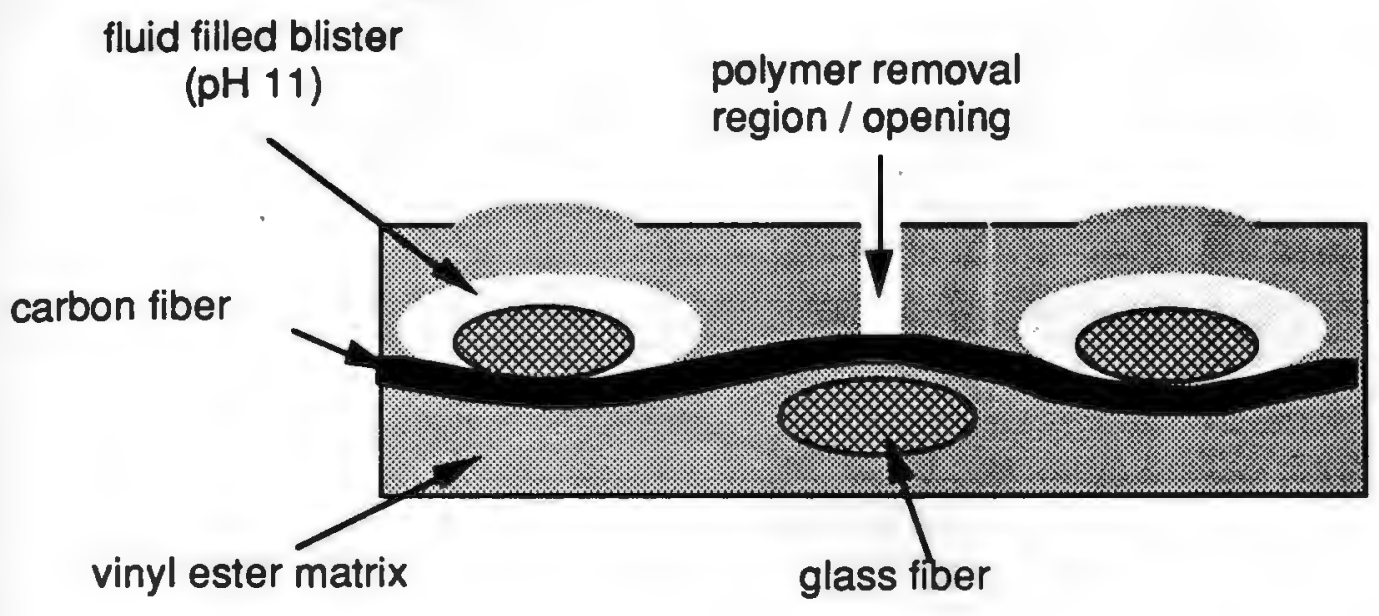

Figure 1. Schematics of the damages found on CGVE composites when coupled to active metals like $\mathrm{Al}$ alloys and steel in seawater. 
(a).

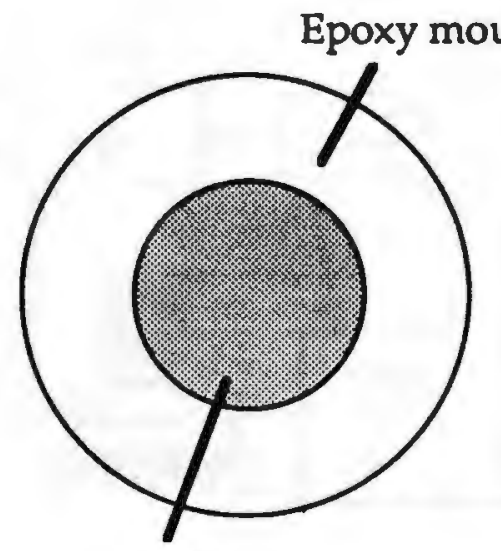

(b).

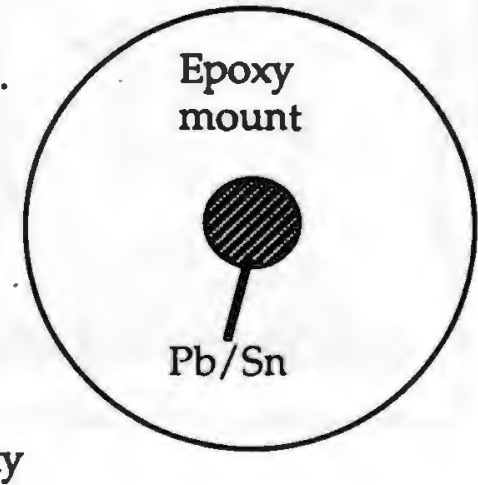

\section{SS}

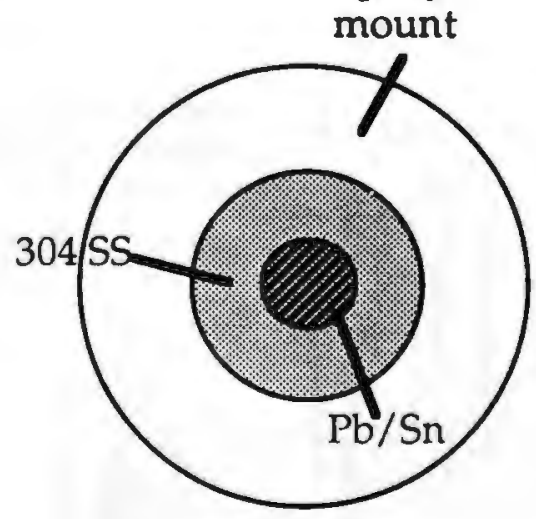

(c).

Figure 3. Schematic of model electrodes used for calibration of LEIS. 

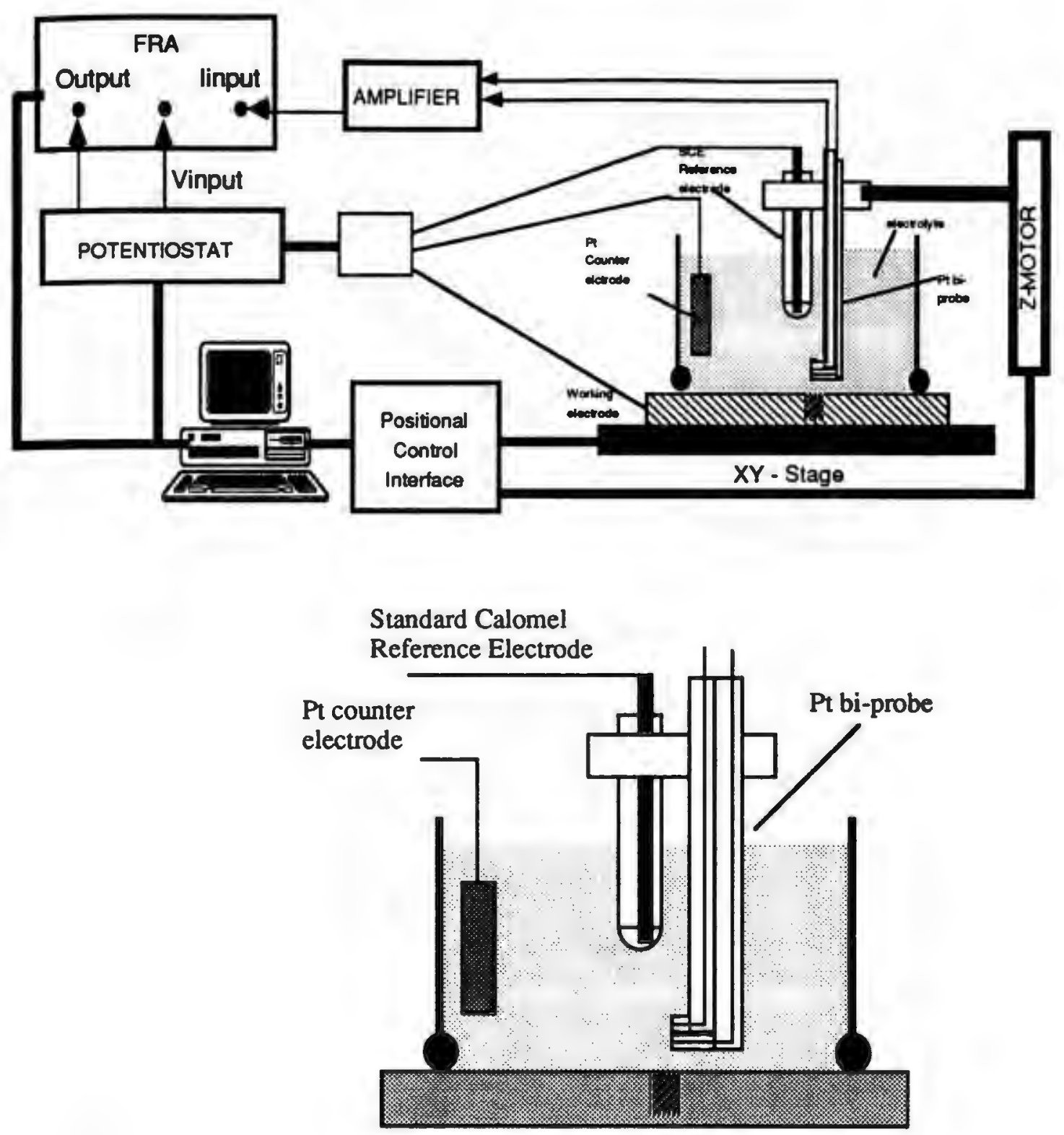

Working electrode

Figure 3. Schematics of the experimental setup and bi-probe configuration for local electrochemical impedance spectroscopy (LEIS). 

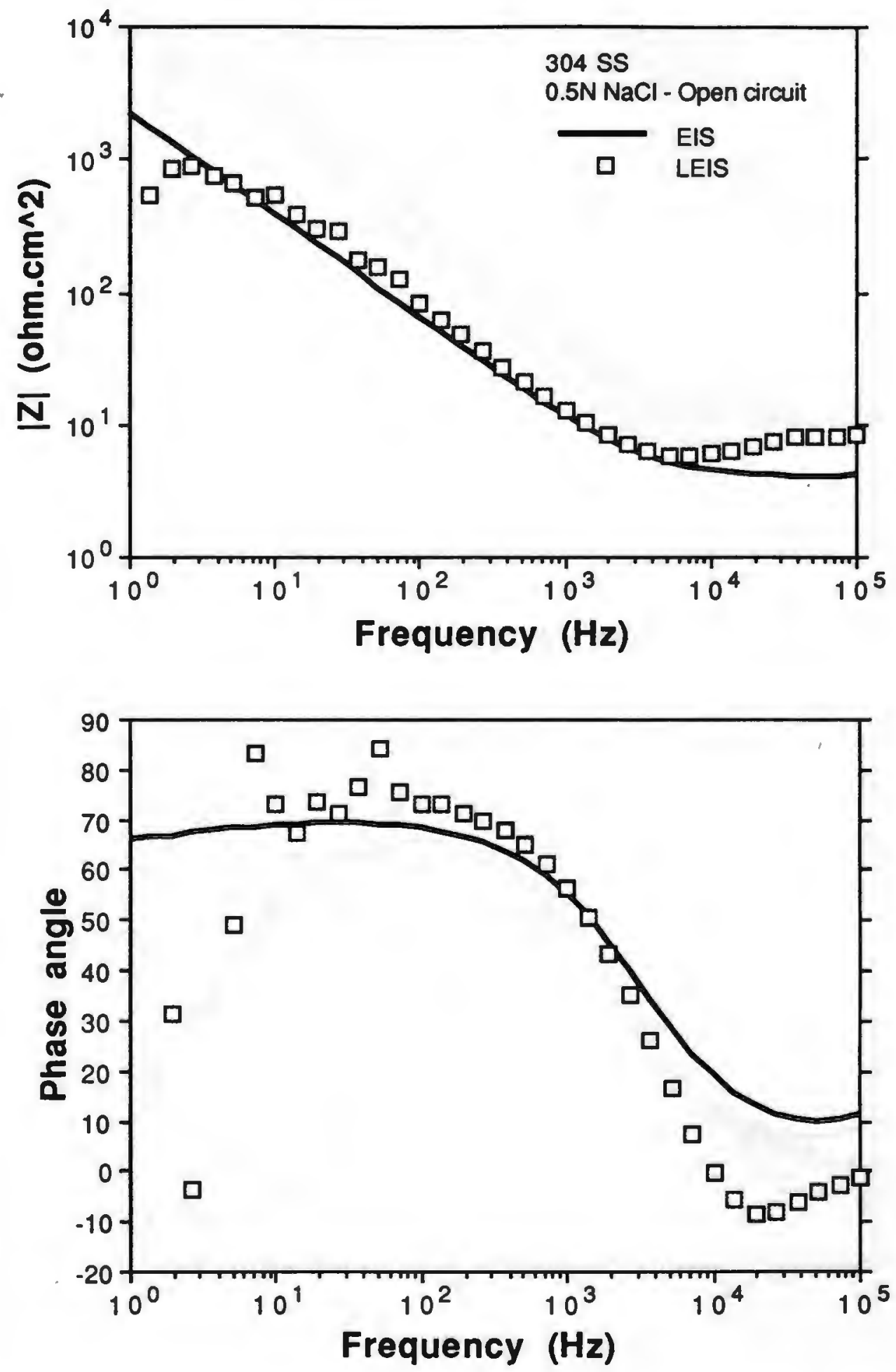

Figure 4. Bode plots of $304 \mathrm{SS}$ electrode in $0.5 \mathrm{~N} \mathrm{NaCl}$ at open circuit as measured from EIS and LEIS. 

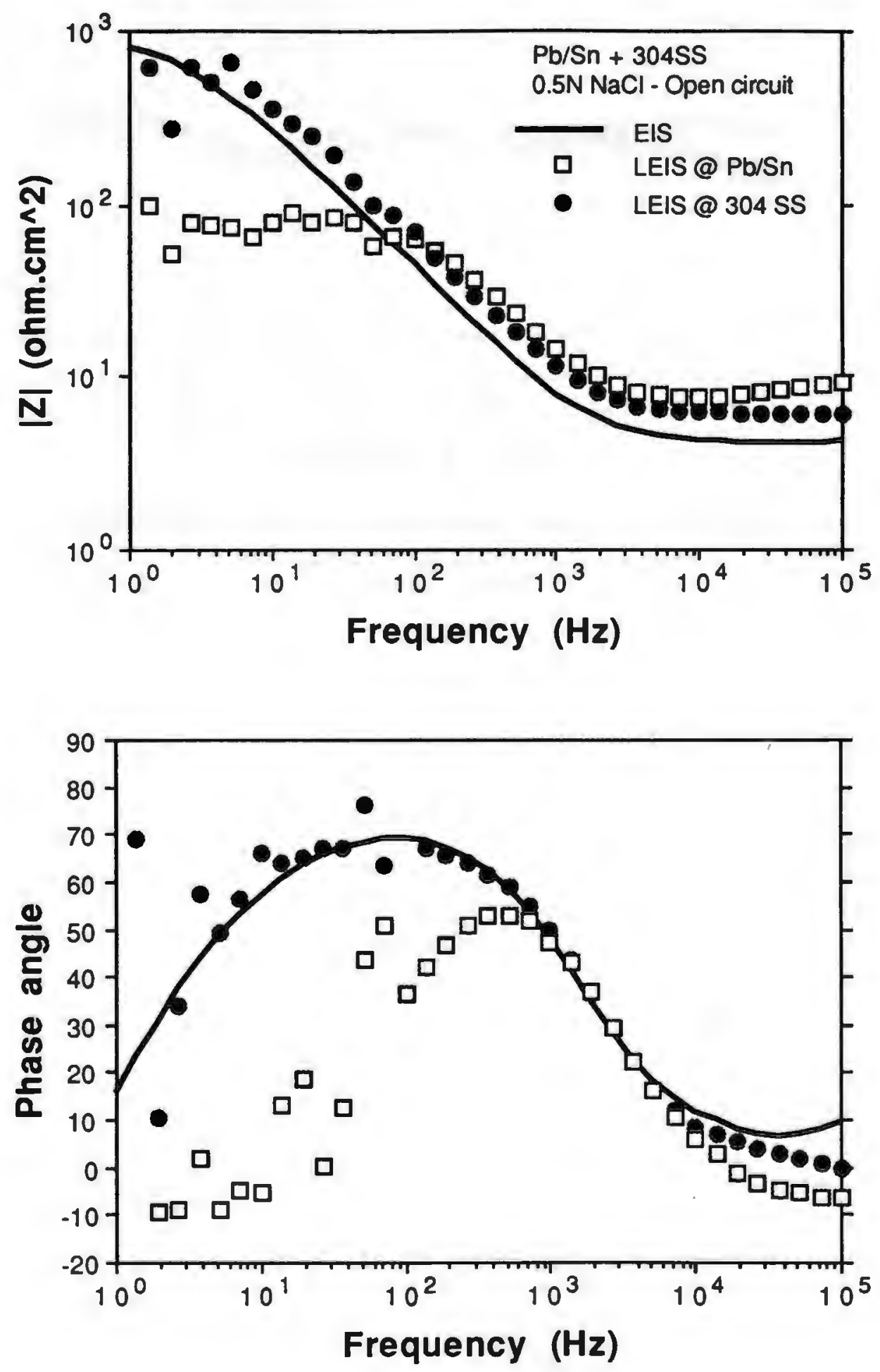

Figure 5. Bode plots of $\mathrm{Pb} / \mathrm{Sn}$ and $304 \mathrm{SS}$ couple electrode in $0.5 \mathrm{~N} \mathrm{NaCl}$ at open circuit as measured from EIS and LEIS. 


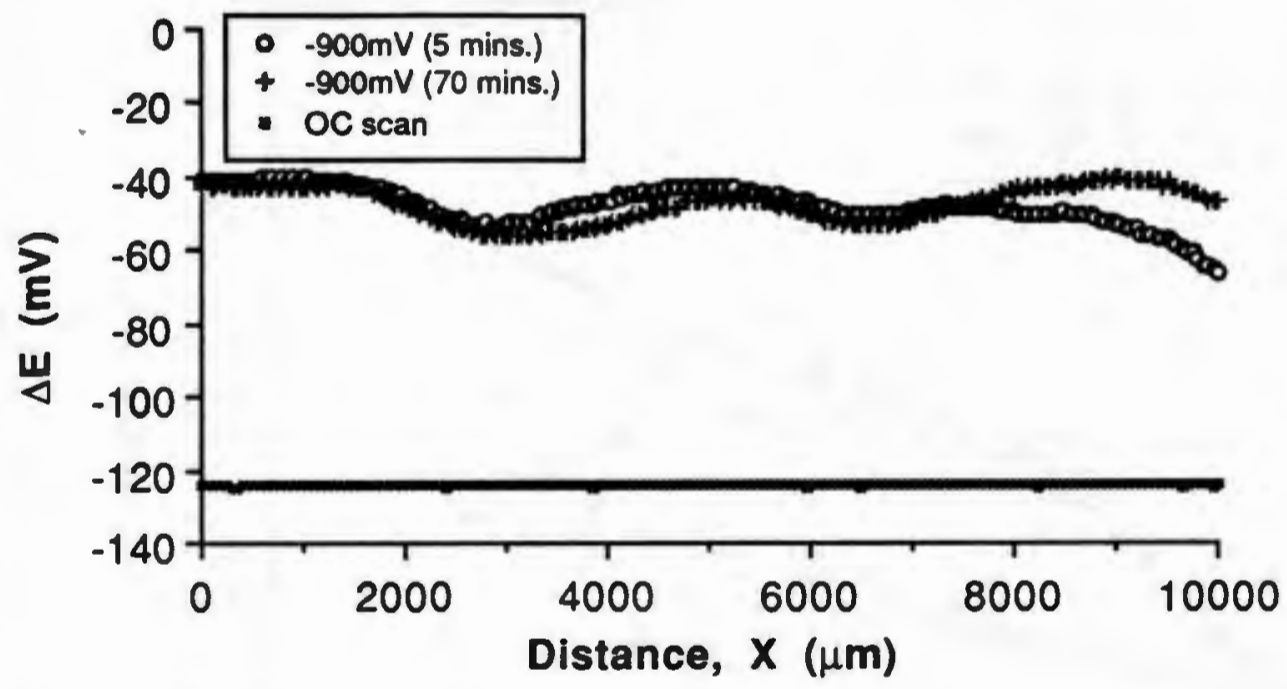

Figure 6. Potential variations in pre-damaged carbon/glass/vinyl ester composite under open circuit and applied potential conditions. 

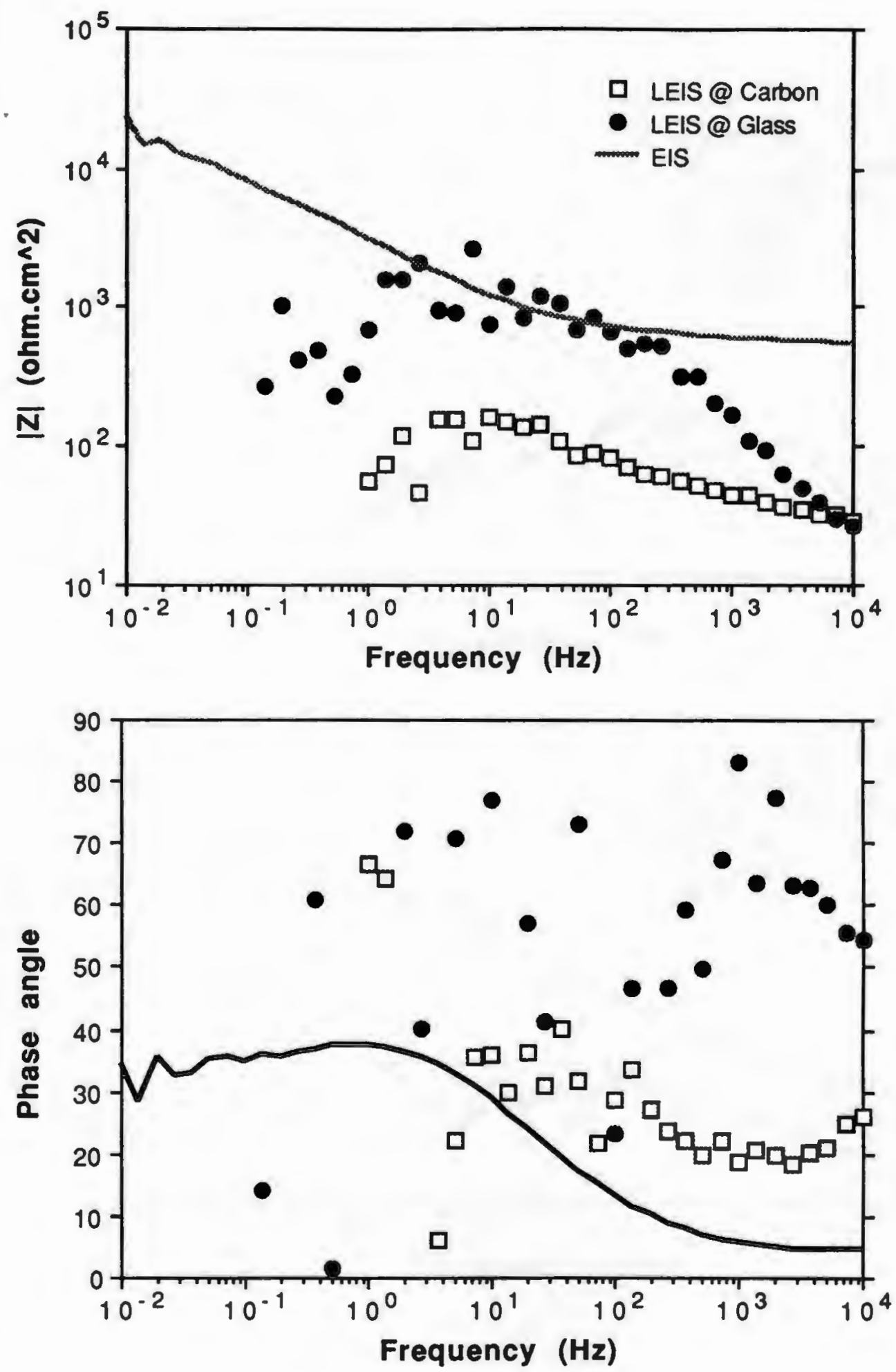

Figure 7. Bode plots of EIS and LEIS spectra of a pre-damaged CGVE composite at $-0.9 \mathrm{~V}(\mathrm{SCE})$ in $0.5 \mathrm{~N} \mathrm{NaCl}$. 

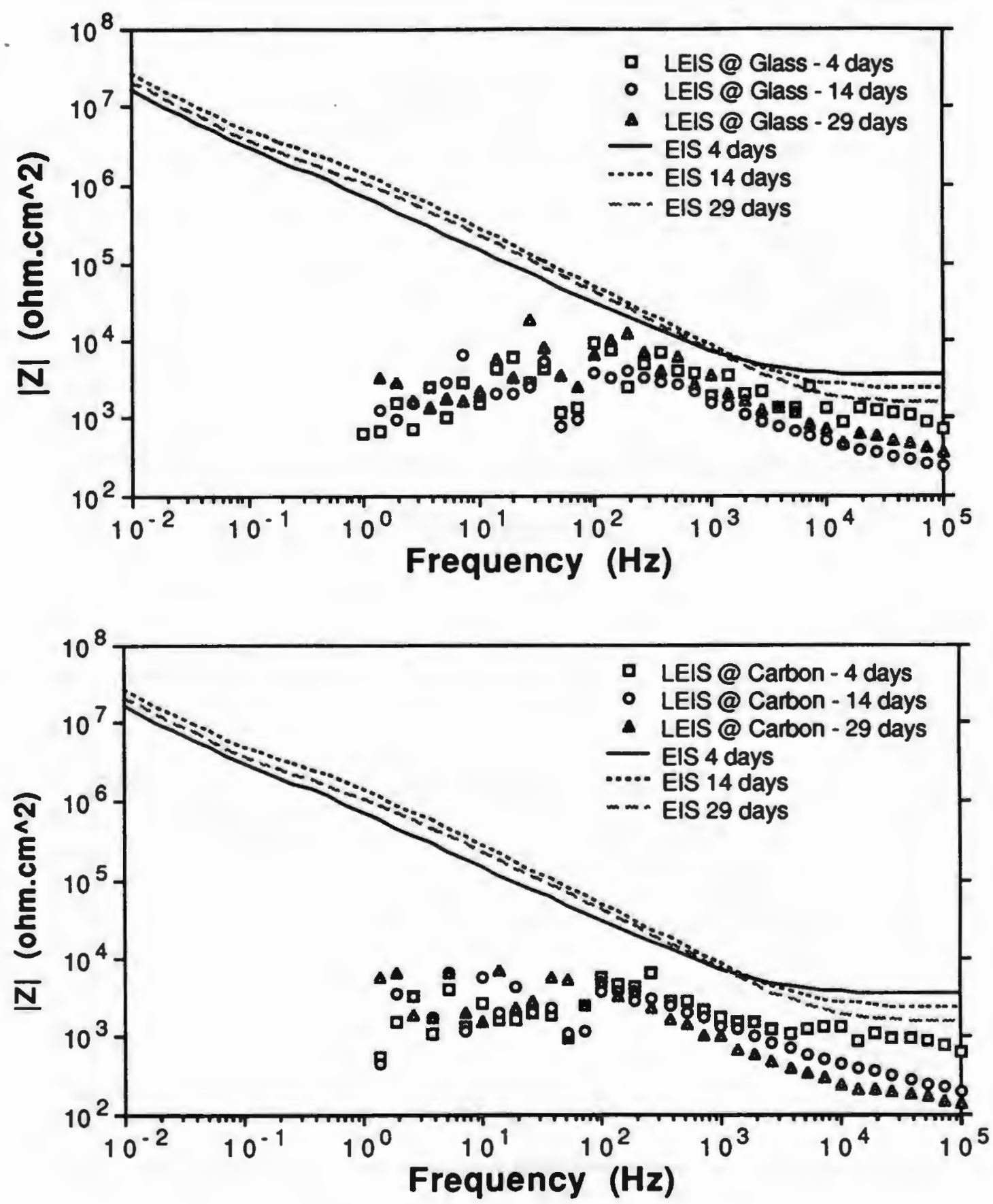

Figure 8. (a) Bode-impedance plots of EIS and LEIS spectra of CGVE composite at open circuit condition at various exposure time. 

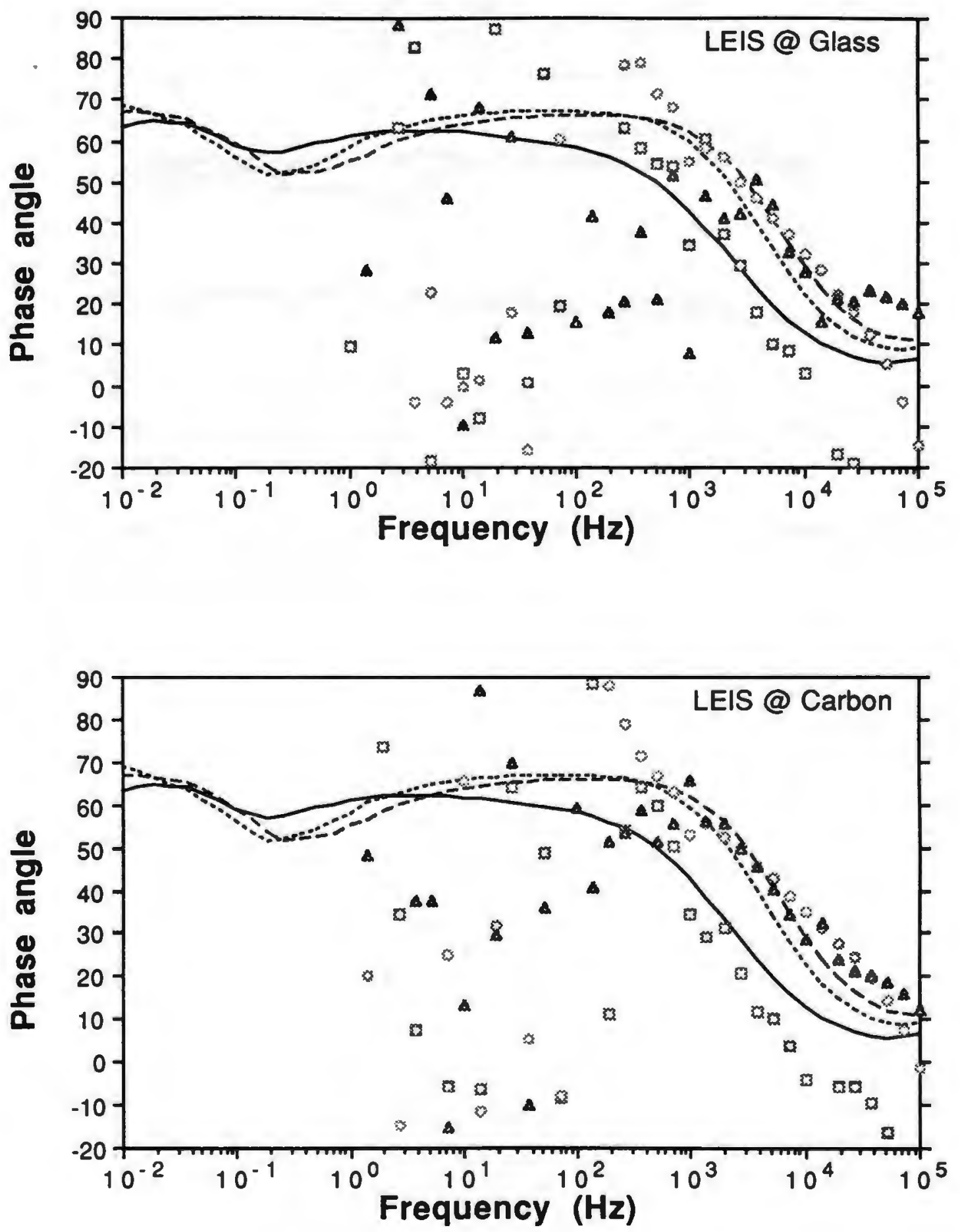

Figure 8. (b). Bode-phase angle plots of EIS and LEIS spectra of CGVE composite at open circuit condition at various exposure time. 


$$
\begin{array}{|l}
+10 \text { mins } \\
+11 \text { days } \\
\text { a } 19 \text { days } \\
\hline
\end{array}
$$

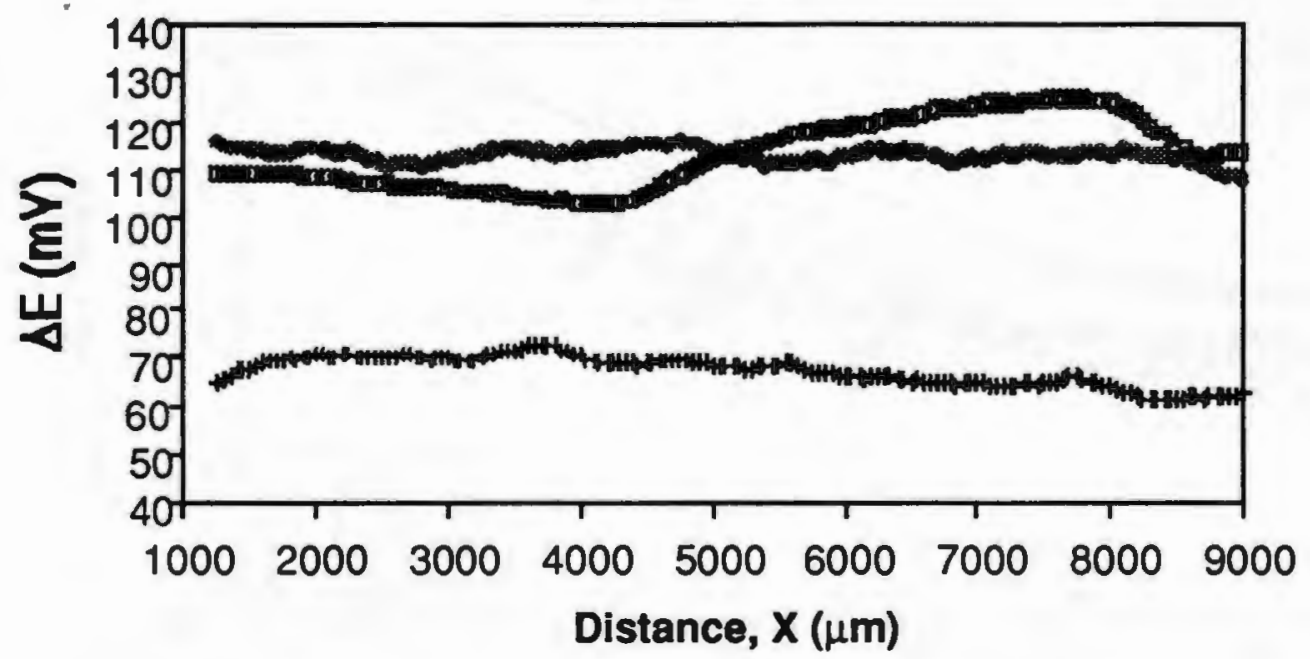

Figure 9. Potential variation on CGVE composite at applied potential of -900 $\mathrm{mV}$ vs. $\mathrm{SCE}$ at various exposure time. 

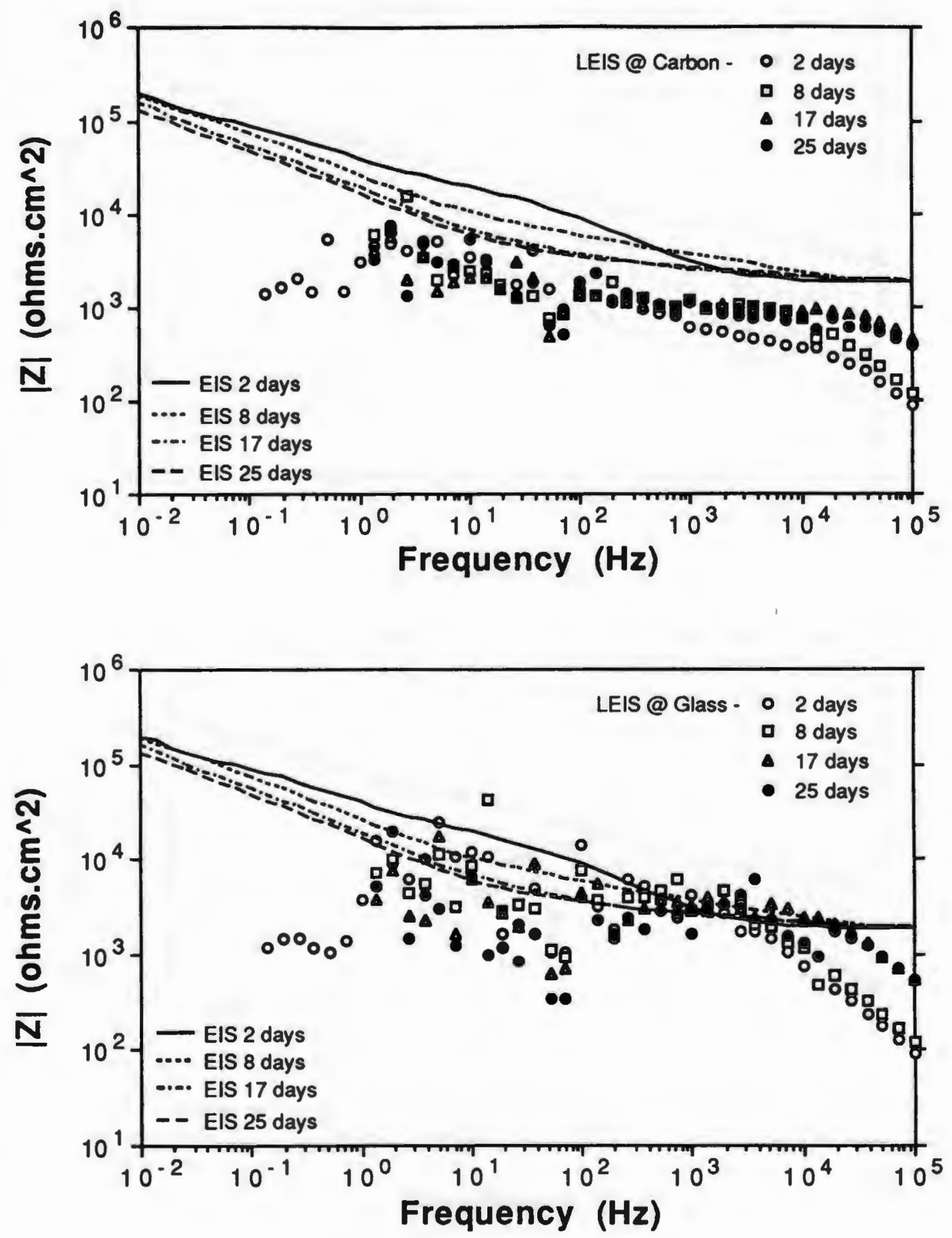

Figure 10. EIS and LEIS impedance spectra of CGVE composite at $-650 \mathrm{mV}$ $(\mathrm{SCE})$ at various exposure time. 

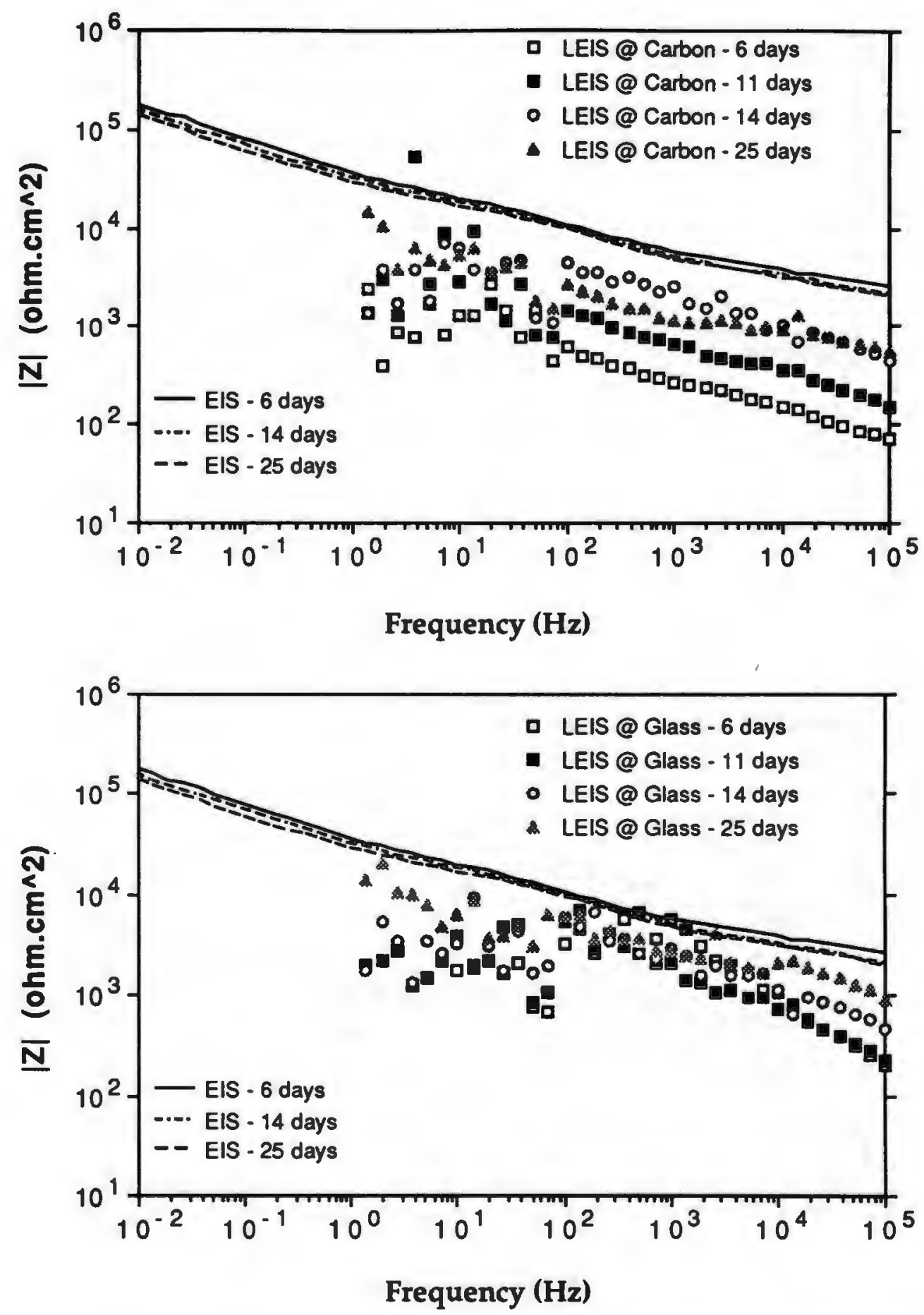

Figure 11. (a) EIS and LEIS impedance plots of CGVE composite under applied potential $-900 \mathrm{mV}(\mathrm{SCE})$ at various exposure time. 

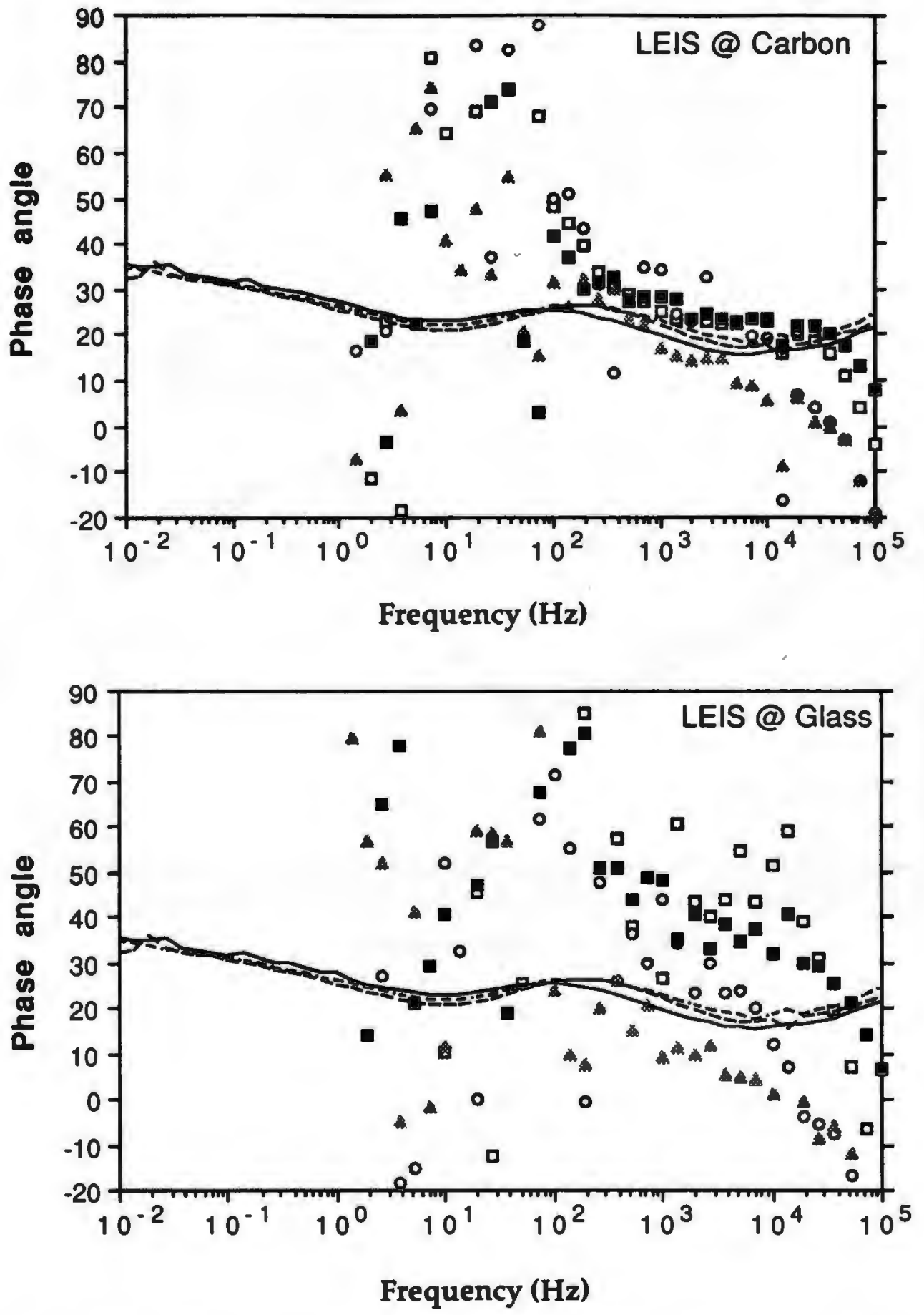

Figure 11.(b) EIS and LEIS phase angle plots of CGVE composite at $-900 \mathrm{mV}$ (SCE) at various exposure time. 


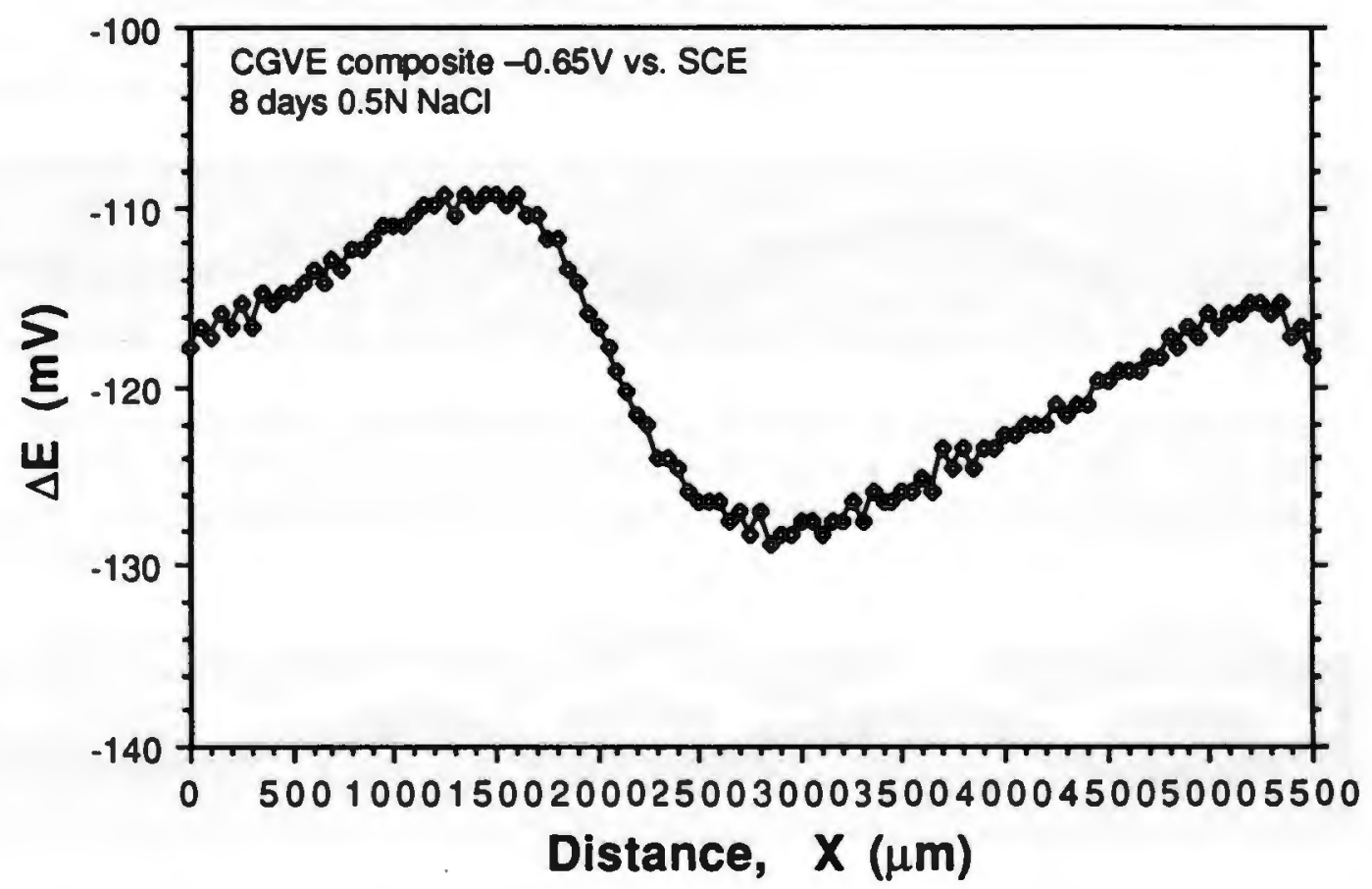

Figure 12. Line scan of local impedance on CGVE composite at $-650 \mathrm{mV}$ (SCE) after 25 days exposure. 


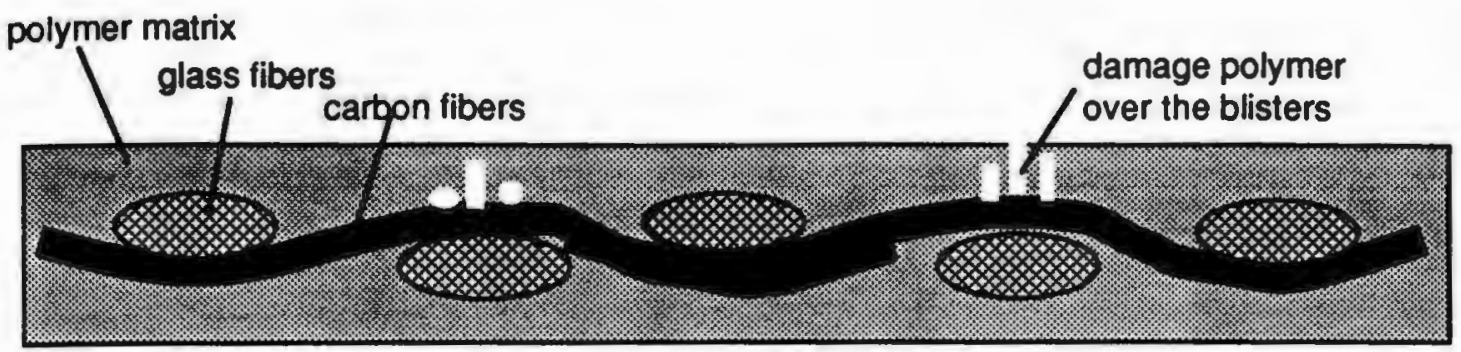

1. Water and ions are driven into the composite near the carbon/polymer interface. Cathodic reduction of oxygen produces hydroxyl ions that help disrupt bonding at the interface. Blisters initiate at carbon fibers closest to the surface which are the thinnest region of polymer in the composite. These blisters may cause the polymer over these regions to break and produce cracks or deep scratches.

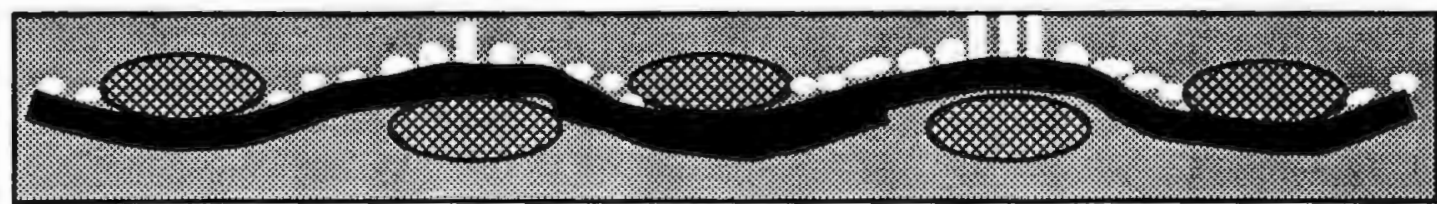

2. More blisters formed along the carbon/polymer interface by debonding of physical and chemical bonds. These may progress to the thickest regions of the composite; the glass regions. Debonding between polymer and both fibers may occur to initiate blisters at the glass regions.

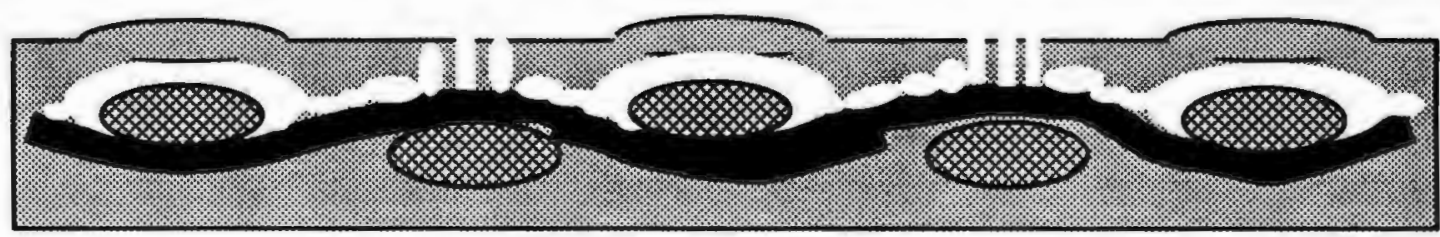

3. Blisters over the glass fibers delaminated the polymer over the fibers, and readily observed by the naked eyes.

Figure 13. Schematic of the possible mechanism for damage formation and progression from regions of carbon fibers closest to the surface to the glass regions to produce large blisters. 


\section{CHAPTER VIII}

\section{FUTURE STUDY}


1. Investigation on effect of probe size to the resolution of local impedance. Presently, good signal to noise ratio is measured down to $1 \mathrm{~Hz}$. More information on local properties can be obtained by extending the measurement to lower frequency.

2. Write new program to combine the impedance measurement software and the scanning program for surface impedance mapping. Surface mapping can be conducted at faster rate than at present rate to map the surface impedance at any time during corrosion.

3. Local impedance of other corrosion systems can be monitored such as underfilm corrosion of painted metals, intergranular corrosion and stress corrosion cracking. 


\section{CHAPTER IX}

\section{APPENDIX : LIST OF PUBLICATIONS}

1. M. N. Alias, R. Brown, "EFFECT OF THICKNESS AND PROCESS PARAMETERS ON CORROSION BEHAVIOR OF ZrN AND TIN COATINGS IN THE MARINE ENVIRONMENT", NACE CORROSION 93, Paper No. 30, NACE, Houston, Texas, 1993

2. R. Brown, M. N. Alias, R. Fontana, "EFFECT OF COMPOSITION AND THICKNESS ON CORROSION BEHAVIOR OF TIN AND ZrN THIN FILMS", Surface and Coatings technology, v62 (1993), p.467-473

3. R. Brown, M. N. Alias, "OXIDATION OF NITRIDE FILMS IN AQUEOUS SOLUTION: CORRELATION BETWEEN SURFACE ANALYSIS AND ELECTROCHEMICAL STUDIES", NACE CORROSION 94, Paper No. 322, NACE, Houston, Texas, 1994 
CHAPTER $X$

\section{BIBLIOGRAPHY}


Alias, M. N., R. Brown, "Damage to Composites from Electrochemical Processes", Corrosion v48 (1993), p.373

Alias, M. N., R. Brown, "Effect of Thickness and Process Parameters on Corrosion Behavior of $\mathrm{ZrN}$ and TiN Coatings in the Marine Environment", CORROSION 93, Paper No. 30, NACE, Houston, Texas, 1993

Arai, T., H. Fujita, and M. Watanabe, Thin Solid Films v154 (1987), p.387

Aromaa, J., H. Ronkainen, A. Mahiout, S.-P. Hannula, A. Leyland, A. Matthews, B. Matthes, E. Broszeit, "A Comparative Study of the Corrosion Performance of $\mathrm{TiN}, \mathrm{Ti}(\mathrm{B}, \mathrm{N})$ and (Ti,Al)N Coatings Produced by Physical Vapour Deposition Methods", Materials Science and Engineering, A140 (1991), p.722

Asami, K., K. Hashimoto and S. Shimodaira, "XPS Determination of Compositions of Alloy Surfaces and Surface Oxides on Mechanically Polished Iron-Chromium Alloys", Corrosion Science, v17 (1977), p.713

Asami, K., K. Hashimoto, T. Masumoto and S. Shimodaira, "ESCA Study of the Passive Film on an Extremely Corrosion-Resistant Amorphous Iron Alloys", Corrosion Science, v16 (1976), p.909

Asami, K., K. Hashimoto, "The X-Ray Photoelectron Spectra of Several Oxides of Iron and Chromium", Corrosion Science, v17 (1977), p.559

Azuma, M., Y. Nakato, H. Tsubomura, "Oxygen and Chlorine Evolution on Niobium, Zirconium and Other Metal-Nitride Amorphous Thin Film Electrodes Prepared by the Reactive RF Sputtering Technique", Iournal of Electroanalytical Chemistry, v255 (1988), p.179

Bard, A. J., R. Parsons, J. Jordan, Standard Potentials in Aqueous Solution, Marcel Dekker, NY, 1985 
Bardwell, J. A., M. C. H. McKubre, "ac Impedance Spectroscopy of the Anodic Film on Zirconium in Neutral Solution", Electrochimica Acta, v36 (1991), p.647-653

Bohe, A. E., J. R. Vilche, K. Juttner, W. J. Lorenz, W. Kautek, W. Paatsch, "An Electrochemical Impedance Spectroscopy of Passive Zinc and Low Alloyed Zinc Electrodes in Alkaline and Neutral Aqueous Solutions", Corrosion Science v32 (1991), p.621

Boukamp, B. A., EOUIVCRT-Users Manual, 2nd ed., revised, University of Twente, Netherlands, 1989

Briggs, D., M. P. Seah, Practical Surface Analysis by Auger and XPS, Wiley, New York, 1982

Brown, R., M. N. Alias, "Efrect of Film Thickness and An Interlayer

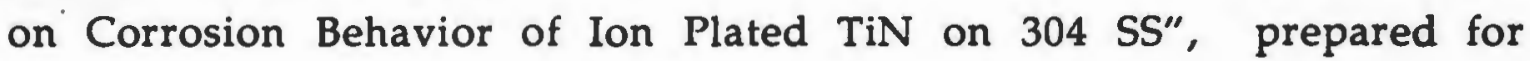
submission to Corrosion

Brown, R., M. N. Alias, "Oxidation of Nitride Thin Films in Aqueous Solution : Correlation Between Surface Analysis and Electrochemical Studies", NACE CORROSION 94, Paper No. 321, NACE, Houston, Texas, 1994

Brown, R., M. N. Alias, "Thermodynamic Equilibrium Diagrams of $\mathrm{ZrN}, \mathrm{HfN}, \mathrm{TaN}, \mathrm{NbN}$ and $\mathrm{CrN}$ in Water", prepared for submission to journal

Brown, R., M. N. Alias, R. G. Fontana, "The Effect of Composition and Thickness on Corrosion Behavior of TiN and ZrN Thin Films", Surface and Coatings Technology v62 (1993), p.467

Brundle, C. R., "Electron Spectroscopy Studies of Adsorption and Oxidation Processes at Metal Surfaces", Iournal of Electron Spectroscopy and Related Phenomena, v5 (1974), p.291 
Bull, S. J., P. R. Chalker, C. F. Ayers, and D. S. Rickerby, "The Influence of Titanium Interlayers on the Adhesion of Titanium Nitride Coatings Obtained by Plasma-Assisted Chemical Vapour Deposition", Materials and Science Engineering, vA139 (1991), p.71

Curly-Fiorino, M. E., and G. M. Schmid, "The Effect of The $\mathrm{Cl}^{-}$Ion on

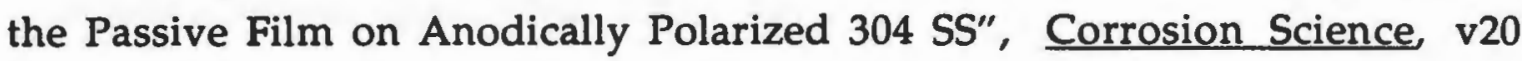
(1980), p.313

Danroc, J., A. Aubert, and R. Gillet, "Molybdenum Hard Coating Prepared by Cathodic Magnetron Sputtering", Thin Solid Films, v153 (1987), p.281

Dmitriev, V. A., L. A. Khvorostukhin, M. A. Tolstaya, Yu. I. Pavlov, A. E. Bolmanenkov, and A. A. Emel'yanov, Translated from Zaschita Metallov v26 (1990), p.151

Erdemir, A., R. F. Hochman, "Corrosion Behavior of TiN Ion Plated M-50 Bearing Steel", Journal of Materials for Energy Systems, v7 (1985), p.265

Erdemir, A., W. B. Carter, E. I. Meletis, and R. F. Hochman, "A Study of the Corrosion Behavior of TiN Films", Materials Science and Engineering, v69 (1985), p.89

Ferreira, M. G. S., J. L. Dawson, "Electrochemical Studies of the Passive Film on 316 Stainless Steel in Chloride Media", Lournal of the Electrochemical Society, v132 (1985), p.760

Gabrielli, C., Identification of Electrochemical Processes by Frequency Response Analysis, Solartron Instrumentation Group, 1980

Gad-Allah, A. G., A. A. Mazhar, "Impedance Studies on the Anodic Passivity of Titanium in Aqueous Media of Different pH", Corrosion v45 (1989), p.381 
Gorbachev, A. K., "Thermodynamics of Oxidation-Reduction Equilibria in the TiN- $\mathrm{H}_{2} \mathrm{O}$ System", Translated from Zashchita Metallov, v19, No. 2 (1983), p.253

Hills, G. J., D. J. G. Ives, "The Hydrogen Electrode", in Reference Electrodes. Theory and Practices, D. J. G. Ives and G. J. Janz, editors, Academic Press, New York, 1961, p.71

Hitzig, J., K. Juttner, W. J. Lorenz, and W. Paatsch, "AC Impedance Measurements on Corrode Porous Aluminum Oxide Films", Iournal of the Electrochemical Society, v133 (1986), p.887

Hitzig, j., K. Juttner, W. J. Lorenz, W. Paatsch, "AC Impedance Measurements on Corroded Porous Aluminum Oxide Films", Iournal of the Electrochemical Society v133 (1986), p.887

Isaacs, H. S., "Application of Current Measurement Over Corroding Metallic Surfaces", Ionic Currents in Developments, 1986, p.37

Isaacs, H. S., "Detection of Defects and Metallurgical Variations in Metal Surfaces", in Novel NDE Methods for Materials, B. K. Rath ed., The Metallurgical Society of AIME, 1983, p.63

Isaacs, H. S., B. Vyas, "Scanning Reference Electrode Techniques in Localized Corrosion", in Electrochemical Corrosion Testing, ASTM STP 727, F. Mansfeld, U. Bertocci, eds., American Society for Testing Materials, 1981, p.3

Isaacs, H. S., G. Kissel, "Surface Preparation and Pit Propagation in Stainless Steel", Journal of the Electrochemical Society v119 (1972), p.1628

Isaacs, H. S., M. W. Kendig, "Determination of Surface Inhomogeneities Using a Scanning Probe Impedance Technique", Corrosion, v36 (1980), p.269 
Isaacs, H. S., "The Effect of Height on the Current Distribution Measured with a Vibrating Electrode Probe", Lournal of the Electrochemical Society v138(1991), p.722

Isaacs, H. S., "The Localized Breakdown and Repair of Passive Surfaces During Pitting", Corrosion Science, v29 (1989), p.313

Isaacs, H. S., "The Measurement of the Galvanic Corrosion of Soldered Copper using the Scanning Vibrating Electrode Technique", Corrosion Science, v28 (1988), p.547

Isaacs, H. S., "The Use of the Scanning Vibrating Electrode Technique for Detecting Defects in Ion Vapor-Deposited Aluminum on Steel", Corrosion v43 (1987), p.594

Jaffe, L. F., R. Nuccitelli, "An Ultrasensitive Vibrating Probe for Measuring Steady Extracellular Currents", The Journal of Cell Biology v63 (1974), p.614

Johansen, O. A., J. H. Dontje, and R. L. D. Zenner, "Reactive Arc vapor Deposition of TiN, ZrN and HfN", Thin Solid Films, v153 (1987), p.75

Johnson, P. C., H. Randhawa, "Zirconium Nitride Films Prepared by Càthodic Arc Plasma Deposition Process", Surface and Coatings Technology v33 (1987), p.53

Juttner, K., "Electrochemical Impedance Spectroscopy (EIS) of Corrosion Proceses on Inhomogeneous Surfaces", Electrochimica Acta, v35 (1990), p.1501

Juttner, K., W. J. Lorenz, M. W. Kendig, F. Mansfeld, "Electrochemical Impedance Spectroscopy on 3-D Inhomogeneous Surfaces: Corrosion in Nuetral Aerated Solutions", Lournal of the Electrochemical Society v135 (1988), p.332 
Kaushik, D., M. N. Alias, R. Brown, "An Impedance Study of a Carbon Fiber Vinyl Ester Composite", Corrosion, v47 (1992), p.859

Klietz, M., J. H. Kennedy, "Resolution of Multicomponent Impedance Diagrams", in Fast Ion Transport in Solids, P. Vashista, J. N. Mundy, and G. K. Shenoy eds., Elsevier-North Holland, New York, 1979, p.185

Knittel, D. R., A. Bronson, "Pitting Corrosion on Zirconium - A Review", Corrosion, v40 (1984), p.9

Kotlyar, A. M., E. K. Sevidova, and T. V. Steglik, Translated from Elektronnaya Obrabotka Materialov No. 4 (1989), p.52-55

Latimer, W. M., Oxidation Potentials, 2nd edition, Prentice Hall, New York, 1952, p.266

Lillard, R. S., P. J. Moran, H. S. Isaacs, "A Novel Method for Generating Quantitative Local Electrochemical Impedance Spectroscopy", Journal of the Electrochemical Society v139 (1992), 1007-1012

Lyubimov, V. V., A. A. Voevodin, S. E. Spassky, and A. L. Yerokhin, "Stress Analysis and Failure Possibility Assessment of Multilayer Physically Vapour Deposited Coatings", Thin Solid Films, v207 (1992), p.117

Macdonald, J. R., Impedance Spectroscopy: Emphasizing Solid Materials and Systems, Wiley, New York, 1987

Massiani, Y., A. Medjahed, P. Gravier, J. P. Crousier, "Effect of a Titanium Underlayer on the Corrosion Behaviour of Physically Vapor Deposited Titanium Nitride Films", Thin Solid Films, v217 (1992), p.31

Massiani, Y., A. Medjahed, P. Gravier, L. Argeme, and L. Fedrizzi, "Electrochemical Study of Titanium Nitride Films Obtained by Reactive Sputtering", Thin Solid Films, v191 (1990), p.305 
Massiani, Y., J. Crousier, L. Fedrizzi, A. Cavalleri, and P. L. Bonora, "Study of the Behavior in the Acidic Solution of Titanium and TiN Coatings by Magnetron Sputtering", Surface and Coatings Technology v33 (1987), p.309

Meletis, E. I., A. Erdemir, and R. F. Hochman, I. of Materials Engineering, v7 (1985), p.173

Meletis, E. I., W. B. Carter, and R. F. Hochman, Microstructural Science, v13 (1986), p.417

Miriyala, S. K., T. J. Rockett, W. C. Tucker, R. Brown, "Corrosion Activated Degradation of Composites in Sea Water", Proceedings of the Annual Tri-Services Conference, Boston, MA, 1992, p.441

Montero, I., C. Jimenez, and J. Perriere, "Surface Oxidation of TiNx Films", Surface Science, v251/252 (1991), p.1038

Nazarenko, P. V., A. G. Molyar, I. E. Polishchuk, O. G. Yachinskaya, and A. A. Il'in, Translated from Metallovedenie i Termicheskaya Obrabotka Metallov No. 4 (April 1990), p.61

Newman, J. S., Electrochemical Systems, Prentice Hall, New Jersey, 1973

Okamoto, G., T. Shibata, "Passivity and the Breakdown of Passivity of Stainless Steel", in Passivity of Metals, R. P. Frankenthal and J. Kruger editors, The Electrochemical Society, Pennington, New Jersey, 1977, p.646

Oltra, R., M. Keddam, "Application of Impedance Technique to Localized Corrosion", Corrosion Science, v28 (1988), p.1

Palit, G. C., H. S. Gadiyar, "Pitting Corrosion of Zirconium in Chloride Solution", Corrosion, v43 (1987), p.140 
Park, M. J., A. Leyland, A. Matthews, "Corrosion Performance of Layered Coatings Produced by Physical Vapour Deposition", Surface and Coatings Technology v43/44 (1990), p.481

Pourbaix, M. J. N., Atlas of Electrochemical Equilibria in Aqueous Solutions, Pergamon, New York, 1966

Pourbaix, M., Lectures on Electrochemical Corrosion Plenum Press, NY, 1973

Randhawa, H., P. C. Johnson, "Technical Note: A Review of Cathodic Arc Plasma Deposition Process and Their Applications", Surface and Coatings Technology, v31 (1987), p.303

Rickerby, D. S., G. Eckold, K. T. Scott, and I. M. Buckley-Goldner, "The Interrelationship Between Internal Stress, Processing Parameters and Microstructure of Physically Vapour Deposited and Thermally Sprayed Coatings", Thin Solid Films, v154 (1987), p.125

Seijka, J., C. Cherki, and J. Yahalom, "A Study of Nickel Passivity by Nuclear Microanalysis of $\mathrm{O}^{16}$ and $\mathrm{O}^{18}$ Isotopes", Electrochimica Acta, v17 (1972), p.2371

Shih, H., F. Mansfeld, "A Fitting Procedure for Impedance Spectra Obtained for Cases of Localized Corrosion", Corrosion, v45 (1989), p.610

Spencer, P. J., "Thermochemical Properties", in Hafnium : PhysicoChemical Properties of Its Compounds and Alloys, K. L. Komarek ed., International Atomic Energy Agency, 1981, p.48

Standish, J. V., H. Leidheiser, Jr., "The Electrical Properties of Organic Coatings On a Local Scale-Relationship to Corrosion", Corrosion, v36 (1980), p.390

Tokuda, K., T. Geushi, K. Aoki, H. Matsuda, "Finite-Element Method Approach to the Problem of the IR-Potential Drop and Overpotential 
Measurements by Means of a Luggin-Haber Capillary", Lournal of the Electrochemical Society v132 (1985), p.2390

Toth, L. E., Transition Metal Carbides and Nitrides, Academic Press, NY, 1971

van Leaven, L., M. N. Alias, R. Brown, "Corrosion Behavior of Ion Plated and Implanted Films", Surface and Coatings Technology v53 (1992), p.25

Vyas, B., H. S. Isaacs, "Detecting Susceptibility to Intergranulaar Corrosion of Stainless Steel Weld Heat-Affected Zones", in Intergranular Corrosion Testing, ASTM STP 656, R. F. Steigerwald, ed., Americal Society for Testing Materials, 1987, p.133

Wagner, C. D., W. M. Riggs, L. E. Davis, J. F. Moulder, G. E. Muilenberg, Handbook of X-ray Photoelectron Spectroscopy Perkin Elmer Corporation, Physical Electronics Division, Eden Prairie, Minnesota, 1979

Walter, G. W., "A Review of Impedance Plot Methods Used for Corrosion Performance Analysis of Painted Metals", Corrosion Science, v26 (1986), p.681

Walter, G. W., "Application of Impedance Measurements to Study Performance of Painted Metals in Aggressive Solutions", Lournal of Electroanalytical Chemistry v118 (1981), p.259

Yahalom, J., A. Poznansky, in Passivity of Metals, P. Frankenthal, ed., The Electrochemical Society, Pennington, New Jersey, 1972 